\section{APN}

Asia-Pacific Network for Global Change Research
Bulletin

Issue 1 | March 2011 (a)

Applicability of Satellite-based Rainfall Product to Flood Runoff Analysis with Integrated Flood Analysis System (IFAS) in Asia

Good Water Governance:

Could Stakeholder Participation Reduce Water Insecurities in River Basins in Asia-Pacific?

Global Change and Capacity Building in Coral Reef Management in the Pacific: Engaging Scientists and Policy-makers in Fiji, Tonga, Samoa and Tuvalu

Global Environmental Change and Food Security in the Indo-Gangetic Plain

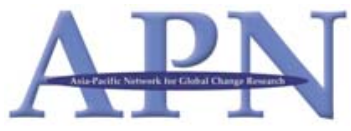

Development of a Co-evolutionary Decision Support System-Food and Water Security Integrated Model System (FAWSIM)

Assessing Impacts of ECHAM4 GCM Climate Change Data on Main Season Rice Production Systems in Thailand

Future Climate Projection for Mainland Southeast Asia Countries: Climate Change Scenario of $21^{\text {st }}$ Century

Climate Change Risk Assessment in Asian Coastal Megacities: Knowledge Gaps and Research Needs for Urban Development Planning

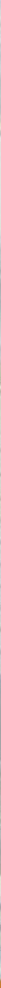


4 Editorial

5 Preface

\section{Featured Articles}

7 ARCP2009-01CMY-Fukami: Applicability of SatelliteBased Rainfall Product to Flood Runoff Analysis with Integrated Flood Analysis System (IFAS) in Asia

11 ARCP2009-03CMY-Nikitina: Good Water Governance: Could Stakeholder Participation Reduce Water Insecurities in River Basins in Asia-Pacific?

15 CBA2010-15NMY-South: Global Change and Capacity Building in Coral Reef Management in the Pacific: Engaging Scientists and Policy-Makers in Fiji, Tonga, Samoa and Tuvalu

19 CRP2008-01CMY-Dixit: Global Environmental Change and Food Security in the Indo-Gangetic Plain

23 CRP2008-02CMY-Yan: Development of a Co-evolutionary Decision Support System - Food and Water Security Integrated Model System (FAWSIM)

29 CRP2008-03CMY-Jintrawet: Assessing Impacts of ECHAM4 GCM Climate Change Data on Main Season Rice Production Systems in Thailand

35 CRP2008-03CMY-Jintrawet: Future Climate Projection for Mainland Southeast Asia Countries: Climate Change Scenario of $21^{\text {st }}$ Century

39 CIA2009-01-Snidvongs: Climate Change Risk Assessment in Asian Coastal Megacities: Knowledge Gaps and Research Needs for Urban Development Planning

\section{Regional Research Projects} funded under the Annual Regional Call for Research Proposals (ARCP)

44 ARCP2010-01CMY-Sthiannopkao: Collaborative Research on Sustainable Urban Water Quality Management in Southeast Asian Countries: Analysis of Current Status (comparative study) and Development of a Strategic Plan for Sustainable Development

45 ARCP2010-02CMY-Phua: Integrated Prediction of Dipterocarp Species Distribution in Borneo for Supporting Sustainable Use and Conservation Policy Adaptation

46 ARCP2010-03CMY-Marambe: Vulnerability of Home Garden Systems to Climate Change and its Impacts on Food Security in South Asia
47 ARCP2010-04CMY-Wang: Building Asian Climate Change Scenarios by Multi-Regional Climate Models Ensemble

47 ARCP2010-05CMY-Luck: The Effects of Climate Change on Pests and Diseases of Major Food Crops in the AsiaPacific Region

48 ARCP2010-06CMY-Schaefer: Quantifying the Role of Dead Wood in Carbon Sequestration

49 ARCP2010-07CMY-Bai: Asian Coastal Ecosystems: An Integrated Database and Information Management System (DIMS) for Assessing Impact of Climate Change and its Appraisal

50 ARCP2010-08NSY-Freeman: Impact of Climate Change on Food Security and Biosecurity of Crop Production Systems in Small Pacific Nations

50 ARCP2010-09NSY-Patankar: Enhancing Adaptation to Climate Change by Integrating Climate Risk into LongTerm Development Plans and Disaster Management

51 ARCP2010-10NMY-Koike: River Management System Development in Asia Based on Data Integration and Analysis System (DIAS) under GEOSS

52 ARCP2010-11NMY-Asanuma: Intercomparison of Landsurface Process Modelling in Asian Drylands

53 ARCP2010-12NMY-Uprety: Community Based Forestry and Livelihoods in the Context of Climate Change Adaptation

54 ARCP2010-13NMY-Bae: Climate Change Impact Assessment on the Asia-Pacific Water Resources under AWCI/GEOSS

55 ARCP2010-14NMY-Li: Analysis on Urban Land-Use Changes and its Impacts on Food Security in Different Asian Cities of four Developing Countries using Modified Cellular Automata (CA)

56 ARCP2010-15NMY-Han: The Impact of Spatial Parameters on Greenhouse Gas Emissions: A Comparative Study between Cities in China and India

54 ARCP2010-16NMY-Huda: Food Security and Climate Change in the Asia-Pacific Region: Evaluating Mismatch between Crop Development and Water Availability

57 ARCP2010-17NMY-Towprayoon: Strategic Rice Cultivation for Sustainable Low Carbon Society Development in Southeast Asia

57 ARCP2010-18NMY-Lutaenko: Coastal Marine Biodiversity of Viet Nam: Regional and Local Challenges and Coastal Zone Management for Sustainable Development
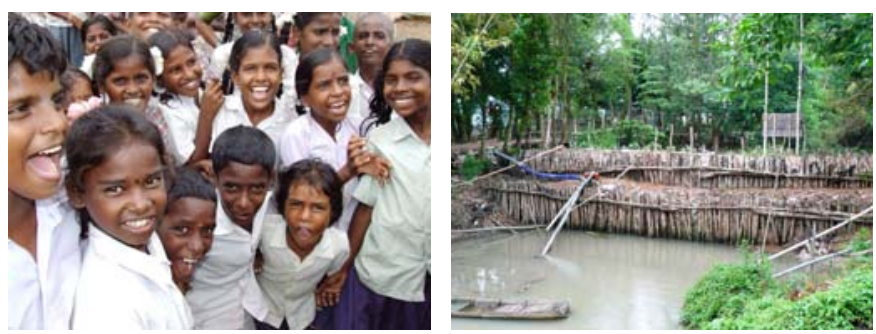


\section{Scientific Capacity Development Projects funded under the CAPaBLE Programme}

59 CBA2010-01CMY-Sang-arun: Promoting Sustainable Use of Waste Biomass in Cambodia, Lao People's Democratic Republic and Thailand: Combining Food Security, Bioenergy and Climate Protection Benefits

60 CBA2010-02CMY-Togtohyn: Dryland Development Paradigm (DDP) Application for the Most Vulnerable to Climate and Land Use Change of Pastoral Systems in the Southern Khangai Mountains of Mongolia (DDPPaS)

62 CBA2010-03NSY-Indrawan: Developing the Capacity for Teaching Biodiversity and Conservation in the Asia-Pacific Region

63 CBA2010-04NSY-Dhakal: Carbon Governance in Asia: Bridging Scales and Disciplines

64 CBA2010-05NSY-Lorrey: Improving Pacific Island Meteorological Data Rescue and Data Visualisation Capabilities through Involvement in Emerging Climate Research Programmes

65 CBA2010-06NSY-Kench: Improving Understanding of Local-Scale Vulnerability in Atoll Island Countries: Developing Capacity to Improve In-Country Approaches and Research

66 CBA2010-07NSY-Stone: Web-based 'Discussion-support' Agricultural-Climate Information for Regional India

67 CBA2010-08NSY-Salinger: Addressing the Livelihood Crisis for Farmers: Weather and Climate Services for Sustainable Agriculture - Development of Tools

67 CBA2010-09NSY-Okayama: Scientific Capacity Development of Trainers and Policy-Makers for Climate Change Adaptation Planning in Asia and the Pacific

68 CBA2010-10NSY-Chen: Promoting a Data Sharing Environment within the Earth Observation System of Systems: The Asia-Pacific Perspective

69 CBA2010-11NSY-De Guzman: Capacity Building for Research and Monitoring of Marine Protected Areas (MPA): An Adaptive Mechanism for Climate Change in the Asia-Pacific Region

70 CBA2010-12NSY-Pradhananga: Graduate Conference on Climate Change and People

71 CBA2010-13NMY-Kawai: Capacity Building of Biodiversity Research in the Coastal Zones of the Asia Pacific Region: Phycology Taxonomy Analysis Training Using Genetic Marker

72 CBA2010-14NMY-Kaihotsu: Drought Monitoring System Development by Integrating In-situ Data, Satellite Data and Numerical Model Output

73 CBA2010-15NSY-South: Global Change and Coral Reef Management Capacity in the Pacific: Engaging Scientists and Policy-Makers in Fiji, Samoa, Tuvalu and Tonga
74 CRP2010-01CMY-Weber: Vulnerability Mapping as a Policy Tool in Developing Countries

75 CRP2010-02CMY-Pereira: Strengthening Capacity for Policy Research on Mainstreaming Adaptation to Climate Change in Agriculture and Water Sectors

\section{Projects funded under the Special Call for Focussed Activities: Climate Change Impact and Vulnerability Assessments}

77 CIA2009-01-Snidvongs: Climate Change Vulnerability Assessment of Floods and Urban Development Planning for Asian Coastal Cities

78 CIA2009-02-Pulhin: Capacity Development on Integration of Science and Local Knowledge for Climate Change Impacts and Vulnerability Assessments

79 CIA2009-03-Lun: Climate Change in Eastern Himalayas: Advancing Community-Based Scientific Capacity to Support Climate Change Adaptation

79 CIA2009-04-Gaol: Increasing Capacity of Local Scientists for Climate Change Impact and Vulnerability Assessments in Indonesia Archipelagos: Training in In-Situ/Satellite Sea Level Measurements

80 CIA2009-05-Jitpraphai: Building Research Capacity on Assessing Community Livelihood Vulnerability to Climate Change Impacts in Central Viet Nam and the Mekong River Delta

81 CIA2009-06-Duc: Capacity Development for Adaptation to Climate Change in the Rural Coastal Zone of Viet Nam

82 CIA2009-07-Lotia: Capacity Development of the Scientific Community for Assessing the Health Impacts of Climate Change
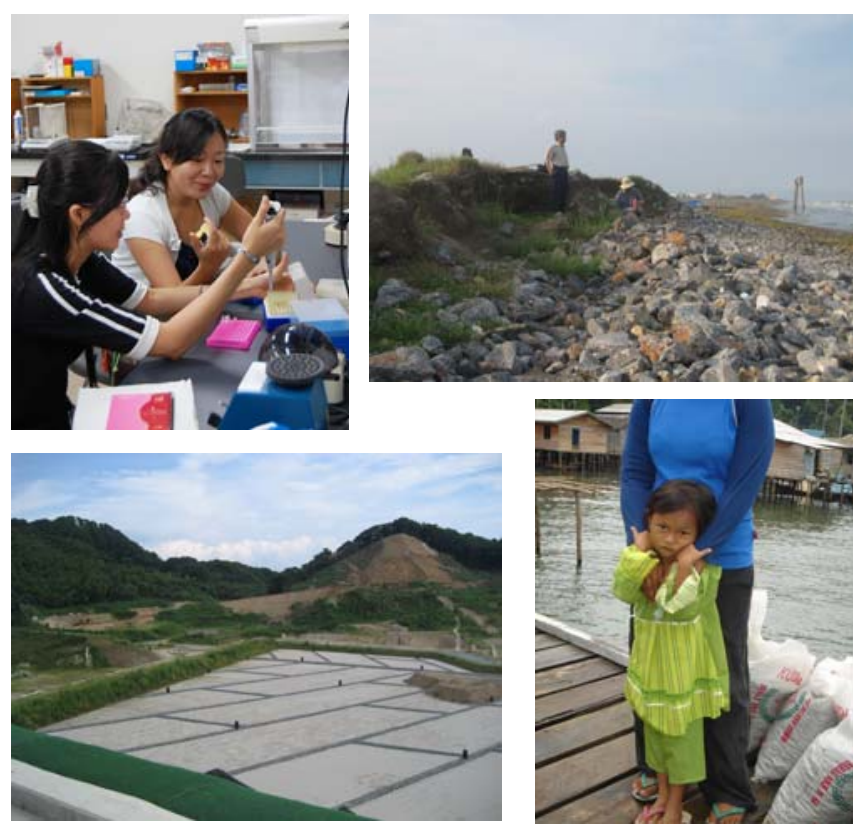


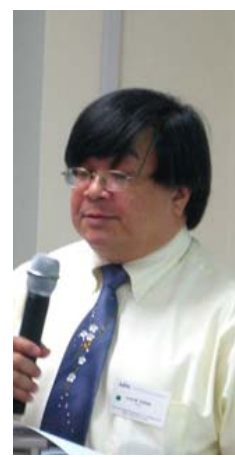

Dr. Tupas

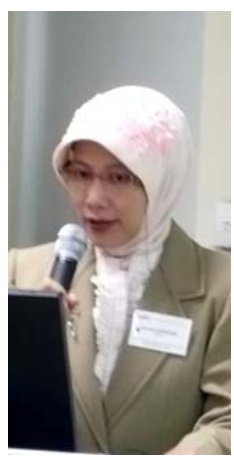

Dr. Adiningsih

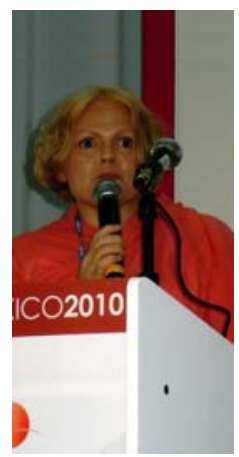

Dr. Stevenson

\section{Editorial}

Tn the past decade, APN has published yearly project reports containing abstracts of APNfunded activities that have been useful for the APN members and other interested - parties. However, with the implementation of the APN third strategic phase (2010-2015) and the need to ensure that the work of the APN reaches all stakeholders, including science, policy and civil-society communities, the APN has launched a new publication series: APN Science Bulletin.

The APN Science Bulletin is an annual publication that highlights all of the projects funded and completed by the APN in the year of publication (the present year running from April 2010 March 2011). The Science Bulletin has four main sections: 1) Featured Articles; 2) Regional Research Projects funded under the Annual Regional Call for Research Proposals (ARCP) Programme; 3) Scientific Capacity Development Projects funded under the CAPaBLE Programme; and 4) Projects funded under the APN's Focussed Activities Programme.

In this first issue of the APN Science Bulletin, March 2011; all activities that were funded and undertaken since April 2010 have been included. Under featured articles, full scientific research papers have been written and cover a number of major themes in the APN's science agenda from looking at high-resolution regional climate models for food security in Southeast Asia to developing scientific capacity for Coral Reef Management in the South Pacific. Sections 2 and 3 look at the work conducted under the APN's two main pillars of activities - the ARCP and CAPaBLE programmes, respectively. Section 4 highlights projects funded through a special focussed activity undertaken from 2009-2010 on Climate Impact and Vulnerability Assessments.

On behalf of the Scientific Planning Group (SPG), who advises the scientific programme of the APN to the APN's governing body, the Inter-Governmental Meeting, we, as the SPG CoChairs are delighted to present the first issue of the APN Science Bulletin to you and hope that you find the contents both interesting and useful for your activities in global environmental change.

\section{Scientific Planning Group Executive Editors:}

Dr. Luis Tupas, SPG Member for U.S.A. and SPG Co-Chair

Dr. Erna Sri Adiningsih, SPG Member for Indonesia and SPG Co-Chair

\section{Managing Editor:}

Dr. Linda Anne Stevenson, Executive Science Officer, APN Secretariat

\section{Citation}

Tupas, L., Adiningsib, E.S., Stevenson, L.A., (2011) APN Science Bulletin: Issue 1; pp84; Asia-Pacific Network for Global Change Research; ISSN 2185-761X

C2011 Asia-Pacific Network for Global Change Research (APN). All rights reserved. 

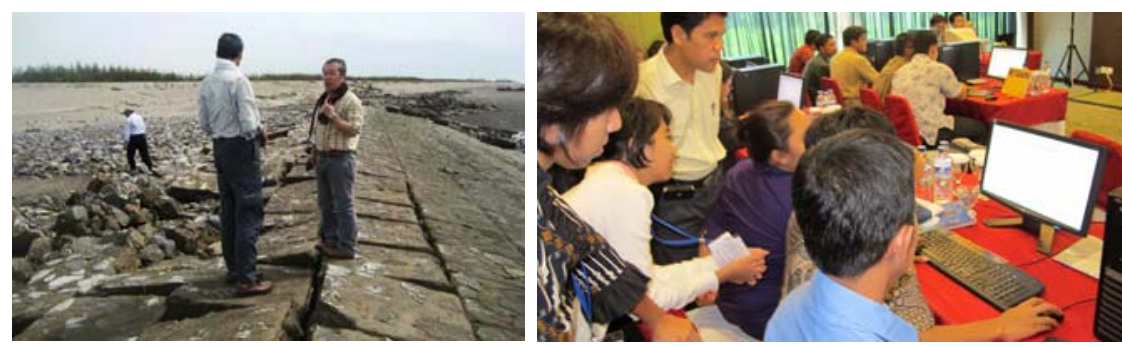

\section{Preface}

Dountries within the Asia-Pacific region support more than half of the world's population, and changes in the Earth's bio-geophysical system are clearly impacting the societies and economies of these countries.

Recent research and supporting observations have provided new insights into some of these changes and their impacts but have, at the same time, opened a number of new and challenging scientific issues and questions. APN seeks to identify these scientific issues to promote, as well as encourage, regional cooperative global change research.

The Asia-Pacific Network for Global Change Research (APN) is an inter-governmental network whose mission is to enable investigations of changes in the Earth's life support systems and their implications for sustainable development in the Asia-Pacific region. The APN, therefore, supports investigations that will:

1. Identify, explain and predict changes in the context of both natural and anthropogenic (human-induced) forcing;

2. Assess potential regional and global vulnerability of natural and human systems; and

3. Contribute, from the science perspective, to the development of policy options for appropriate responses to global change that will also contribute to sustainable development.

The core strategies of the APN are to:

1. Promote and encourage research that can improve the understanding of global change and its implications for the region and contribute to sound scientific basis for policy-formulation and decision-making; and

2. Identify and help address, in consultation with policy-makers and other end-users, present and future needs and emerging challenges.

APN's activities promote Global Change Research (GCR $)^{1}$ that improves understanding of the physical, biological and human dimensions of change in the Earth system and science that informs adaptation and mitigation decisionmaking in four thematic areas: Climate Change and Climate Variability; Ecosystems, Biodiversity and Land Use; Changes in the Atmospheric, Terrestrial and Marine Domains; and Resources Utilisation and Pathways for Sustainable Development. These themes are interrelated and involve the interface of natural, social and political sciences. Thus, APN also supports research on crosscutting issues, science-policy linkages and the human dimensions of global change.

As part of its dissemination activities, the present publication features selected scientific articles from recently completed and ongoing APN-funded projects; abstracts of currently-funded activities under the APN's Annual Regional Call for Research Proposals (ARCP) Programme, its Capacity Development Programme (CAPaBLE), and its Special Focussed Activities Programme on Scientific Capacity Building for Climate Change Impacts and Vulnerability Assessments (SCBCLA).

The APN supports and encourages the dissemination of the information contained in this publication and specifically notes that the potential results of the present research and capacity development activities can facilitate policy development relating to Global Change in the Asia-Pacific Region.

The present publication is also available on the APN website at www.apn-gcr.org

Secretariat

Asia-Pacific Network for Global Change Research (APN)

\footnotetext{
${ }^{1}$ The APN defines Global Change Research as "research regarding global change (the set of natural and human-induced processes in the Earth's physical, biological, and social systems that, when aggregated, are significant at a global scale) and its implications for sustainable development in the Asia-Pacific region."
} 


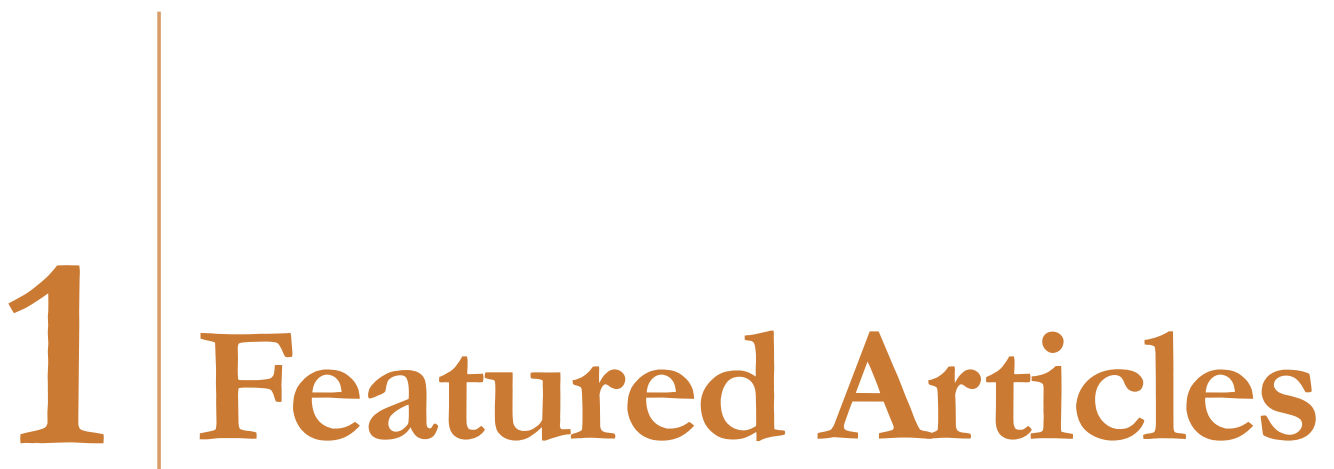




\title{
Applicability of Satellite-Based Rainfall Product to Flood Runoff Analysis with Integrated Flood Analysis System (IFAS) in Asia
}

\author{
Kazuhiko Fukami ${ }^{1}$, G. Ozawa, M. Miyamoto, H. Inomata
}

Corresponding author ${ }^{1}$

International Centre for Water Hazard and Risk Management (ICHARM) under the auspices of the United Nations Educational, Scientific and Cultural Organisation (UNESCO), Public Works Research Institute (PWRI), Ibaraki, Japan.

Email: k-fukami@pwri.go.jp

\section{Abstract}

Monsoon Asia suffers from flood disasters every year. Flood forecasting and warnings are key measures implemented to reduce casualties and damage caused by floods. However, the implementation of flood forecasting and warning systems has not really progressed in developing countries despite the availability of recommendations in documents such as the Hyogo Framework for Action (2005-2015). Therefore, the International Centre for Water Hazard and Risk Management (ICHARM) under the auspices of the United Nations Educational, Scientific and Cultural Organisation (UNESCO) has been promoting the application of the Integrated Flood Analysis System (IFAS) as the basis for a flood forecasting system for poorly-gauged rivers in developing countries through the Global Earth Observation System of Systems-Asian Water Cycle Initiative (GEOSS-AWCI) and other international frameworks. One of the key technologies of IFAS is to utilise satellite-based rainfall data for flood runoff analyses in poorly gauged rivers. IFAS implemented a self-correction system for satellite-based data, without any ground-based in-situ rain gauge data, to modify under-estimated satellite-based rainfall data in poorly gauged river basins. The verification studies revealed the high potential of IFAS, coupled with satellitebased rainfall data with a self-correction algorithm, to identify extreme flood events. Further areas to improve IFAS-based flood runoff analyses and forecasting are also discussed.

Keywords: satellite-based rainfall data, GSMaP_NRT, self-correction algorithm, Integrated Flood Analysis System (IFAS), Global Precipitation Measurement Mission (GPM), flood forecasting

\section{Introduction}

Monsoon Asia experiences flood disasters every year during the monsoon season. Typical examples observed in the past two years have included flood disasters caused by Typhoon Morakot and Typhoon Ketsana (2009), floods in Southern China and the Indus River floods in Pakistan (2010). The implementation of flood forecasting and warning systems is a key strategy to reduce casualties and damage caused by large-scale flood events such as these. However, implementation in developing countries has not made sufficient progress and, for that reason, UNESCO/ICHARM developed the Integrated Flood Analysis System (IFAS) as a base flood forecasting system for poorly gauged rivers in developing countries. The present paper describes the concept to promote the implementation of a flood forecasting/ warning system using IFAS coupled with satellite-based rainfall data in poorly gauged rivers. The significance of satellite-based rainfall data and IFAS were also investigated and discussed in the context of flood disaster mitigation through flood early warning in developing countries.

\section{Concept of Integrated Flood Analysis System (IFAS)} The design concept of IFAS as a common fundamental tool for flood forecasting/warning systems in poorly gauged rivers was developed in a joint research endeavour (2005-2007) with the Infrastructure Development Institute (IDI) and nine private consultancy companies (Figure 1) with the following objectives:

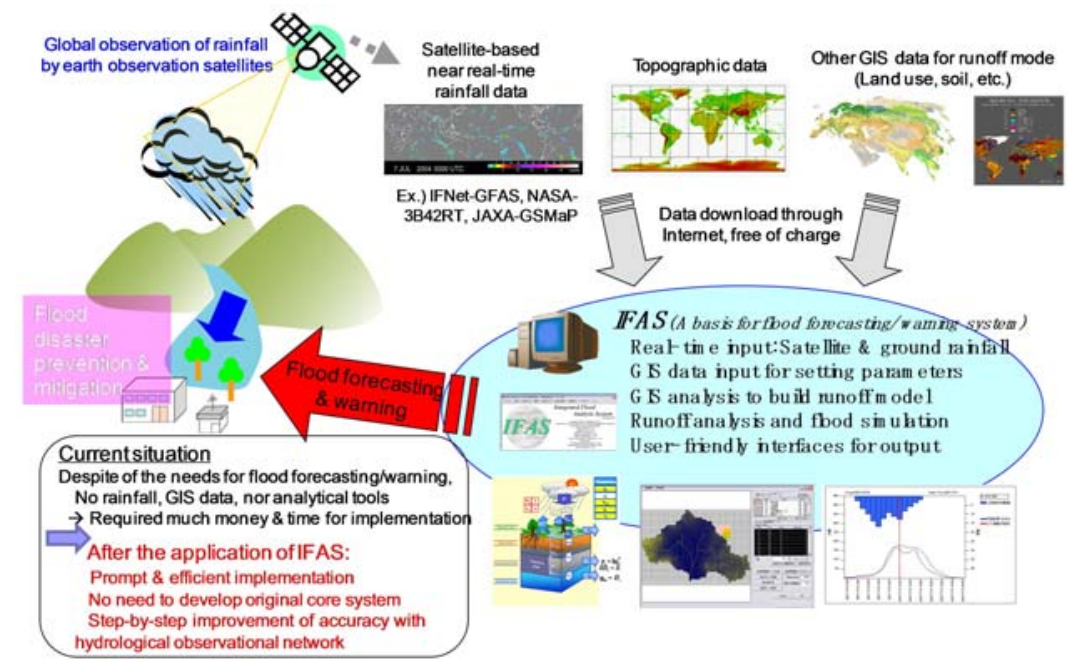

Figure 1. Concept of Integrated Flood Analysis System (IFAS) 
i. Develop interfaces to obtain satellite-based rainfall data and ground-based rainfall data to secure worldwide availability of data for flood forecasting/ analysis;

ii. Adopt two types of distributed-parameter hydrological models, PWRI Distributed Hydrologic Model (PDHM) Ver.2 and Block-wise TOP (BTOP) model, the parameters of which can be estimated as the first approximation based on globally-available GIS databases to secure worldwide availability of hydrological models for flood forecasting/analysis;

iii. Implement GIS analysis modules in the system to set up the parameters for the flood forecasting/analysis model, therefore no need to depend on external GIS software;

iv. Prepare a series of easy-to-understand graphical user interfaces for data input, modelling, runoff-analysis and output display; and

v. Distribute the executable program, free of charge, from the ICHARM/PWRI website.

ICHARM also offers technical training seminars so that developing countries can utilise provided information and technologies as easily as possible. Such packaged activities have been regarded as one of the core activities of the Flood Working Group of GEOSS-AWCI to build capacities for flood runoff analysis and management in developing countries. The overall structures, features and interfaces of IFAS have already been introduced (Sugiura et al., 2009). In the present paper the authors focus on the applicability of satellite-based rainfall data to flood runoff analysis in terms of accuracies of areal rainfall \& flood runoff estimation.

\section{Accuracy of Satellite-based Rainfall Data} and the Effect of its Self-correction Method According to the concept of IFAS, IFAS has a function to incorporate not only ground-based rainfall data (csv data) but also satellite-based near-real-time rainfall products such as NASA-3B42RT, NOAA-CMORPH, JAXAGSMaP_NRT, etc. (Table 1) for flood runoff simulations.

From the table, GSMaP_NRT seems more promising for the purpose of flood forecasting due to its high temporal and spatial resolution and its quick delivery. According to the validation study for a few river basins of Japan and USA (black plots, Figure 2), however, it was clarified that GSMaP_NRT (3hr-cumulative catchment-area-averaged rainfall amount) tended to underestimate rainfall intensity, in particular, in cases of heavy rainfall. Then Shiraishi et al., 2009 disovered an empirical relationship between spatial correlation factor (presumably corresponding to the movement speed of precipitation cells, Figure 3) and the degree of underestimation. Based on this empirical relationship, they developed a self-correction method for GSMaP_NRT without ground-based rainfall data (red plots, Figure 2). This method is expected to be very

\section{ARCP2009-01CMY-Fukami}

Flood Risk Management Demonstration Project under the Asian Water Cycle Initiative for the Global Earth Observation System of Systems (FRM/ AWCI/GEOSS)

\section{Project Leader:}

Mr. Kazuhiko Fukami

International Centre for Water Hazard and Risk Management (ICHARM) under the auspices of United Nations Educational, Scientific and Cultural Organisation (UNESCO)

Public Works Research Institute (PWRI)

JAPAN

Tel: +81298796779

Fax: +81298796809

Email: k-fukami@pwri.go.jp

\section{APN Funding:}

US\$84,000 (For 2 Years)

\section{Research Highlights}

- The authors (UNESCO-ICHARM) developed a free toolkit: the Integrated Flood Analysis System (IFAS), as the basis for a flood forecasting system for poorly-gauged rivers in developing countries. IFAS can incorporate not only ground-based rain gauge data but also satellite-based rainfall products and can build two types of distributed-parameter flood-runoff models based on global GIS data without the need for GIS analytical software.

- A typical satellite-based rainfall product, JAXAGSMaP_NRT, underestimated heavy rainfall intensity. Therefore, ICHARM developed an original algorithm to make self-corrections for GSMaP_NRT data without using ground-based rainfall data. This empirical algorithm has worked well as a whole to modify such a systematic underestimation.

- The combination of the self-corrected satellitebased rainfall data, global GIS data and IFAS has very high potential to promptly and efficiently implement a flood analysis and forecasting system even in poorly-gauged rivers, in the sense that major extreme flood phenomena can be identified even if the coincidence of hydrographs are not sufficient from low to high flow.

- To improve the reliability and accuracy of IFASbased flood runoff analyses with satellite-based rainfall data, we need more frequent direct observation from space (i.e. GPM mission) and the coupling of satellite-based rainfall data with ground-based in-situ rain gauge data. 
Table 1. Major satellite-based rainfall products freely available on the Internet

\begin{tabular}{|c|c|c|c|}
\hline Productname & 3B42RT & CMORPH & GSMaP_NRT \\
\hline Developer and provider & NASA/GSFC & $\mathrm{NOAA} / \mathrm{CPC}$ & JAXA/EORC \\
\hline Coverage & \multicolumn{3}{|c|}{$N 60^{\circ}-560^{\circ}$} \\
\hline Resolution & $0.25^{2}$ & $0.25^{\circ}$ & $0.1^{\circ}$ \\
\hline Resolution time & 3 hours & 3 hours & 1 hour \\
\hline Time lag & 10 hours & 15 hours & 4 hours \\
\hline Coordinate system & \multicolumn{3}{|c|}{ WGS } \\
\hline Historical data & Dec 1997 . & Dec 2002 & Dec. 2007 \\
\hline Sensors & $\begin{array}{l}\text { TRMMMTMI } \\
\text { AqUa/AMSR-E } \\
\text { AMSU-B } \\
\text { DMSP/SSMI } \\
\text { IR }\end{array}$ & $\begin{array}{c}\text { Aqua/AMSR-E } \\
\text { AMSU-B } \\
\text { DMSPISSM/ } \\
\text { TRMMTMI } \\
\text { IR }\end{array}$ & $\begin{array}{l}\text { TRMMMTMI } \\
\text { Aqua/AMSR-E } \\
\text { ADEOS-II/ } \\
\text { AMSR } \\
\text { SSMA } \\
\text { IR } \\
\text { AMSU-B }\end{array}$ \\
\hline
\end{tabular}

practical and useful for poorly gauged river basins to use satellite-based rainfall data for flood forecasting purposes since it is difficult to prepare a fully designed network of telemeter rain gauges when starting the implementation of a flood forecasting system.

According to another study for the case of Typhoon Morakot in Taiwan in 2009, this method seemed effective to get the first-order approximated areal rainfall distribution in poorly-gauged river basins. Figure 4 clearly shows the effect of the self-correction method on $3 \mathrm{hr}-$ cumulative rainfall amount (mm) of JAXA-

GSMaP_NRT.

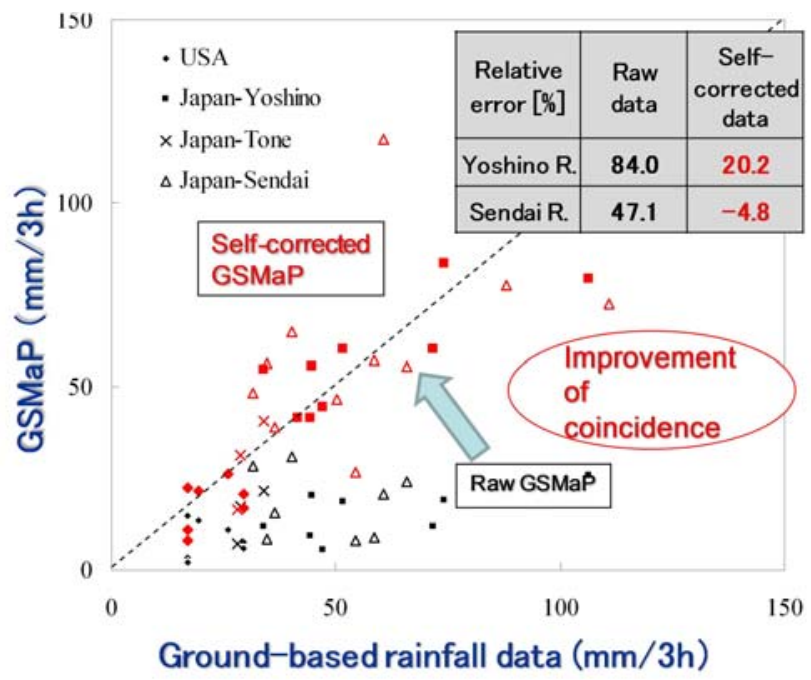

Figure 2. Comparison between satellite-based (JAXAGSMaP_NRT) and ground-based areally averaged rainfall data for a few river basins in Japan and USA.

(Black plots: raw GSMaP_NRT; red plots: self-corrected GSMaP_NRT)

Figure 3. Empirical relationship between spatial correlation (rainfallfield movement speed) and the degree of underestimation of JAXAGSMaP_NRT

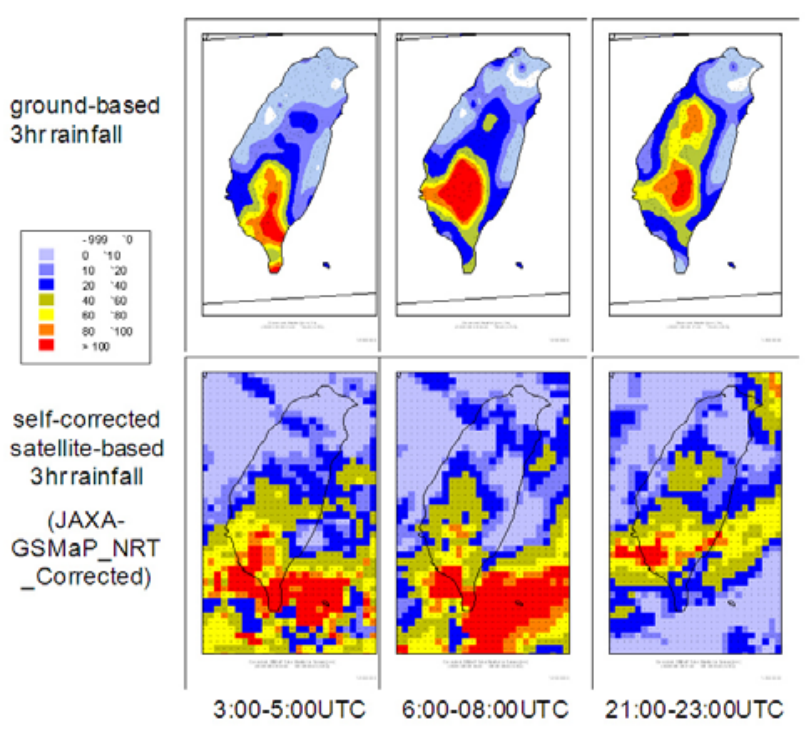

Figure 4. Comparison of temporal \& spatial distribution of ground-based (upper) and satellite-based (selfcorrected GSMaP_NRT, below) 3-hr cumulative rainfall, August 8, 2009 (Typhoon Morakot, Taiwan)

However, we also discovered some cases in which selfcorrected satellite-based rainfall data cannot reproduce flood hydrographs properly (Figure 5). It was clarified that such poor results could be obtained if the frequency of real observation of rainfall from space was insufficient during the rainfall increasing period. Therefore, it is almost apparent that we need the real implementation of Global Precipitation Measurement (GPM) mission, which has been planned by JAXA, NASA and other space agencies making it possible to observe any area in the world once every three hours (in 5-6 hours at present). Figure 6 shows another application of IFAS with self-corrected GSMaP_NRT rainfall data for hydrograph simulation at the Hkamti streamflow gauging station of the Chindwin River in Myanmar $\left(27,420 \mathrm{~km}^{2}\right)$. There is only one rain gauge at Hkamti and no rain gauge in the upstream area. Therefore, it is not surprising that runoff simulation with self-corrected satellite-based rainfall data was better than that with one rain gauge data, in the sense that the former hydrograph was not so coincident under low flow conditions but very successful in identifying three of the biggest flood peaks of 2008 . This suggests that self-corrected satellite-based rainfall data without any ground-based rain gauge data are insufficient not enough to precisely reproduce
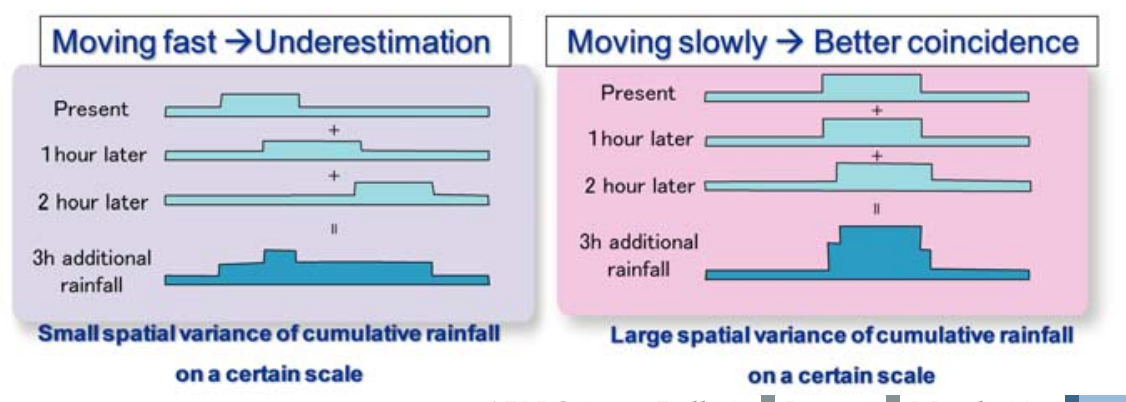


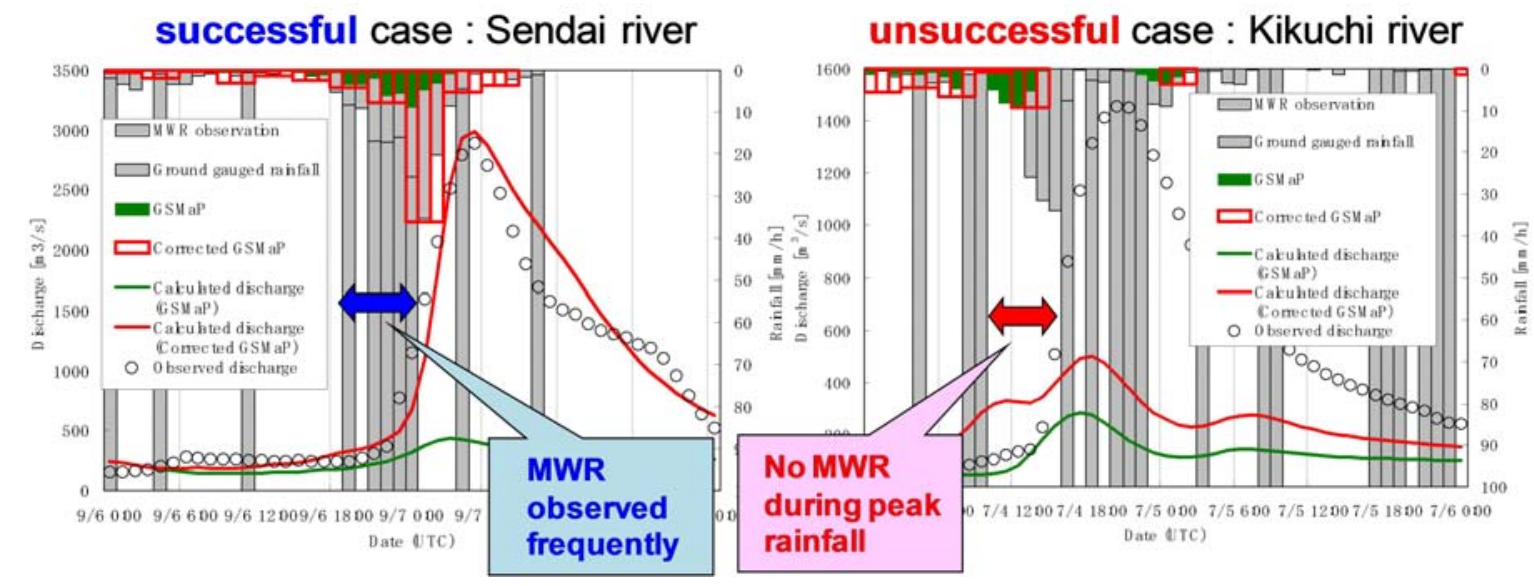

Figure 5. Difference of frequency of microwave radiometric observation from satellites between successful and unsuccessful cases to reproduce flood hydrograph

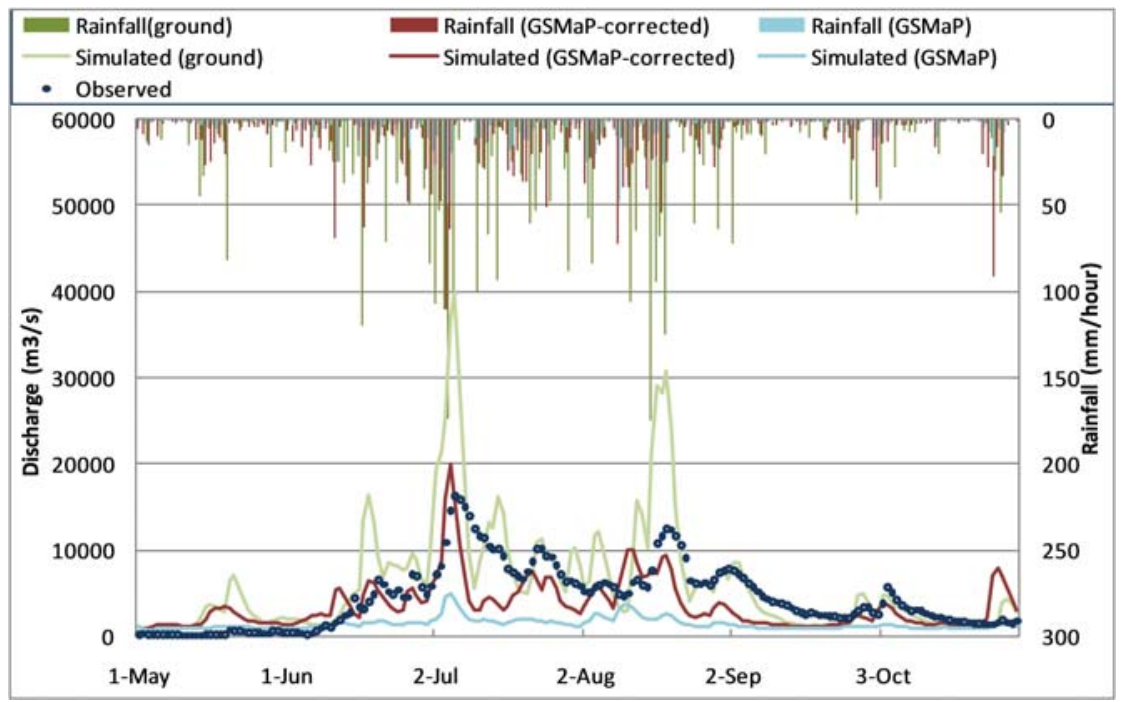

Figure 6. IFAS-based hydrograph simulation with ground-based \& satellite-based (raw \& self-corrected GSMaP) rainfall data and observed hydrograph for flood season of 2008 at Hkamti station of Chindwin River of Myanmar.

hydrographs from low to high flow, but still of some use to identify major extreme flood events.

\section{Conclusions}

Our tentative conclusions regarding the potential of IFAS and satellite-based rainfall data for flood forecasting and early warning are as follows:

i. The combination of satellite-based rainfall information (with ICHARM's original self-correction algorithm), global GIS data and IFAS has very high potential to promptly and efficiently implement a flood analysis \& forecasting system even in poorly gauged rivers;

ii. Namely, major extreme flood phenomena can be identified through satellite-based flood runoff analysis and forecasting even if hydrographs observing low to high flow are inaccurate and;

iii. To further improve the reliability and accuracy of IFAS-based flood runoff analysis with satellite-based rainfall data, we need more frequent direct observations from space (i.e. GPM mission) and the coupling of satellite-based rainfall data with groundbased in-situ rain gauge data.

\section{References}

- Sugiura, T. et al. 2009. Development of Integrated Flood Analysis System (IFAS) and its Applications. Proceedings of the $8^{\text {th }}$ International Conference on

Hydroinformatics, 12-16 January 2009. Concepción, Chile.

- Shiraishi, Y. et al. 2009. A proposal of correction method using the movement of rainfall area on satellite-based rainfall information by analysis in the Yoshino River Basin. Annual J. Hydraulic Eng., JSCE, 53, 385-390 (in Japanese).

\section{Acknowledgements}

The authors express sincere thanks to all members of the Flood Working Group activities of GEOSS-AWCI and for the financial support from APN, the University of Tokyo and Japan Aerospace Exploration Agency (JAXA), which made this international study possible. 


\title{
Good Water Governance: Could Stakeholder Participation Reduce Water Insecurities in River Basins in Asia-Pacific?
}

\author{
Elena Nikitina ${ }^{1}$, L. Lebel, B.T. Sinh
}

Corresponding author ${ }^{1}$

EcoPolicy Research and Consulting, Moscow, Russia. Email: elenanikitina@bk.ru

\begin{abstract}
This article focusses on water governance at a river basin level and the role of coordination, participation and partnerships between multiple stakeholders to reduce water insecurities they are facing. Water-related risks are attributed not only to escalating global and local changes, but to a high extent to failures in good water governance in river basins or their sub-basins. The key finding is that river basins in the Asia-Pacific region vividly demonstrate the emerging trend of state-centric governance evolving towards encompassing multi-stakeholder approaches. Broadening engagement, interaction and consolidating partnerships between public, private and civil society actors appears to be among the effective tools in good water governance. One of the messages is that stakeholder participation, related opportunities and barriers is a very 'context' oriented issue being dependent on existing specific national and local socio-economic, cultural, political and sustainability priorities. The article explores and compares stakeholder involvement and partnerships in water management in river basins in Australia, China, Russia, Thailand and Viet Nam. Findings are aggregated and contrasted to worldwide trends.
\end{abstract}

Keywords: stakeholder participation, partnerships, water governance, river basins

\section{Introduction}

Pervasive land-use and water-use changes are being compounded by changes in global climate to fundamentally alter water insecurity in all river basins across the Asia-Pacific region - in developed and developing countries, and in transition economies. Water risks include common challenges of shifting flood regimes, seasonal water shortages and multi-year droughts, deteriorating water quality, and problems of access to safe drinking water and sanitation. There is a growing recognition worldwide that poor water governance is among the major factors underlying aggravated water problems and risks. Inadequacies of existing water governance systems and mechanisms through which they currently perform in river basins, explain to a high extent the vulnerabilities of societies to water insecurities.

Today, new trends and patterns in water governance are emerging in Asia-Pacific countries. In many places, water governance begins to shift from strongly state-centric approaches towards more inclusive and participatory modes with greater opportunities for interactions between stakeholders. It becomes clear that success depends on multi-scale efforts not only by governments, who remain critical players, but also on the roles of other actors having an interest, or capacity, to act.

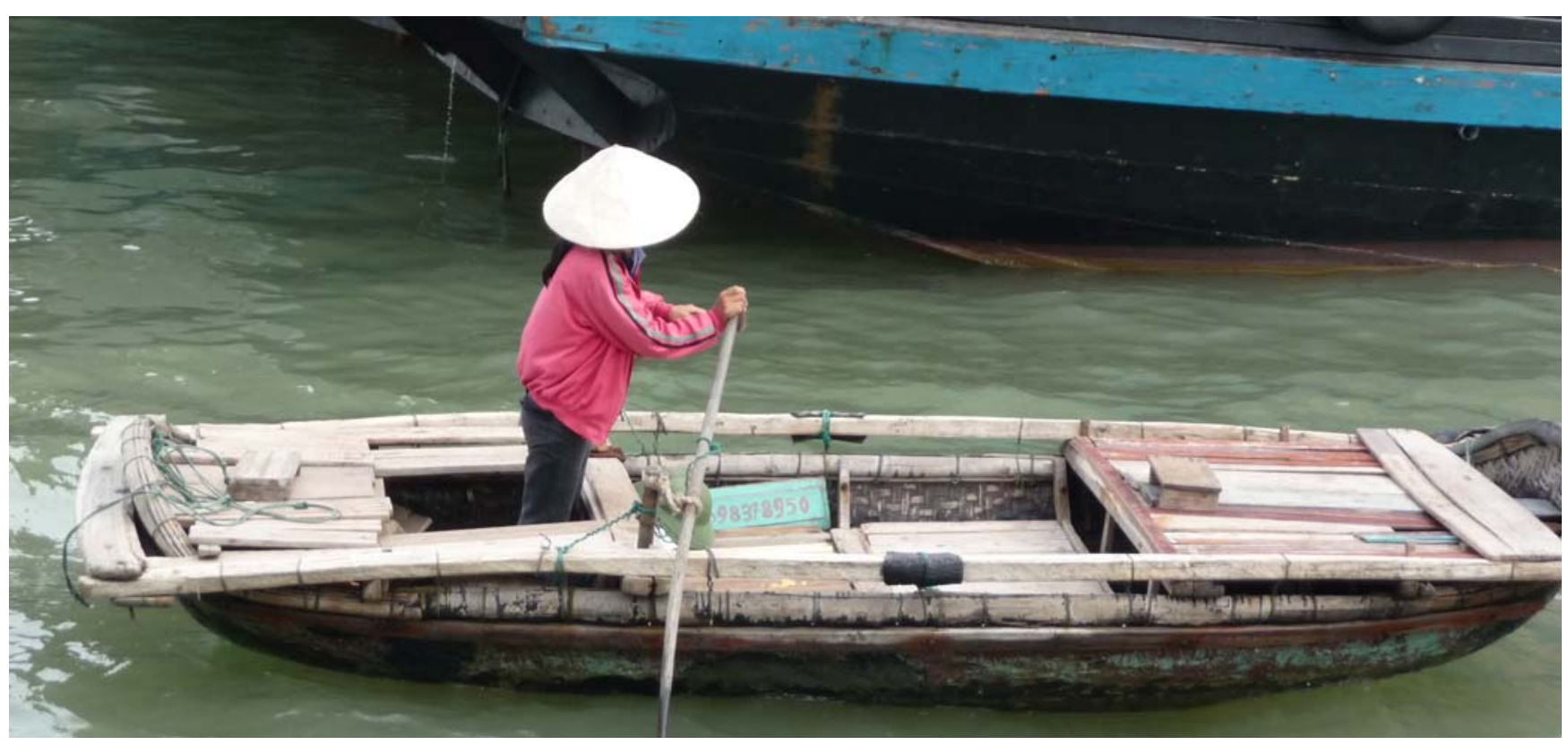


The present article presents the findings of a comparative and synthetic study based on gathering of new empirical data and new analyses of responses to reduce waterrelated risks with a particular focus on how stakeholders are engaged in water governance in river basins. It looks at the new trends and lessons learned about stakeholder participation in basin water management in five AsiaPacific countries: Red and Mekong in Viet Nam; Amur in Russia, Salween in China, Ping-Chao Phraya in Thailand, and Latrobe in Australia. Opportunities and constraints for stakeholder participation and lessons learned about success and failures are discussed.

\section{Material and Methods}

The research method was based on a comparison and synthesis of results from river basins in five Asia-Pacific countries, including findings related to (i) responses to water insecurities and their impacts ${ }^{1}$, (ii) roles and engagement of multiple stakeholders, and (iii) opportunities and limitations for stakeholder participation/partnerships in water governance. Three major clusters of stakeholders were compared within the country studies: government authorities at various levels, business, and civil society.

This was a country-based and river basin/sub-basin-based analysis and empirical data collection. The studies were undertaken in sub-basins of Latrobe in the Gippsland region of Australia, in northern sub-basins of the $\mathrm{Nu}$ Salween and northern Mekong in China, Ping-Chao Phraya in northern Thailand, Red and Mekong in Viet Nam and in the Russian provinces of the Amur.

Analytical exploration and data compilation about stakeholders' participation in river basins were organised according to a common format applied by each country case study. Aggregation of results from case-studies and comparing them with worldwide trends was also part of the research methodology applied.

\section{Results}

Our research shows that states in the Asia-Pacific river basins tend to respond to water-related insecurities with increasingly sophisticated institutional frameworks. This is a worldwide trend. A variety of water governance arrangements $^{2}$ are in place in all five countries under study and, taken together, they potentially provide substantial capacity to address water insecurities and to adapt to global change. But practices and their actual performance demonstrate many limitations, weaknesses and gaps (Kotov, 2009). There are a number of priorities for reforms and innovation, including, for example, application of integrated water resources management (IWRM) and basin-level planning and coordination, and adaptation to global change.

\section{ARCP2009-03CMY-Nikitina}

Reducing Water Insecurity through Stakeholder

Participation in River Basin Management in the AsiaPacific

Project Leader:

Dr. Elena Nikitina

EcoPolicy Research and Consulting

RUSSIAN FEDERATION

Tel: +79857733687

Fax: +7985 7733687

Email: elenanikitina@bk.ru

APN Funding:

US $\$ 95,000$ (For 2 Years)

\section{Research Highlights}

- Diversified water governance systems are in place in many Asia-Pacific countries: potentially providing substantial capacity to address water insecurities and to adapt to global change.

- Water governance in the region is gradually shifting from strongly state-centric approaches towards more inclusive and participatory modes with greater opportunities for interactions between stakeholders.

- Success in water-related risk reduction depends on multi-scale efforts not only by governments, who remain critical players, but also on the roles of other actors having an interest, or capacity, to act.

- Stakeholder participation and partnerships between state and non-state actors is a good tool in dealing with water-related insecurities.

- Stakeholder engagement is a very 'context' oriented issue that is dependent on existing specific national and local socio-economic, cultural, political and sustainability priorities.

Today, water governance begins to gradually shift towards more inclusive and participatory modes with greater opportunities for interactions between stakeholders. They include state and non-state actors. The synthesis shows that a variety of different stakeholders are involved in water management in river basins. Interests, capacities, influence and power of stakeholders vary widely across problem domains and scales (Nikitina et al., 2010).

\footnotetext{
${ }^{1}$ The set of risks analysed includes (1) water quality, especially the quality of drinking water, (2) water supply and water availability for agriculture; (3) floods, (4) water in urban areas. Exploring possible insecurities associated with global climate change is emphasised.

${ }^{2}$ Existing arrangements include, for example, legislation, programs, water administrations and river basin organisations, pollution and flood control institutions, water services, management of hydro technical facilities, as well as bilateral and multilateral arrangements in shared rivers.
} 


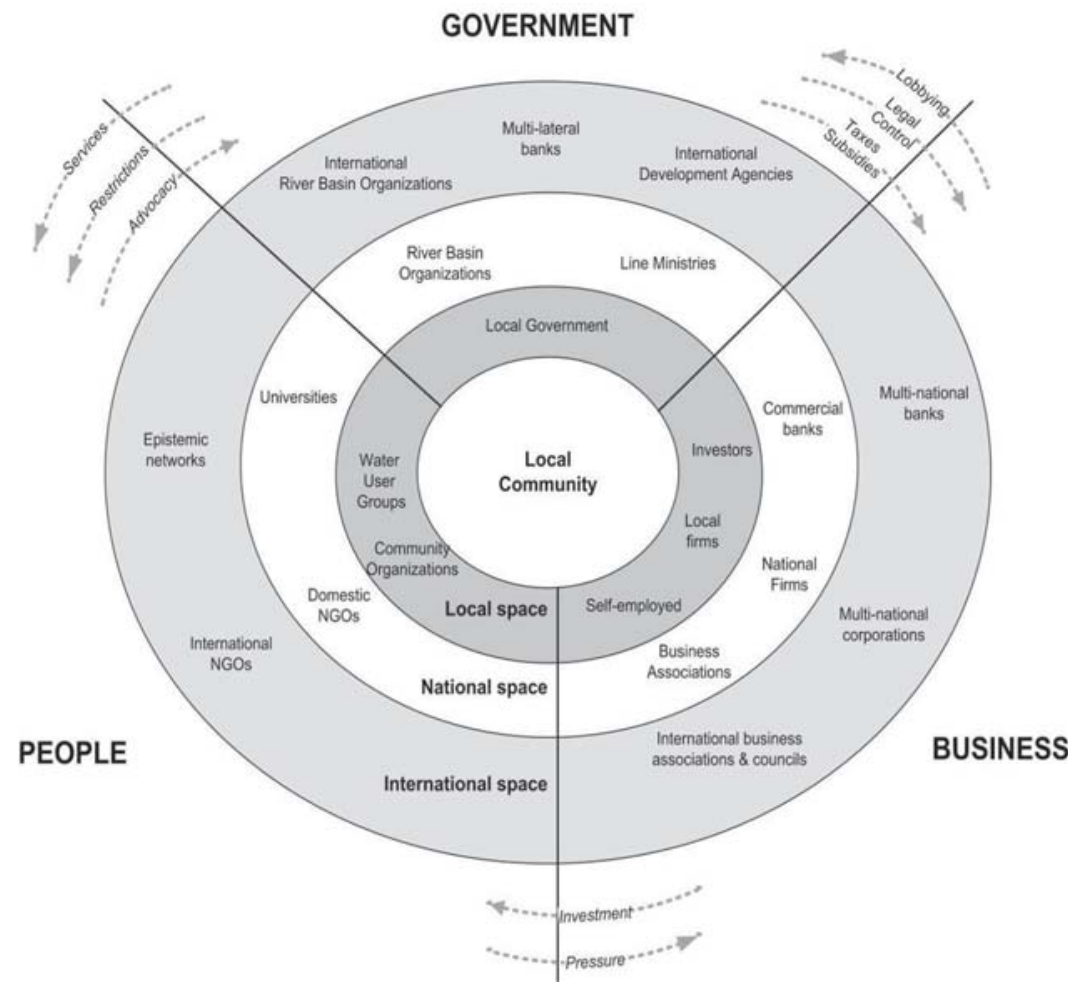

Figure 1. Conceptual framework for thinking about different types of stakeholders at different levels

While discussing the issues of stakeholder participation it is often perceived that stakeholders mainly include actor groups representing the public. But, we suggest a wider approach that encompasses the multiplicity of stakeholders, including, for example, government authorities, river basin organisations (RBO) and intergovernmental international bodies and the private sector. Close interactions between them is a key to good water governance. Aggregated findings from river basins indicate that stakeholders can be classified into three main actor groups- government authorities, business and people- at different levels (Figure 1). The stakeholder meta-class 'people' in this framework is also described as 'civil society' or 'non-profit' or 'the public' by others.

There is a number of common features of stakeholder involvement in river basins in the Asia-Pacific: (i) in all countries and river basins stakeholder engagement is an underlying trend during the last decade; (ii) although forms of public engagement vary significantly - from dialogues and discussions on water planning, or better flood protection, to regular participation in activities, river basin councils their set is typical for major river basins; (iii) the role of the government, river basin authorities in water management remains high in all countries; (iv) the increased role of various businesses is a new trend; (v) public participation is widely touted as critical to gaining public acceptance for policies and projects; (vi) in developing countries and transition economies the role of international agencies and organisations in mobilising stakeholder involvement is high; and (vii) relationships between actors are critical and success depends on the ability to develop mutual trust between actors: when government agencies are committed and play active roles to promote increased partnerships, it increases the chances for successful outcomes (Lebel and Sinh, 2009)

\section{Discussion}

Integrated approaches to river basin water management imply more frequent engagement with a broader diversity of stakeholders from within government, business and public spheres. One of the messages from our studies is that stakeholder participation needs to be further supported and promoted through various incentive mechanisms and capacity building, through enhancing awareness-based approaches, information sharing, dialogues, consultations, constructing state-private partnerships, organising campaigns for rehabilitation of river sites and joint actions in flood risk reduction at the locales.

Cross-country comparisons indicate that the extent of public awareness and participation in water management varies significantly across cases and river basins. Public participation as a social norm is more extensive in Thailand than in either Russia or Viet Nam. Here, the domestic non-governmental organisations and various advocacy networks regularly challenge state policies and decisions on water-related infrastructure with critiques in mass media and well-organised protests and campaigns. In Russia, environmental awareness of the public and responsibility to take water-related actions are low, and the public still heavily relies on 'paternalism' of government authorities; environmental awareness had been subdued during the communist regime (Nikitina et al., 2009). In Australia, with its well developed democratic traditions, civil society involvement is much higher.

Detailed pathways and mechanisms through which stakeholder participation and coordination reduce water insecurities deserve further investigation. Potentially important mechanisms include: (i) making interests, capacities and risks of the most vulnerable groups, 
otherwise marginalised from assessment and planning procedures, more visible within and across national boundaries; (ii) wider sharing and better understanding of knowledge and practices, critical for the reduction of disaster risks; (iii) social learning around risks and vulnerabilities leading to new management goals and more opportunities for collective responses, linking where appropriate domestic and international efforts; and (iv) higher public acceptance of policies and measures proposed by governments or under international agreements (Lebel et al., 2009).

The study provides a great deal of evidence about good practices and useful lessons learned from experiences in stakeholder participation and partnerships in the countries of Asia-Pacific on how to deal with water-related insecurities (Lebel et al., 2010). More attention should be given in the future to selecting mechanisms and tools for exchange of good practices across countries. At the same time, in many cases direct automatic transfer of national experiences without their prior adaptation to natural, socio-economic, cultural and political specifics of the recipient river basins of the Asia-Pacific region does not always provide for expected results. Thus, 'transfer and adaptation' of good practices and experiences should go hand in hand; analysis and assessment of related problems and challenges is among one of the important avenues for future action.

More theoretical and practical thinking needs to be given to assessing particular roles and influences of each stakeholder group in the river basins under study, and to understanding how stakeholder participation-partnerships are, or will be, embedded into water governance regimes and in future institutional innovations.

\section{Conclusions}

Institutional reforms undertaken in the water sector are frequently unsuccessful in meeting mandates and targets. Constraints and limitations for good water governance include: (i) shortages in public policies and their performance, (ii) weaknesses in identifying clearly waterrelated risks and respective response options, (iii) inadequate coordination (horizontal and vertical) between actors, (iv) poor support and incentives for stakeholder engagement, (v) weak respect of the rights of indigenous groups and those actors who have 'long-standing relations with a river,' (vi) limited use of scientific and traditional knowledge, and (vii) fragmented adaptation by stakeholders to climate change. These are regarded as common gaps in addressing water insecurities through existing water management systems in river basins under study. They are compounded by specific problems and 'situational factors' in particular places.

Stakeholder participation is expanding in all river basins under study, although the scales and forms vary across basins. More intensive and diversified lies in those countries with developed economies and democracies
(Australia), while in transition societies (Viet Nam, China, Russia) it is more limited for various reasons, including the heritage of the centrally planned systems and lower public awareness. The importance of non-state actors across all river basins is growing. Multiple local stakeholders such as business, indigenous people organisations, households, non-governmental organisations, river councils and sub-national units of government, are starting to play increasing roles in reducing water-related insecurities. The role of the government and river basin authorities in water management remains high in all countries.

\section{References}

- Kotov, V. 2009. Russia: Changes in water management and the water law, in: Dellapenna, J., Gupta, J. (Eds.), The Evolution of the Law and Politics of Water. Springer Science-Business Media BV.

- Lebel, L. and Sinh, B.T. 2009. Risk reduction or redistribution? Flood management in the Mekong region. Asian Journal of Environment and Disaster Management. 1, 23-39.

- Lebel, L., Foran, T., Garden, P., and Manuta, B.J. 2009. Adaptation to climate change and social justice: challenges for flood and disaster management in Thailand, in: Ludwig, F., Kabat, P., Van Schaik, H., Van der Valk, M. (Eds.). Climate change adaptation in the water sector. Earthscan, London.

- $\quad$ Lebel, L., Sinh, B. T., Nikitina, E., 2010. Governing risks: climate change, water insecurities, and disaster management, in: Shaw, R. (Ed.), Climate Change Adaptation and Disaster Risk Reduction, Emerald Publishers.

- Nikitina, E., Ostrovskaya, E., and Fomenko M. 2009. Towards better water governance in river basins: Some lessons learned from the Volga. Regional Environmental Change, Springer. 9,2, 1-13.

- $\quad$ Nikitina, E., Lebel, L., Kotov, V., and Sinh, B.T. 2010. How stakeholder participation and partnerships could reduce water insecurities in shared river basins, in: Ganoulis, J. (Ed.). Water Resources Across Borders: A Multidisciplinary Approach to Transboundary Water Management. Wiley VCH, Germany.

\section{Acknowledgments}

This article is based on results of a two-year close collaboration of all APN project partners and their teams. We thank external experts for their advice and contributions. We thank national organisations for support of our activities, including Unit for Social and Environmental Research, National Institute for Science and Technology Policy and Strategy Studies, EcoPolicy, Russian Scientific Fund on Humanities, and collaborating international projects, including Twin2Go, M-Power, CABRI, ASEMWaterNet. We would like to extend our sincere appreciation for the APN support. 


\title{
Global Change and Capacity Building in Coral Reef Management in the Pacific: Engaging Scientists and Policy-Makers in Fiji, Tonga, Samoa and Tuvalu
}

\author{
G. Robin South ${ }^{1}$, S. Bala, P. Chand, L. Limalevu, C. Morris, J. Veitayaki, C. Wilkinson
}

Corresponding author ${ }^{1}$

The University of the South Pacific, Institute of Marine Resources, Alafua Campus, Samoa. Email: south_g@usp.ac.fj

\begin{abstract}
Four successful workshops on Climate Change Adaptation were held for 130 senior officials from Fiji, Samoa, Tonga and Tuvalu between June and August 2010. These workshops, organised by the University of the South Pacific, featured briefings on likely impacts of climate change on Pacific Islands and sought suggestions for policy changes for island adaptation. Climate change will increase existing threats to coral reefs due to unsustainable fishing, pollution from the land and habitat destruction via sea level rise, sea temperature rise, ocean acidification and increased strengths of cyclones. Rapid population growth will exacerbate these. All countries recognise the threats posed by climate change and have signed relevant United Nations (UN) Conventions and Agreements. They all have policies to tackle climate change threats. However, the governments have a lack of capacity to seriously address climate change threats and these are yet to be incorporated as a cross-cutting theme among the relevant government departments. The countries recognise a need to raise awareness of the issues and include these in school curricula, which are often based on developed country models. Tonga recognises that existing government departments will need to improve communication and coordination to develop an integrated approach. Fiji questions whether a national ocean policy could serve the purpose of addressing issues such as
\end{abstract}

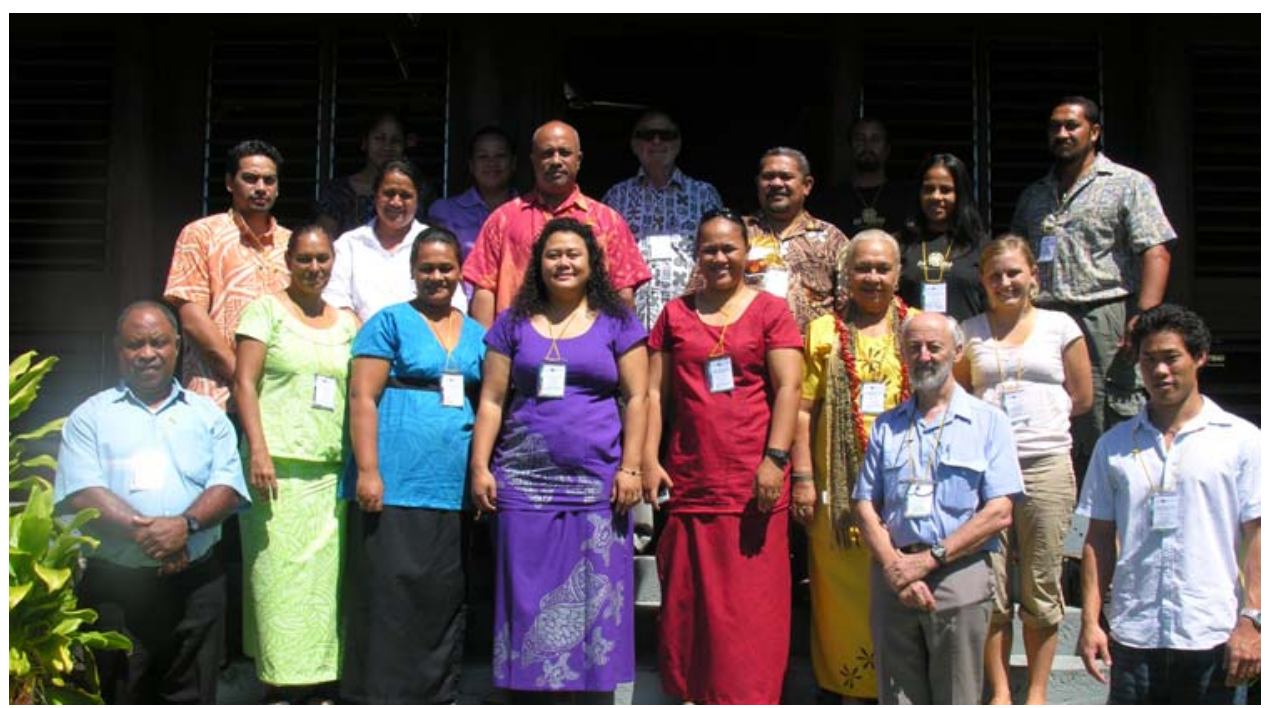

sustainable fisheries management (including ecosystembased management), cross-sectoral corporation, linking scientists with policy makers, education and awareness. Samoa recognises the challenges presented by developing an integrated approach, which involves cutting across ministries. Tuvalu has several existing social and economic threats despite their traditional leadership system. The governments recognise that an expansion of Marine Protected Areas (MPAs) offers a potential mechanism, however only Fiji and Samoa have active MPA programmes in association with user communities. The countries recognised that building on the Regional Oceans Policy template approved by the Forum Leaders in 2002 was an essential first step in improving policy and all recognise the important role of climate change in the long-term sustainability of their marine resources and food security.

\section{Introduction}

Healthy coral reefs are vital to the sustainability of the peoples' livelihoods in the Pacific Islands. However, global change including sea level rise, increased sea surface temperature, ocean acidification, and numerous natural phenomena like cyclones coupled with the effects of higher population, have increasing and often worsening impacts on Pacific coral reefs, leading to increased vulnerability of coastal communities. Integrating the knowledge of global change across various national government sectors, then translating this into policies that lead to sustainable management of coastal ecosystems is the challenge that the present project is ultimately aimed at addressing. The project brought senior Pacific Leaders in Fiji, Tonga, Samoa and Tuvalu together with scientists and experts on the sustainable management of coral reefs, so that they could be apprised of the impacts of global changes and 
of those factors that are affecting the health of their coral reefs. This engagement process was conducted through face-to-face dialogue between reef experts familiar with the science of climate change, and government, non-governmental organisations and civil society personnel responsible for the development of appropriate policies focussing on the sustainable management of coral reefs in the four target countries.

\section{Methodology}

Workshops were held between June and August 2010, at which some 130 senior officials from the four countries attended. Prior to the workshop, detailed country dossiers were prepared by the project team in consultation with the countries. The workshop format comprised presentations on the current status of coral reef and climate change issues and policies and some existing initiatives given by the project team leaders, government officials, NGOs and civil society representatives. Following open discussions, break-out groups reviewed and analysed the needs and gaps (as per country dossier) and recommended modifications, additions and comments. The resulting conclusions were then discussed in Plenary, where a national coral reef action plan was formulated using the suggestions from the breakout groups.

\section{Results and Discussion}

Most people heavily depend on coral reefs and their resources for their livelihood especially in the Pacific Islands. This over dependence on coral reef ecosystems can have adverse effects to the continuance of a balanced ecosystem. Some of the major threats that affect the reef ecosystem are: global climate change, overfishing, pollution, coastal development and biological threats. Exacerbating all of these is rapid population growth. All of these threats are evident to greater or lesser extents in the target countries. However, monitoring results in the South West Pacific have indicated that reefs in this region appear to be resilient in the face of continuing acute threats from increased sea surface temperatures, cyclones, tsunamis and crown of thorns, although there are suggestions that reefs are experiencing an increase in exposure to chronic stresses such as human-induced impacts, which are difficult to measure (Whippy-Morris, 2009). As suggested by Veitayaki et al., (2007), the challenge for the Pacific Islands is to design and institute a disaster management plan at the regional, national and district local levels.

\section{Conclusions}

Although there are great differences among the four target countries in terms of size, environment, culture and population, the workshops agreed on a number of common and recurrent themes. All of the countries are signatory to the relevant UN Conventions and Agreements relevant to global change and the environment, although for some, reporting presents

\section{CBA2010-15NMY-South}

Global Change and Coral Reef Management

Capacity in the Pacific: Engaging Scientists and Policy-

Makers in Fiji, Samoa, Tuvalu and Tonga

Project Leader:

Prof G. Robin South

Institute of Marine Resources

University of the South Pacific

FIJI

Tel: +6793232151

Fax: + 6793232158

Email: robin.south@orda.com.au; south_g@usp.ac.fj

APN Funding:

US\$ 40,000 (15-month period)

challenges. All countries have in place and are currently reviewing or updating necessary policies regarding the conservation and sustainable use of their coral reefs and marine resources, and all recognise the important role of climate change in the long-term sustainability of their marine resources and food security, but climate change issues have not yet been incorporated as a cross-cutting theme among the relevant government departments. In Tonga, for example, the Ministry of Environment and Climate Change seeks to put things in perspective under one umbrella, but it was evident that there are difficulties between them and Fisheries regarding allocation of funding and responsibilities.

In general, the governments recognise the need for integrated planning, but there is a need to improve communications among those line departments responsible for the management of coral reefs: for some this will require a significant change in mind-set and modus operandi. There was a universal lack of knowledge of the 2002 Pacific Islands Regional Oceans Policy (PIROP), developed and approved by the Forum Leaders and presented at the World Summit on Sustainable Development (WSSD) held in Johannesburg, South Africa. In discussions, two countries (Tonga and Tuvalu) resolved to examine the possibility of using the PIROP as a template for the development of National Oceans Policies.

The need to raise public awareness about global change and coral reef issues were recognised by all, as was the need to find ways to incorporate marine issues in the school curriculum. Much of the curriculum is currently based on developed country principles. This would require the necessary teacher education. Common threats to coral reefs throughout the region include unsustainable fishing causing stock depletion, pollution from land-based sources, habitat destruction and global climate change. All of these threats are evident to greater or lesser extents in the targeted countries. 
All four countries recognise over-fishing and depletion of reef fish stocks as a major problem and this, coupled with ever-increasing population growth rates indicate that there will be serious fish shortages within the next twenty years, unless some strong conservation and management measures are put in place. The importance of monitoring in support of management and policy is considered a high priority in all countries, although the lack of monitoring capacity is a limiting factor. The difficulty in enforcement of fishery regulations is a serious problem throughout, largely because of a lack of capacity and the logistical challenge posed by the scattered nature of islands. Alternative livelihoods will need to be developed for disenfranchised fishers. The expansion of aquaculture is seen as a possible replacement source for reduced protein supplies; however, the scope for this is limited in Samoa and Tuvalu. With the exception of Fiji, National Biodiversity inventories are seriously inadequate and much of the marine biodiversity, with the exception of commercially important species, is unrecorded. All countries recognised the need for much more work on the development of their National Marine Biodiversity Inventories (NMBIs). The scarcity of national or regional experts in taxonomy is a hindrance and training in this area is urgently needed.

The establishment and management of MPAs (or similarly designated areas) is of high priority in all the countries, as well as the recognition of the important role they play in conservation; but only in Fiji and Samoa has this reached a high level of community engagement through the Fiji Locally Managed Marine Areas programme, and the Village Fish Reserves, accompanied by Village By-Laws in Samoa. Community engagement was seen as crucial to the long-term effectiveness of protected areas. Tonga has a variety of reserves and parks, with policies and community engagement still evolving, whereas in Tuvalu there is only one significant MPA (involving strong community participation), while the Falekaupule (traditional assembly) in the outer islands are exercising control in the use of their fisheries resources.

The project team will re-visit the target countries in 2011 in order to measure progress in the implementation of their workshop actions and/or respective coral reef action plans.

\section{References}

- Foale, S. 2008. Conserving Melanesia's coral reef heritage in the face of climate change. Historic Environment. Vol 21. No.1.

- Gillie, R. 1994. Distinctive physical features of Pacific Island coastal zones. In: Coastal protection in the Pacific Islands: current trends and future prospects. Proceedings of the first and second regional coastal protection meetings held 21-23 February 1994 in Apia, Western Samoa and on 16-20

\section{The workshops} identified the following action for follow up:

- Need to upgrade NMBIs, and for surveys in Tonga, Samoa and Tuvalu.

- Introduction of the Seagrass Watch programme recommended for Tonga and Samoa.

- Development of a regional climate change clearing house proposed, preferably at USP.

- Need for capacity building in all countries.

- Need to address the disconnection between communities, government and other players.

- Need to harmonise projects so as to have better coordination among agencies.

- Need to assist with the marine science programme at the National University of Samoa.

- Need to raise public awareness of coral reef issues, and to find ways of introducing relevant curriculum in schools.

- Support the Two Samoas initiatve.

- Facilitate attachments of USP students with their home governments.

- Introduce coral identification training in Tonga, Samoa and Tuvalu.

- Encourage closer cooperation with SPREP on coral reef and coral reef management issues.

- Need for good governance at the community level.

- Need for continuous monitoring in support of government policies, and create relevant statistics on stock and fishing in order to understand trends. Need for more MPAs 
May 1994 in Suva, Fiji. Secretariat of the Pacific Regional Environment Programme and South Pacific Geoscience Commission.

- Lovell, E. 2004. Baseline biological survey of Tu'atuga reef (5 mile reef), Samoa. Unpublished report.

- Lovell, E., Sykes, H., Deiye, M., Wantiez, L., Garrigue, C., Virly, S., Samuelu, J., Solofa, A., Poulasi, T., Pakoa, K., Sabetian, A., Afzal, D., Hughes, A., and Sulu, R. 2004. Status of Coral Reefs in The South West Pacific: Fiji, Nauru, New Caledonia, Samoa, Solomon Islands, Tuvalu and Vanuatu. In: Status of Coral Reefs of the World: 2004. Vol. 2. pp. 337-361. C. Wilkinson. Global Coral Reef Monitoring Network. c/- Reefs and Rainforest Research Centre, Townsville, Australia.

- Lovell, E. 2005. Coral Bleaching In Fiji and the South Pacific. PIMRIS Newsletter.Vol. 17. No. 4. PIMRIS Coordination Unit. Marine Studies Programme, University of the South Pacific.

- $\quad$ Lovell, E., Samuelu Ah Leong, J., Bell, L., Ifopo, P., McAdoo, B., Skelton, P., and Ward, J. 2009. Inspection of selected coral reefs on Upolu Samoa following the 30 September 2009 Tsunami. Unpublished report.

- Mosley, L. and Aalbersberg, B. 2005. Nutrient levels and macro-algal out-breaks in Fiji's coastal waters. IAS Technical report No. 2005/01. University of the South Pacific.

- Newton, K., Cote, I.M., Pilling, G.M., Jennings, S., and Dulvy, N.K. 2007. 'Current and future sustainability of island coral reefs fisheries' Current Biology 17, 655-658, April 3.

- Palaki, A., Samani, T. and Masi, M. 2005. Soil sedimentation effect on the coastal marine environment, Tefisi Village, Vava'u. Department of Environment, Tonga. Unpublished report.

- Pippard, H. 2009. The Pacific islands: an analysis of the status of species as listed on the 2008 IUCN Red List of Threatened Species ${ }^{\mathrm{TM}}$. International Union for Nature Conservation.

- $\quad$ Pomeroy, R.S., Parks, J.E., and Balboa, C.M. 2004. 'Farming the reef: is aquaculture a solution for reducing pressure on coral reefs?'. Marine Policy. 20p.

- Roberts, C.M. 1995. 'Effects of fishing on the ecosystem structure of coral reefs,' Conservation Biology, 9 (5): 988-995pp.
- Sadovy, Y. and Domeier. 2005. Are aggregationfisheries sustainable? Reef fish fisheries as a case study. Coral Reefs (2005) 24: 254-262.

- Samuelu, J.I. and Sapatu, M. 2007. 'Status of Coral Reefs in Samoa,' In: Status of Coral Reefs in the South-West Pacific: 2007,' Cherie Whippy-Morris (Ed), CRISP publication.

- $\quad$ Scales, H., Balmford, A., and Manica, A. 2007. 'Impacts of the live reef fish trade on populations of coral reef off northern Borneo,' Proceedings of the Royal Society B 274: 989-994.

- Solomon, S., Qin, D., Manning, M., Alley, R.B., Berntsen, T., Bindoff, N.L., Chen, Z., Chidthaisong, A., Gregory, J.M., Hegerl, G.C., Heimann, M., Hewitson, B., Hoskins, B.J., Joos, F., Jouzel, J., Kattsov, V., Lohmann, U., Matsuno, T., Molina, M., Nicholls, N., Overpeck, J., Raga, G., Ramaswamy, V., Ren, J., Rusticucci, M., Somerville, R., Stocker, T.F., Whetton, P., Wood, R.A., and Wratt, D. 2007: Technical Summary. In: Climate Change 2007: The Physical Science Basis. Contribution of Working Group I to the Fourth Assessment Report of the Intergovernmental Panel on Climate Change [Solomon, S., Qin, D., Manning, M., Chen, Z., Marquis, M., Averyt, K.B., Tignor M., and Miller, H.L., (Eds.)]. Cambridge University Press, Cambridge, United Kingdom and New York, NY, USA.

- Veitayaki, J., Manoa, P., and Resture, A. 2007. Addressing climate change and sea level rise in the Pacific Islands.

- Whippy-Morris, C. (Ed.) 2009. South-West Pacific status of coral reefs report 2007. CRISP.

\section{Acknowledgements}

The Global Change and Capacity Management in the Pacific Project (CBA2010-15NMY-South) would not have been possible without the financial support provided by the Asia-Pacific Network for Global Change Research (APN). The Institute of Marine Resources is appreciative of this opportunity. The Institute of Marine Resources gratefully acknowledges our partners, the Pacific Centre for Environment and Sustainable Development and START Oceania at the University of the South Pacific (USP).

In addition, our gratitude to the Governments of Fiji, Tonga, Samoa and Tuvalu, the USP centres in Tonga and Samoa and the Secretariat of the Pacific Regional Environment Programme for their logistical support and encouragement.

\section{websites}

http: //www.msnbc.msn.com/id/33358072/

http://www. tellusconsultants.com/Thread/ACANTH. HTM

http://www.sprep.org/topic/marine.htm

http://www. noaa.gov

http://www.coris.noaa.gov 


\title{
Global Environmental Change and Food Security in the Indo-Gangetic Plain
}

\author{
Ajaya Dixit ${ }^{1}$, Kanchan Mani Dixit \\ Corresponding author ${ }^{1}$ \\ Nepal Water Conservation Foundation, Nepal. Email: adbaluwatar@ntc.net.np; adbadbaluwatar@wlink.com.np
}

\begin{abstract}
The intensification of technological and economic globalisation escalating the emission of greenhouse gases (GHGs) into the atmosphere has contributed to global climate change. The result is more erratic rainfall, frequent and intense floods and increasing water scarcity (NCVST, 2009). Both flood and drought affect food security in many developing countries. Because they own few assets, are uneducated, have no skills, and are, in general, deprived, many poor people do not possess the ability or the resources to recover when extreme floods and droughts disrupt their livelihoods. Since conditions on which their livelihoods depend are increasingly stressed, their lack of capacity to respond to these impacts implies that poor people will continue to live in an impoverished condition. The consequences of these changes in food security on the poor are serious and varied, depending on the food production systems involved. This challenge in the Indo-Gangetic Plain (IGP) is serious. The present collaborative study attempts to understand food system vulnerabilities and identify its challenges in IGP.
\end{abstract}

Keywords: food system, vulnerability, IGP, food system determinants, adaptation, GEC

\begin{abstract}
Introduction
Climate change is only one of the processes transforming societies in the IGP. Other drivers are urbanisation and the penetration of communication systems. As both proceed, populations, particularly those in urban regions and nearby towns, are growing increasingly dependent on ecosystems outside their immediate environments for meeting their water and food needs. Even rural populations import food, opening them up to new sources of vulnerabilities. As urbanisation and developments in communication continue apace and ecosystems degrade, the dependence of local populations on globalised labour, products and markets increases. Indeed, while the impacts of climate change differ according to local conditions, many of these impacts are transmitted to local regions through interactions with globalised systems to create second-order impacts.
\end{abstract}

Food systems contribute to environmental and other insecurities as interactions between and within biogeophysical and human environments influence both food system activities and their outcomes (Ericksen, 2007). The over-extraction of groundwater to

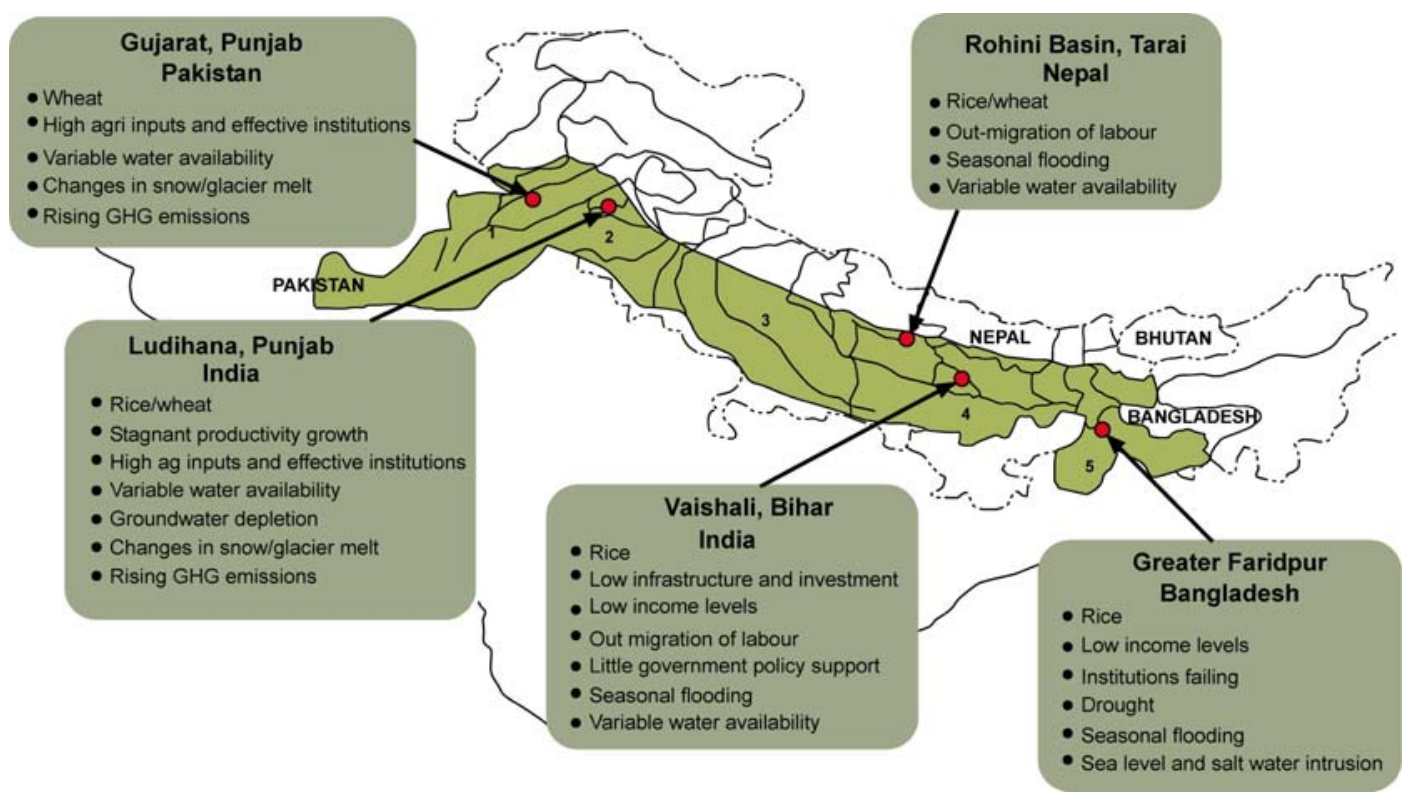

Figure 1. Study sites in IGP Source: Modified from GECAFS (2008) 
overcome drought and the rising demand associated with population growth and development, and the deterioration of surface water sources through pollution have placed additional stress on food systems.

Food system vulnerability can be conceived as both a function and the outcome of the intersection of marginality and the exposure of systems to climate shocks. No matter what the climate change scenario of the future is, local food security will be affected and addressing this issue will require the consideration of multiple expressions of vulnerability. FAO (2009) has predicted that food production will have to increase by $70 \%$ by 2050 in order to feed an additional 2.3 billion people and there will have to be much more effort to improve the distribution of and access to food.

The Nepal Water Conservation Foundation (NWCF) with support from the Asia-Pacific Network for Global Change Research (APN) conducted a collaborative study in the IGP to understand food system vulnerabilities, examined from the systemic perspective of food security dimensions: food availability, food accessibility, and food utilisation (Figure1).

The collaborating partners of the study were: Gorakhpur Environment Action Group (GEAG), Global Change Impact Studies Centre (GCISC), Pakistan and Punjab Agricultural University (PAU), Centre for Global Change (CGC), Bangladesh. In addition, the Global Environmental Change and Food Systems (GECAFS), London officers and the Australian National University faculties supported the study.

\section{CRP2008-01CMY-Dixit}

Improving Policy Responses to Interactions between Global Environmental Change and Food Security across the Indo-Gangetic Plain (IGP)

\section{Project Leader:}

Dr. Ajaya Dixit

Nepal Water Conservation Foundation (NWCF)

Post Box 2221, Patan Dhoka, Lalitpur

NEPAL

Tel: +977 15542354

Fax: +97715524806

Email: adbaluwatar@ntc.net.np;

adbaluwatar@wlink.com.np

APN Funding:

US\$180,000 (For 3 Years)

Agricultural and food systems are influenced by socioeconomic conditions, which themselves are affected by macro-level policies and the spread of infectious diseases. These systems, along with changes in climate and demographics and poor agriculturerelated infrastructure and widespread poverty contribute to food insecurity in the IGP. The predicted rise in food insecurity and its negative outcomes lower the potential of the IGP, which is characterised by fertile soil, a favourable climate and an abundant supply of water (Agrawal et al., 2004). Its people depend on small-scale and rain-fed agriculture and are among the poorest in the world. Their poverty is often attributed to the regular floods and drought that prevail afterwards (Bandhyopadhyaya, 1999). One of the

\section{Local food collection point: How will climate change and other stressors affect these decentralised systems and contribute to local food insecurity?}

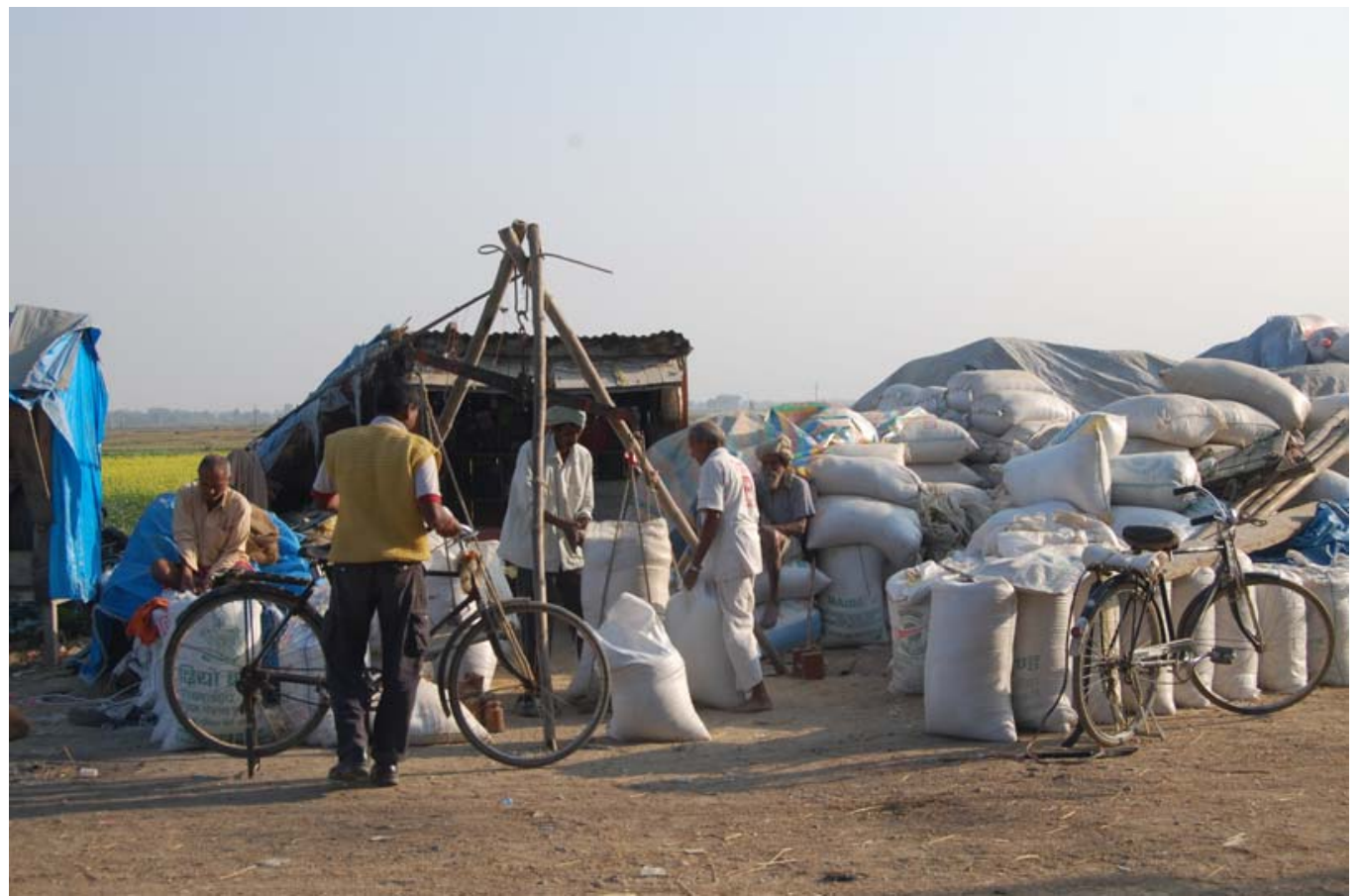




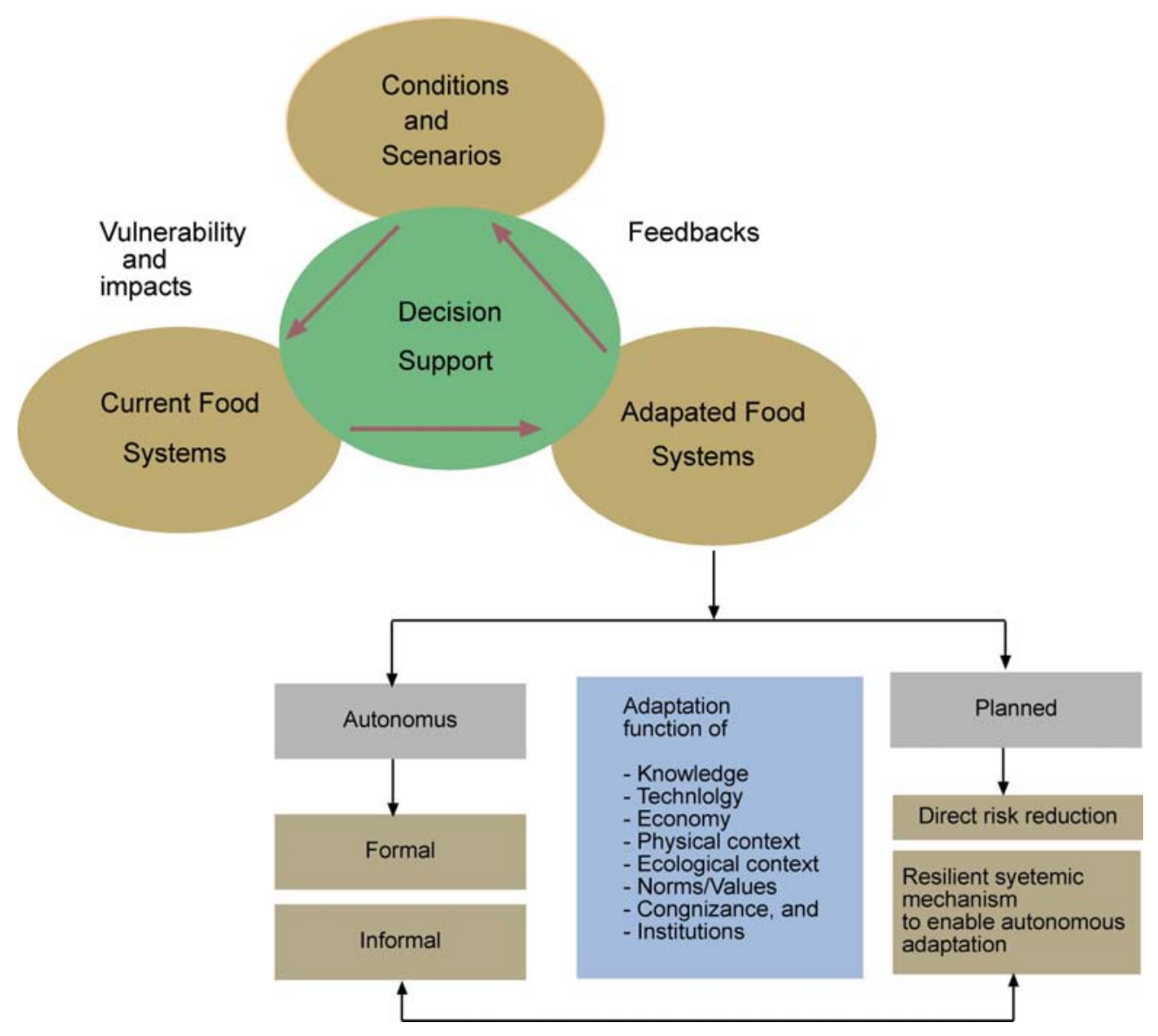

Figure 2. Conceptualising food system adaptation Modified from GECAFS 2008

major impacts of climate change in the IGP will be serious as precipitation is likely to be more uncertain. A downscaling exercise by Stapleton and Gangopadhya, (2009) in the Rohini Basin, which is a small basin in the IGP, suggests that local climate will become more erratic as more GHGs are emitted into the atmosphere.

In the IGP people will be subjected to more flooding and its effects, including inundation, bank-cutting and sand deposition. Coastal Bangladesh and Pakistan are likely to face stress in the form of tropical cyclones, storm surges, rising sea levels and salt-water intrusion. The poor in the IGP may face major impacts if climate change-related hazards decrease rice yields and riceproducing countries increase their prices or restrict exports. In addition, while the population of the IGP is part of the global labour market, it has little leverage to increase wages. Also, much attention is focused on location-specific events such as extreme storms, but these types of second-order impacts, where the effects of climate change are transmitted across regions through interconnected systems, may become more profound and difficult to manage. Enhancing food security needs to focus on these challenges too.

\section{Insights}

By exploring responses to the interaction between Global Environmental Change (GEC) and food security issues across selected sites of the IGP, the present study brought to light the following insights:

i. Efforts need to be made to document the utility of different types of decision support tools, including cost-benefit analysis, vulnerability assessments, climate risk assessments, planning for uncertainty and resilience planning, gender and social dimensions, multi-stakeholder consultations and SLDs. Decision support systems can help translate research evidence into policy action.

ii. Communication among locals, policy-makers and researchers needs creative approaches to develop decision support systems. In developing such systems we must recognise that policy activities need to involve plural actors, and that such activities occur at various scales from local to national to global.

iii. Scenario development is a useful tool for displaying various options for addressing issues under different sets of conditions. Irrespective of the climate change scenario used, food security will be affected and will hamper the ability of local populations to adapt.

iv. Food systems are vulnerable to disruptions caused by the impacts of climate change and can be improved by increasing productivity through 
promoting different farming systems or off-farm activities. Improving the preservation of food improves the utility and productivity of farm produce. Food-processing activities help make food available during the lean season. Cropprocessing could provide employment for women and the poor.

v. The links and interdependence between basic energy, water, food, finance, health, communication and other infrastructures, the diversification of livelihoods, and the ability to shift strategies as conditions change contribute to overcome household food insecurity.

Diversification away from climate-sensitive livelihoods like rain-fed agriculture will increase adaptive capacity because diversification increases the number of independent income flow options a household has.

vi. Households with the ability to anticipate and respond to climatic-related hazards and to recover from them can adapt better than others who cannot. The impact of climate change-related hazards is worsened when geophysical vulnerability interacts with the vulnerabilities created by social, economic and political processes. Existing forms of marginalisation created by gender and social exclusion lower an individual's capacity to adapt to hazards created by the changing climate and multiply existing threats.

vii. Adaptation occurs at two levels: planned and autonomous. Autonomous adaptation is defined as those decisions made independently of the direct involvement of the state or its organisations. Attributing impacts to climate change will be necessary for implementing targeted activities as planned adaptation. Adaptation is a function of knowledge, technology, economy, physical and ecological contexts, norms/values, cognisance and institutions (Figure 2).

viii. Multi-stakeholder partnerships and social networks serve as important foundations that enable adaptation to occur. Resilient communities should be prepared for any eventuality and learn from the unexpected in order to strengthen their anticipation, response and recovery strategies.

ix. The formulation of appropriate policies to address food insecurity requires integrating skill and knowledge of governments, markets and society. Interaction among researchers and policymakers is important in generating, transferring and using knowledge that combine modern and locally-based mechanisms.

\section{Conclusions}

In the IGP the vulnerability of food systems to GEC is increasing. Food determinants like production levels, land quality and infrastructure will all be negatively impacted by GEC stresses, with the result being an increase in food prices, deterioration in food storage and handling, and a decline in household income. GEC is likely to increase the vulnerability of the population which already has a low adaptive capacity. Building resilience requires ensuring access to food, drinking water, sanitation, education and reliable energy.

\section{References}

- Agrawal, P. K, Joshi, P. K., Ingram, J. S. I. and Gupta, R. K. 2004: Adapting Food Systems of the Indo-Gangetic Plain to Global Environmental Change: Key Information Needs to Improve Policy Formulation, Environmental Science and Policy 7 , pp. 487-498, www.elsevier.com/locate/envsci.

- Bandhyopadhyay, J. 1999: Need for a Realistic View, Seminar, pp. 52-55, Malvika Singh, New Delhi.

- Ericksen, P. J. 2007. Conceptualising Food Systems for Global Environmental Change Research, Available online 25 October, Global Environmental Change.

- FAO. 2009: http://www.fao.org/spfs/spfs-home/ en/.

- GECAFS. 2008. GECAFS Indo-Gangetic Plain Science Plan and Implementation Strategy, GECAFS Report No. 5; Oxford.

- NCVST. 2009. Vulnerability Through the Eyes of the Vulnerable: Climate Change-Induced Uncertainties and Nepal's Development Predicaments, Institute for Social and Environmental Transition-Nepal (ISET-N), Kathmandu and Institute for Social and Environmental Transition (ISET) Boulder, Colorado for Nepal Climate Vulnerability Study Team (NCVST), Kathmandu.

- Optiz-Stapleton, S., and Gangopadhyay, S. 2009. Downscaling Climate Information in Data Limited Contexts: Potential Changes in the Rohini Basin, Nepal and India, in Catalysing Climate and Disaster Resilience, Processes for Identifying Tangible and Economically Robust Strategies, March.

\section{Acknowledgements}

Several people deserve our appreciation. We specially thank Polly Erickson of GECAFs, Dr. Linda Anne Stevenson, Ms. Maricel Tapia, Mr. Yukihiro Imanari, and Ms. Kristine Garcia of APN for their support in implementing this project. We also thank our project partners for the time and effort they provided to implement the project. 


\title{
Development of a Co-evolutionary Decision Support System - Food and Water Security Integrated Model System (FAWSIM)
}

\author{
Yinpeng $\mathrm{Li}^{1}$, W. Ye, X. Yan
}

Corresponding author ${ }^{1}$

START Regional Centre for Temperate East Asia (TEACOM), Institute of Atmospheric Physics, Chinese Academy of Sciences, China.Email: lyp@mail.iap.ac.cn

\begin{abstract}
This study presents FAWSIM - Food and Water Security Integrated Model System, which is a co-evolutionary decision support system for climate change impact assessments. The objective of the system is to assist with the assessment of adaptation options and sustainable development opportunities in relation to water and food security at global, regional and local scales. This is achieved through the effective transfer of climate change and impact information to planners, policy-makers and the wider scientific community. Case studies in Jilin province, China and Mongolia verifies and validates the feasibility of the system. The application of the FAWSIM system extends our understanding of the local food and water security issues in the context of climate change.
\end{abstract}

Keywords: FAWSIM, SimCLIM, food and water security, climate change, Integrated Assessment Model, Decision Support System

\begin{abstract}
Introduction
Adapting to climate change while sustaining and/or improving food and water security has become a strategically important question for scientists and policy-makers at various levels (United Nations, 2010). This challenge has been identified as one of the major knowledge gaps. In an attempt to close the gap, we detail the development of a Decision Support System, FAWSIM - Food and Water Security Integrated Model System, developed through an APN-funded project and conducted by researchers from China, New Zealand, Mongolia and Russia (Li et al., 2010).
\end{abstract}

\section{Methodology}

A multi-disciplinary approach was required to develop the food and water assessment system as a single model cannot cover concerns of all stakeholders especially as each has different interests with regard to how climate change may impact food and water

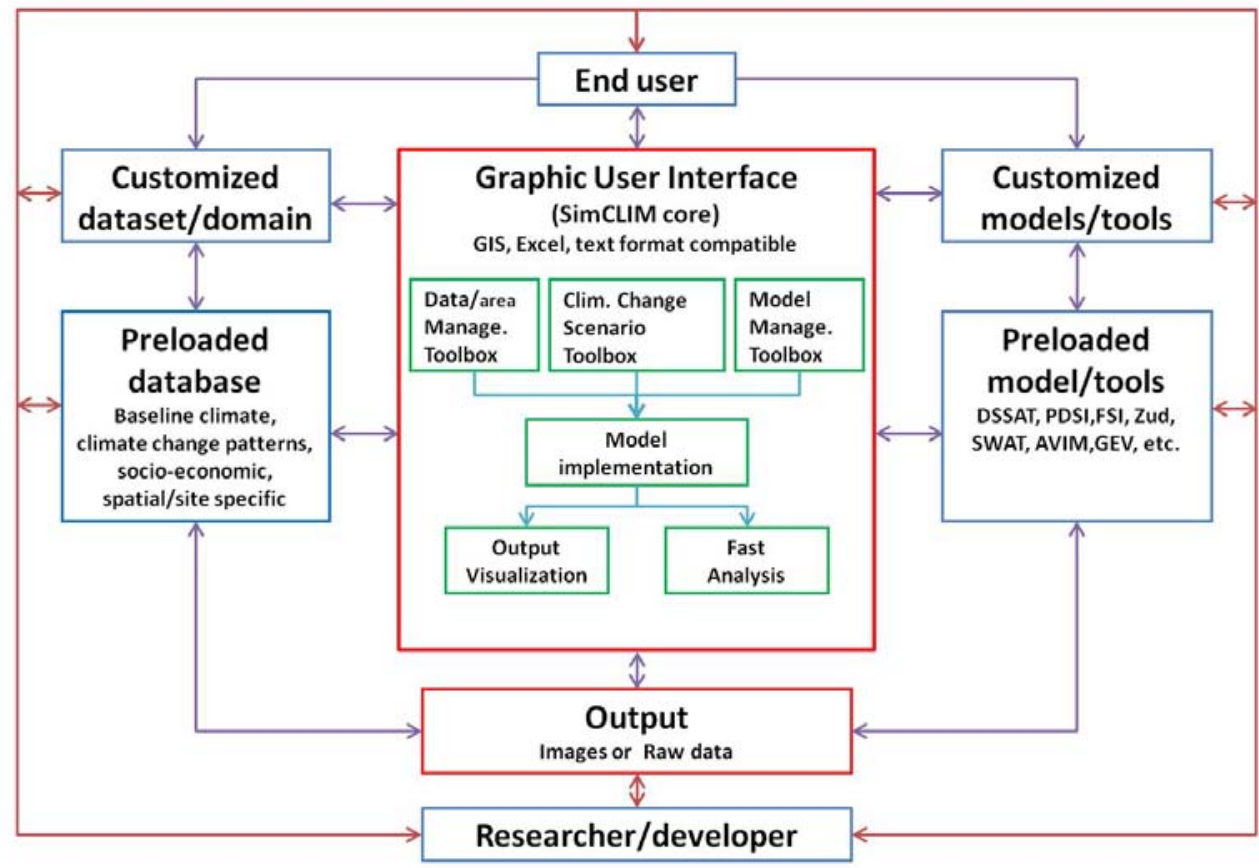

Figure 1. FAWSIM schematic illustration 
security at different spatial/temporal scales. Paramount to system development is interaction and information exchange among stakeholders, experts and model developers. In the present study, such information exchange was carried out through a participatory assessment approach, with stakeholders' concerns and ideas of potential solutions being collected by the research team for the target area. SimCLIM, a state-ofthe-art climate change impact assessment software system, was used to integrate the information and data collected, and to generate climate change scenarios. SimCLIM's open framework structure and userfriendly interface provided the foundation for this study. Figure 1 shows the flowchart of the FAWSIM system.

\section{FAWSIM Description}

FAWSIM consists of three major components: a database that supports climate change scenario generation; a set of impact models; and an interface for end-users.

\section{Database}

\section{Climate change scenarios}

Climate change scenarios drive the system. All FAWSIM functions, data and models are linked to the scenarios. FAWSIM provides scenarios at the global level, as well as customised local scenarios at the scale of the case study.

The ensemble pattern scaling method made use of six IPCC illustrative emission scenarios and all 21 IPCC

Fourth Assessment Report (IPCC AR4) Global Climate Models (GCMs) results. All data was pre-processed and stored in the system. The inclusion of a wide range of emission scenarios and GCM simulation results makes climate sensitivity analysis easier within the FAWSIM system.

To support impact assessments at the local scale, a statistical downscaling method was applied to the GCM data. The Self Organising Maps Statistical Downscaling (SOM-SD) approach embraces the advantage of a synoptic classification method and a stochastic resampling technique. The SOM-SD output allows probability and risk analysis, which is important, especially given uncertainties in climate change projections (Yin et al., 2010).

\section{Baseline climate data}

FAWSIM integrated various historical data, from gridded spatial data to time series data of sub-daily, daily and monthly climate data at global, regional and local (for the case study area) levels, to meet the sitespecific impact assessment requirement.

\section{CRP2008-02CMY-Yan}

Integrated Model Development for Water and Food Security Assessments and Analysis of the Potential of Mitigation Options and Sustainable Development Opportunities in Temperate Northeast Asia

\section{Project Leader:}

Prof. Xiaodong Yan

START Regional Centre for Temperate East Asia (TEACOM), Institute of Atmospheric Physics,

Chinese Academy of Sciences

Deshengmenwai, Qijiahuozi 100029, Beijing

CHINA

Tel: +861062383015

Fax: +861062045230

Email: yxd@tea.ac.cn

\section{APN Funding:}

US\$180,000 (For 3 Years)

\section{Research Highlights}

- Development of a co-evolutionary decision support system -Food and Water Security Integrated Model System (FAWSIM): A software package

- Climate change and drought: a risk assessment of crop-yield impacts. (Published in Climate Research, Li et al., 2009)

- Statistical downscaling of regional daily precipitation over Southeast Australia based on self-organising maps. (Published in Applied and Theoretical Climatology, Yin et al., 2010)

- Climate change and maize production: Impacts and potential adaptation measures: A case study in Jilin Province, China. (publishing in Climate Research, Wang et al., 2011)

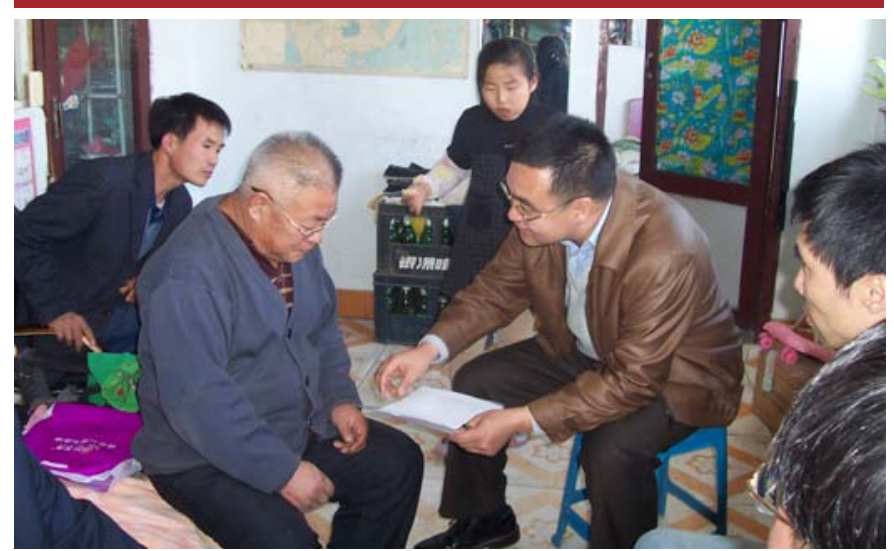


Socio-economic census data

Based on the specific requirement of an impact model, FAWSIM can integrate other census data related to crop and/or food production, such as agricultural census, soil types and vegetation cover.

\section{Impact models applied for the case studies}

\section{Food Security Index (FSI) Model}

An FSI model was developed to assess the food security level for each county in Jilin province, China. The FSI integrates relevant indicators from food production to consumption to classify the food security level at the county level (Figure 2).

Partial equilibrium food balance model: The model includes production (supply), and consumption (demand) specified separately for rural and urban consumers, buffer stocks, trade, and market clearing for 18 food commodities or commodity groups. Agricultural supply is assumed to respond to the product's own-price, prices of other commodities and inputs, quasi-fixed inputs, and other exogenous shocks.

\section{Crop production model - Decision Support System for Agrictechnology Transfer (DSSAT)}

The DSSAT simulations show that yield is highly likely to decline in the western and central regions of Jilin. The average maize yield in the west and central regions is thus projected to decrease by $15 \%$ or more by 2050 as predicted by $90 \%$ of 120 projected scenarios. Two potential adaptation strategies, i.e., improving irrigation facilities and cultivar shift, were identified from the vulnerability assessment and were further tested for the reduction areas (Wang et al., 2010) (Figure 3).

\section{The hydrological model - Soil and Water} Assessment Tool (SWAT)

The SWAT model is a basin-scale distributed hydrological model. In this study, the Diersonghuajiang River basin was chosen as the study area. SWAT generates a comprehensive range of hydrological results, including: water yield, soil water, and snow melt. The integration of the SWAT model provided an assessment the climate change impacts on water resources.

\section{The snow storm hazard model}

The snow storm hazard (Zud or Dzud) model was developed to simulate the frequency and magnitude of Zud risk in Mongolia. The Zud Index combines the growing season humidity index (HI), cold season precipitation index (PI) and cold season temperature anomaly (TA). The future Zud Index was calculated based on the ensembled monthly precipitation and temperature projections of GCMs.

\section{Drought risk assessment model}

This model simulates climate change impacts on global drought using a revised Palmer Drought Severity Index (PDSI) (Li et al., 2009).
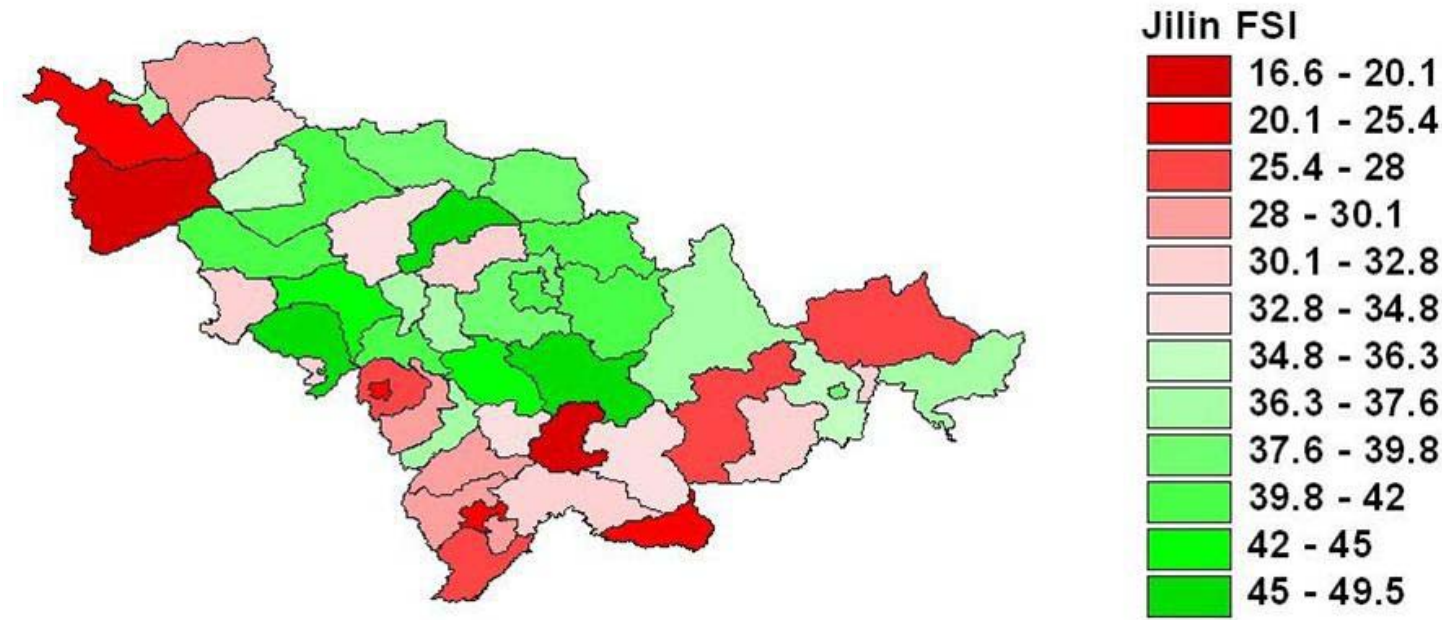

Figure 2. Spatial distribution of the FSI model in Jilin province, China 


\section{User Interface}

The Graphic User Interface (GUI) of FAWSIM employed and enhanced SimCLIM's open framework structure developed by the SimCLIM team (Warrick, 2009). SimCLIM essentially facilitates a series of toolboxes:
Climate change scenario generator tools enable users to generate climate change projections for any year in the $21^{\text {st }}$ century. The scenario generator's functionality, including global projection, ensemble, pattern viewer tools, facilitates the effective transfer of climate change projections to users' for applications in impact and risk assessments (Figure 4).

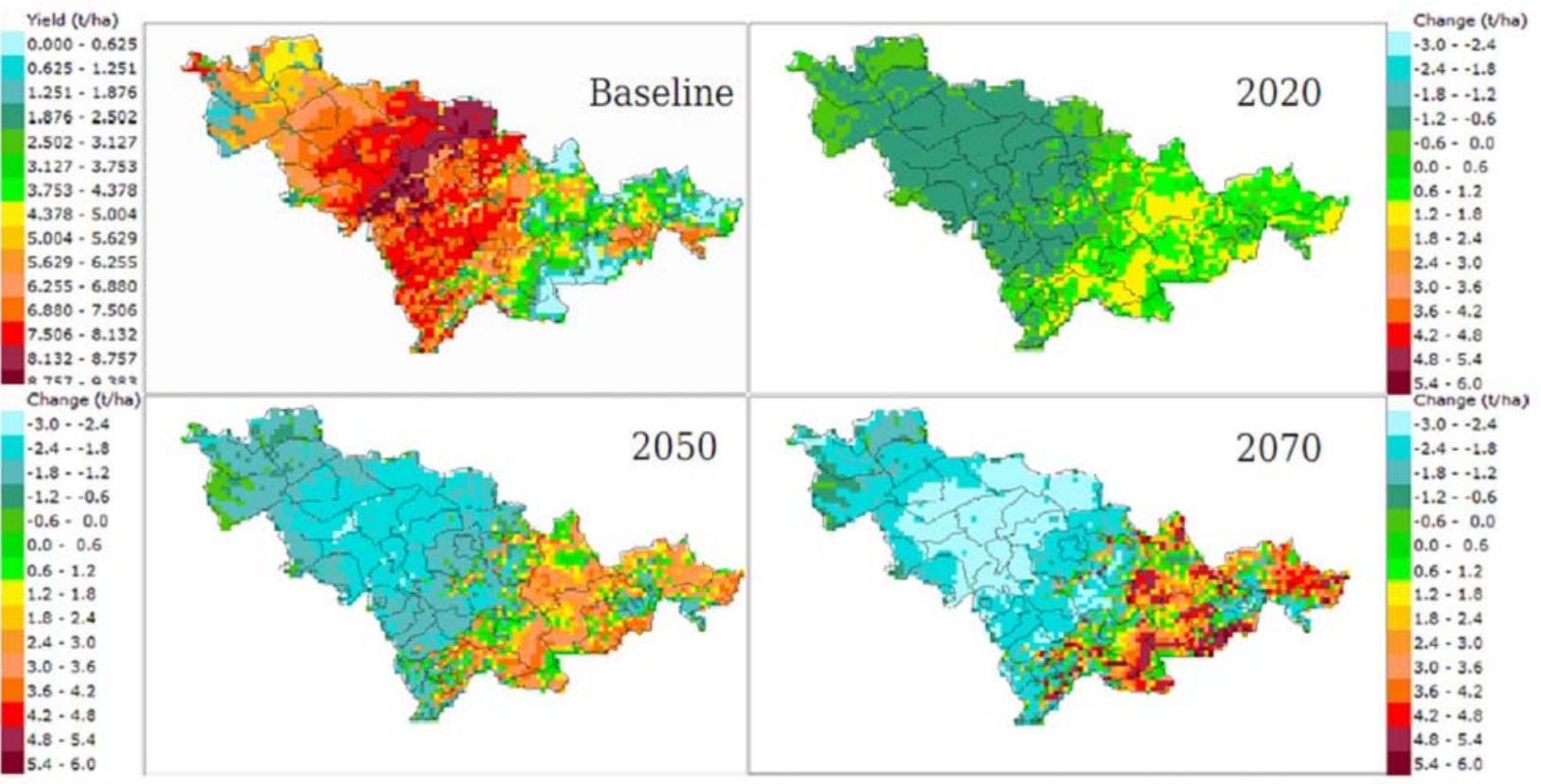

Figure 3. Climate change impact on maize production in Jilin province, the simulated maize yield $\left(\mathrm{t} \mathrm{ha}^{-1}\right)$ at baseline and the changes in 2020, 2050, and 2070

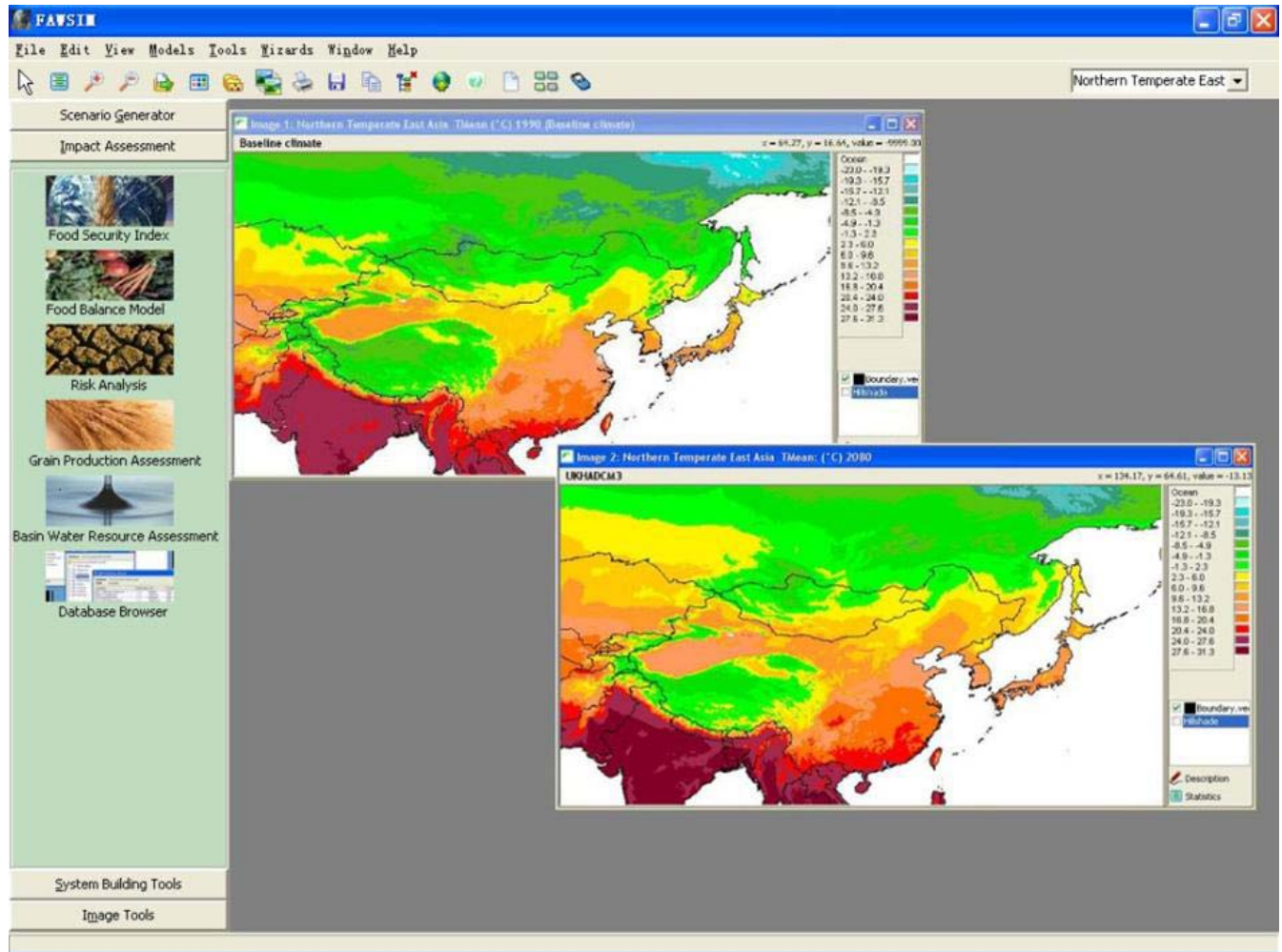

Figure 4. Annual mean temperature of East Asia: baseline (top) and 2080 projection (bottom) 


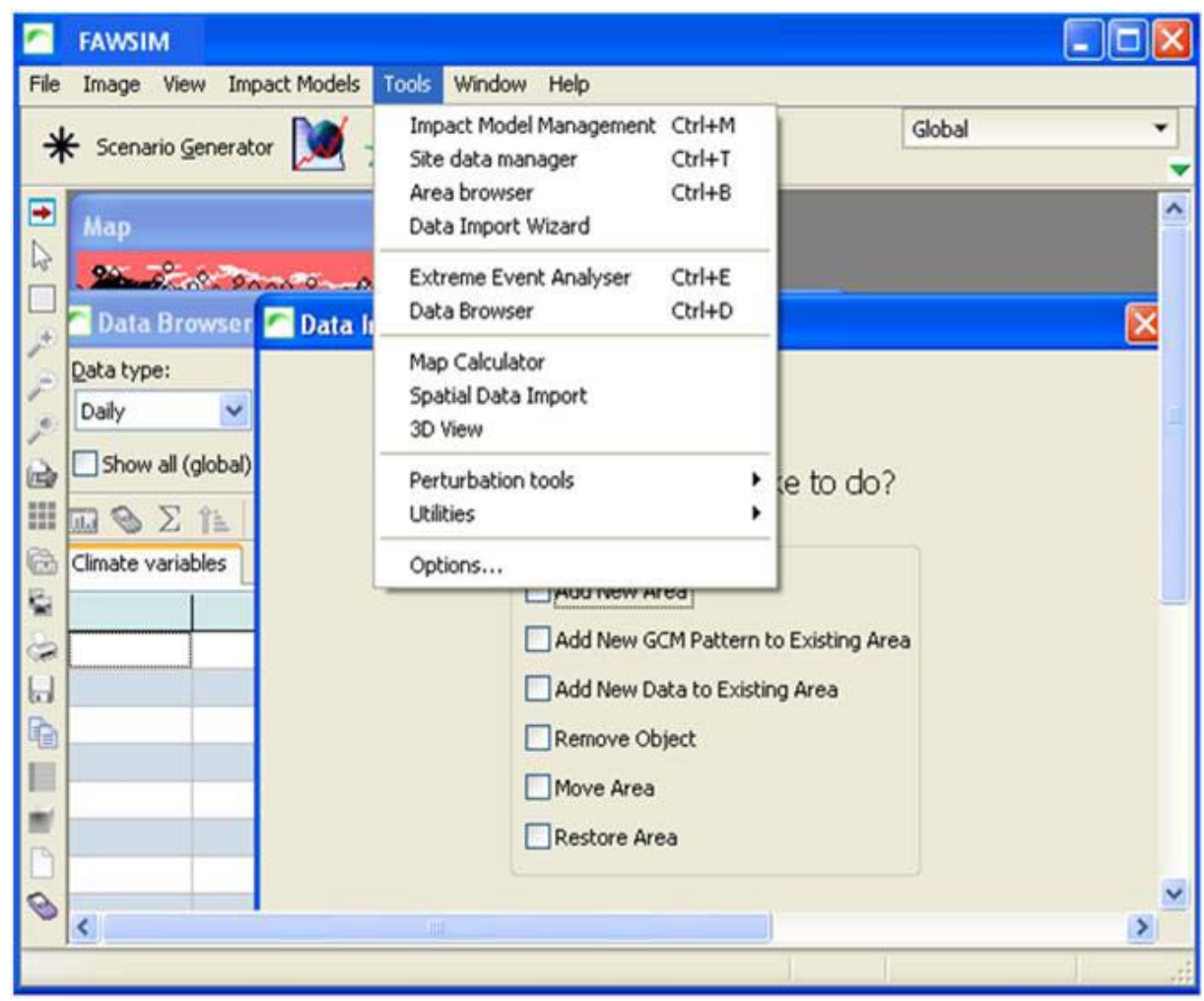

Figure 5. FAWSIM data management tools interface

Data management tools enable users to import and export climate, land and socio-economic data, in time series (monthly, daily, hourly, sub-hourly) or spatial patterns (ARC-GIS grids and polygon layers, for example) (Figure 5).

Model management tools enable users to incorporate impact models using FAWSIM compatible DLL and BPLs. Simple models, such as the Zud model and FSI were written in Delphi and incorporated into SimCLIM. More sophisticated models such as DSSAT and SWAT were built as Fortran DLLs, and linked with SimCLIM.

\section{Conclusions}

FAWSIM provides an efficient tool for stakeholders by integrating baseline climate, climate change scenarios and relevant environment, and socio-economic data with a series of impact models and a graphic user interface. FAWSIM currently includes in its system models of DSSAT, SWAT, PDSI, FSI, ZUD; as well as the land cover and socio-economic data of China and Mongolia.

FAWSIM allows for multi-scale, multi-disciplinary impact assessments; climate change scenario uncertainty analysis; and, with a built-in GIS tool, the assessment results can be visualised and further analysed thus facilitating training and capacity building.

The open framework makes FAWSIM a coevolutionary Decision Support System that can be regularly upgraded and improved through interaction between end-users and the developers.

\section{References}

- $\quad$ Li, Y., Ye, W., Wang, M., Yan, X. 2009. Climate change and drought: A risk assessment of cropyield impacts. Climate Research, 39: pp31-46.

- $\quad$ Li, Y., Ye, W., Yan, X., Togtohyn, C., Karakin, V.P., Wang, M., Yin, C. 2010. Integrated model development for water and food security assessments and analysis of the potential of mitigation options and sustainable development opportunities in temperate northeast Asia: APN CAPaBLE project (CRP2008-02CMY-Yan) Final report.

- United Nations. 2010. High-level task force on the global food security crisis: Updated comprehensive framework for action.

- Wang, M., Li, Y., Ye, W., Bornman, J., Yan, X. 2011. Climate change and maize production: Impacts and potential adaptation measures: A case study in Jilin Province, China. Climate Research (in press). 
- Warrick, R. 2009. From CLIMPACTS to SimCLIM: Development of an integrated assessment system. in: Integrated Regional Assessment of Global Climate Change, Knight, C.G., Jager, J. (Eds.) Cambridge University Press UK, pp. 280-311.

- $\quad$ Yin, C., Li, Y., Ye, W., Bornman, J., Yan, X., 2010. Statistical downscaling of regional daily precipitation over southeast Australia based on self-organising maps. Applied and Theoretical Climatology (DOI: 10.1007/s00704-010-0371-y).

\section{Acknowledgements}

We greatly appreciate all institutions for providing the essential support of their staff working on this project and facilitating workshops. The local experts and communities in Jilin province, China and Mongolia kindly supported the project activities. Great appreciation is also extended to the generous support from CLIMsystems Ltd, New Zealand. CLIMsystems provided the SimCLIM software and worked with the project team for the development of the FAWSIM system.

\section{workshop photos}

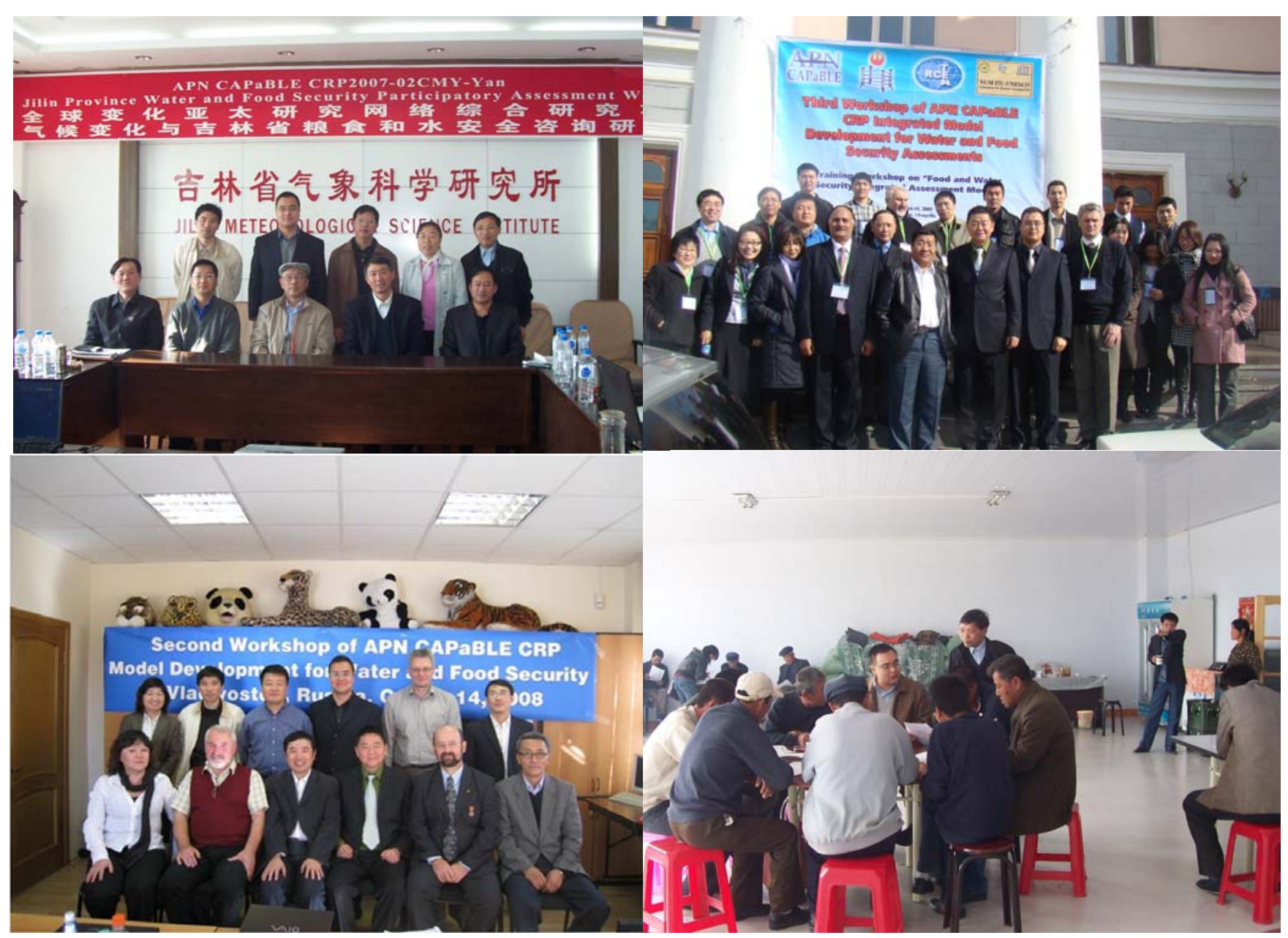




\title{
Assessing Impacts of ECHAM4 GCM Climate Change Data on Main Season Rice Production Systems in Thailand
}

\author{
Attachai Jintrawet ${ }^{1}$, Suppakorn Chinvanno \\ Corresponding author ${ }^{1}$ \\ Crop Sciences and Natural Resources Department and Multiple Cropping Centre, Faculty of Agriculture, Chiang Mai University, \\ Thailand.Email: attachai@chiangmai.ac.th or attachaij@gmail.com
}

\begin{abstract}
Main season rice-based cropping systems in Thailand are sensitive to the influence of climatic characteristics and patterns, which are induced by global warming. Despite uncertainties regards the precise magnitude of climate change projection at high resolution at regional scales as well as the timescales which are far into the future, an assessment of the possible impacts on our agricultural resources is important in formulating an adaptive response for rice production strategies. In the present study, CropDSS shell was used to link the CSM-CERES-Rice model version 4.0.2.0 with future climate scenarios from the PRECIS regional climate model (RCM) to downscale the ECHAM4 Global Climate Model (GCM) for Thailand. Data obtained from the ECHAM4 GCM under SRES A2 and B2 GHG emission scenarios were downscaled to higher resolution to project climate scenarios for the period 1980-2099. A slight decline in main season rice yields was predicted under all production systems before the 2040 period with a drastic decline in yield after the 2040 period. However, one should also bear in mind the predicted amount of rainfall and the relationship of more incidents of insect pests. The CropDSS shell and the CSM-CERES-rice model may be used to evaluate alternative adaptive production strategies under future climate scenarios projected by the ECHAM4 GCM in Thailand and other countries,
\end{abstract}

providing that datasets are available for model testing and evaluation.

Keywords: CSM-CERES-rice model, PRECIS RCM, ECHAM4 GCM, CropDSS, large area rice production estimation, Thailand

\section{Introduction}

The majority of main season rice production systems in Thailand are rainfed systems, which are one of the most sensitive systems to the impacts of climate change. Thailand is a major exporter of rice to the world market, thus any changes in production systems especially main season rice production systems, in various parts of the country are important for the export and domestic decision-making processes. Despite uncertainties about the precise magnitude of climate change projections at high resolution on regional and time scales, an assessment of the possible impacts of change in key climatic elements on our agricultural resources is important for formulating appropriate response strategies.

The purpose of the present paper is to report on the assessment study undertaken and performance of the main season rice production in Thailand, using the CSM-CERES-Rice model together with climate change

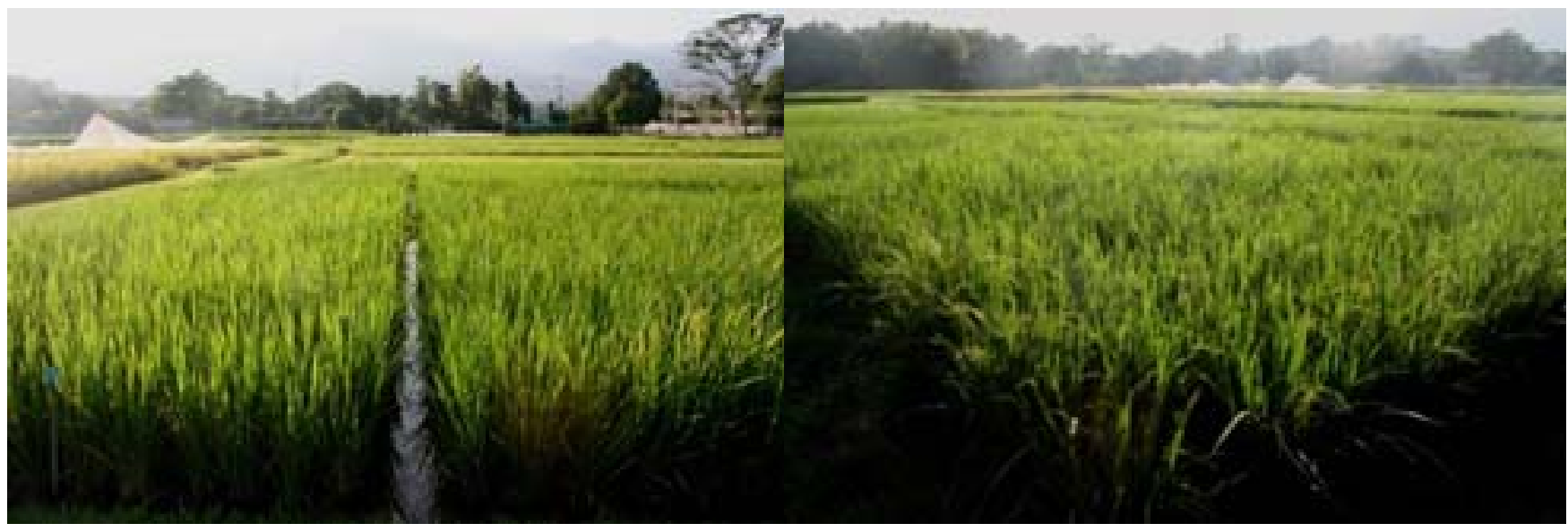


$\mathrm{A} 2$ and $\mathrm{B} 2$ scenarios as predicted by the PRECIS RCM, using ECHAM4 GCM dataset as initial data for future climate simulation.

\section{Materials and Methods}

\section{The CSM-CERES-Rice model}

The CSM-CERES-Rice model (Cropping System Model-Crop Environment Resource Synthesis) was developed along the lines of the CERES-Maize and the CERES-Wheat models (Jones and Kiniry, 1986). It was modified for transplanted rice by researchers at the International Fertiliser Development Centre (Godwin and Singh, 1989) and tested in various production systems in Thailand (Jintrawet, 1991). It is still undergoing testing and refinement by scientists of the International Consortium of Application of System Approaches (ICASA).

The model requires daily weather data including solar radiation, maximum and minimum air temperature, and rainfall. Initial soil conditions required by the model include drainage and runoff coefficients, evaporation and radiation reflection coefficients, rooting preference factors, and initial soil water, mineral nitrogen and organic matter content for each horizon. Day-length is calculated from latitude and day of the year. Grain yield is determined by the rate and duration of panicle growth as influenced by genotype and environmental conditions. The model, as yet, does not incorporate genetic coefficients for resistance to insects and pathogens.

\section{The PRECIS RCM and ECHAM4 climate dataset}

We used the PRECIS regional climate model (RCM) to downscale the ECHAM4 GCM data, based on SRES A2 and B2 GHG emission scenarios, which represent the high and low atmospheric concentration of GHGs in the future (SRES, 2000). The downscaling resolution was $20 \times 20 \mathrm{~km}$. The model was designed to cover the domain between $0-30^{\circ}$ North Latitude and 90-112 ${ }^{\circ}$ East Longitude. A detailed description of the ECHAM4 climate model can be found in Roeckner et al. (1996). Daily weather data generated from ECHAM4 GCM was formatted for CSM-CERES rice model for the period 1980-2099 for Thailand (Chinvanno et al., 2009).

\section{CRP2008-03CMY-Jintrawet}

Climate Change in Southeast Asia and Assessment on Impacts, Vulnerability and Adaptation on Rice Production and Water Resources

\section{Project Leader:}

Dr. Attachai Jintrawet

Multiple Cropping Centre, Faculty of Agriculture Chiang Mai University, Chiang Mai 50200

THAILAND

Tel: +66 53221275

Fax: +94 53210000

Email: attachai@chiangmai.ac.th

\section{APN Funding:}

US $\$ 180,000$ (For 3 Years)

\section{Research Highlights}

- The present paper details an assessment study of the performance of main season rice production in Thailand, using the CSMCERES-Rice model together with climate change A2 and B2 scenarios as predicted by the PRECIS RCM, using ECHAM4 GCM dataset.

- Impact of climate change during the period 1980-2099 on rice production in Thailand was studied and a slight decline in main season rice yields is predicted for all production systems before 2040 and a drastic decrease predicted after the 2040 period.

- Simulation of adaptive production options show that, during the period 2010-2019, an application of $60 \mathrm{~kg}$ of urea per ha can produce $15 \%$ and $36 \%$ higher simulated rice yield than an application of $200 \mathrm{~g}$ of green manure per $\mathrm{m}^{2}$ or no nitrogen application production option, respectively.

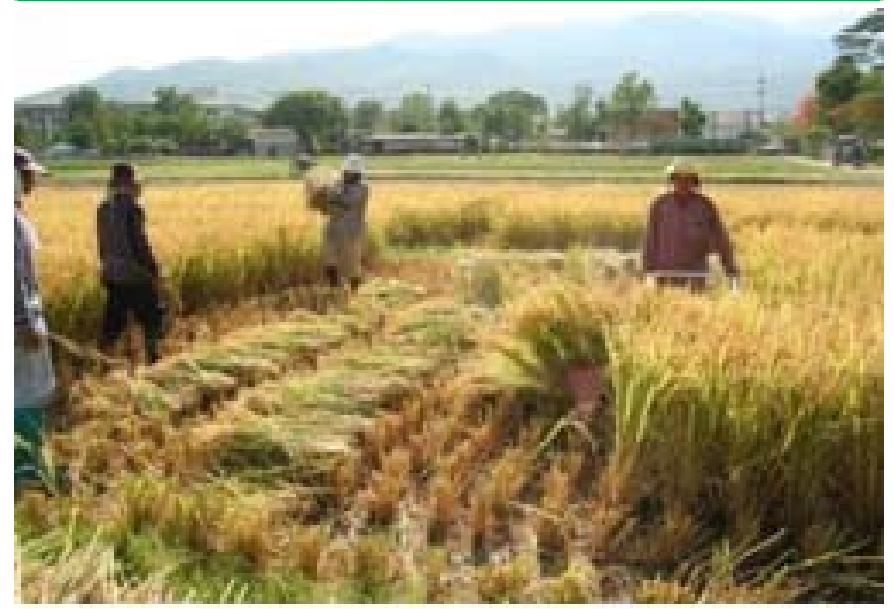




\section{CropDSS shell framework}

CropDSS shell (Jintrawet, 2009) includes SDBMS (Spatial Database Management System), MBMS (ModelBase Management System), the analysis module, and the visualisation module for map display. The CropDSS shell requires two kinds of minimum dataset (MDS) for crop yield and production estimation at the various administrative levels, which are the spatial and attributes datasets. These datasets have the smallest possible number of spatial and attributes for a practical assessment.

\section{Rice production systems simulation settings}

To assess the impacts of future climate pattern under A2 and B2 SRES scenarios on rice production in Thailand, we used the CropDSS shell to simulate rice yields under three production practices; namely; potential production practices, well-irrigated and wellfertilised production practices, and rainfed and nitrogen-limited production practices (Penning de Vries, 1982). We used one planting date, August 15, for main season rice, with three 25 day-old seedlings per hill, at 16 hills per square meter plant density. The rice variety was a non-photoperiod sensitive variety, Rice Department \#7, thus RD7.

\section{Results}

Table 1 presents simulated rice yields of $\mathrm{RD} 7$ in the main season cropping systems for Thailand based on three production scenarios, namely; potential production scenarios, well-irrigated and well-supplied nitrogen fertiliser, and rainfed with no nitrogen fertiliser application. Potential rice production scenario yields ranged from 4,100-6,400 and 4,900-6,000 kg/ha for A2 and B2 SRES scenarios, respectively. Wellirrigated and well-supplied nitrogen fertiliser rice production scenario yields ranged from 3,700-6,000 and 4,000-5,700 kg/ha for A2 and B2 SRES scenarios, respectively. Rainfed with no nitrogen fertiliser application rice production scenario yields ranged from 2,100-2,200 and 2,000-2,100 kg/ha for A2 and B2 SRES scenarios, respectively.

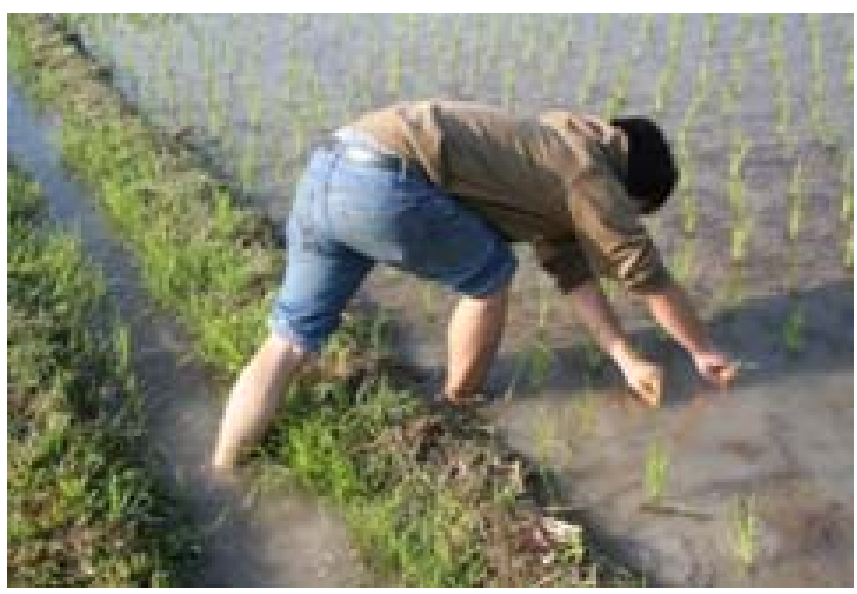

Table 1. Mean and standard deviatioin of simulated rice yields in Thailand under ECHAM4 A2 and B2 SRES scenarios for three production options

\section{Potential production}

\begin{tabular}{lllll}
\hline & A2 & & B2 & \\
\hline Year & Mean & SD & Mean & SD \\
\hline $1980-1989$ & 6,190 & 660 & & \\
$1990-1999$ & 6,030 & 663 & & \\
$2000-2009$ & 5,901 & 624 & & \\
$2010-2019$ & 5,881 & 620 & 5,963 & 945 \\
$2020-2029$ & 5,829 & 665 & 5,956 & 681 \\
$2030-2039$ & 5,797 & 676 & 5,815 & 758 \\
$2040-2049$ & 5,522 & 691 & 5,718 & 689 \\
$2050-2059$ & 5,191 & 644 & 5,568 & 763 \\
$2060-2069$ & 4,919 & 714 & 5,381 & 740 \\
$2070-2079$ & 4,692 & 723 & 5,240 & 738 \\
$2080-2089$ & 4,387 & 762 & 5,146 & 692 \\
$2090-2099$ & 4,060 & 710 & 4,857 & 708 \\
\hline
\end{tabular}

Well-irrigated and well-supplied nitrogen fertiliser production

\begin{tabular}{lllll}
\hline & A2 & & B2 & \\
\hline Year & Mean & SD & Mean & SD \\
\hline $1980-1989$ & 6,023 & 692 & & \\
$1990-1999$ & 5,841 & 715 & & \\
$2000-2009$ & 5,719 & 679 & & \\
$2010-2019$ & 5,684 & 673 & 5,714 & 996 \\
$2020-2029$ & 5,629 & 713 & 5,695 & 772 \\
$2030-2039$ & 5,585 & 742 & 5,542 & 865 \\
$2040-2049$ & 5,276 & 760 & 5,403 & 817 \\
$2050-2059$ & 4,947 & 732 & 5,282 & 912 \\
$2060-2069$ & 4,622 & 812 & 5,004 & 927 \\
$2070-2079$ & 4,373 & 831 & 4,886 & 938 \\
$2080-2089$ & 4,026 & 923 & 4,781 & 879 \\
$2090-2099$ & 3,706 & 869 & 4,427 & 955 \\
\hline
\end{tabular}

Rainfed and no nitrogen application production

\begin{tabular}{lllll}
\hline \multicolumn{3}{l}{ A2 } & \multicolumn{3}{c}{ B2 } \\
\hline Year & Mean & SD & Mean & SD \\
\hline $1980-1989$ & 2,215 & 795 & & \\
$1990-1999$ & 2,231 & 785 & & \\
$2000-2009$ & 2,226 & 773 & & \\
$2010-2019$ & 2,234 & 773 & 2,026 & 693 \\
$2020-2029$ & 2,221 & 772 & 2,045 & 696 \\
$2030-2039$ & 2,252 & 766 & 2,049 & 701 \\
$2040-2049$ & 2,239 & 749 & 2,050 & 683 \\
$2050-2059$ & 2,230 & 732 & 2,054 & 681 \\
$2060-2069$ & 2,217 & 712 & 2,048 & 685 \\
$2070-2079$ & 2,200 & 699 & 2,050 & 684 \\
$2080-2089$ & 2,158 & 687 & 2,044 & 675 \\
$2090-2099$ & 2,125 & 664 & 2,029 & 672 \\
\hline
\end{tabular}


Impacts of future climate pattern under A2 and B2 SRES scenarios on potential rice production Simulated potential rice yields governed by air temperature, solar radiation, and crop characteristics, averaged yields using simulated climate data for the baseline period of $1980-89$ was $6,190 \mathrm{~kg} / \mathrm{ha}$. As compared to the 1980-89 period, rice yields during 1990-2049 period decreased by 2.6-6.4 and 3.7-6.1 percent from change in climate pattern based on A2 and B2 SRES scenarios, respectively. However, rice yield reduction was more pronounced after the 2040 period towards the 2090 period. Simulated rice yields reduction ranged from 10.8-34.4 and 7.6-21.5 percent under future climate pattern based on A2 and B2 scenarios, respectively, as compared to simulated yields during 1980s.

\section{Impacts of future climate pattern under A2 and B2} SRES scenarios on well-irrigated rice production

In addition to air temperature, solar radiation, and crop characteristics, water in the soil and plant systems is the key factor influencing simulated rice yields under well-irrigated and well-supplied nitrogen fertiliser production practice. An averaged simulated yield using simulated climate data for the baseline period of 198089 was $6,023 \mathrm{~kg} / \mathrm{ha}$. As compared to the 1980-89 period, rice yields during 1990-2049 decreased by 3.0-
Rainfed, $60 \mathrm{~kg}$ of Urea per ha

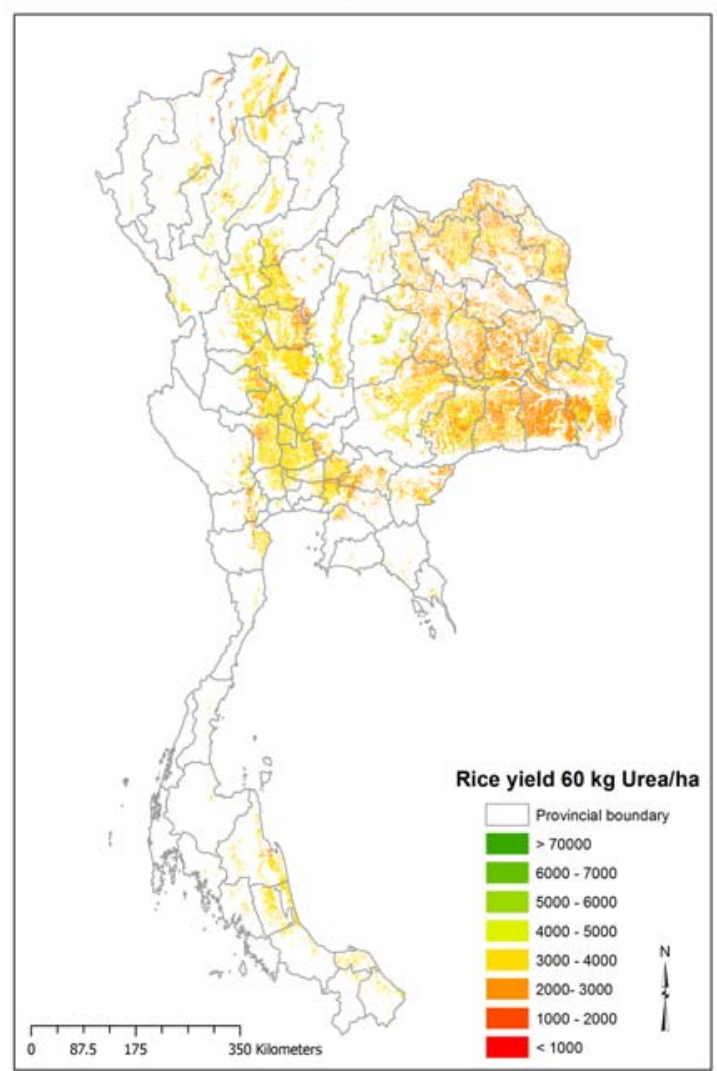

Rainfed, $200 \mathrm{~g}$ of Green Manure per sq.m.

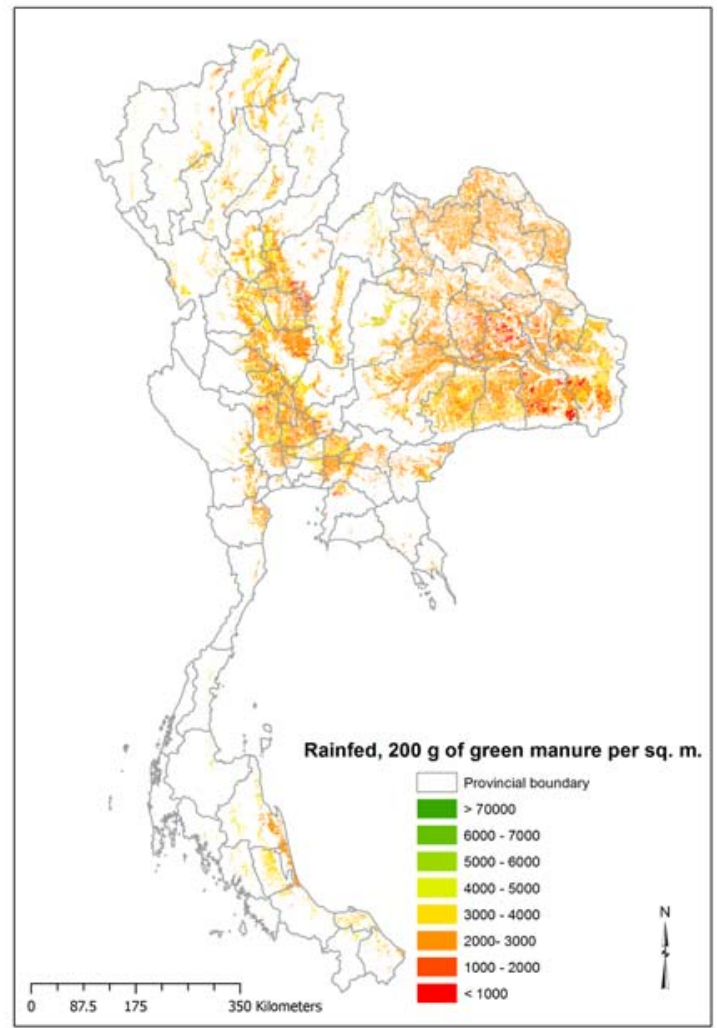

Figure 1. Distribution of simulated rice yields $(\mathrm{kg} / \mathrm{ha})$ in Thailand, under ECHAM4 A2 SRES scenario during 2010s, for three production options 
7.3 and 5.1-8.0 percent from changes in climate pattern based on A2 and B2 SRES scenarios, respectively. However, rice yield reduction is seriously affected between the 2040 and 2090 period. Simulated rice yields reduction ranged from 12.4-38.5 and 10.3-26.5 percent under future climate patterns based on A2 and B2 GHG scenarios, respectively, as compared to simulated yields during 1980 s.

\section{Impacts of future climate pattern under $\mathrm{A} 2$ and $\mathrm{B} 2$ SRES scenarios on rain fed rice production}

Simulated rice yields in this production scenario are further constrained by nitrogen in the soil and plant systems. An averaged simulated yield using simulated climate data for the baseline period of 1980-89 was $2,215 \mathrm{~kg} / \mathrm{ha}$. As compared to the $1980-89$ period, rice yields during the 1990-2039 period under future climate pattern based on A2 SRES GHG scenario would increase by $0.8-1.7$ percent and decrease by 7.58.5 percent under future climate pattern during 20102049 based on B2 SRES GHG emission scenario. However, rice yield reduction is more pronounced in the 2040-2090 period. Simulated rice yields reduction ranged from 1.1-4.0 and 7.4-8.4 percent under future climate patterns based on both A2 and B2 scenarios, respectively, as compared to simulated yields during 1980s.

In addition, we used the CropDSS shell to simulate main season rice yields during the 2010-19 period under two soil nutrient management options, namely; a) Application of $200 \mathrm{~g}$ of green manure per $\mathrm{m}^{2}$ (200GM), and b) Application of $60 \mathrm{~kg}$ of urea per ha (60UREA) and compared with the averaged simulated rice yield $(0 \mathrm{~N})$ of the same period to illustrate adaptive production strategies. The 60UREA production strategy produced $15 \%$ and $36 \%$ higher simulated rice yield than 200GM and 0N, respectively (Figure 1).

\section{Discussion}

The potential and well-irrigated scenarios gave averaged yields of 6,040 and $5,861 \mathrm{~kg} / \mathrm{ha}$, respectively, and were relatively higher than reported averaged national rice yields during the period 1980-2009 by the Office of Agricultural Economics (OAE, 2010) of Thailand. The averaged and standard deviation of reported rice yields during the periods 1980-89, 1990-99, and 2000-2008 were $2,024 \pm 66,2,335 \pm 166$, and $2,690 \pm 313 \mathrm{~kg} / \mathrm{ha}$, respectively. The rainfed with no nitrogen fertiliser application production scenarios yielded closer to the reported rice yields by OAE, and averaged 2,224 \pm 772 $\mathrm{kg} / \mathrm{ha}$. This is due mainly to the fact that the majority of rice fields in Thailand are under rainfed conditions and low nitrogen fertiliser applications, with the exception of the central plain of Thailand. Improving and maintaining rice production under rainfed conditions can be achieved by introducing green manure crop or adding chemical fertiliser.

Simulated rice yields decreased drastically after 2040 due mainly to increases in air temperature that result in slower crop growth rate. Future research needs to be conducted to fully develop and disseminate such new rice varieties for higher temperature environments during the reproductive phase of the crop, which is particularly prone to male sterile phenomenon and thus reduced yields. The other aspect of climate change is the increase of surface air temperature, which will reduce the total duration of the crop by inducing early flowering and maturity, thus causing shortening of the grain filling period. The shorter the crop duration, the lower the yield per unit area. A warmer atmosphere could therefore lead to reduced agricultural productivity.

Both climate and rice models were based on certain assumptions. The PRECIS-ECHAM4 climate model resolution is $20 \times 20 \mathrm{~km}$ and needs a great deal of work on its prediction as influenced by increased $\mathrm{CO}_{2}$ concentration and the tropical monsoon system. The CSM-CERES rice model assumed that weeds, insects, and disease are fully controlled by farmers during the growing season. Crop losses, which may accrue due to the occurrence of extreme events such as floods, are also not accounted for. Currently, the model does not allow for a gradual increase of gas. The current version of the DSSAT-CERES rice simulation model handles only plant and soil processes at the field level, with uniform management practices.

\section{Conclusions}

Assessing impacts of climate change scenarios by linking crop simulation models to geographic information system (GIS) databases, with its data handling capabilities and its spatial manipulation functions, makes it practical to apply the CSM-CERESRice model together with the PRECIS RCM-ECHAM4 GCM climate models over a large area for yield estimation of rice and other crop production systems. Climate change under SRES A2 and B2 scenarios, produced by PRECIS RCM-ECHAM4 GCM climate models, impacted rice production scenarios in Thailand in similar trends, i.e., simulated rice yields decrease with a more pronounced decrease observed after the 2040 period, assuming no policy and implementation decisions are taken to adapt to these changes. 


\section{References}

- Chinvanno, S., Laung-Aram, V., Sangmanee, C. and Thanakitmetavut, J. 2009. Future Climate Projection for Thailand and Mainland Southeast Asia Using PRECIS and ECHAM4 Climate Models. Southeast Asia START Regional Centre Technical Report. Bangkok, Thailand, START SEA RC. 18.

- Godwin, D. and Singh, U. 1989. Nitrogen balance and crop response to nitrogen in upland and lowland cropping systems. Understanding Options for Agricultural Production. G.Y. Tsuji, Hoogenboom G. and Thornton P.K. London, Kluwer Academic Publishers: 55-78.

- Jintrawet, A. 1991. A Decision Support System for Rapid Appraisal of Rice-Based Agricultural Innovations. Ph.D. Dissertation, University of Hawaii at Manoa, Honolulu, Hawaii, USA, 167.

- Jintrawet, A. 2009. A Decision Support System to Study the Impact of Climate Change on Food Production Systems. Khon Kaen University Research Journal 14: 589-600.

- Jones, C.A. and Kiniry, J.R. Eds., 1986. CERESMaize: A Simulation Model of Maize Growth and Development. College Station, Texas A\&M University Press.
- OAE. (2010). "Agricultural Statistics." 2010, from http://www.oae.go.th/download/article/ article_20090417180213.html.

- Penning de Vries, F.W.T. 1982. Systems analysis and models of crop growth. Wageningen, the Netherlands, CABO.

\section{Acknowledgements}

The Asia-Pacific Network for Global Change Research (APN) provided funding for our research activities for a 3-year period from 2006-2009, beginning with grant number CRP2006-03CMY-Jintrawet. The Thailand Research Fund (TRF) provided funding for the development of CropDSS shell under grant number RDC52O0001. We are grateful to the Southeast Asia START Regional Centre in Bangkok for its kind provision of the ECHAM4-PRECIS A2 and B2 SRES scenarios and the Land Development Department (LDD) in Bangkok for the kind provision to access the soil map and soil profile attributes data. The corresponding author completed the manuscript while taking a sabbatical, from December 2010 to May 2011, as a visiting research fellow at the Centre for Southeast Asia Studies (CSEAS) at Kyoto University, Japan.

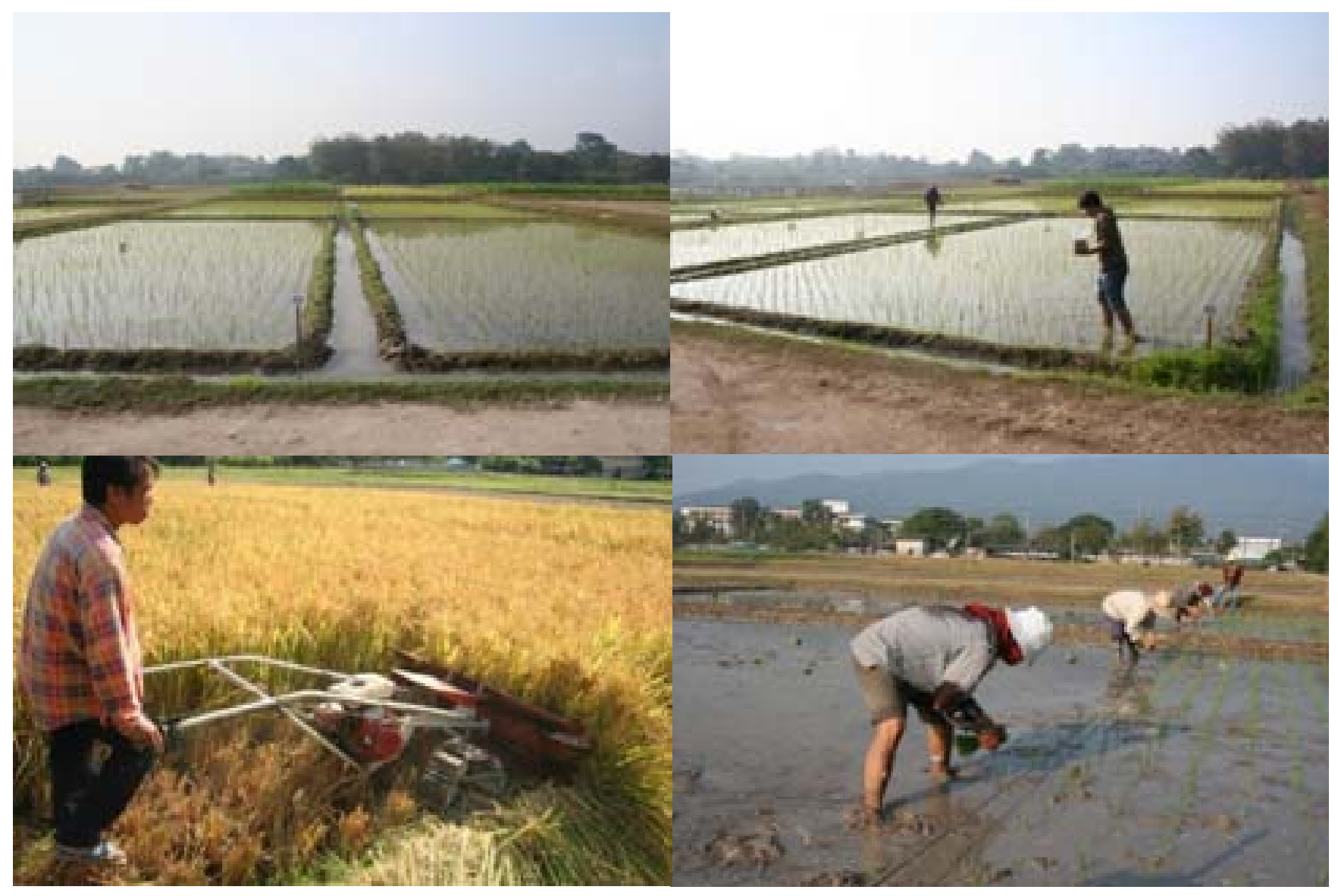




\title{
Future Climate Projection for Mainland Southeast Asia Countries: Climate Change Scenario of $21^{\text {st }}$ Century
}

\author{
Suppakorn Chinvanno ${ }^{1}$, V. Luang-aram, C. Sangmanee, J. Thanakitmetavut \\ Corresponding Author ${ }^{1}$ \\ Southeast Asia START Regional Centre, Bangkok, Thailand. Email: suppakorn@start.or.th
}

\begin{abstract}
Long term climate projection at high resolution is a fundamental dataset for climate change studies, especially for assessing the impact of climate change at the local scale. This future climate projection, which provides a scenario of climate for Southeast Asia at $20 \times 20 \mathrm{~km}$ resolution up to the end of the 21 st century, is a result of a dynamic downscaling process using a regional climate model (RCM) from the Hadley Centre, The Met Office of United Kingdom, to simulate high-resolution climate data for the region based on datasets from the Global Circulation Model (GCM) ECHAM4 - A2 GHG emission scenario. Results from the RCM show that a wide area of Southeast Asia will become warmer and the duration of the warm period will extend substantially in the future, especially in the latter half of the century. Even though warmer temperatures are detected for both daily maximum and daily minimum values, the daily minimum temperature tends to have a higher trend. Precipitation tends to fluctuate in the first half of the century but shows an increasing trend with higher intensity, which will be clearly seen in the latter half of the century where higher precipitation will be observed throughout the region.
\end{abstract}

Keywords: climate change, Southeast Asia, regional climate model (RCM), PRECIS, ECHAM4

\section{Introduction}

Climate change has become a global concern as it may have many adverse consequences on various systems and sectors that may threaten human wellbeing (IPCC, 2001). Understanding climate change is the foundation for proper planning of adaptation measures to cope with future risk. However, climate change is a slow process and requires rather long-term future climate projections to be able to accurately predict changes in future climate patterns (IPCC, 2007). Therefore, long-term future climate projection is crucial for the assessment of climate change impacts on certain sectors in specific areas, particularly at the local scale. GCMs were developed and have been used to simulate future climate conditions, but most of the simulations, especially those GCMs that were used in the IPCC AR4, were conducted at coarse scales due to limitations in technology. These GCMs are not as effective for climate change impact assessments at local scales where high-resolution future climate data is required.

Typically, there are three types of techniques for obtaining high-resolution regional climate change projections: statistical, dynamical and hybrid (statisticaldynamical) techniques. The use of RCMs falls into the dynamical category. An RCM is a downscaling tool that adds fine scale (high-resolution) information to large-scale projections of GCMs. GCMs are typically run with horizontal scales of a few hundred kilometers, while models can resolve features down to much smaller scales, e.g. $50 \mathrm{~km}$ or less. This makes for a more accurate representation of many surface features, such as complex mountain topographies and coastlines (Jones et al., 2004). The present paper discusses approaches and results of dynamic downscaling of GCM data using RCMs to develop high-resolution future climate change scenarios for mainland Southeast Asia over the $21^{\text {st }}$ century.

\section{Methodology}

The high resolution climate projection for mainland Southeast Asia was developed based on a dynamic downscaling technique using the PRECIS RCM. PRECIS was developed by the Hadley Centre for Climate Prediction and Research, The Met Office, UK. It can be used as a downscaling tool that adds fine scale (highresolution) information to the large-scale projections of a GCM. It has been ported to run on a PC (under Linux) with a simple user interface, so that experiments can easily be set up over any region. PRECIS was developed in order to help generate high-resolution climate change information for as many regions of the world as possible. These scenarios can be used in impact, vulnerability and adaptation studies (Simson et al., 2006).

The GCM dataset, which was used as the initial dataset for the simulation was the ECHAM $4^{1}$ model from the Max-Planck-Institute for Meteorology (MPI), Germany. It was based on SRES A2 GHG scenario, which represents the scenario that atmospheric GHGs will increase at a relatively high rate (IPCC, 2000). The period 
of simulation covers the years 1970-2100. The simulation provides output with daily time-step throughout the simulating period. The downscaling process was set to a resolution of $0.22^{\circ}$ and output was rescaled to $20 \times 20 \mathrm{~km}$ resolution. Domain coverage was latitude $0-35^{\circ} \mathrm{N}$ and longitude $90^{\circ}-112^{\circ} \mathrm{E}$ (Figure 1).

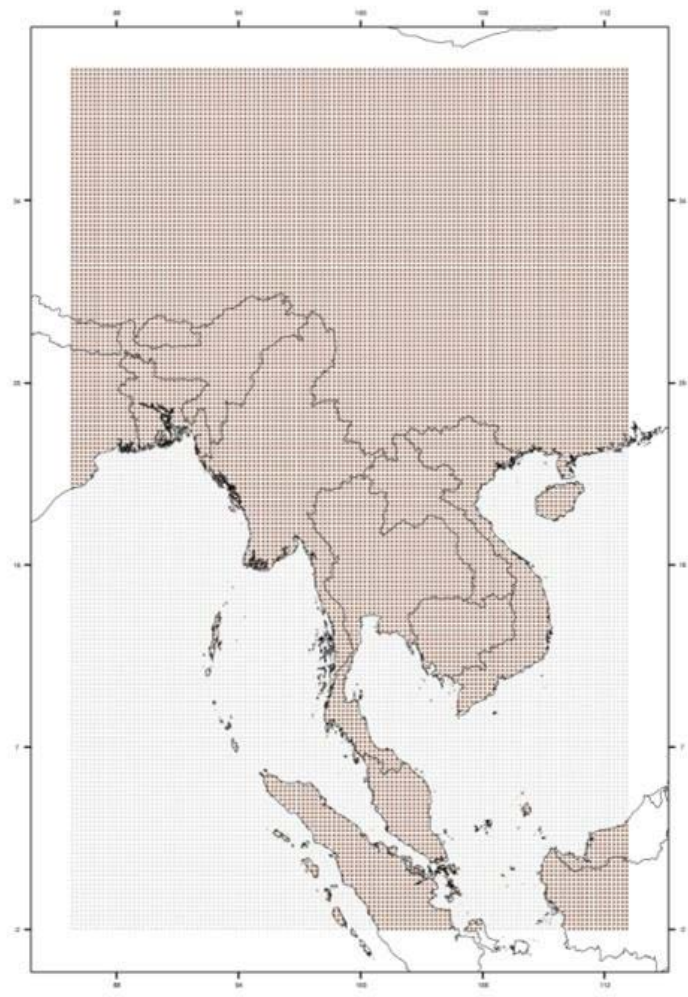

Figure1. Domain of future climate projection

The results from PRECIS RCM were verified by comparing against data from observation stations and the period of 1980s was selected as the baseline for verification. The comparison shows that the RCM result is somewhat different from the observed weather data. The PRECIS model tends to overestimate temperature and underestimate precipitation in many areas. A "rescaling" technique was developed and applied to the simulation results from the PRECIS model in order to adjust the simulated data to better match real conditions based on the observed data.

\section{Results and Discussion}

The simulation results from the PRECIS RCM, after the rescaling process, shows that the average maximum temperature as well as average minimum temperature in Southeast Asia in will increase in the future, with increases tending to be more prominent from the middle of the century onward. The warming trend is clearly seen in the central plain of Thailand and most of Cambodia as well as the Malaysian peninsular (Figures 2 and 3).
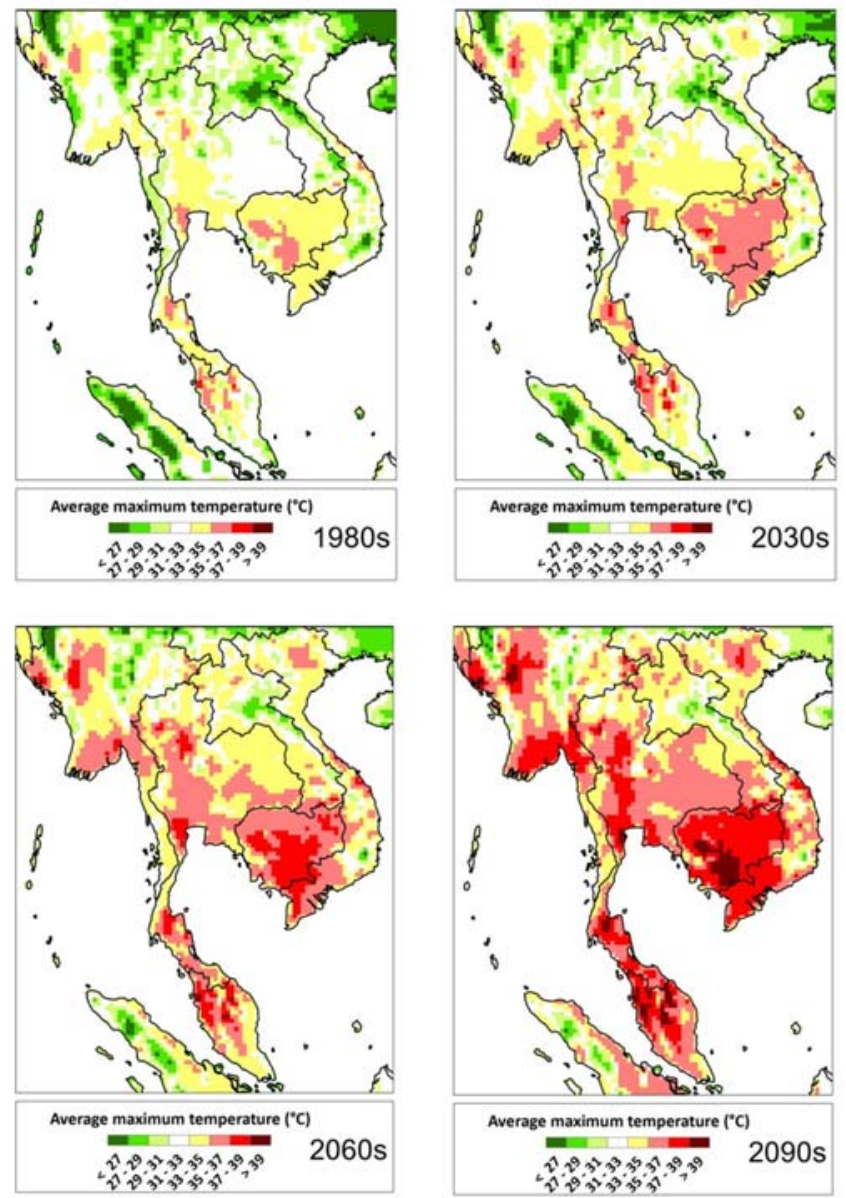

Figure 2. Average daily maximum temperature

In addition to the changing magnitude aspect, change in future temperature also occurs in the temporal aspect. Southeast Asia tends to have longer hot periods over the year. This change in temporal aspect can be seen in the changes in the number of hot days in a year, or in other words the length of summer-time, i.e., the number of 'hot days,' (defined in this study as days where maximum temperature exceeds $35^{\circ} \mathrm{C}$ ) will increase in the future, which could be longer by a few months in a year (Figure 4). On the other hand, PRECIS results also show a slight trend of change for the 'cool period,' (defined in this study as days where minimum temperature is $16^{\circ} \mathrm{C}$ or below). The cool period, or in other words, winter-time, in Southeast Asia will become shorter than the baseline climate pattern, even though not as prominent as the trends in the 'hot period' (Figure 5).

Annual total precipitation may fluctuate in the early decades of the $21^{\text {st }}$ century, but simulation results show a trend of higher precipitation throughout Southeast Asia in the future, especially towards the end of the century, which could be around 25-50\% in some areas (Figure 6).

This long-term climate projection can be used to assess the impacts of climate change in various sectors as well as

\footnotetext{
${ }^{1}$ ECMWF Atmospheric General Circulation Model coupled with University of Hamburg Ocean Circulation Model (http://www.ipccdata.org/is92/echam4_info.html)
} 

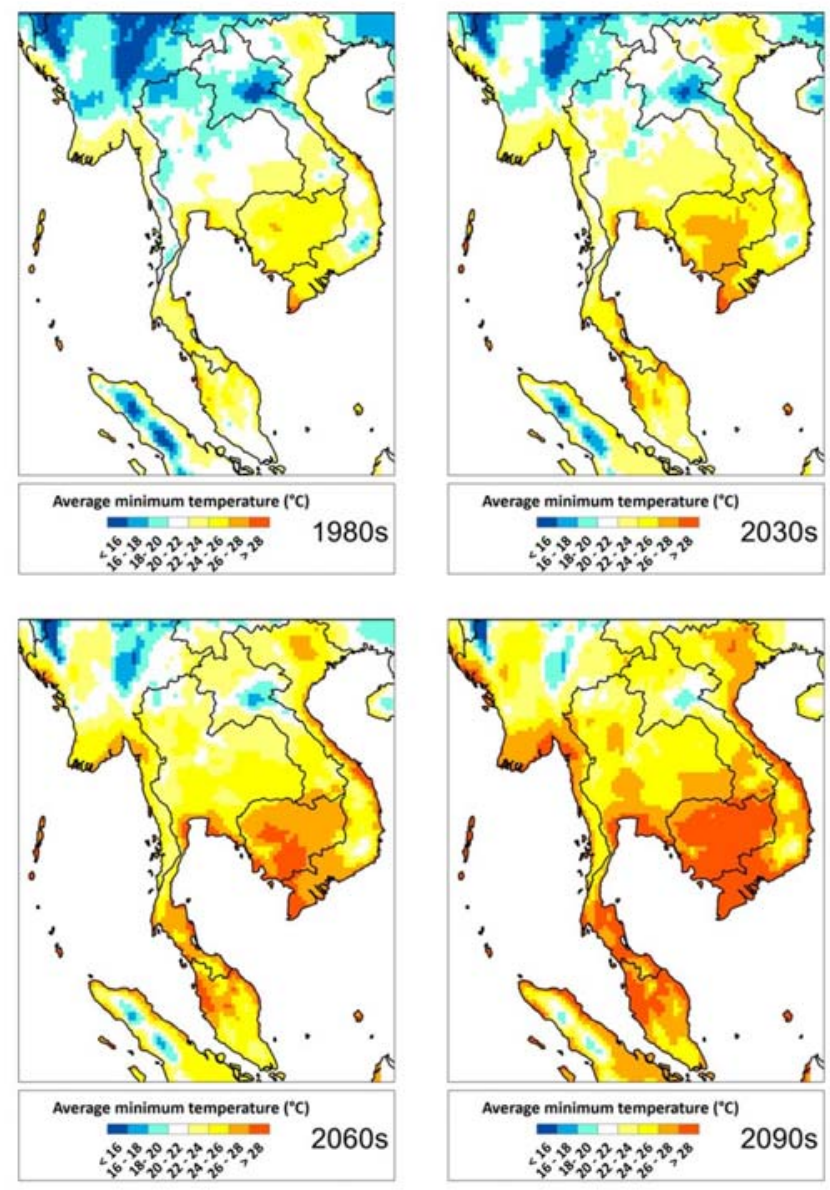

Figure 3. Average daily minimum temperature
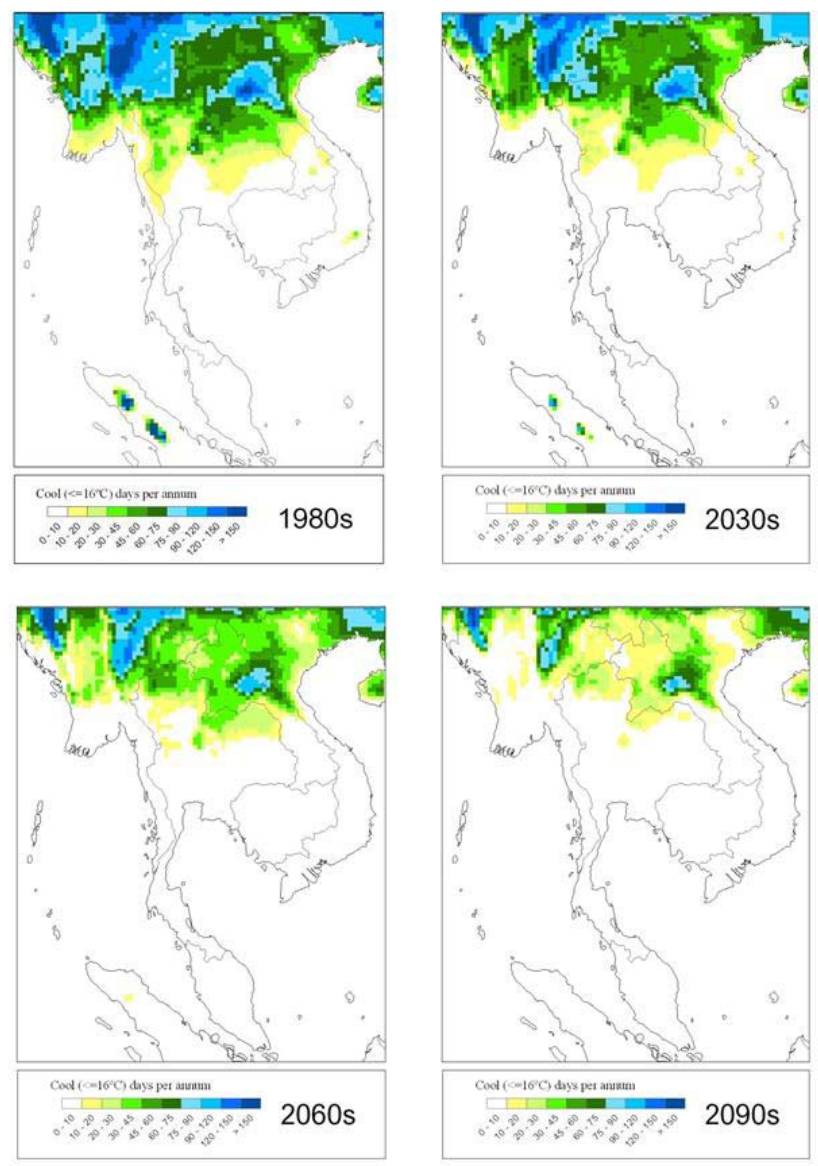

Figure 5. Length of cool period over the year - number of days with minimum temperature $\leq 16^{\circ} \mathrm{C}$
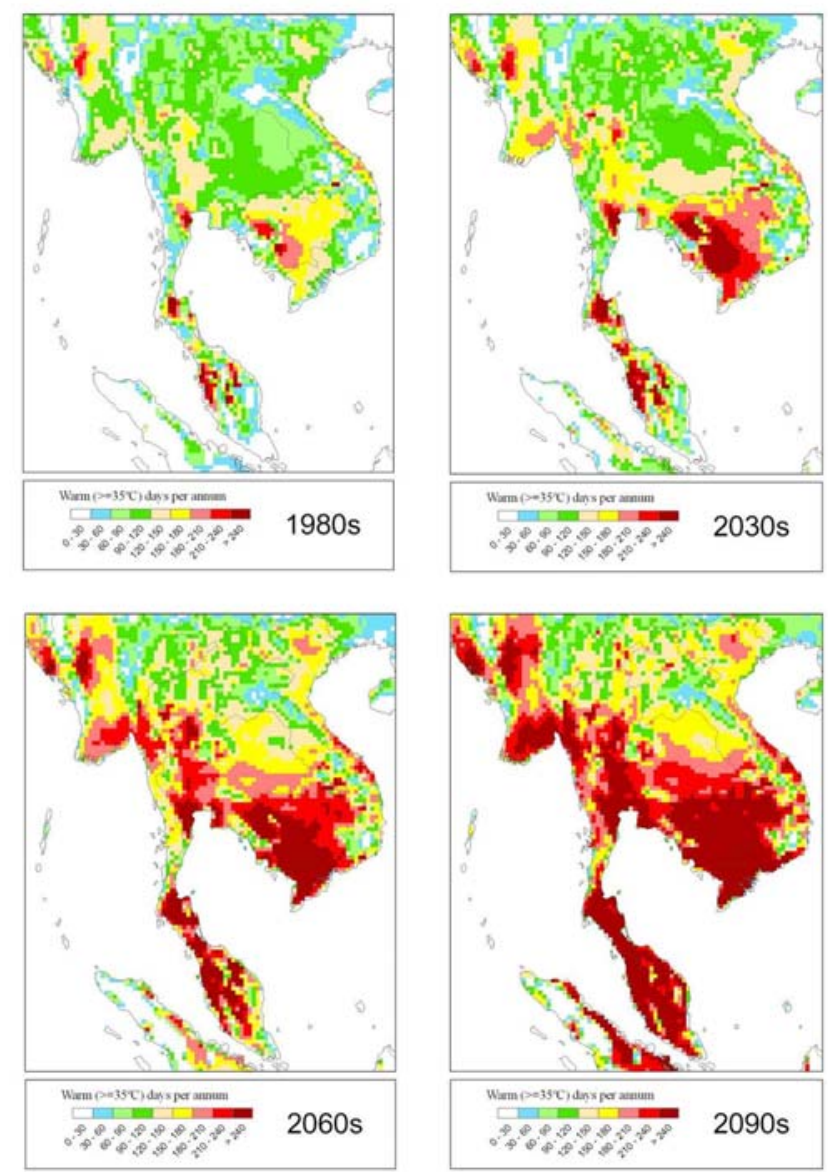

Figure 4. Length of hot period over the year - number of days with maximum temperature $\geq 35^{\circ} \mathrm{C}$
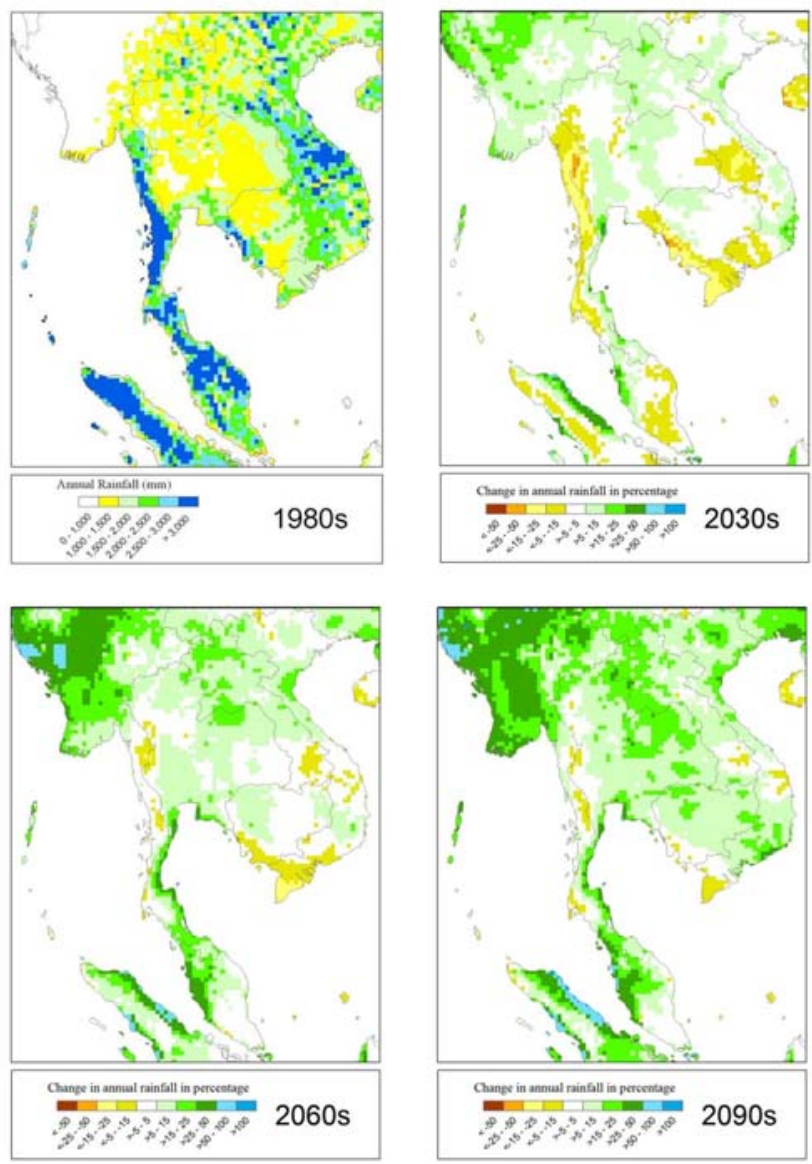

Figure 6. Annual precipitation $(\mathrm{mm})$ and future change compared to 1980 s (\%) 
support long-term planning. Using long-term climate projections for strategic planning to cope with climate change should not only consider change in average climate variables but also take various aspects of changes in climate pattern into consideration too; especially, change in the extreme value of any climate parameters and also the temporal aspect of change, e.g., changes in the length of seasons and shifting season patterns, etc. Moreover, it is important to be aware that this projection is a scenario of plausible future and cannot be taken as a long-term forecast. While there is a certain degree of uncertainty in the simulation result, however, it can still be used for strategic planning purposes.

One way to cope with uncertainty of long-term climate projection is the use of multiple scenarios, which are developed using various climate models and/or under different conditions. The use of multiple scenarios in strategic planning or long-term policy planning also requires changes in the thought paradigm of policy planners to become familiar with the use of multiple climate datasets for policy planning. The use of multiple scenarios is not a matter of placing effort to seek the 'best' scenario, thus should be selected for the planning exercise; but the planning process should be based on a wide range of scenarios and examine whether or not plans for the future are resilient to various future conditions under climate change.

\section{Conclusion}

In brief, future climate in Southeast Asia tends to be warmer with longer summer-time and higher rainfall intensity during the rainy season with higher annual total precipitation. These changes are unlikely to be irreversible and would have impact on various systems and sectors. However, this future climate projection is just one plausible future scenario, which was simulated by a single climate model and single initial dataset. Additional climate change scenarios need to be further developed to address the uncertainty of long-term climate projection.

Moreover, inter-comparison among other climate models is required to evaluate the results of the present study thus leading to improvement in future regional climate scenario simulations in the future.

\section{Announcement}

The dataset of future climate projection for A2 and B2 GHG scenarios is available for download at http:// cc.start.or.th/.

\section{References}

- IPCC. 2000. Special Report on Emission Scenarios (SRES). Cambridge University Press, Cambridge.

- IPCC. 2001. Climate Change 2001: Impacts, Adaptation and Vulnerability. Contribution of Working Group II to the Third Assessment Report of the Intergovernmental Panel on Climate Change (IPCC). Cambridge University Press, Cambridge, UK.

- IPCC. 2007. Climate Change 2007: The Physical Science Basis. IPCC Secretariat, Geneva, Switzerland.

- Jones, R.G., M. Noguer, D.C. Hassell, D. Hudson, S. Wilson, G. Jenkins and J.F.B. Mitchell (2004). Generating high resolution climate change scenarios using PRECIS, Met Office Hadley Centre, Exeter, UK, 40pp, April 2004.

- $\quad$ Simson, W., D. Hassell., D. Hein, R. Jones. and R. Taylor. 2006. Installing using the Hadley Centre regional climate modeling system, PRECIS: version 1.4.6. Met Office Hadley Centre, Exeter, UK.

- $\quad$ The IPCC Data Distribution Centre: HadCM3 Description [on-line]. Available at: http://cerawww.dkrz.de/IPCC_DDC/IS92a/HadleyCM3/ hadcm3.html. Accessed on 20 April 2009.

- The IPCC Data Distribution Centre: ECHAM4/ OPYC3 Description [on-line]. Available at http:// cera-www.dkrz.de/IPCC_DDC/IS92a/Max-PlanckInstitut/echa4opyc3.html. Accessed on 20 April 2009.

\section{Acknowledgements}

The research team at the Southeast Asia START Regional Centre would like to thank the Asia-Pacific Network for Global Change Research (grant number CRP200803CMY-Jintrawet) and Thailand Research Fund for their financial support in developing this climate change scenario. Also thanks to the Hadley Centre-The Met Office, UK for their technical support and provision of software and initial dataset for the simulation. 


\title{
Climate Change Risk Assessment in Asian Coastal Megacities: Knowledge Gaps and Research Needs for Urban Development Planning
}

\author{
Anond Snidvongs, Richard Cooper ${ }^{1}$
}

Corresponding author ${ }^{1}$

Southeast Asia START Regional Centre, Chulalongkorn University, Bangkok, Thailand. Email: rcooper@start.or.th

\begin{abstract}
The present paper highlights key issues confronting Asian coastal megacities in planning for future climate change. Critical gaps in information/knowledge for carrying out risk and vulnerability assessments to support urban development planning were highlighted at an APN and Ibaraki University-sponsored workshop by expert teams representing Bangkok, Ho Chi Minh City, Jakarta, Manila and Mumbai.
\end{abstract}

The workshop - Climate Change Vulnerability Assessment and Urban Development Planning for Asian Coastal Cities - held from 22-28 August 2010 in Nakhon Pathom, Thailand, brought together over 40 participants including academics, urban planners and officials, and experts in disaster management.

The workshop identified current information/knowledge gaps and challenges, and identified future research opportunities. Key findings distilled from the workshop were grouped into three categories - 'assessment of climate change related risk,' 'information/knowledge management,' and 'governance.' Across these themes, some 25 specific observations and recommendations for future research were identified.

It is anticipated that key findings from this workshop will shape the future research agenda in these cities. Some of the key findings and research recommendations included the following: Risk assessments were hampered by inadequate information, ranging from the lack of baseline climate data to the need for developing indicators for determining socio-economic vulnerabilities; food and water security and health assessments demanded greater attention; access and dissemination of information was limited, with development of online information/ knowledge management systems deficient; future capacity building activities proposed included developing an integrated course on urban development and climate change; and, a spectrum of governance-related matters were raised including issues of institutional coordination, deficiencies in existing city plans, development of building codes, vulnerability of the poor, and challenges of funding.

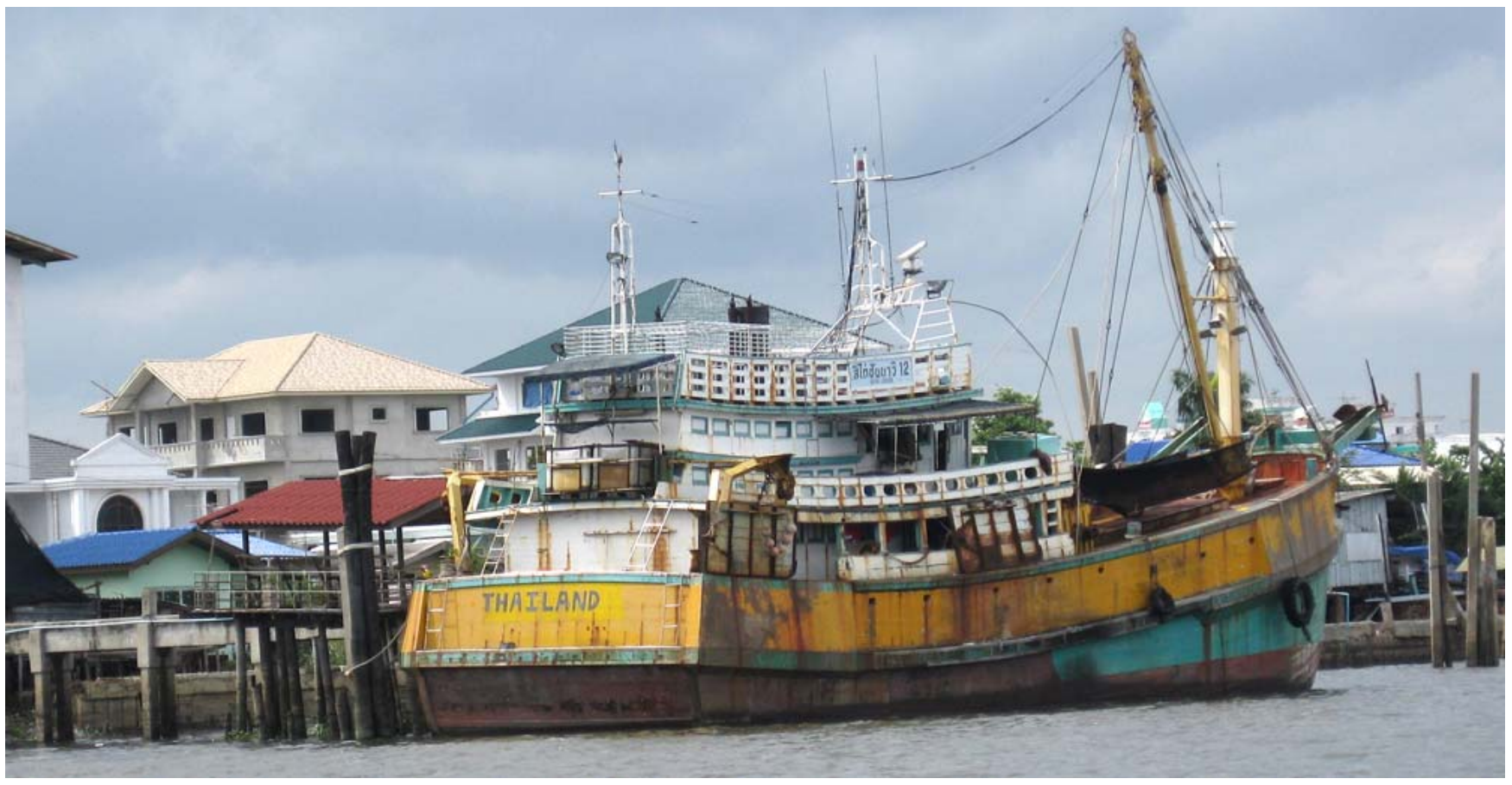


Keywords: climate change, risk assessment, adaptation, urban planning, knowledge management, megacities

\section{Introduction}

The workshop built on the first Cities at Risk (CAR) workshop held February 2009 in Bangkok - Developing Adaptive Capacity for Climate Change in Asia's Coastal Megaities - supported by APN and partners (CBA200806NSY, 2008). The CAR workshop highlighted the misled perception, particularly on the part of city officials, on the size of growing risks and vulnerabilities that now confront coastal Asian megacities. Moreover, UNESCAP (2009) stated recently that "it is paramount that risk reduction becomes part and parcel of urban planning," which unfortunately is not the case at present; a situation that the workshop directly addressed. Climate change risk and vulnerability assessments can play a key role in raising awareness of climate-related risks, and in leading to more informed decision-making. Unfortunately, as noted in the CAR workshop, the capacity to carry out such assessments is currently lacking in most coastal Asian cities.

The workshop conducted through the present activity (CIA2009-01-SNIDVONGS, 2010) aimed to raise awareness and improve capacity to assess climate changerelated risk and vulnerability in five Asian coastal megacities - Bangkok, Ho Chi Minh City, Jakarta, Manila, and Mumbai. Workshop objectives included:

i. helping develop capacity on the part of urban planners, managers, and researchers in climate change vulnerability assessment and application to urban development planning and governance;

ii. promoting locally-led vulnerability research in Asian coastal cities linked to user needs; and

iii. helping develop partnerships between researchers, planners, and policy-makers, and to develop communities of knowledge for vulnerability assessments in each participating city.

The workshop was primarily funded by APN with additional financial support from Ibaraki University (Japan), hosted by the Southeast Asia START Regional Centre (SEA START RC) of Chulalongkorn University and co-organised with the East-West Centre, Hawaii.

\section{Material and Methods}

\section{Pre-workshop Activity: Preparation of City Reports}

Prior to the workshop, groups of researchers and urban planning practitioners representing each City at the workshop - Bangkok, Ho Chi Minh City (HCMC), Jakarta, Manila and Mumbai - were invited to prepare a 'City Report' on climate change risk and vulnerability assessments in relation to urban development planning for their home City. These reports represented a key source of information for better understanding current efforts in integrating climate risk into development and planning in

\section{CIA2009-01-Snidvongs}

Climate Change Vulnerability Assessment of Floods and Urban Development Planning for Asian Coastal Cities

\section{Project Leader:}

Dr. Anond Snidvongs

Southeast Asia START Regional Centre

Chulalongkorn University

$5^{\text {th }}$ Floor, Chulawich 1 Building, Henri Dunant

Road, Bangkok 10330

THAILAND

Tel: +66 22189469

Fax: +6622519416

Email: anond@start.or.th

\section{APN Funding:}

US\$45,000 (For 1 Year)

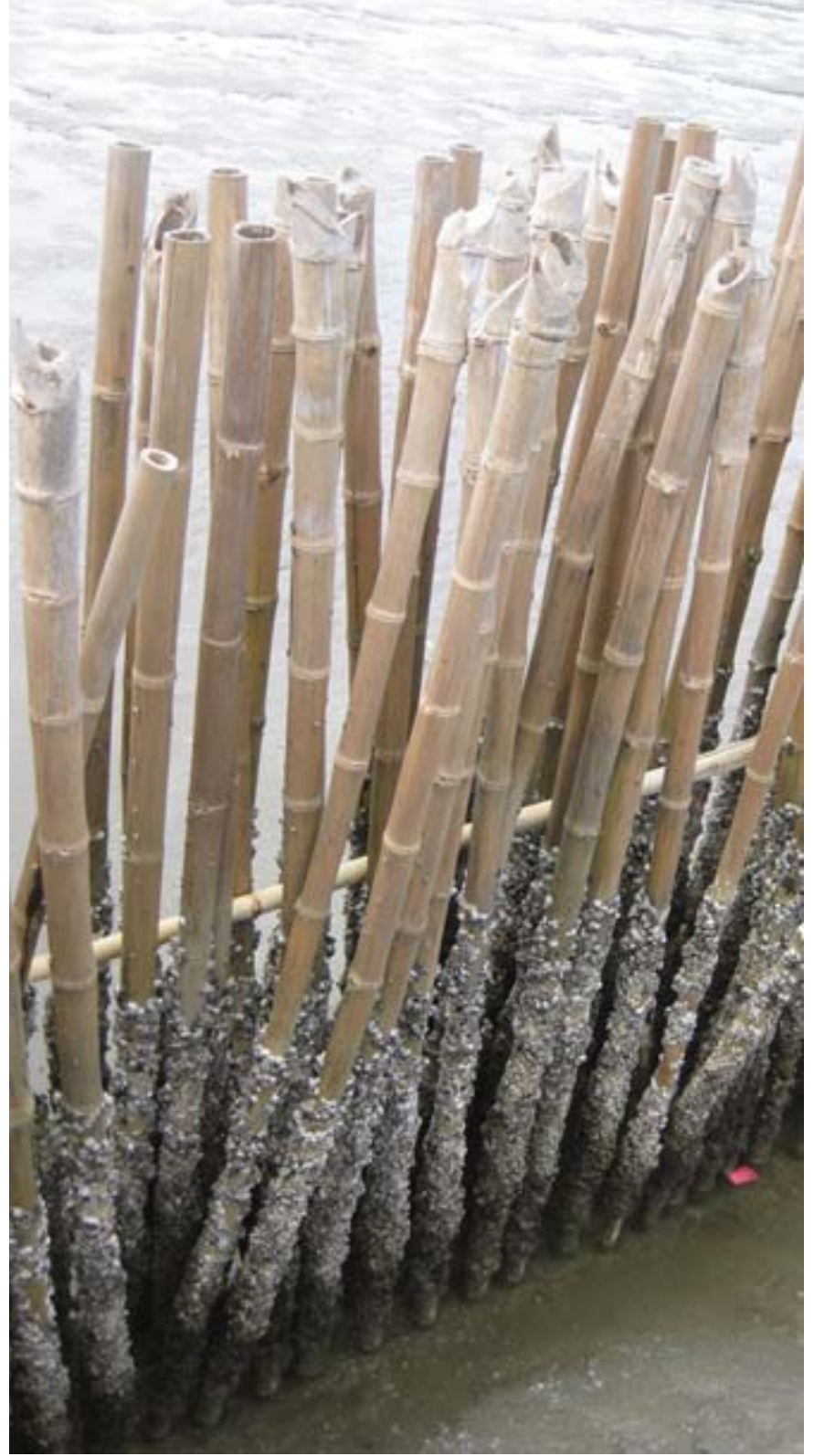


each of the five Cities and for better identifying future research and capacity building needs.

\section{Approach to Synthesis}

Pertinent information was extracted from the City Reports (submitted prior to the workshop), City Report Presentations (workshop day 2), Research Proposal presentations (workshop day 6) and abstracts (submitted post-workshop) ${ }^{1}$. City teams were requested postworkshop to prepare one page abstracts based on the City Reports and presentations under three main categories 'assessment of climate change related risks,' 'information/ knowledge management,' and 'governance.'

\section{Results and Discussion}

The workshop identified current information/knowledge gaps and future research opportunities for addressing climate change-related risks and vulnerability in Bangkok, HCMC, Jakarta, Manila and Mumbai. These are summarised below.

Category 1: Assessment of climate change related risks (hazards and socio-economic vulnerabilities)

1. Improve stakeholder perception of risk

- acknowledging the vulnerability of the poor to the impacts of climate change

2. Better define urban hazard factors

3. Assess risk to water and food security, including

- consumption, water quality, sanitation, waste management, agriculture, aquatic systems

4. Address lack of baseline climate data, including

- temperature, sea level and social impact (see item 8 below on socio-economic vulnerabilities)

5. Conduct health risk assessments, including

- $\quad$ assessing the link between climate change and health impacts
6. Recognise the importance of green space in moderating air temperature and flood prevention

7. Recognise the potential future impacts of coastal erosion

8. Conduct socio-economic vulnerability assessments

- addressing limited information on social aspects of vulnerability

- $\quad$ integrating existing studies to better understand the current situation

- refining/identifying measures of risk

- developing measures of social vulnerability

- mapping vulnerabilities

- integrating exposure, places, sectors, activities, individuals, households, social groups, communities, livelihoods into assessments

- understanding how urban and rural areas are linked by migration

- $\quad$ assessing the vulnerability of marginal groups/ informal sector

Category 2: Information/knowledge management

9. Address provision of an information/knowledge management system, including

- lack of a central information system, poor data collection and storage

- the need for an interdisciplinary approach to development

10. Address limited availability of geographic information

11. Address integration of geographic information with socio-economic data

12. Address lack of GIS and mapping tools, and understanding of their application

13. Ensure access to information by stakeholders

14. Develop materials for information dissemination and target the most vulnerable communities

- make better use of mass media

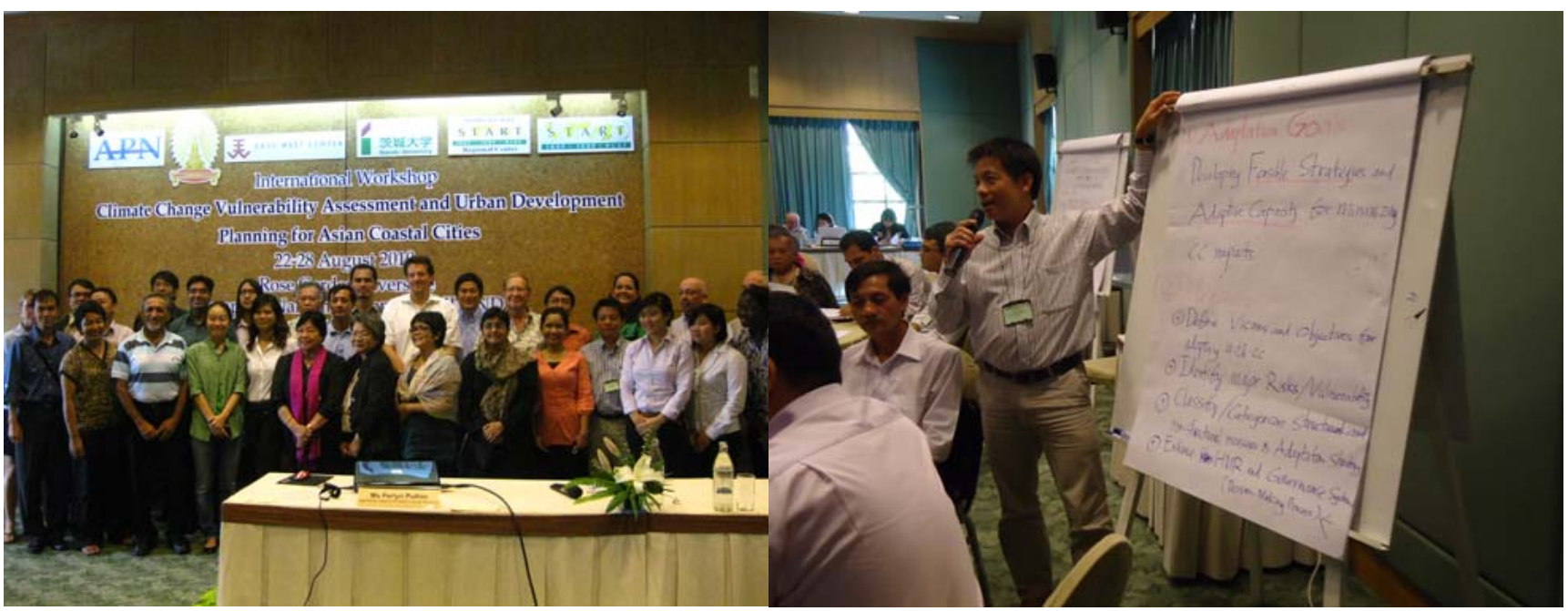

${ }^{1}$ City Reports, City Report Presentations, Research Proposal Presentations, and abstracts are accessible from the workshop report (CIA2009-01-SNIDVONGS, 2010) at http://www.apn-gcr.org/newAPN/resources/list2009capableprojects.htm 
15. Expand capacity building activities, including

- developing a course on urban development and climate change

- integrating climate risk content into other courses (e.g., engineering)

- conducting stakeholder workshops

16. Recognise limitations of existing early warning systems

\section{Category 3: Governance}

17. Address the need for an institutional linking mechanism

18. Address the lack of coordination between government agencies, NGOs, and the private sector 19. Build capacity of City officials

20. Assess the role of civil society groups in urban governance

21. Address deficiencies in existing planning instruments in incorporating climate change risk and vulnerability 22. Address development and enforcement of land use regulations and building and sanitation codes

23. Address vulnerability of marginal groups, including

- invisibility in plans/assessments

- inadequate dissemination of information to the poor

24. Investigate potential for climate-induced migration of population

25. Address challenges to allocating funds for climate change-related risks and vulnerabilities, including

- availability and commitment

- $\quad$ project-based and donor-driven support

- $\quad$ raising of funds through fees paid by the local community

- $\quad$ sustainability of initiatives

\section{Future Opportunities}

Opportunities to address these challenges faced by the Cities are anticipated through new projects commencing in 2011, including an APN-funded project titled - Enhancing adaptation to climate change by integrating climate risk into longterm development plans and disaster management - and an IDRC (of Canada) proposal - Coastal Cities at Risk (CCaR): Building Adaptive Capacity for Managing Climate Change in Coastal Megacities.

\section{References}

- CBA2008-06NSY-Fuchs (2009). Cities at Risk: Developing Adaptive Capacity for Climate Change in Asia's Coastal Mega Cities, Final Report. URL: http:/ /www.apn-gcr.org/newAPN/resources/ list2008capableprojects.htm [last accessed 27 Jan 2011].

- CIA2009-01-SNIDVONGS (2010). Climate Change Vulnerability Assessment and Urban Development Planning for Asian Coastal Cities, Final Report. URL: http://www.apn-gcr.org/newAPN/resources/ list2009capableprojects.htm [last accessed 25 Jan 2011].

- UNESCAP (2009). UN Economic and Social Commission for Asia and the Pacific, Committee on Disaster Risk Reduction, First Session 25-27 March 2009, Bangkok. URL: http://www.unescap.org/idd/ events/cdrr-2009/CDR_INF4.pdf [last accessed 28 January 2011].

\section{Acknowledgements}

We would like to acknowledge our gratitude to workshop sponsors (Asia-Pacific Network for Global Change Research and Ibaraki University), co-organisers (Southeast Asia START Regional Centre of Chulalongkorn University, and East-West Centre), and all of our collaborators and participants.

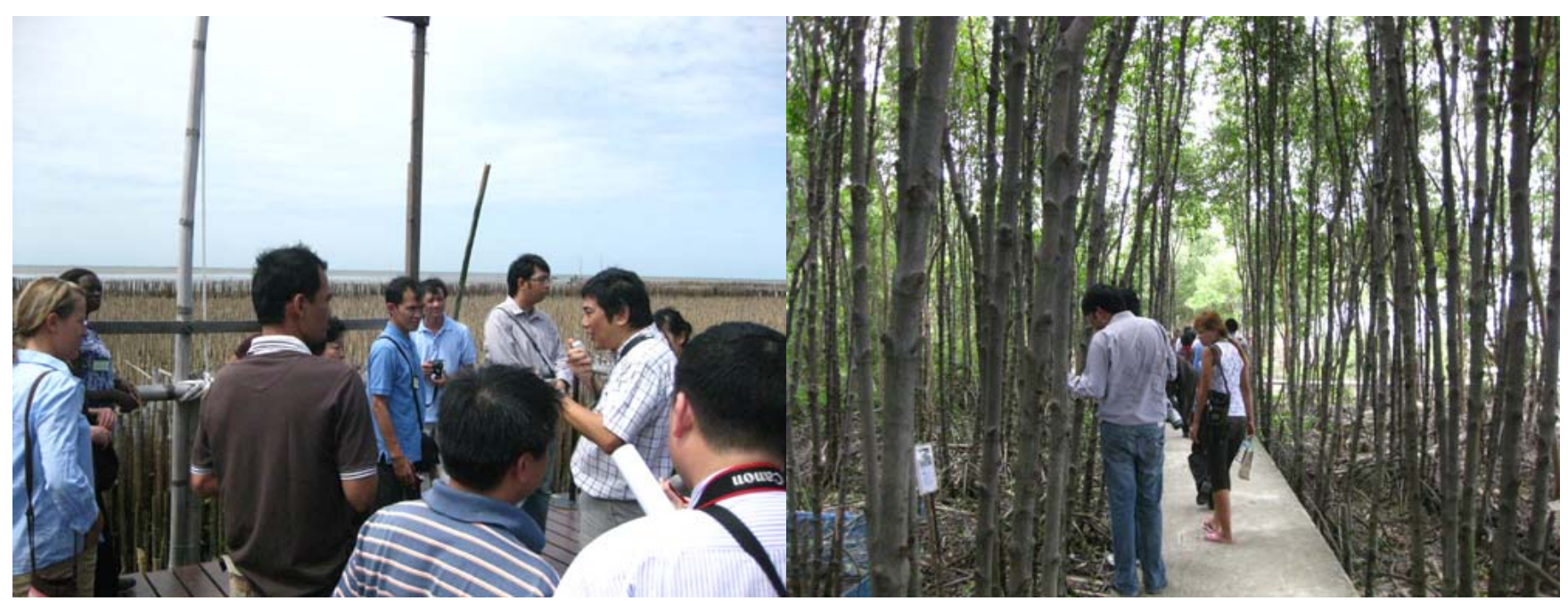




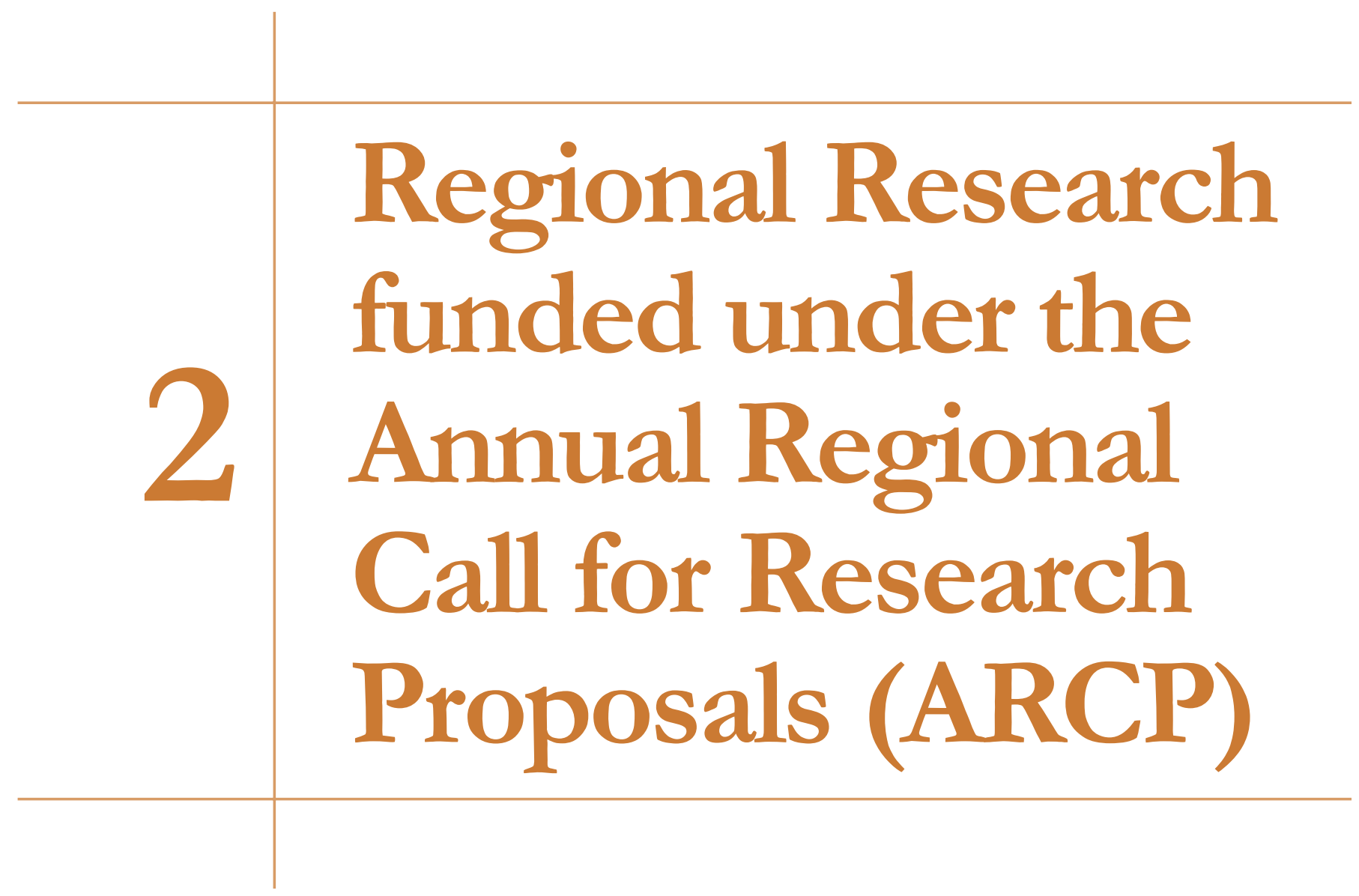




\section{ARCP2010-01CMY-Sthiannopkao \\ Collaborative Research on Sustainable Urban Water Quality Management in Southeast Asian Countries: Analysis of Current Status (comparative study) and Development of a Strategic Plan for Sustainable Development}

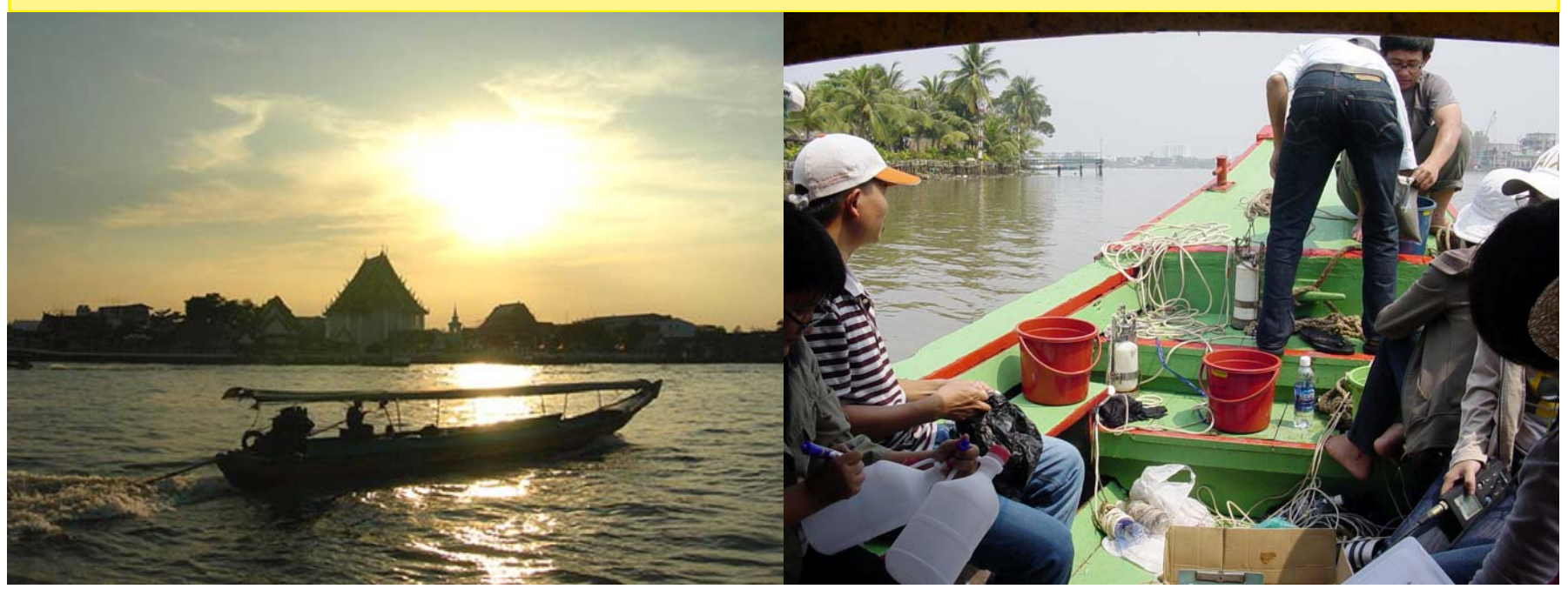

$\mathrm{F}$ locusing on sustainable urban water quality management in Southeast Asian cities, namely Bangkok (Thailand), Bandung (Indonesia), Ho Chi Minh City (Viet Nam), and Phnom Penh (Cambodia); the project team has carried out a range of activities including: i) monitoring of heavy metals, pathogenic E. coli and total coliforms in surface waters and sediments; ii) analysing past water quality data for a comparative study by applying Canadian Council of Minister of the Environment-Water Quality Index (CCME-WQI); and iii) pre-studying secondary data using Soil and Water Assessment Tool (SWAT) modelling.

The present Project encompasses capacity building activities including a four-month internship programme at IERCGIST and visionary workshops. With additional funding provided by IERC-GIST since 2009, the programme recruited four interns; a Cambodian, a Thai and two Vietnamese. Three visionary workshops were organised in Bangkok (10-11 November 2009), Ho Chi Minh City (2728 July 2010) and Manila (15-16 November 2010) involving regional and local scientists and policy-makers. Workshops have facilitated greater dissemination of knowledge, information and experience on urban water quality management. Upon fruitful workshop discussions, project members agreed to invite potential partners to participate in future Project activities to explore financial support and international promotion of Southeast Asian Water Environmental Database (SEAWED). It is worth noting that this Project has earned an endorsement from the International Human Dimensions Programme on Global Environmental Change (IHDP).

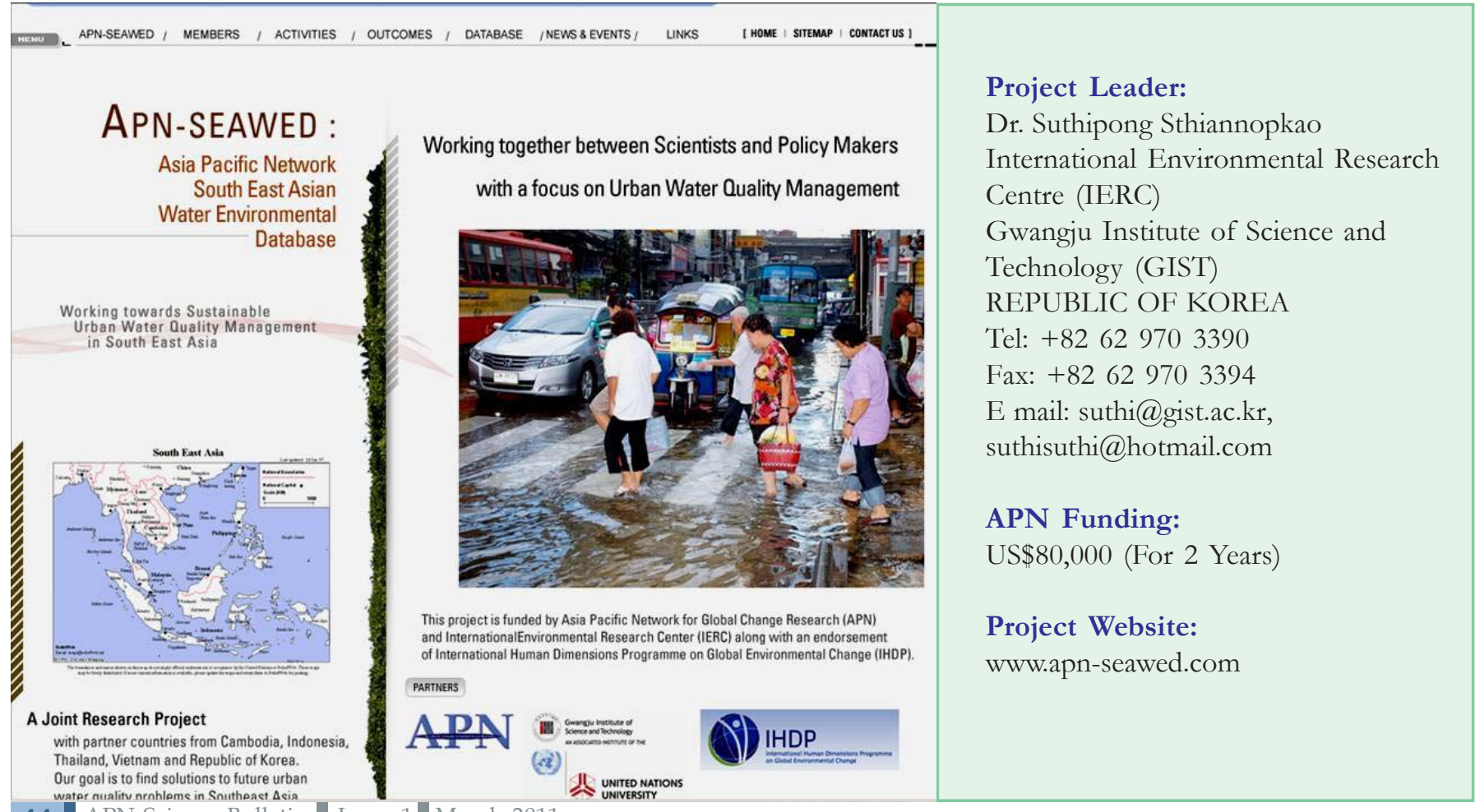

Project Leader: Centre (IERC)

Gwangju Institute of Science and Technology (GIST) REPUBLIC OF KOREA

Tel: +82629703390

970339

E mail: suthi@gist.ac.kr,

APN Funding:

US\$80,000 (For 2 Years)

Project Website:

www.apn-seawed.com 


\section{ARCP2010-02CMY-Phua \\ Integrated Prediction of \\ Dipterocarp Species \\ Distribution in Borneo for \\ Supporting Sustainable Use and Conservation Policy Adaptation}

$\mathrm{T}$ hrough an integrated approach that combines remote sensing, Geographic Information System (GIS) and field data collection, the present Project investigates deforestation, distribution of dipterocarps and conservation gaps on a landscape scale in Borneo's rain forest.

The project team has completed the analysis quantifying deforestation in Sarawak, the largest state in Malaysia, using post-

classification of land cover types between 1990 and 2009. Supervised classification on nine Landsat-Thematic Mapper (TM) scenes produced land cover map for 1990 (Figure 1) with overall accuracy of $86 \%$. For the land cover map of 2009 (Figure 2), at least three images were needed for correcting missing lines in each of nine Landsat-Enhanced Thematic Mapper Plus (ETM+) scenes and the overall accuracy of the classification is $80 \%$. Of the total loss of 1.2 million ha of forests in the past two decades, analysis shows that more than $90 \%$ of the land cover were peat swamp and intact forests. The overall deforestation rate of Sarawak is $0.64 \%$.

In order to improve the temporal resolution of the deforestation rate, the project team is also analysing land cover for 2000. Outcomes indicate that deforestation is most evident at coastal divisions (e.g. Mukah Division) due to 'forest-to-oil palm' conversion.

Similar analysis for East Kalimantan is also making remarkable progress. The results will soon be available for comparison between the two policy regimes of Sarawak and East Kalimantan. The deforestation information will be integrated with potential distribution of dipterocarps in GIS environment for addressing conservation gaps of existing protected area networks and supporting policy analysis.
Project Leader:

Dr. Phua Mui How

School of International

Tropical Forestry

Universiti Malaysia Sabah

MALAYSIA

Tel: +6088320000

Ext. 8773

Fax: +60 88320876

Email: pmh@ums.edu.my

APN Funding:

US\$75,000 (For 2 Years)

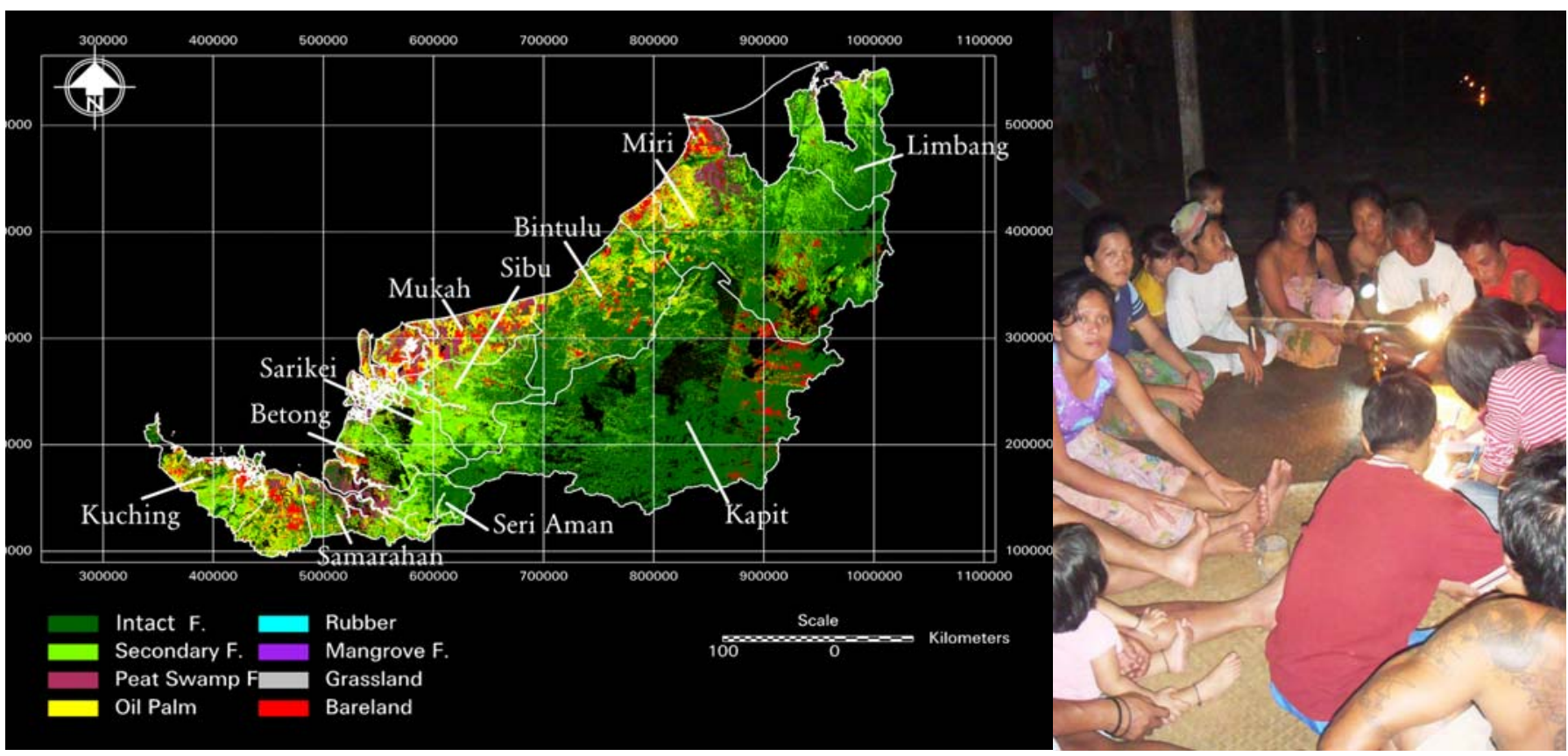

Figure 2. Sarawak 2009 land cover map using nine Landsat-ETM+ scenes 


\section{ARCP2010-03CMY-Marambe Vulnerability of Home Garden Systems to Climate Change and its Impacts on Food Security in South Asia}

$\mathrm{P}$ rojections at the global level indicate strongly that climate change could severely affect agricultural production, with cereal production in developing countries being affected the most. Therefore, ensuring national and regional level food security for all and at all times is needed in the face of projected climate change. Food security in rural South Asia and food production in home gardens is intrinsically related; hence, climate change may have significant implications on food security.

According to recent studies conducted in Sub Saharan Africa, home gardens can better cushion shocks arising from climate change compared with monocultures; and farmers use a variety of adaptation measures to combat the adverse effects of climate change. The influence of climate change on food production and food security has not been well established yet. Food production in many developing countries, especially in South Asia, is carried out in home gardens.

The present Project assesses the effects of climate change on home garden systems, which are the predominant type of highland farming in South Asia, under changing climate. This Project, which is now in its second phase, is being implemented as a multi-country collaboration among three countries: Sri Lanka, India and Bangladesh. Using a pre-tested questionnaire, 368 home gardens were surveyed in selected villages in the three countries. The sites were selected based on their extent

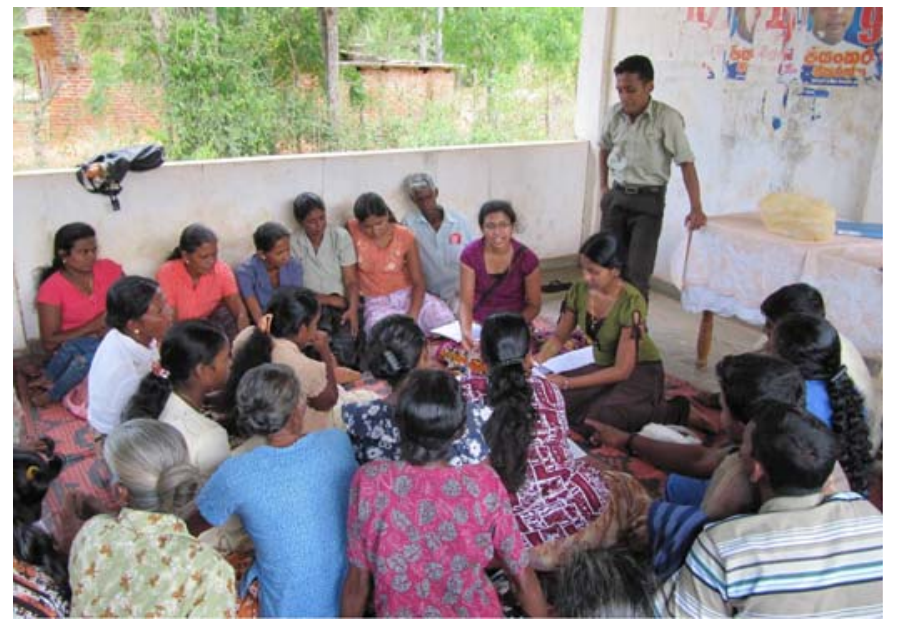

Participatory Rural Appraisal, Keeriyagaswewa, Sri Lanka

( $<0.5$ ha), maturity (at least $20 \mathrm{yr}$ ), composition, and structure (at least a three-tiered plant structure).

The project team has taken stock of the trees, crops and farm animals in the home gardens to establish the current status. The extent to which climate shock has influenced the present status of home gardens has been assessed. The data analysis is in progress to draw conclusions of the survey results. Participatory Rural Appraisals (PRAs) and Focus Groups Discussions (FGDs) were carried out to verify information provided during the surveys and also to recall memories of the elderly community in the villages regarding change in climate over the past 20 years. The rainfall and temperature data obtained from the Departments of Meteorology in the respective countries are being analysed to elucidate the relationship to changes in the home gardens.

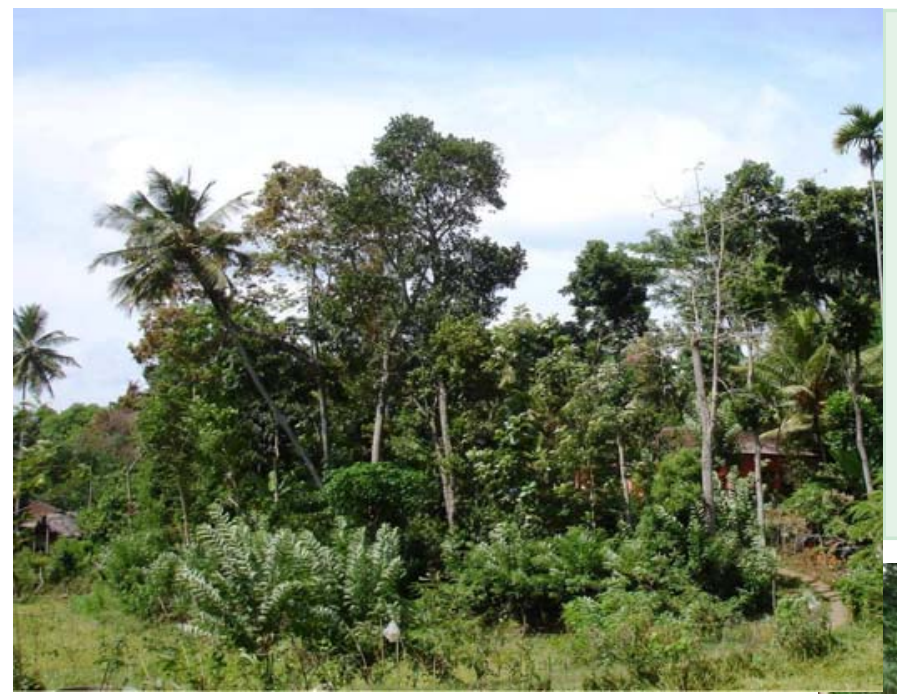

\section{Project Leader:}

Prof. Buddhi Marambe

Faculty of Agriculture

University of Peradeniya

SRI LANKA

Tel: +94812 395100

Fax: +94812 395110

Email: bmarambe@pdn.ac.lk; marambeb@gmail.com

\section{APN Funding:}

US\$75,000 (For 2 Years)

Home garden in Pethiyagoda, Sri Lanka

Food production in many developing countries, especially in South Asia, is carried out in home gardens. Home Garden is a complex sustainable land use system that combines multiple farming components, such as annual and perennial crops, livestock and occasionally fish, of the homestead and provides environmental services, household needs, and employment and income generation opportunities to the households.

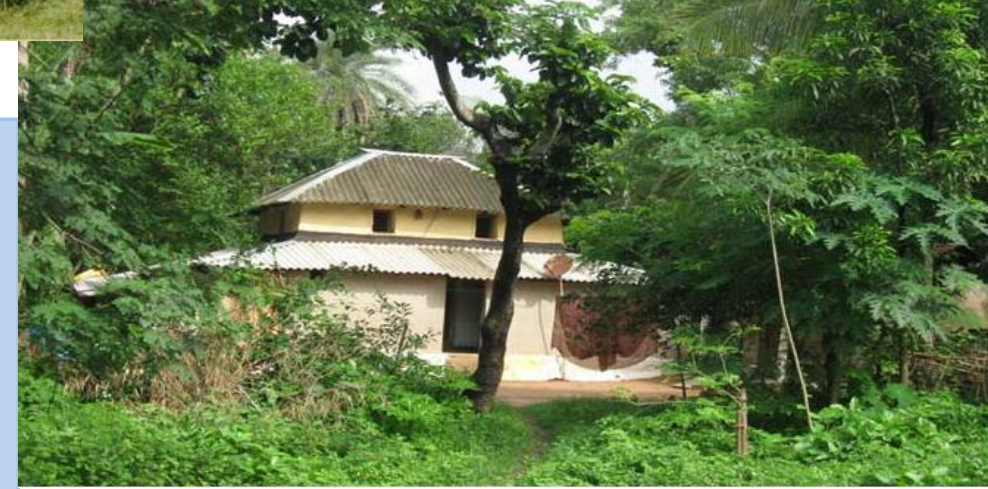

Home garden in West Bengal, India 


\section{ARCP2010-04CMY-Wang Building Asian Climate Change Scenarios by Multi-Regional Climate Models (RCMs) Ensemble}

\begin{abstract}
$\Lambda$ s a long-term regional collaboration to promote Asian climate studies, the present Project is working to enable multi-RCMs change and scientific bases for impact assessments and concerned policymakers. Along its research methodology, the Project has set up a regional climate study network promoting scientific cooperation.
\end{abstract}

In an effort to develop high-confidence scenarios, the Project organised an inception workshop from 28-29 January 2010, in Tsukuba, Japan. Thirty participants attended the workshop bringing project scientists from 11 project groups, invited scientists, and observers from Australia, China, Denmark, Japan, Republic of Korea, Russian Federation, and U.S.A. The leading scientists presented their latest research results, including model validation over the research domain, investigation of the effects of key factors and processes that affect the monsoon system and climate extremes, etc. Upon active discussion, the project team decided to use the simulation design consisting of two time slices: periods from 1978-2000 for control climate, and 2038-2070 for Asian high-resolution climate change projection. For both time slices, the two-year spin-up time is being applied.

To date, the Project has completed studies of model validation and uncertainty analyses, and carried out biases correction to assist in
Project Leader:

Dr. Shuyu Wang

Institute of Atmospheric Physics

Chinese Academy of Sciences, CHINA

Tel: +8610 82995159

Fax: +86106202 8604

Email: wsy@tea.ac.cn

APN Funding:

US $\$ 79,760$ (For 2 Years)

(Year 3 expected funding is US\$40,000)

developing the regional climate change projection. The project team identified key physical processes that either control or modulate the Asian-Monsoon-System, and investigated their impact mechanisms on regional climate. Currently the project continues to integrate both control and future climates. The project team is analysing the simulation results and building climate change scenarios. With the preliminary modelling results, the timing and magnitude of climate change in Monsoon Asia and uncertainties in the projection can be assessed.

\section{ARCP2010-05CMY-Luck The Effects of Climate Change on Pests and Diseases of Major Food Crops in the Asia-Pacific Region}

\begin{abstract}
I
n order to assess the research being done on climate change and pests and diseases of important crops in the Asia-Pacific Region, the present Project successfully convened its first workshop at Bidhan Chandra Krishi Viswavidyalaya (BCKV) University in Kalyani, Kolkata. A consensus was reached after some discussion that the project team would focus on Potato Late Blight for the common
\end{abstract}

Project Leader:

Dr. Joanne Elizabeth Luck

Department Primary Industries Victoria (DPI)

Cooperative Research Centre

National Plant Biosecurity

AUSTRALIA

Tel: +61 392109248

Fax: +61 398003521

Email: jo.luck@dpi.vic.gov.au

APN Funding:

US\$78,240 (For 2 Years) disease, with Potato Virus Y and Potato Leaf-roll Virus as secondary priorities.

Potato is the world's third most important staple food crop and its production is increasing at $4.5 \%$ per annum. In 2005, for the first time, developing countries were growing more potatoes than developed nations, with China contributing 20\% of the world's production.

Consecutively, the Project organised its second workshop which was held at DPI Victoria, Knoxfield and University of Western Sydney, Hawkesbury campus in Australia from 18-22 October 2010. These meetings focussed on Potato Late Blight in India and Bangladesh, which is emerging as a major issue for growers in these countries potentially due to increased drought and flooding cycles. Indian and Bangladeshi scientists from BCKV University and Bangladesh Agriculture

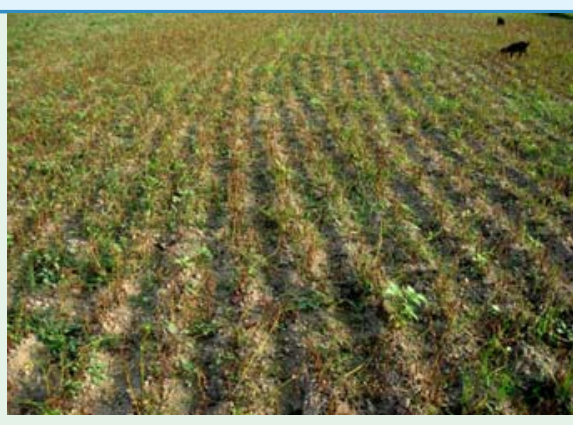

Research Institute (BARI), respectively, described the Late Blight problem as a constant race against a rapidly evolving pathogen. The apparent futility associated with the multiple fungicide application was also highlighted.

The historical datasets (1972-2010) for planting times, late blight initiation and severity were presented for both countries with climatic data sets associated with late blight establishment presented by project agrometeorologists for the same period. In addition, downscaled climate projections to 2100 will be used in conjunction with published Late Blight models to determine if there will be increased risk in Late Blight incidence under future climates for India, Bangladesh and Australia. 


\section{ARCP2010-06CMY-Schaefer \\ Quantifying the Role of Dead Wood in Carbon Sequestration}

A pproximately 300 wood samples have been labelled and are being individually monitored for $\mathrm{CO}_{2}$ production as part of the activities in the present Project. These samples were equally distributed among 3 dominant tree species in the Ailao Mountain forest in South West China; Lithocarpus chintungensis, Lithocarpus xylocarpus and Schima noronhae. They were also evenly distributed among 3 qualitative decay classes: 3 (knife blade penetrates easily), 2 (intermediate) and 1 (knife blade does not penetrate). The project team also has measured the weight, dimensions and moisture content of each wood sample and $\mathrm{CO}_{2}$ production rates can be expressed per unit weight, per gram of wood carbon contained, per unit wood volume or per unit surface area.

Previous studies have shown relationships between $\mathrm{CO}_{2}$ production (decomposition rate) and wood density and wood moisture content. This Project observes that, as well, however, these factors explain very little about the variability among samples (Figures 1 and 2). This is significant for this Project, because it implies that other factors exert very strong controls on wood decomposition rates.

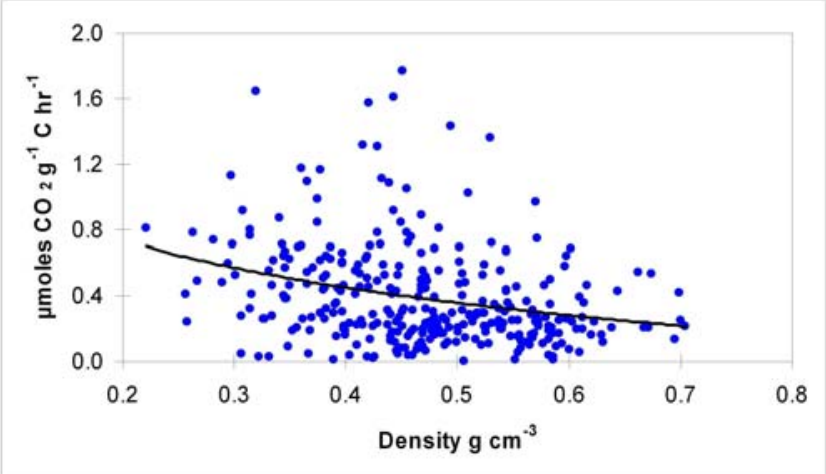

Figure 1. For Ailao Mountain wood, there is a weak negative correlation between wood density and $\mathrm{CO}_{2}$ production, but individual samples show greater than tenfold variation for most values of wood density

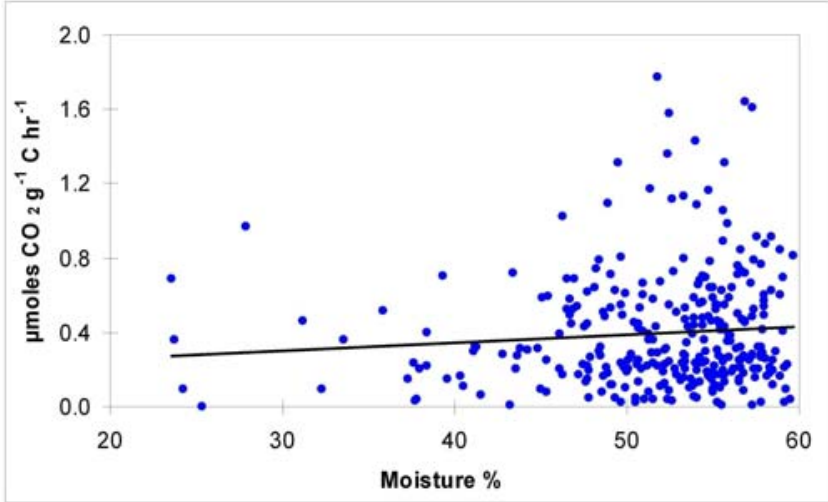

Figure 2. For Ailao Mountain wood, there is a weak positive correlation between wood moisture content and $\mathrm{CO}_{2}$ production, but individual samples show greater than tenfold variation at the same moisture content

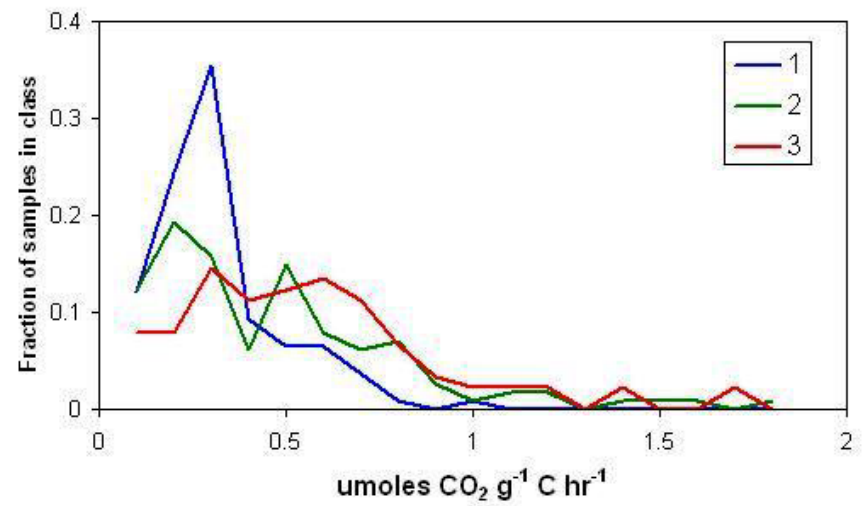

Figure 3. Wood decomposition patterns at Ailao Mountain in Southwest China

Furthermore, initial results in Figure 3 shows that wood samples that are very 'fresh' (decay class 1) decompose at very similar rates. In contrast, wood that has undergone more extensive decay (especially decay class 2) show two distinct peaks in decomposition rates. This could be evidence for the development of distinct wood-decaying fungal communities with different rates of decomposition. Further analysis will be conducted including the use of slow-decomposing wood to inoculate fresh wood much the same as mushroom growers inoculate logs with fungal spawn to establish pure communities. The effectiveness of this procedure will be examined over time with the same respiration measurement technique.
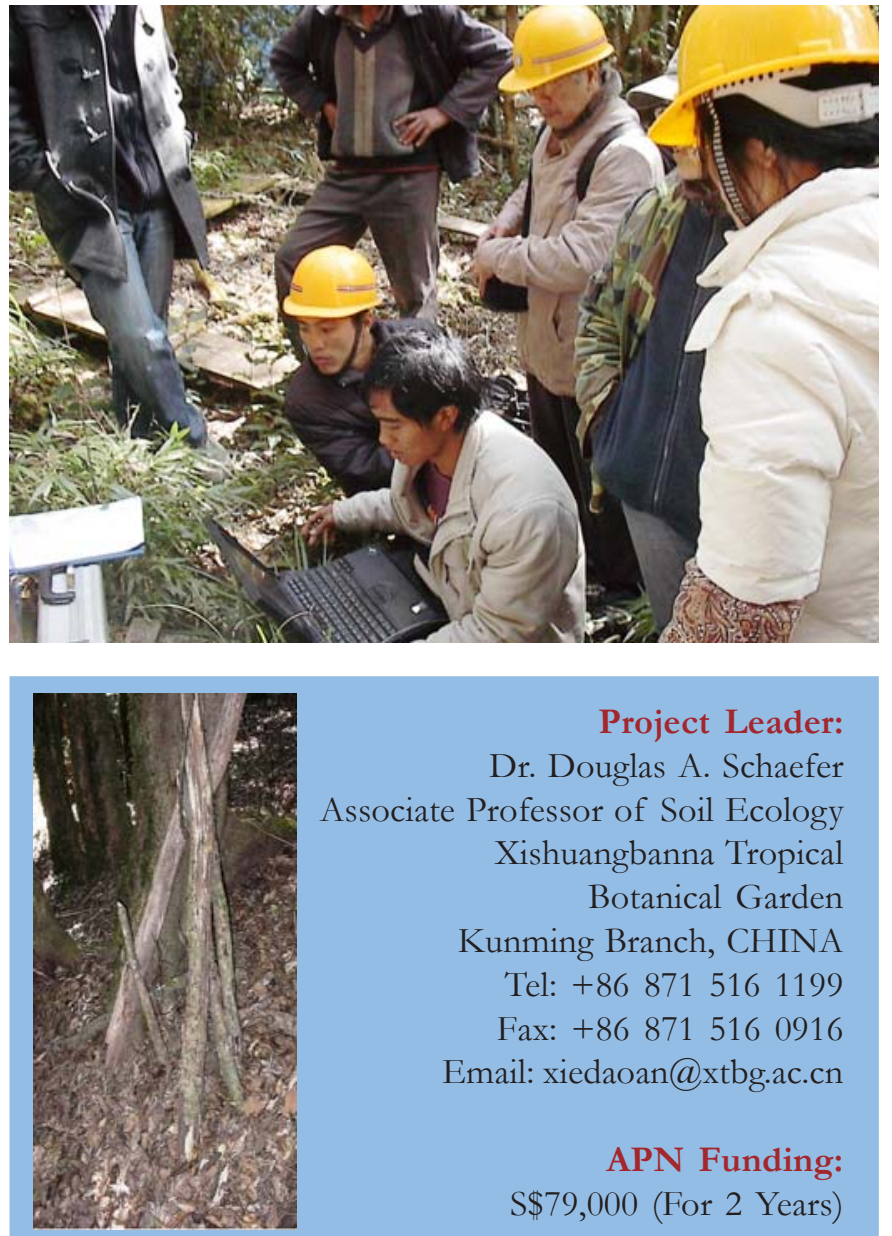

Project Leader: Dr. Douglas A. Schaefer Associate Professor of Soil Ecology Xishuangbanna Tropical Botanical Garden Kunming Branch, CHINA Tel: +86 8715161199

Fax: +86 8715160916 Email: xiedaoan@xtbg.ac.cn

APN Funding: S\$79,000 (For 2 Years) 


\title{
ARCP2010-07CMY-Bai \\ Asian Coastal Ecosystems: An Integrated Database and Information Management System (DIMS) for Assessing Impact of Climate Change and its Appraisal
}

\begin{abstract}
A s more research is being conducted in the region to help understand climate change and the factors attributed to it, it has become crucial to ensure research results, information, and data are accessible to all. The project team composed of researchers from Malaysia, India, Singapore and England has embarked on developing an Integrated Database and Information Management System (DIMS), an easily accessible information outlet.
\end{abstract}

Developed initially for the collaborating developing countries, DIMS includes physical, chemical, and biological parameters. DIMS is expected to be extended for other countries in the Asia-Pacific region in the future through further study and maintenance of the project website. A sample snap shot taken of the website is shown below.

As part of the project activities, a conference on "Climate Change and DIMS Technology" was organised from 1-3 December 2010 at the University of Nottingham, Malaysia. Reaching out to some 50 individuals from various disciplines, this conference held in-depth discussions following several lectures on climate change modelling methodology and effective prediction of environmental change. Participants learned about and developed their skills in the use of GIS tools, maps and relational databases and took part in opportunities for networking.

- Bai, R.V. and Mohan, S. 2009. Groundwater Model for Investigating Seawater Intrusion Hazards. Proc. of Int. conference on Disaster Mitigation and Management (ICDMM2009), Dec 1618, 2009, PSNA, Tamil Nadu, India.

- Mohan, S. and Janardhanan, G. 2009. Climate Change: Is it a Disaster? Proc. of Int. conference on Disaster Mitigation and Management (ICDMM2009), Dec 1618, 2009, PSNA, Tamil Nadu, India.

- Bai, R.V. and Gopinath R. 2010. Real Time Water Quality. Workshop on Sustainable Urban Stream Restoration (rehabilitation) by UNIVERSITAS 21, Nov 12-14, 2010, Delhi, India.

- Bai, R.V. and Kabiri, R. 2010. Climate Change Modelling for Environmental Wealth. $2^{\text {nd }}$ International Conference \& Exhibition on Waste to Wealth, 27-28 July 2010, Putra World Trade Centre, Malaysia.

- Bai, R.V., Mohan S. and Kabiri R. 2011. New Database Information Management System for Climate Change - An online resource. In Leal Filho, W. (Ed) "Climate Change and the Sustainable Management of Water Resources”, Springer Verlag, Berlin (in Press)
Project Leader:

Dr. Ramani Bai V.

Department of Civil Engineering

Faculty of Engineering

University of Nottingham Malaysia Campus

MALAYSIA

Tel: +6 38924 8604/8106

Fax: +6 389248017

Email: Ramani-Bai.V@nottingham.edu.my

APN Funding:

US\$80,000 (For 2 Years)

Project Website: www.globalclimate-engine.org/index.php

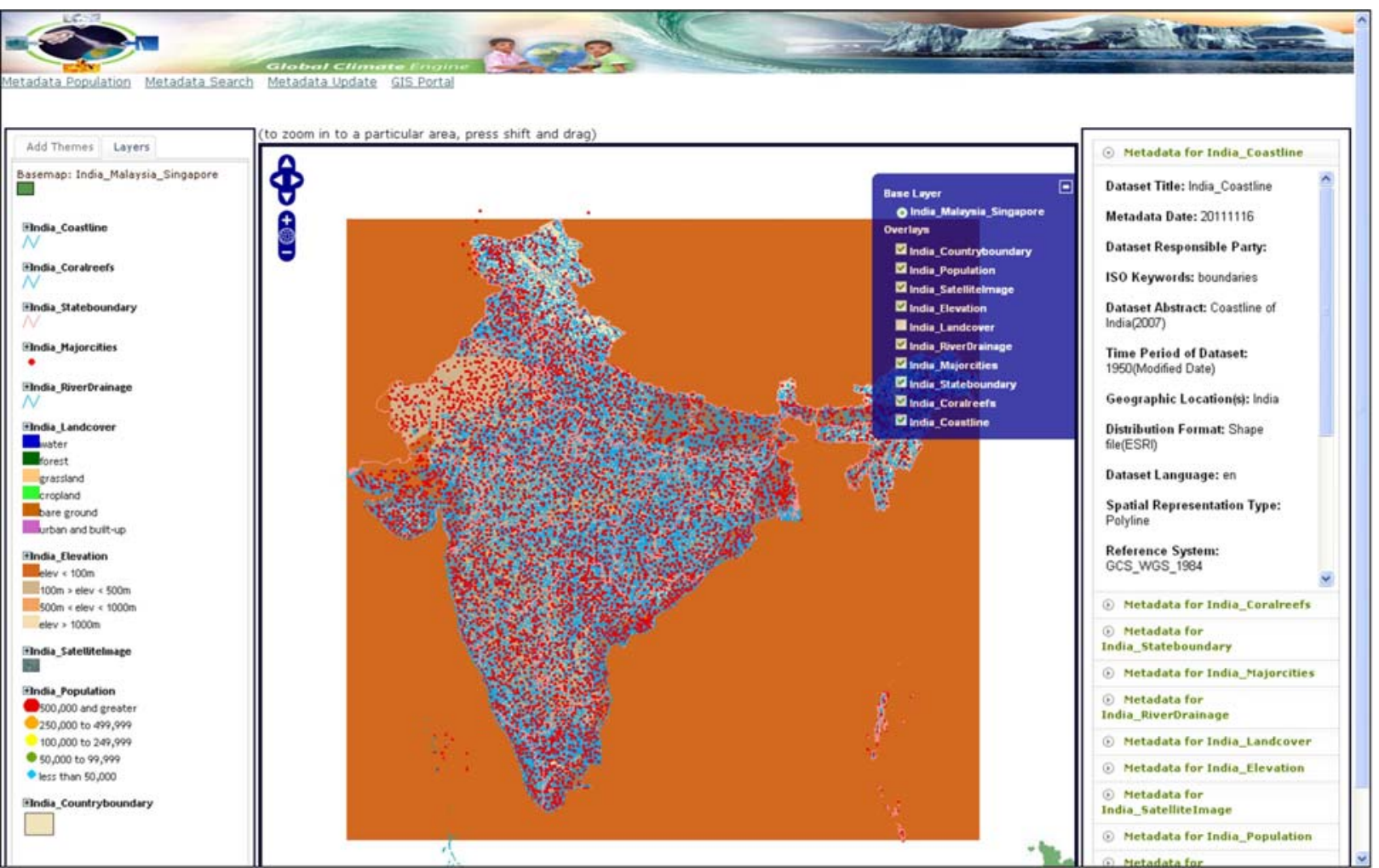



and impacts of recovery time such as replacement of lost crop germplasm and the need to import food substitutes. The present Project is identifying the key impacts of climate change on the unique cropping systems in four small Pacific nations and providing solid data to enable development of strategies/policies to minimise these risks and identify training and research opportunities. It will examine key issues

angela.freeman@dpi.vic.gov.au

APN Funding:

US\$55,000 (For 1 Year) including the maintenance of crop genetic resources and the availability of varieties adapted to future climate and the need to assess germplasm in collection or initiate breeding efforts; biosecurity impacts of climate change on food crops (including impacts on endemic pests and diseases and likelihood of incursions of exotic pests and diseases) and implications for international trade; and impacts of recovery rates from natural disasters on both food security and biosecurity.

Based on Food and Agriculture Organisation (FAO) procedures and accepted biosecurity risk assessment practice, the project team is developing questionnaires to identify the key impacts of climate change on food crop security and biosecurity. The team will visit each country to discuss collected data with the country collaborators and other key scientists. Potential research and training opportunities for regional scientists will be identified and concepts and linkages will be developed.

\section{ARCP2010-09NSY-Patankar \\ Enhancing Adaptation to Climate Change by Integrating Climate Risk into Long-Term Development Plans and Disaster Management}

$\mathrm{U}$ ndertaking a comparative analysis of secondary data and the immediate to medium-term post-disaster recovery scenario in the aftermath of extreme weather events of flooding faced by vulnerable cities in three Asian developing countries of Mumbai (India), Bangkok (Thailand) and Manila (Philippines), the present Project plans to fill gaps in research and to develop policy implications for long term investment and development plans. Secondary data pertaining to the selected extreme events of flooding and their resultant physical, economic, environmental and social impacts in the case study cities will be analysed. A comparative analysis will then be carried out to understand the policy implications of extreme weather events for disaster management, adaptation strategies, city resilience and development planning in the long term.

Project Leader:

Dr. Archana M Patankar

K J Somaiya Institute of Management

Studies and Research

Mumbai, INDIA

Tel: +91 2267283065

Fax: +919820501438

Email: archana.patankar09@gmail.com

APN Funding:

US\$65,000 (For 1 Year)

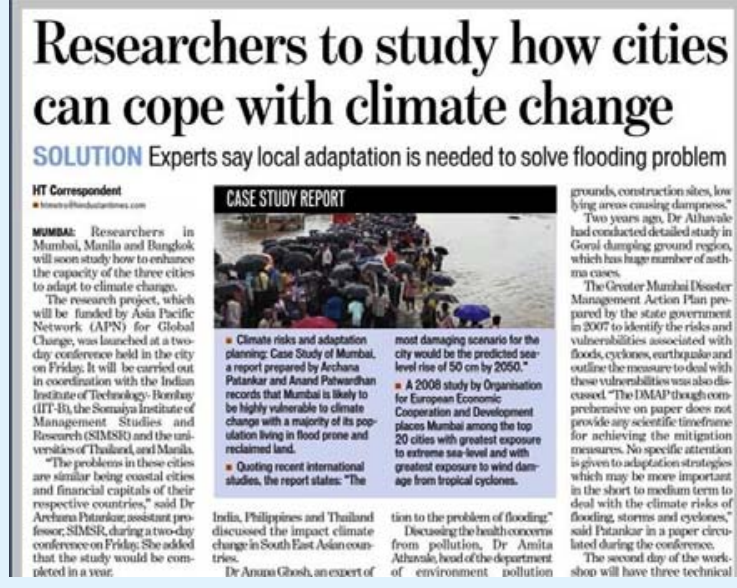

Prior to data collection/analyses and further formulation of policy recommendations, the Project organised its first inception workshop from 17-18 December, 2010 in Mumbai. The core team members from Mumbai, Bangkok and Manila gathered and finalised the methodology for the case studies. The workshop was successful in bringing together 27 experts from academia, urban planning, local government and industry. In addition to research planning and insights, the participants discussed technical sessions in the following themes: urban challenges and climate risks; risks and vulnerability assessment; specific aspects of economical and social vulnerability; and mainstreaming adaptation and linkages with development planning. The inception workshop generated growing interest among academia, industry and, most importantly, local government authorities. 


\section{ARCP2010-10NMY-Koike River Management System Development in Asia Based on Data Integration and Analysis System (DIAS) under the Global Earth Observation System of Systems (GEOSS)}

he present Project has been under the GEOSS/ AWCI framework and aims to develop an advanced river management system in member countries by exploiting the DIAS data and data integration capabilities. The system is based on integration of data from earth observation satellites and in-situ networks with other types of data, including numerical weather prediction model outputs, climate model outputs, geographical information, and socio-economic data to generate information for making sound water resources management decisions while taking global climate change into account.

The $7^{\text {th }}$ AWCI International Coordination Group (ICG) was held in Tokyo from 5-6 October 2010, which included a session focused on initial discussion on the implementation strategy of this Project. Following the meeting, a whitepaper on the GEOSS/AWCI Climate Change Impact Assessment and Adaptation (CCAA) study was developed. Also, all of the AWCI country representatives were asked to nominate a suitable river basin for which sufficient data records would be available allowing for the development of a distributed hydrological model for that basin and for evaluating recent climate history and assessing possible climate change and its impacts. So far, 13 river basins in 11 AWCI countries have been nominated for the CCAA study, and some of the countries have already submitted basic sets of necessary data. A teleconference was held among the representatives of countries that are affected by snow and glacier phenomena that must be considered in the planned study and also experts on these phenomena from the modelling community.

As a part of this Project, a training course on downscaling techniques was organised at the University

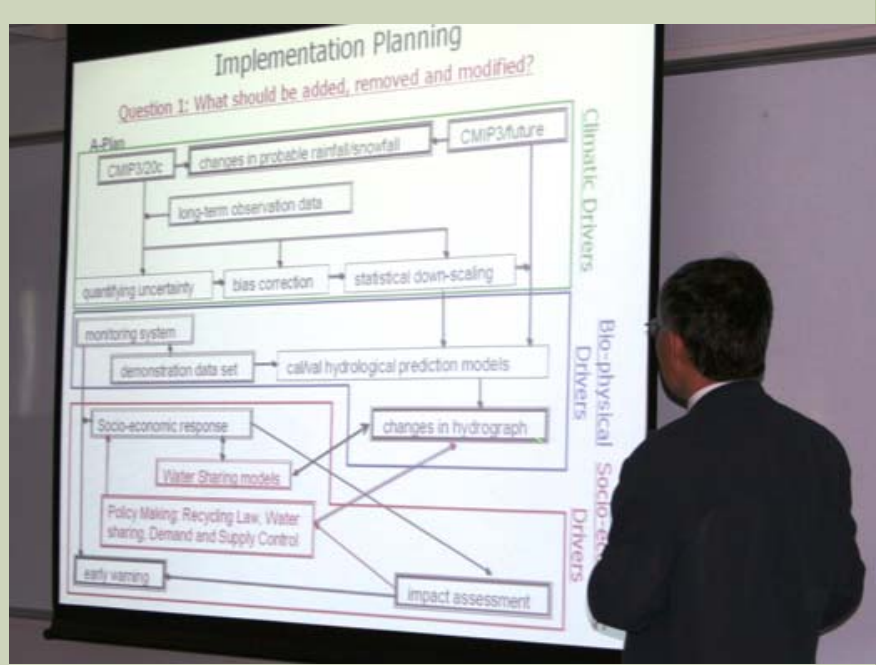

of Tokyo, from 11-12 March 2011, and will be followed by a series of AWCI-related events including the Global Terrestrial Network - Hydrology (GTN-H) meeting (1213 March), The Integrated Global Water Cycle

Observation (IGWCO) meeting (14-15 March), and the $5^{\text {th }}$ GEOSS Asia Pacific Symposium (16-18 March). All these events will include sessions focused on observation and data integration issues in the Asia Pacific region, or dedicated directly to AWCI activities. With support of this Project and collaborative projects also funded by the APN (ARCP2010-13NMY-Bae and CBA2010-14NMYKaihotsu), the AWCI ICG members and the nominated leaders of the CCAA study in the proposed basins are invited to participate in the training course as well as the subsequent meetings.

\section{Publication}

Whitepaper on the GEOSS/AWCI Climate Change Impact Assessment Activity.

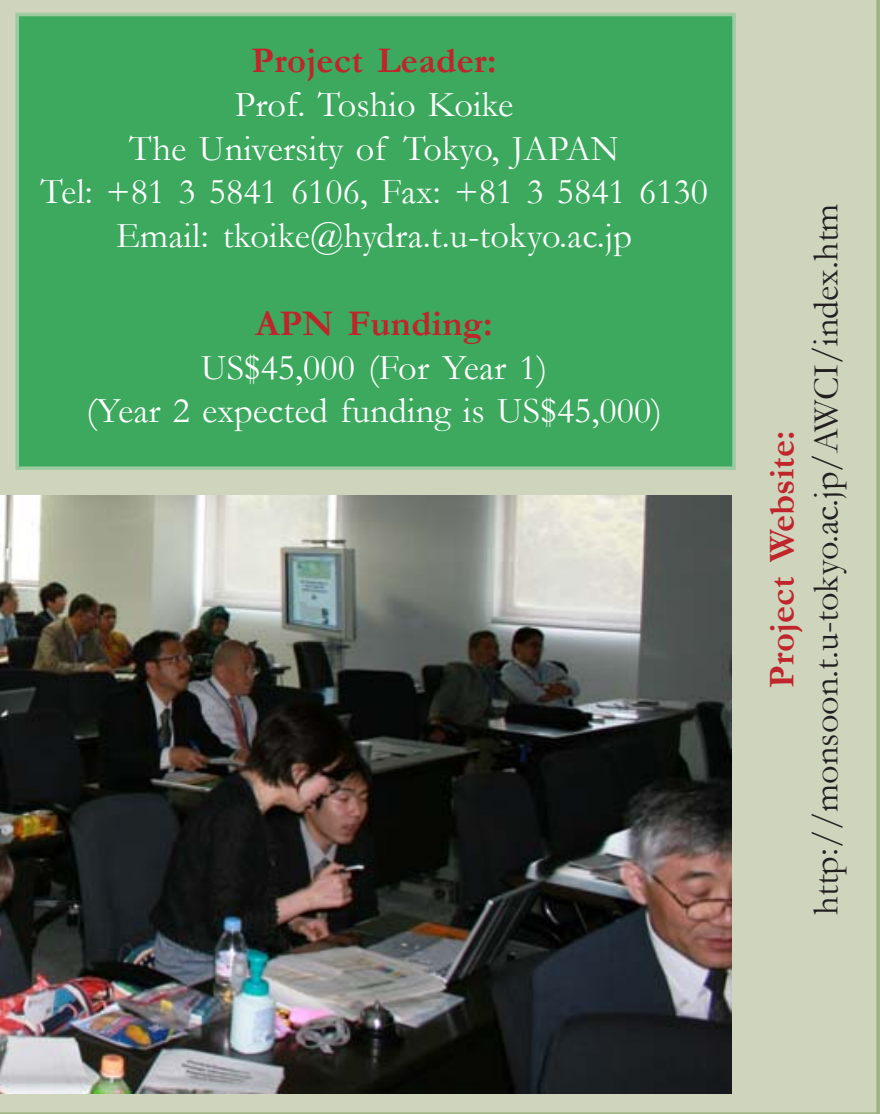




\section{Intercomparison of Landsurface Process Modelling in Asian Drylands}

D rylands account for $40 \%$ of the Earth's land surface and a similar fraction of Asian land surface. Characterised by dry climate, low vegetation cover and low nutrients, its ecosystem and the society that depends on drylands are inherently vulnerable to external perturbations such as climate change and land-use change. The present Project - Asian Dryland Model Intercomparison Project (ADMIP) is assessing uncertainties in the prediction of landsurface environments with models and improving prediction accuracies. With additional support from the Chinese Academy of Sciences and the Japanese Society for Promotion of Science, this Project is working with 16 registered models run by 13 groups worldwide.

In order to predict the landsurface environment of drylands, the project teams utilise landsurface models (LSMs) and terrestrial ecosystem models (TEMs). Hence, by addressing the challenges of different process representations and large differences in their predictive capabilities, the project team is carrying out an intercomparison study with a suite of models and data from a selected set of well-documented study sites from the Asian dryland region.

A Project inception meeting was held from 11-12 July 2010 in Beijing, China and members discussed forthcoming tasks, datasets for the model intercomparison and a project timeline. At the target sites of the analysis, three observation stations were identified: two in China and one in Mongolia. To facilitate easier data exchange and the analysis of model outputs, the project team collectively avails of the Protocol for the Analysis of Land Surface models (PALS) from the University of New South Wales. A group from Kyoto University plays a major role in collecting key data and hosting the project website. Currently the project teams are working on data preparation and model runs.
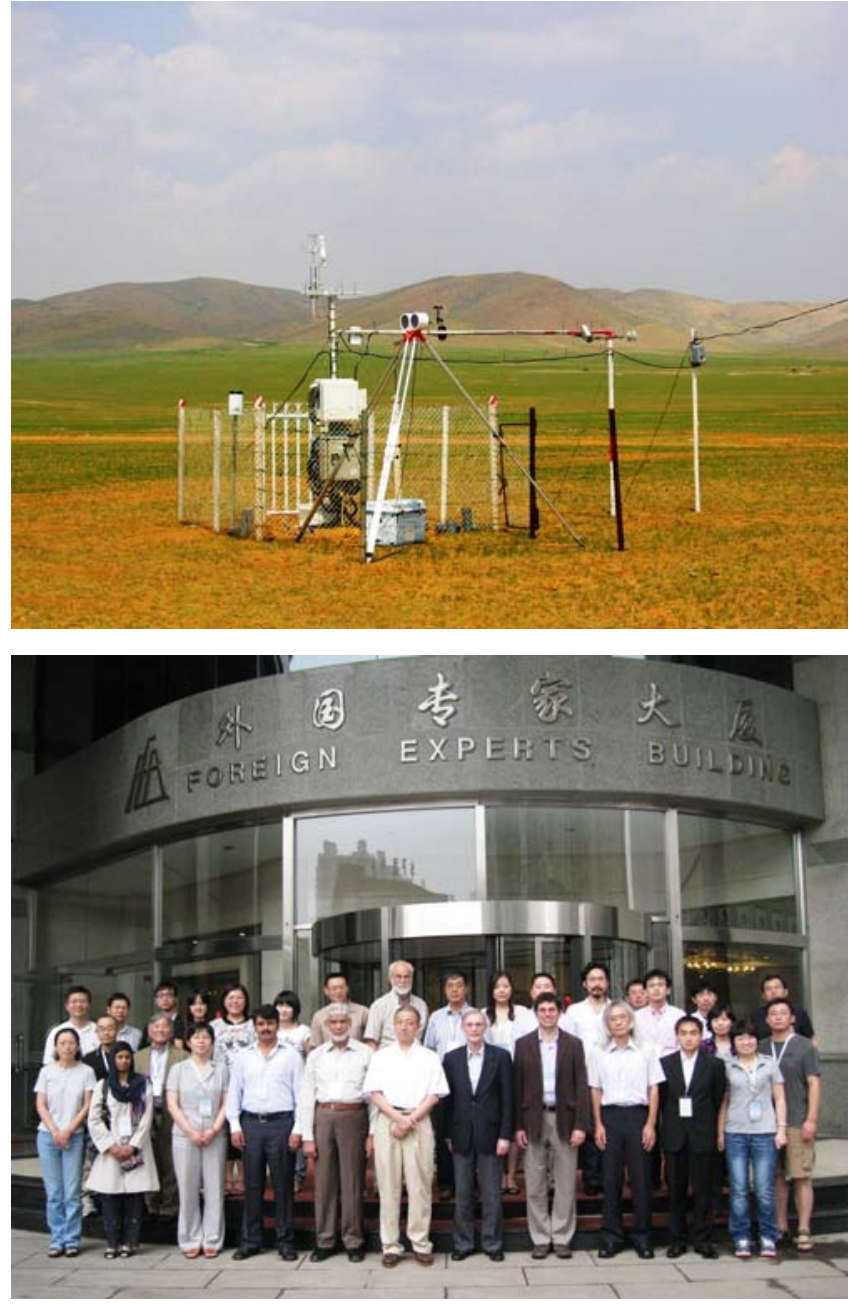

Asian Drylands Process Model Intercomparison Project (ADMIP) is supported by: Asia-Pacific Network for Global Change Research (APN), Monsoon Asia Integrated Regional Study (MAIRS), and Japan Society for the Promotion of Science (JSPS)
ADMIP

Asian Drylands Landsurface Process Model Intercomparison Project

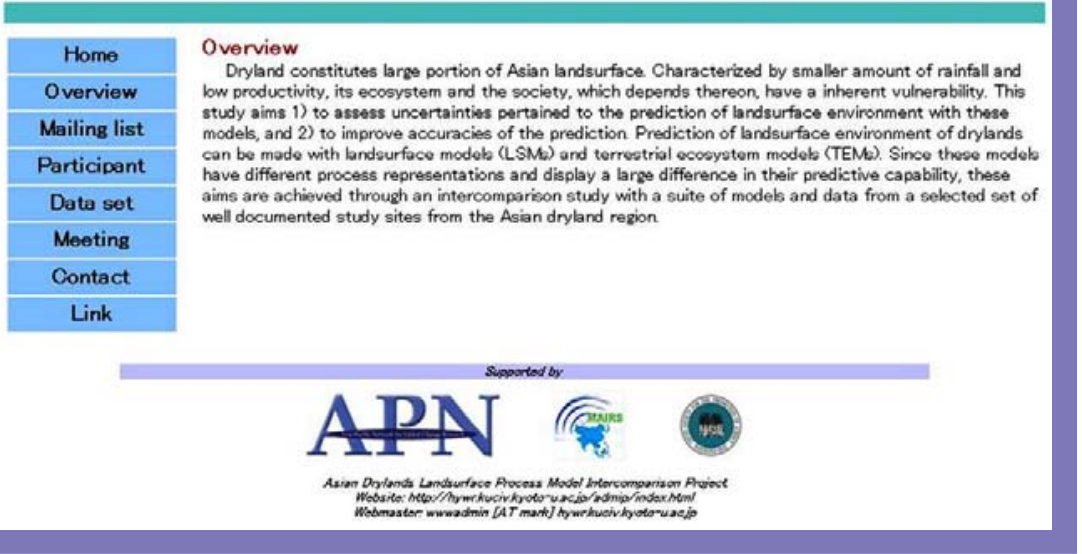

Project Website: http://hywr.kuciv.kyoto-u.ac.jp/admip/index.html

\section{Project Leader:}

Dr. Jun Asanuma

Terrestrial Environment Research

Centre

University of Tsukuba, JAPAN

Tel: +81298536704

Fax: +8128 8536704

Email: asanuma@suiri.tsukuba.ac.jp

APN Funding:

US\$58,700 (for Year 1)

(Year 2 expected funding is

US $\$ 47,100$ ) 


\section{ARCP2010-12NMY-Uprety \\ Community Based Forestry and Livelihoods in the Context of Climate Change Adaptation}

\section{T}

The present Project investigates how climate change is affecting forest-dependent communities in one of the world's most vulnerable regions and the actual and potential adaptation measures that enable households, communities, and networks to remain resilient in the changing contexts in four countries of Bangladesh, Nepal, Thailand and Viet Nam.

Following a literature review, the Project has taken into account important points published by relevant studies to minimise the risk of climate change effect in rural farmers.

These are:

- Awareness of climate change is
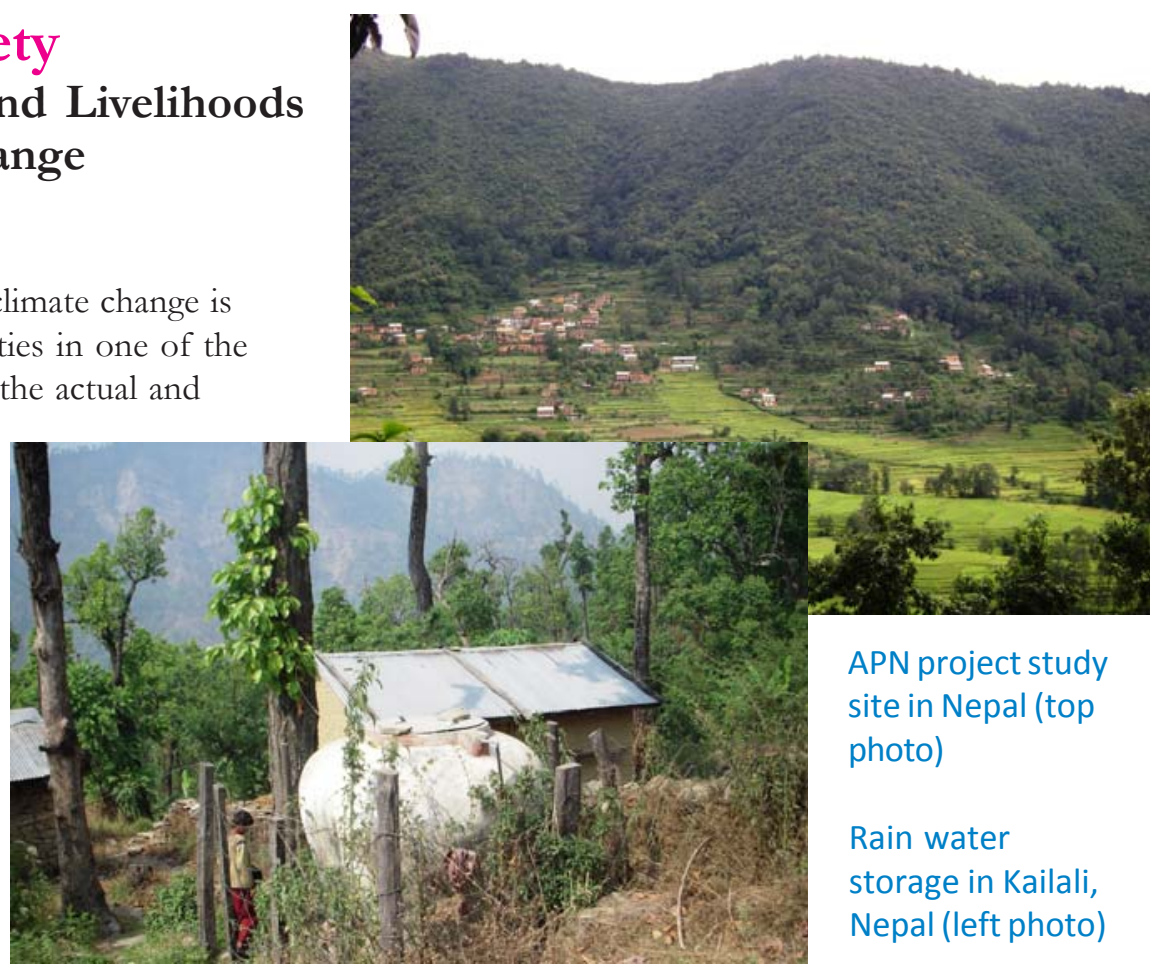

Rain water storage in Kailali, Nepal (left photo)

a key pillar of community based adaptation. Active participation in workshops, meetings and events that have been organised within communities can allow them to relate their own experiences to climate change and understand how future weather patterns may differ to those they have known in the past.

- Action on adaptation can produce benefits now and in the future. Many adaptation activities help to provide communities with diversified livelihoods, alternative sources of income, or better infrastructure. Such 'no regrets' strategies are attractive as they have immediate positive impacts whilst also supporting the ability of communities to adapt to climate change in the future.

- Adaptation can be made more effective by focusing on two existing areas of policy: disaster risk reduction and supporting livelihoods. When undertaken through community organisations, these overlapping activities address key climate vulnerabilities and build capacity to deal with future challenges.

In the next 2 years, the Project will develop methods and tools based on the selected sites and local communities.

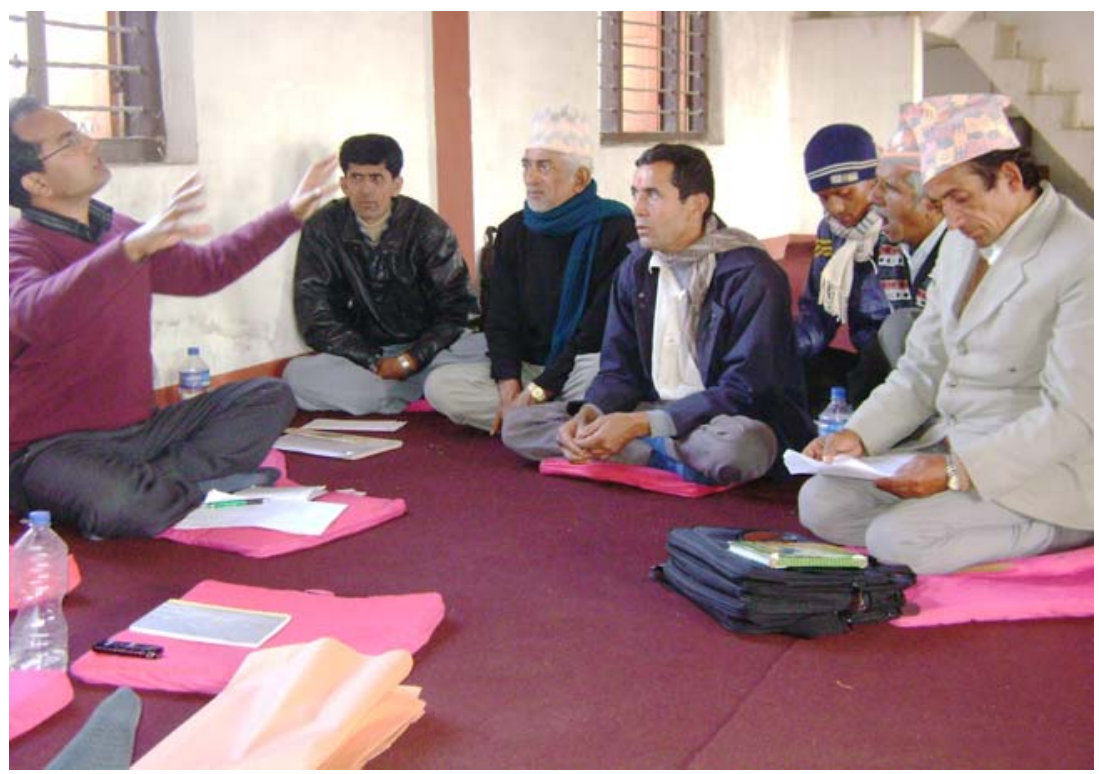

APN project leader interacting with community leaders at Nawalparasi

Project Leader:

Dr. Dharam Raj Uprety

Forest Resource Studies and

Action Team

International Forestry Resources and Institutions (IFRI)

NEPAL

Tel: +977 $15550631 / 2924$

Fax: +97715535190

Email: forestaction@wlink.com.np; dharam.uprety@gmail.com

APN Funding:

US\$40,000 for Year 1

Year 2 expected funding is US\$39,400

The effects of climate change are expected to deepen poverty and adversely affect livelihoods, assets, infrastructure, environmental resources and economic growth. Developing countries have lesser capacity to adapt and are more vulnerable to climate change. Therefore, adaptation is now acknowledged as necessary for responding effectively and equitably to the impacts of both climate change and climate variability. Local communities possess relevant knowledge and experience in coping with climate change. This knowledge needs to be documented and disseminated in order to be used effectively. 
ARCP2010-13NMY-Bae Climate Change Impact Assessment on Asia-Pacific Water Resources under AWCI/GEOSS

$\mathrm{I}$ n partnership with GEOSS/AWCI to promote necessary capacity building for Lassessment technology, this project sets forth two approaches for evaluating climate change impact assessments on water resources in the Asia-Pacific region. The approaches are described in Figure 1: i) the analysis of past historical hydrologic and meteorological observation data to detect climate change trends; and ii) the use of Global Climate Model (GCM) outputs with downscaling and hydrologic models under future GHG emissions scenarios.
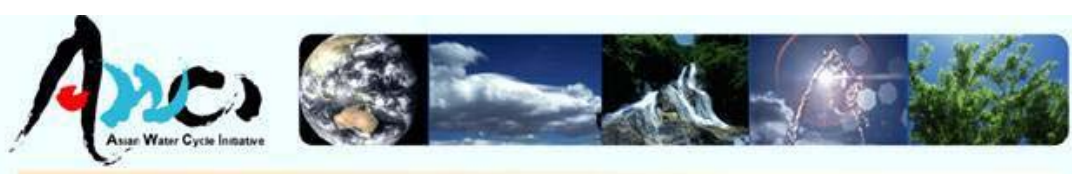

Global Earth Observation System of Systems / Asian Water Cycle Initiative

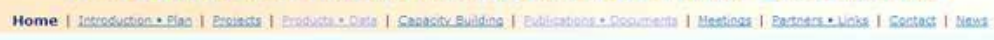
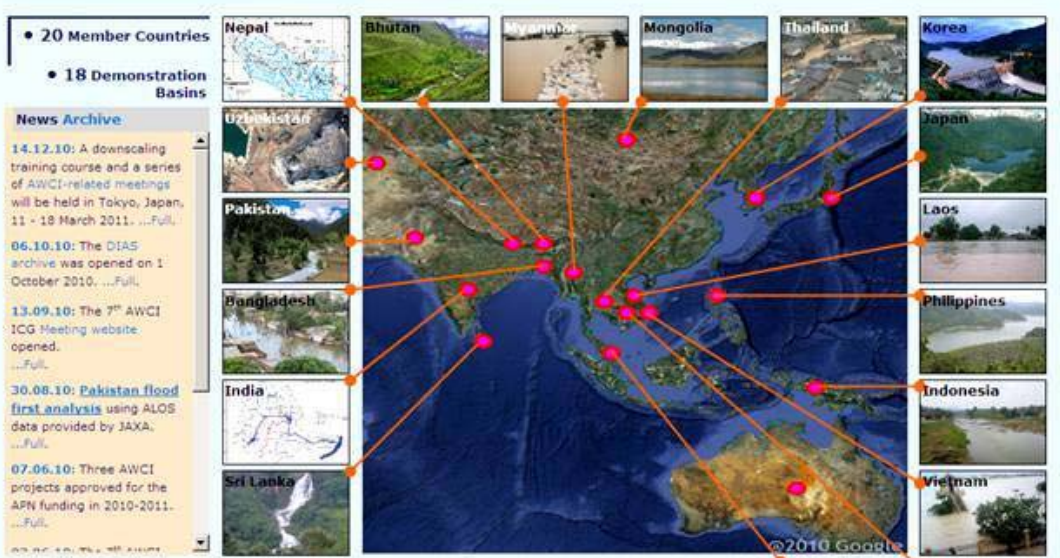

- GEOSS/AWCI: To promote integrated water resources management by
making usable information from GEOSS, for addressing making usable information from GEOSS, for addressing
the common water-related problems in Asia.

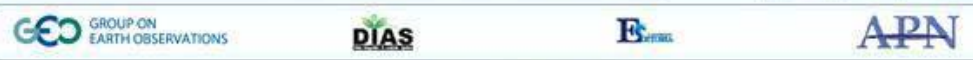

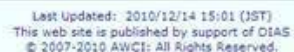

Project Website: http://monsoon.t.u-tokyo.ac.jp/AWCI/index.htm

Project Leader: Prof. Deg-Hyo Bae Sejong University REPUBLIC OF KOREA

Tel: +82 234083814 Tel: +82234084332 Email: dhbae@sejong.ac.kr

APN Funding: US\$42,000 (for Year 1)

(Year 2 expected funding is US\$42,000)

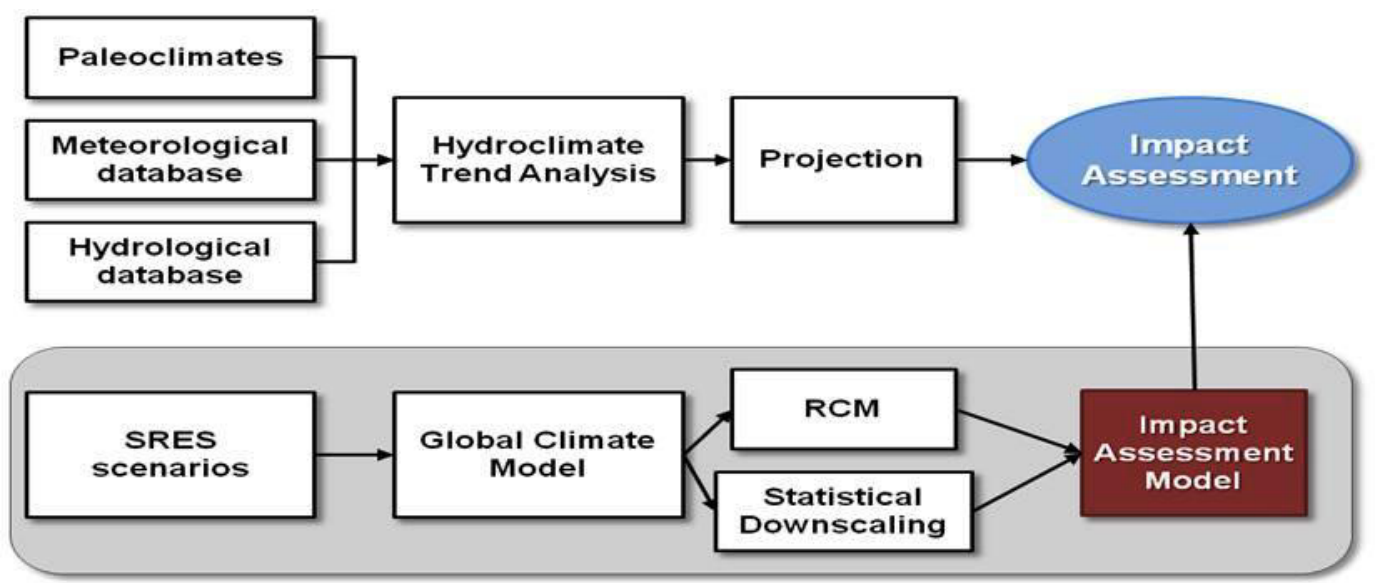

Figure 1. Two approaches for climate change impact assessments on water resources

In this Project, Mann-Kendall statistical test and linear regression is being used to analyse past historical hydrological data to determine the significance of trends in precipitation and runoff data in more than 18 countries of GEOSS/AWCI. For future climate and hydrologic projections over the East Asia monsoon area, this Project will use GCM simulations with downscaling schemes and

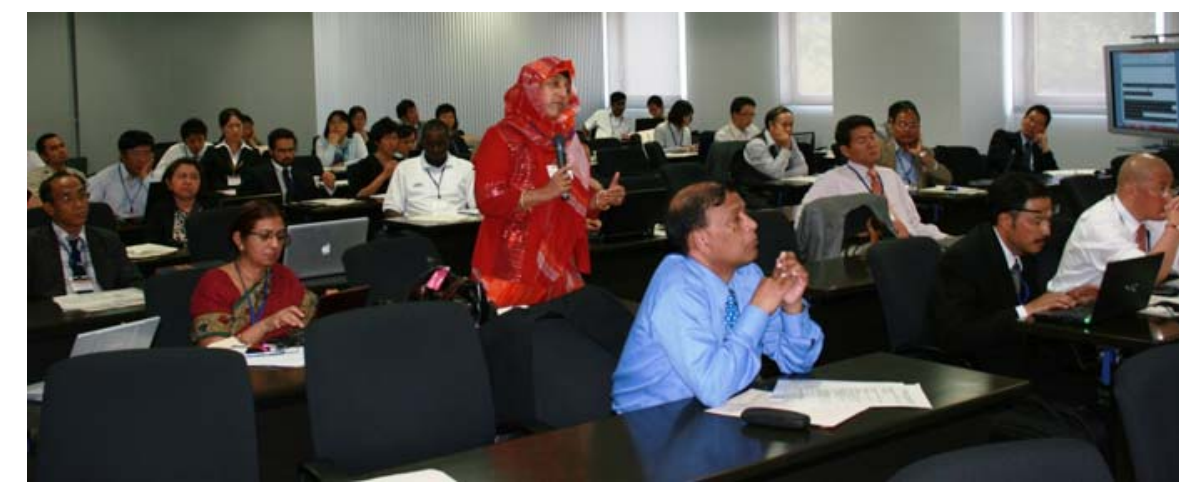
hydrologic models. Climate projections (the outputs of GCMs obtained by using GHG emission scenarios) will be used for generating Multi Model Ensemble (MME) scenarios and for evaluating the difference of the hydro-meteorological variables during the periods of 2011-2040, 2041-2070 and 2071-2100 relative to the past 30-year reference period (1980-2010). In this study, 13 GCM results out of 23 GCM simulations provided by the IPCC Data Distribution Centre are being used.

Currently the project is focussing on past historical data collection, quality control and preliminary application of the data in the 18 GEOSS/AWCI countries. 


\section{ARCP2010-14NMY-Li \\ Analysis on Urban Land-Use Changes and its Impacts on Food Security in Different Asian Cities of Four Developing Countries using Modified Cellular Automata (CA)}

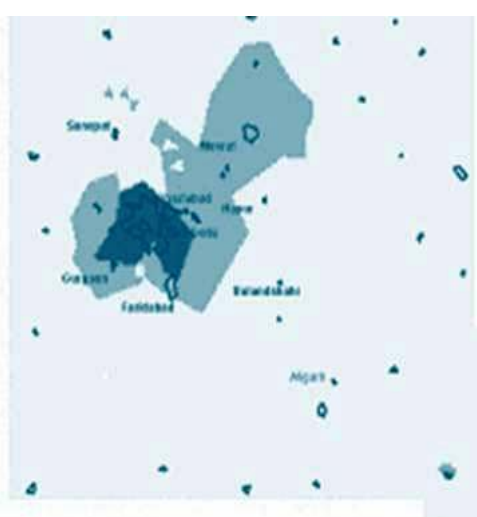

Publications

- Yang, Q., Gan, X., Li, J., et al. 2010. Cellular Automata for Urbanisation Hotspot Based On Land Use

Urbanisation Level in Medium-sized Cities_-A Case Study in Zhangjiagang. International Journal Remote Sensing, 2010, (5): 1212-1225.

- Zou, X., Shang, Z., Li, J., et al. 2010.

Comparative Analysis on Spatial-Temporal Land Use and Land Cover (LULC) Characteristics in Three Asian Cities. Proceedings of the $3^{\text {rd }}$

he present Project will quantify the level of urbanisation from the aspect of land use and connecting land use patterns with urbanisation processes in China, India and Viet Nam. It works on building and enhancing scientific capacity in support of the research with experts from Australia and U.S.A. The Project plans to produce an integrated technical report of the land-use/land-cover change and urban landscape patterns, and to disseminate findings to farmers, policy-makers and the international community.

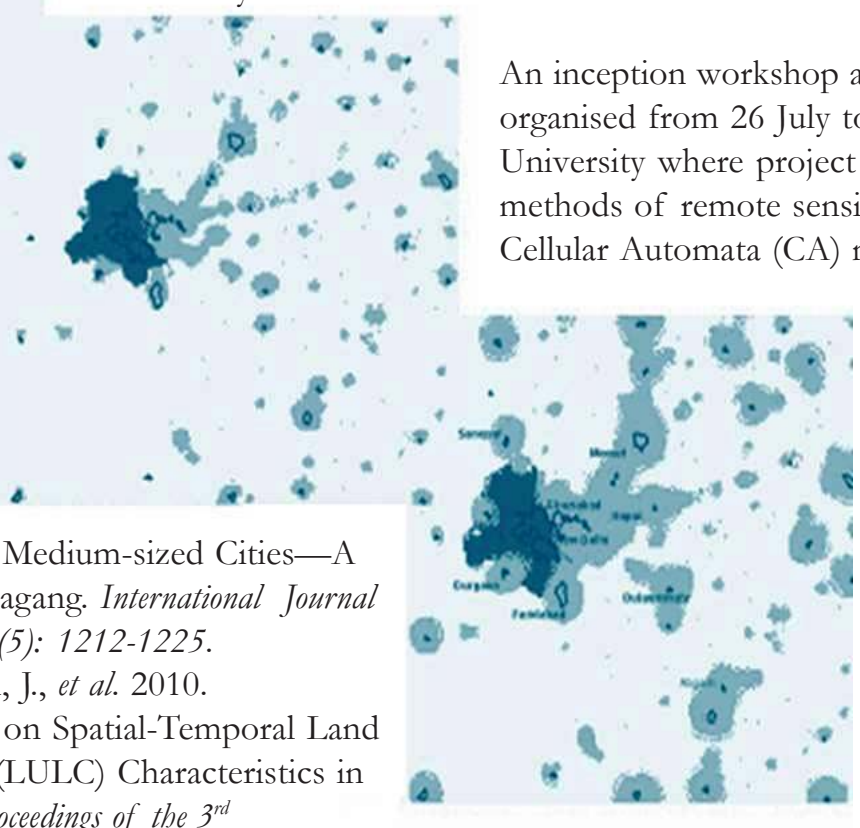

International Conference on Computational Intelligence and Industrial Application(PACIIA),2010 in Wuban: 461-464.

- Chen, Y., Huang, J., Li, J. 2010. Analysis on Dynamic Landscape Patterns of Urbanisation in Four Asian Cities Using 3S Technologies and CA Model.

Proceedings of the $3^{\text {rd }}$ International Conference on Computational Intelligence and Industrial Application (PACILA), 2010 in Wuhan: 465-468.

- Sun, C., Gan, X., Li, J., et al. 2010. Analysis on Spatial -Temporal Landscape Pattern and Ecological Security in Zhangjiagang City Using 3S Technologies and CA Model. Proceedings of the $3^{\text {rd }}$ International Conference on Computational Intelligence and Industrial Application (PACIIA), 2010 in Wuban: 469-472.

- Zhang, J. and Li, J. 2010. Establishment of Early Warning System of Grain Security in Zhangjiagang, China Using Immune-Based Optimised BP Neural Network Model. Proceedings of the $3^{\text {rd }}$ International Conference on Computational Intelligence and Industrial Application (PACILA), 2010 in Wuban: 473-476.

- $\quad$ Sun, Z., Sun, C., Li, J., et al. 2010. Efficient Water-saving Irrigation Solution for Direct Seeding Rice under No-Tillage after Cultivating Wheat. Poceedings of the $1^{\text {st }}$ International Conference on Cellular, Molecular Biology, Biophysics and Bioengineering, 2010 in Qiqibr: 553-556.

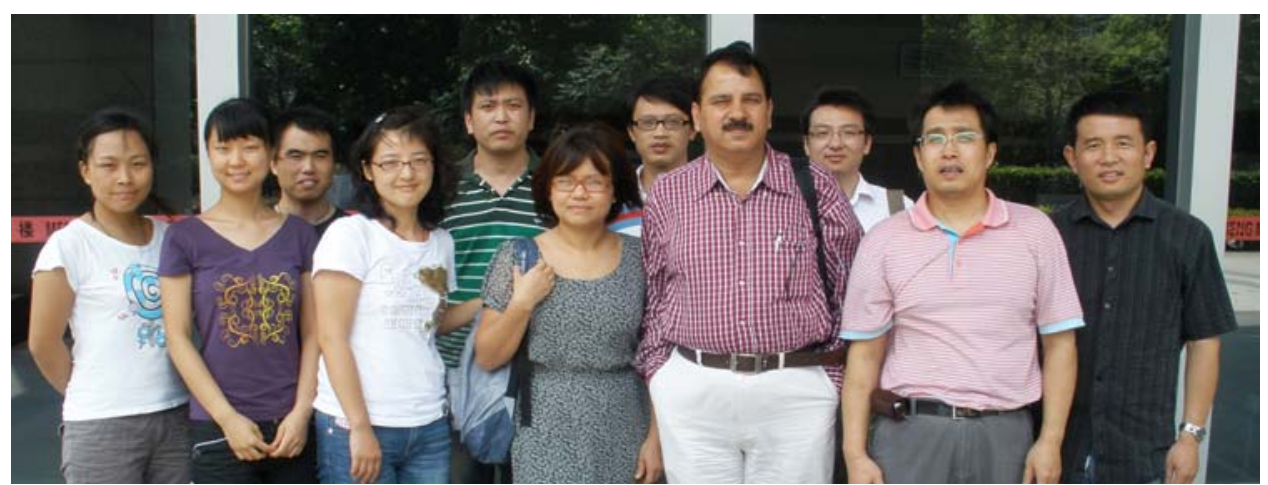

Project Leader: Prof. Jianlong Li The Global Change Research Institute Nanjing University CHINA

Tel: +86 2583592715 Fax: +862583302728 Email: jlli2008@nju.edu.cn; jianlongli@sina.com.cn

APN Funding: US\$22,750 (For Year 1) (Year 2 expected funding is US\$22,750) 


\section{The Impact of Spatial Parameters on Greenhouse} Gas Emissions: A Comparative Study between Cities in China and India

he present Project is examining the role of urban spatial restructuring in reducing greenhouse gas (GHG) emissions by assessing the impacts of urban spatial parameters in China and India. The idea of reducing energy use and household GHG emissions via modifying land-use mix, transportation arrangements and population density is novel and complementary to the technology-oriented efforts (e.g., development of energy-saving products, use of renewable energy sources, etc.). This Project develops and implements a conceptual and methodological innovation using two case study cities that provide distinctive but comparable contexts to study energy-use behaviour and urban planning policies. By providing findings on the association between GHG emissions and spatial parameters, the Project will enable a more informed choice by planning agencies between these different visions and in turn, provide confidence in the articulation of policy designed to reshape land use patterns.

\section{Project Leader:}

Dr. Sun Sheng Han Faculty of Architecture, Building and Planning The University of Melbourne

AUSTRALIA

Tel: +61 383447055

Fax: +61383445532

Email: sshan@unimelb.edu.au

APN Funding:

US $\$ 41,560$ (For Year 1)

(Year 2 expected funding is $\mathrm{US} \$ 38,440)$

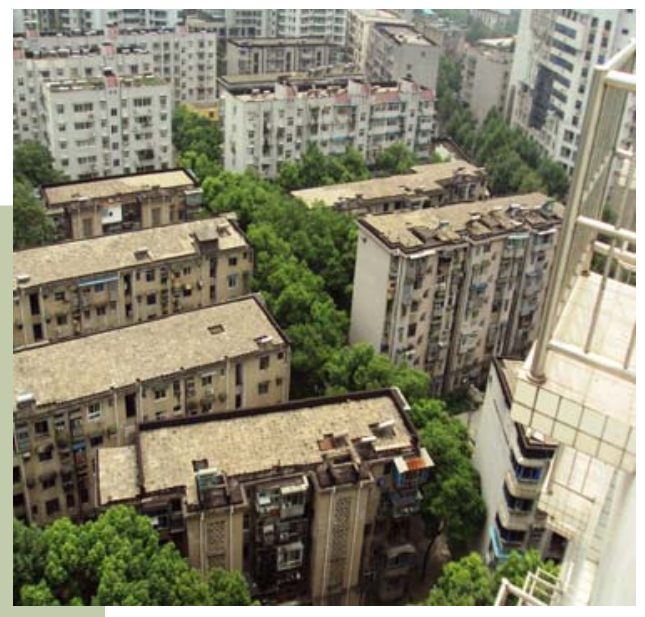

In May 2010, the project team gathered in Wuhan to discuss the research methodologies. In July, a pilot questionnaire survey was conducted in Xi'an, China followed by a full scale survey of 1200 sample households. The project team is currently working on geo-coding the survey data and, at the same time, undertaking preliminary analysis of the data. A part of the project team is completing the questionnaire for survey in Bangalore, and also preparing a precinct survey for both Xi'an and Bangalore.

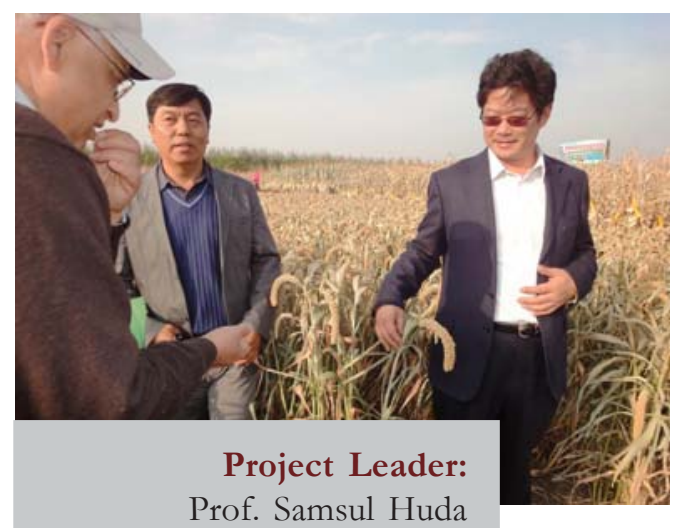

\section{ARCP2010-16NMY-Huda}

Food Security and Climate Change in the AsiaPacific Region: Evaluating Mismatch between Crop Development and Water Availability

Centre for Plants and the Environment

University of Western Sydney

AUSTRALIA

Fax: +61 245701750

Email:s.huda@uws.edu.au

APN Funding: US\$60,000 (For Year 1) (Year 2 expected funding is US\$59,700)
Tel: +61245701390

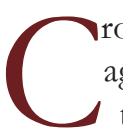

rop adaptation to environmental stresses is central to sustainable agriculture. In southern Australia, central India, and north China temperature has increased and phenological patterns of major grain crops have shifted over the past 40 years. Cropping systems and varieties are designed so that water availability and crop water requirements are well matched. Mismatches between crop and environment occur when the critical period of crop yield determination coincides with stressful conditions.

Possible mismatches arising from realised warming were the subject of the training and project-planning workshop held in Beijing in September 2010. The workshop determined case studies in China, India and Australia, and realised the significant input to the project that would be made by young researchers in China and India, based on the training provided at this and a subsequent workshop in India. Strategies are being developed to enhance capacity building of these researchers during the project, including training in Australia and their involvement in the international project workshop.

The workshop discussed the relevance of available methods for research studies planned in three countries and the scope of the research is focusing on crops of local importance including rice, wheat, maize and chickpea at key sites. The project identified appropriate models, modelling framework and data needs to incorporate relevant climate risk factors for matching crop development with water availability. Part of the workshop focused on training in crop science, climate analysis and modelling to assess the mismatch of crop phenology and water availability. The workshop concluded with field trips - the first field visit was for discussion with students of the FACE (Free-air carbon dioxide enhancement) experiment in Beijing. Project scientists provided input on physiological principles of wheat responses to $\mathrm{CO}_{2}$ to postgraduate students. The second field trip was to Harbin Province, which is one of the planned experimental sites in China. 


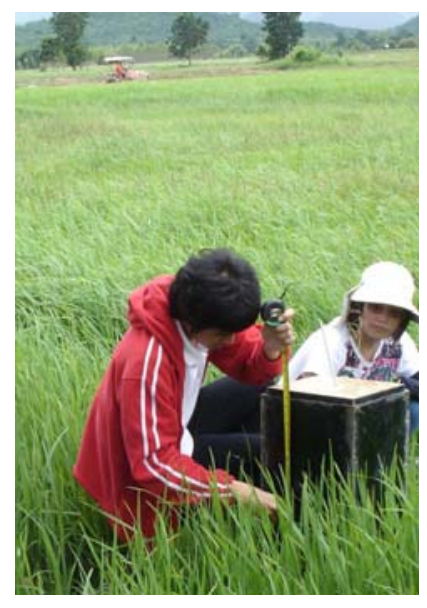

ARCP2010-17NMY-Towprayoon

Strategic Rice Cultivation for Sustainable Low Carbon Society

Development in Southeast Asia

he present Project aims at sustainable agriculture in Southeast Asia (SEA) by identifying strategic rice cultivation practices involving rotation with energy crops for mitigating GHGs, while enhancing capacity in energy production and long term soil carbon storage. In addressing this, project members in the three collaborating countries have undertaken a literature survey to assess current practices in the case study sites. They have also developed questionnaires that will be used to collect information on agricultural practices from farmers and assess the potential for crop rotation, i.e. with maize and sorghum.

Preliminary assessment of GHG emissions and soil carbon stock looks at the current practices of rice cultivation and rotation in Thailand. For this particular investigation, the research team prepared an experimental field site in Thailand (Ratchaburi Campus) for cultivating rice under different management conditions and rotating with maize and sorghum. Then, the team aims to measure the GHG emissions and soil carbon stock of this experiment. This activity provides the basis to evaluate the influence of selected crop rotations with rice in terms of soil carbon dynamics and GHG emissions (carbon cycle) as well as socio-economic implications in order to identify feasible sustainable cultivation practices under specific conditions of management.

\section{Project Leader:}

Assoc. Prof. Dr. Sirintornthep Towprayoon

King Mongkut's University of Technology

THAILAND

Tel: +6 624708309

Fax: +6 628719805

Email: sirin@jgsee.kmutt.ac.th

APN Funding:

US $\$ 40,000$ (For Year 1)

(Year 2 expected funding is $\mathrm{US} \$ 40,000)$
Project Leader:

Dr. Konstantin Lutaenko

Institute of Marine

Biology, Far East Branch

RUSSIAN

FEDERATION

Tel: +74232317111

Fax: +7 42323109000

Email: lutaenko@mail.primorye.ru;

lutaenko@mail.ru

APN Funding:

US\$40,000 (For Year 1)

(Year 2 expected funding is US\$40,000)

Project Website:

www.imb.dvo.ru/misc/vietnam/

\section{ARCP2010-18NMY-Lutaenko}

\section{Coastal Marine Biodiversity of Viet Nam:} Regional and Local Challenges and Coastal Zone Management for Sustainable Development

\section{he present Project is looking at the marine biological diversity in coastal zones of the South China Sea with emphasis on Viet, Nam its modern status, threats, recent and future modifications} due to global climate changes and human impact, and methods for its conservation.

As a part of the planned project activities, the International Conference of Marine Biodiversity of East Asia Seas: Status, Regional Challenges and Sustainable Development was held in the Institute of Oceanography, Viet Nam Academy of Science and Technology in Nhatrang from 6-7 December 2010. Over 30 participants attended the meeting, and among them there were scientists from five countries (Germany, Japan, Republic of Korea, Russia and Viet Nam), representatives of some Vietnamese governmental agencies and international organisations. Forty-seven full-length papers were published in the conference proceedings. Among these, a number of scientific papers are being prepared for submission to peer-reviewed journals. The research papers deal with significant scientific aspects of marine biodiversity.

Rare biota of intertidal zone of Vietnamese islands was studied based on previous collections. Belt-forming communities of macrobenthos were investigated in five bionomical types of the intertidal zone. The distribution of the taxonomical composition and the density of meiobenthos have been studied in bottom sediments of the northern estuary part of $\mathrm{Ha}$ Long Bay for the first time. A total of sixty-six species belonging to 17 families and 52 genera were identified. The project team regards that these data may serve as a basis for future long-term monitoring of biodiversity changes. Currently the project team is working to develop a summary book on biodiversity and coastal zone management in Viet Nam.

\section{Publication}

T.N., Dautova and Lutaenko, K.A. (Eds.) Proceedings of the International Conference on Marine Biodiversity of East Asian Seas: Status, Challenges and Sustainable Development, Nha Trang, Vietnam, December 6-7, 2010. 202pp. 


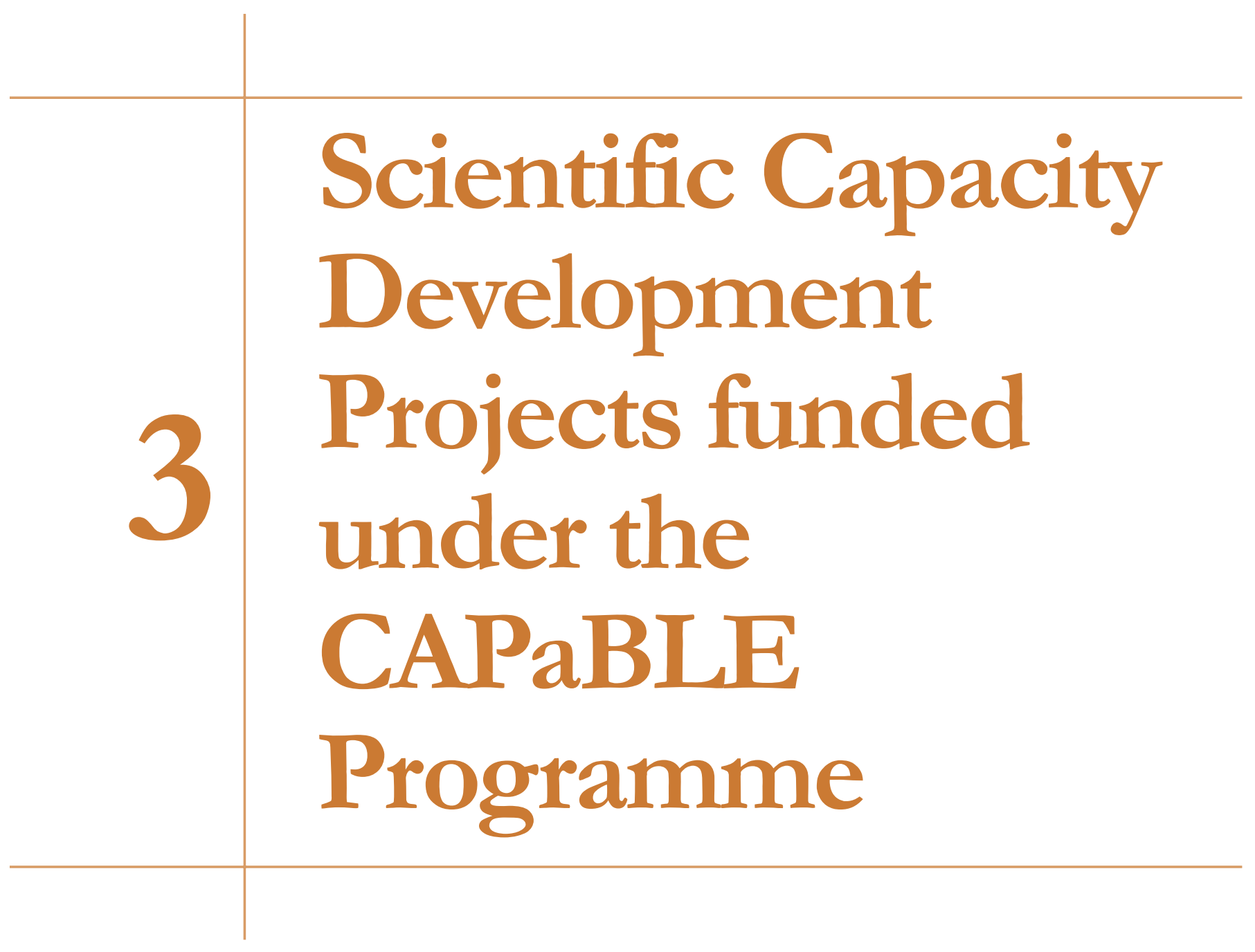


Project Leader:

Dr. Janya Sang-arun

Institute for Global

Environmental Strategies (IGES)

JAPAN

Tel: +81468269573

Fax: +8146855 3809

Email: sang-arun@iges.or.jp

APN Funding:

US\$66,700 (For 2 Years)

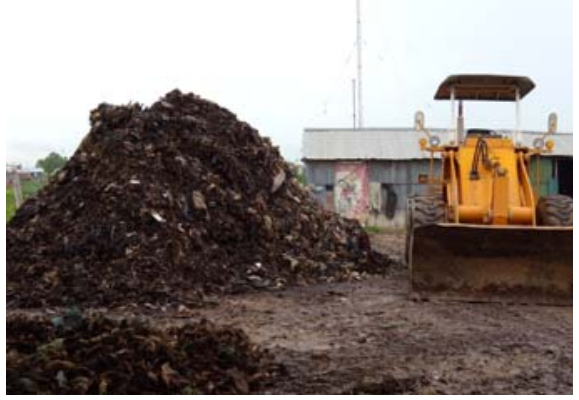

Windrow composting

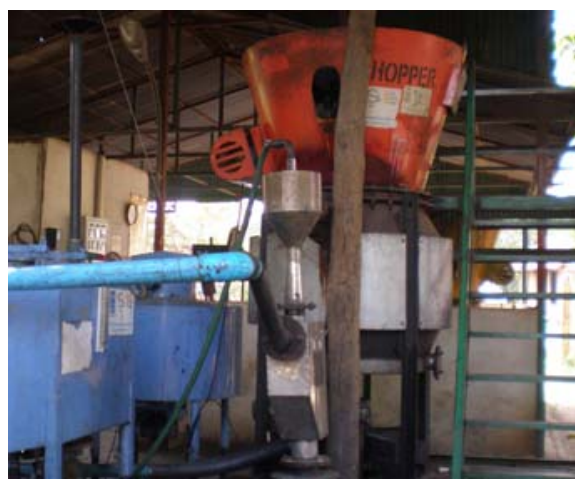

Gasification

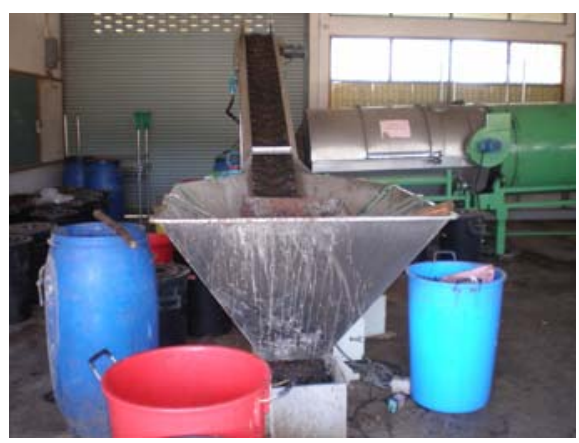

In-vessel composting

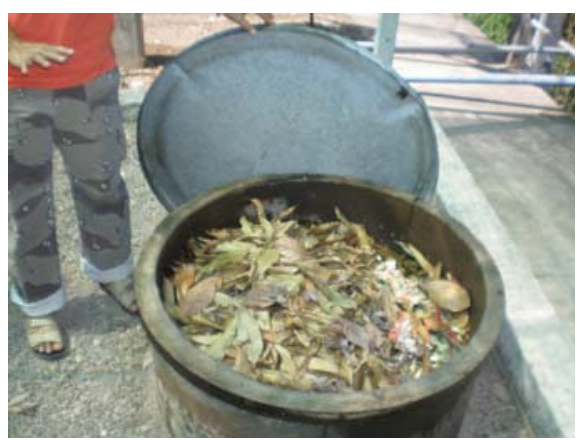

Household composting

\section{CBA2010-01CMY-Sang-arun}

Promoting Sustainable Use of Waste Biomass in Cambodia, Lao People's Democratic Republic and Thailand: Combining Food Security, Bio-energy and Climate Protection Benefits

T he present Project promotes the use of waste biomass for food and energy production, and identifies viable approaches for utilising biomass conversion technology in Cambodia, Lao PDR and Thailand. In addressing this, the project to date has conducted review assessments of regulations and policy in themes of biomass management and carried out field surveys related to technical facilities and other issues with officers-in-charge in the three countries. Results to date show that the most sustainable uses of converting waste biomass to a useful resource are found to be in three viable technologies: composting, biogas generation, and gasification. These technologies are being used for agricultural waste such as rice straw, manure and wood waste; however, their application into urban organic waste is not widely practiced.

Through surveys, the project team has investigated practical examples in Asian countries. For example, it was found that the conversion of urban organic waste to compost is practiced in Bangkok and Rayong, Thailand and in Phnom Penh, Battambang and Siem Reap, Cambodia. Biogas generation from urban organic waste is being implemented in Rayong and Bangkok, Thailand. These case examples show that there is high potential for shared learning and technology transfer between neighbouring countries.

It is important to note that piloting of transferred technology requires effective implementation. For this reason of advocating broad utilisation of urban organic waste, the project team is currently developing guidelines for decision-making and implementation, which will be translated into local languages: Khmer, Laotian and Thai.

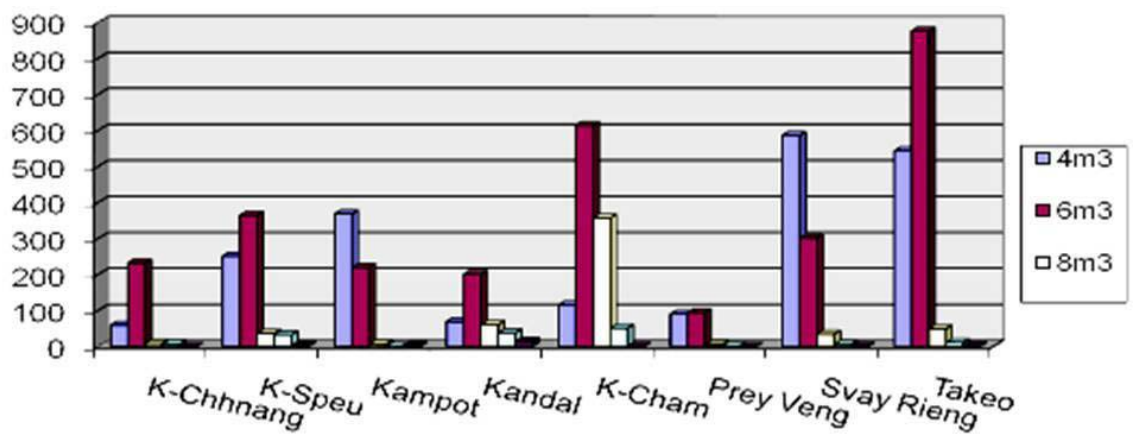

Numbers of biogas plants using manure in Cambodia 2009

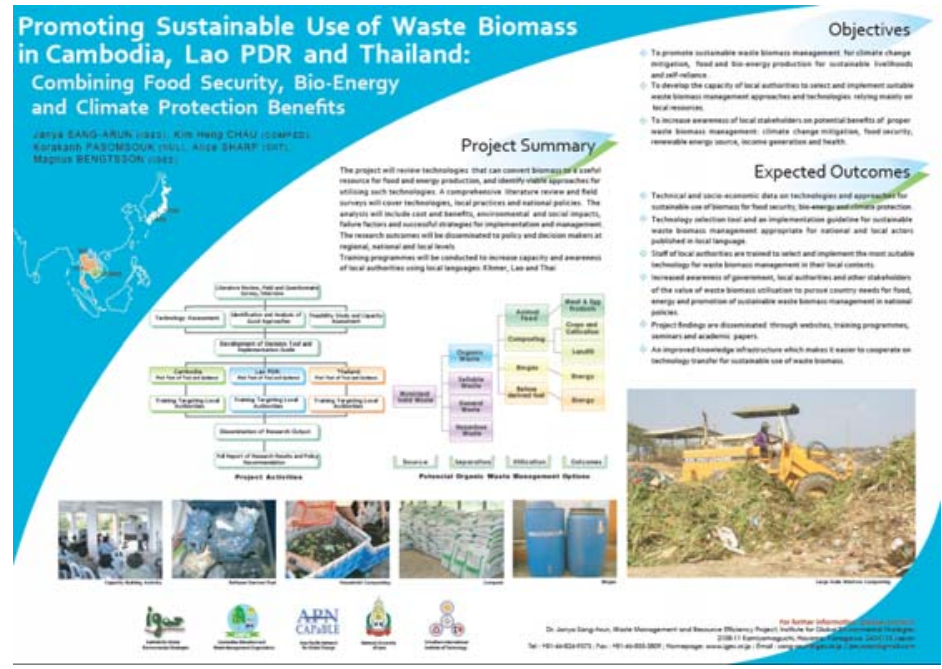

APN Science Bulletin Issue 1 March 2011 
CBA2010-02CMY-Togtohyn

\section{Dryland Development Paradigm (DDP) Application for the Most Vulnerable to Climate and Land-Use Change of Pastoral Systems in the Southern Khangai Mountains of Mongolia (DDPPaS)}

I n consultation with the local community, decision-makers and researchers, this project has applied the five principles of DDP for identifying changes in human-environmental systems of the Tuin and Baidrag river basins of Mongolia. Utilising climate data (since 1940) and livestock data (1986-2008), the project team measured the integrated drought-Zud index (extreme winter disaster), pasture use and ecological vulnerability indexes for rural communities. Findings attributable to the five principles are as follows:
Project Leader:

Dr. Chuluun Togtohyn

Institute for Dryland Sustainability (IDS), National University of Mongolia

MONGOLIA

Tel: +9761 1463089

Email: chuluun@nrel.colostate.edu

APN Funding:

US\$60,000 (For 2 Years)

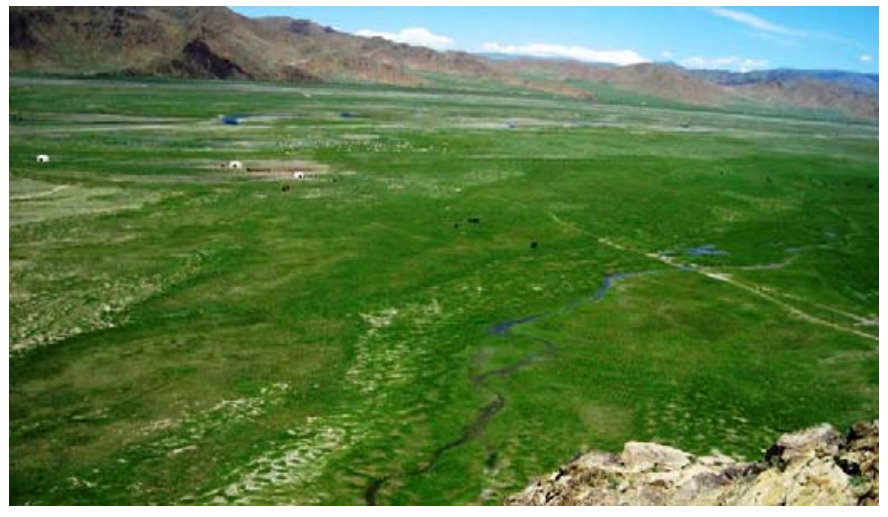

i) Natural disasters (drought and $Z u d$ ) and climatic extreme events, which affect livestock dynamics, are main drivers of dynamics of the human-environmental systems in the region.

ii) Global warming and the decline of surface water have been identified as critical slow variables, making the human-environmental systems gradually more vulnerable to natural and anthropogenic shocks. Field site data reveals that temperature increased by more than $2^{\circ} \mathrm{C}$ since 1940 (Figure 1).

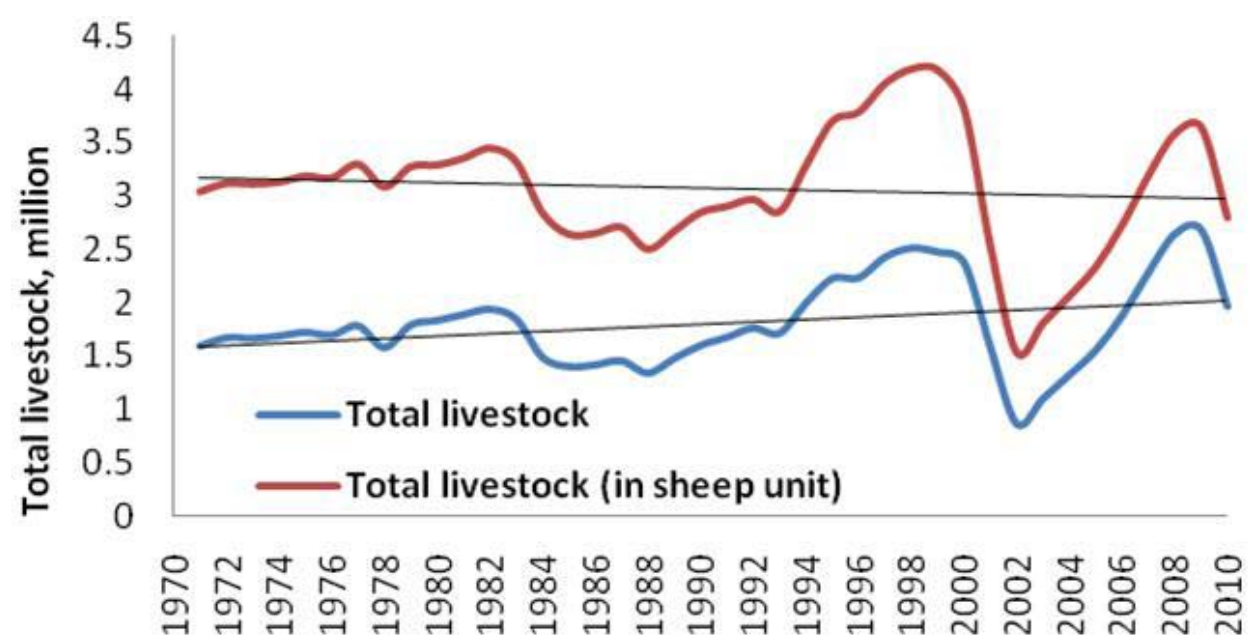

Figure 1. Annual air temperature in Bayanhongor

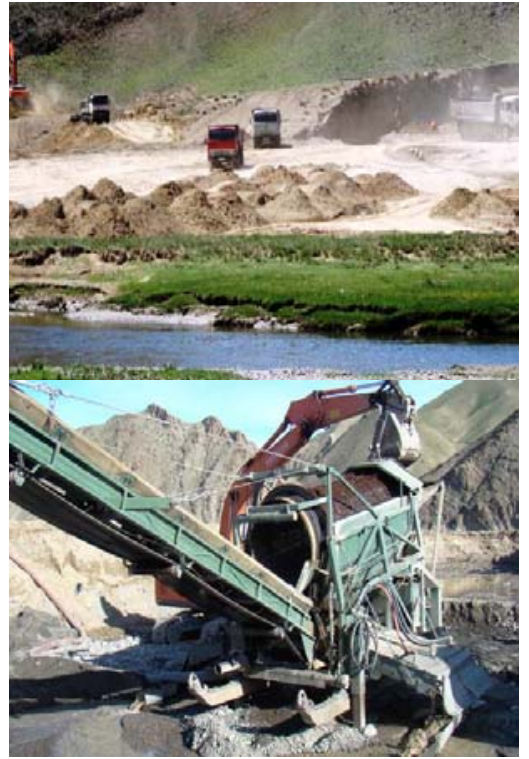

The "Odod Gold co.Ltd" operates right on the Olziit river bank in Bombogor sum

iii) According to a local community survey, the decrease of surface water has already crossed the threshold level and is leading to the collapse of many traditional human-environmental systems in the region.

iv) Global level regulation (with climate change as the main driver) is considered as the most important in the Tuin river basin whereas local level regulation (human activities such as mining and climate change) was important in the Baidrag river basin. Placer gold mining activities are harming the riparian ecosystems in the areas as shown in the photos to the right and on the next page.

v) Mixed use of modern and traditional knowledge is considered as fair by local stakeholders. Analysing long-term climate and socio-economic data (Figures 2 and 3), the rural Gobi region is more vulnerable in terms of drought-Zud (previous summer followed by severe winter) and socio-economic indicators (GDP, remoteness, inadequate infrastructure) than in steppe and forest steppe regions. 
Based on the scientific findings and local knowledge in collaboration with the Tuin river basin consul, the project team has developed a draft management plan for sustainability of human-environmental systems in the Tuin river basin. The team is currently working on an adaptation strategic plan for the Baidrag river basin.

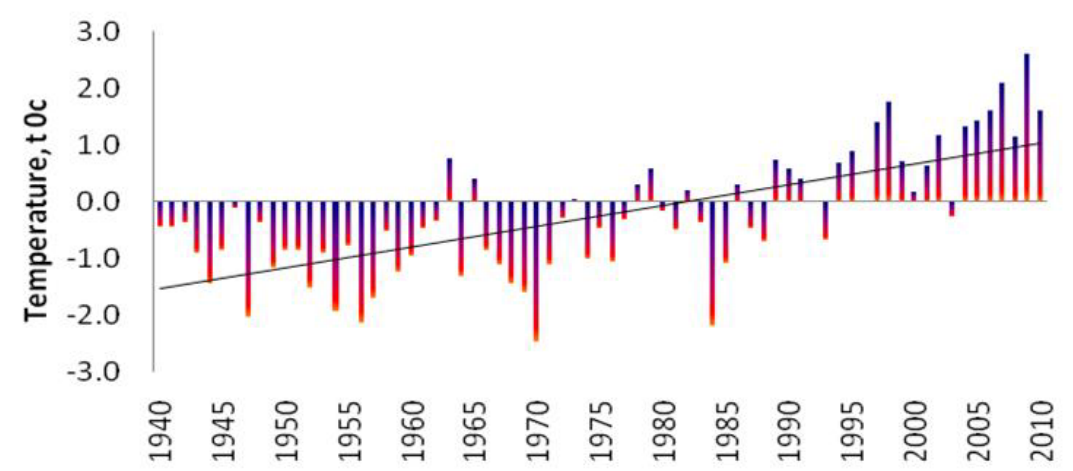

Figure 2. Integrated Zud Index in the Baidrag and Tuin river basins by ecosystem type

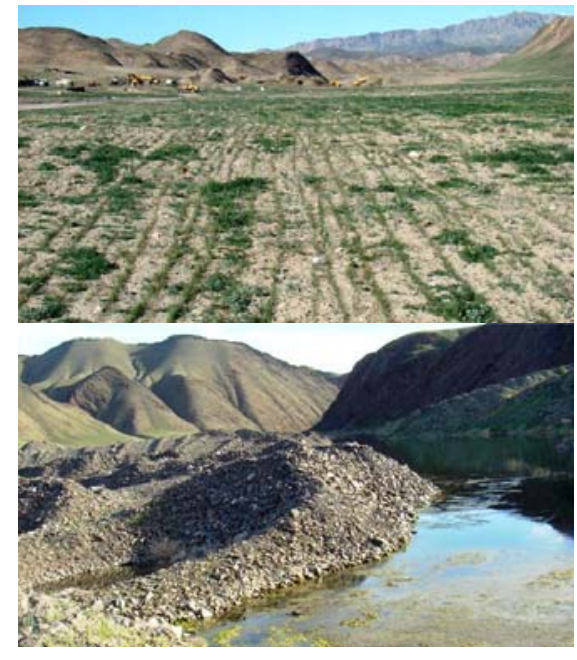

Restored and disturbed sites along the Baidrag river

\section{Publications}

- Chuluun, T. 2010. Land degradation and desertification in Mongolia. Background paper for the Human Development Report2010-Mongolia (commissioned paper).

- $\quad$ Altanbagana, M. and Chuluun, T. 2010. Vulnerability assessment of socialecological system of Mongolia. The Proceedings of the $4^{\text {th }}$ International and National workshop Applications of Geoinformatics for Natural Resource and Environment, June 2010, Ulaanbaatar, Mongolia.

- Altanbagana, M., Chuluun, T. and Ojima, D. 2010. Vulnerability Assessment of the Mongolian Rangeland Ecosystems. pp. 42-62 In: Chuluun Togtokh and Masataka Watanabe (Eds). 2010. Proceedings for Consultative Meeting on Integration of Climate Change Adaptation into Sustainable Development in Mongolia, 17-18 June 2010, Ulaanbaatar, Mongolia.

- Chuluun, T., Tserenchunt, B., Altanbagana, M. and Stafford Smith, M.. 2011. Applying the Dryland Development Paradigm to Pastoral Systems in Mongolia. IXth IRC, April 2-8, 2011, Rosario, Argentina (accepted).

- Chuluun, T. 2011. Vulnerability and Adaptation of Pastoral Human-Environmental Systems to Climate Impact at Multiple Scales in Mongolia. IXth IRC, April 2-8, 2011, Rosario, Argentina (invited paper).

\section{Integrated Zud index in Baidrag \& Tuin river basin}

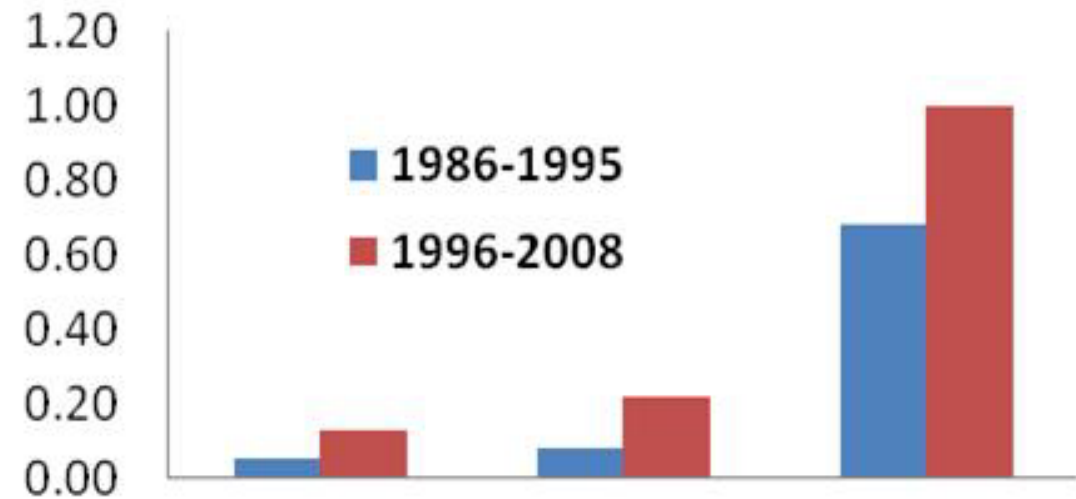

\section{Forest steppe Steppe Desert steppe}

Figure 3. Socio-economic vulnerability assessment in Baidrag river basin

\section{"Climate change has become a critical slow variable, already surpassing thresholds in terms of its negative impact on surface water; and is leading to collapse" according to a social survey in the Tuin river community.}

The results of the project were presented at following events:

- August 16-20, 2010. Panel on "Climate Change Adaptation and Sustainable Development of Mongolia”. The Second International Conference on Climate, Sustainability and Development in semiarid regions - ICID, Fortaleza, Brazil.

- October 17-19, 2010. Chuluun, T., Ojima, D., Altanbagana, M., Davaanyam, S., and B. Tserenchunt, B. Vulnerability and Resilience of Pastoral SocialEcological Systems in Mongolia. Global Land Project (GLP) Open Science Meeting, Tempe Campus, Arizona, USA.

- October 21-22, 2010. Chuluun, T., and Tsogoo, B. Vulnerability of pastoral social-ecological systems at multiple scales in Mongolia. Asia-Pacific Climate Change Adaptation Forum: Mainstreaming Adaptation into Development Planning, Bangkok, Thailand. 


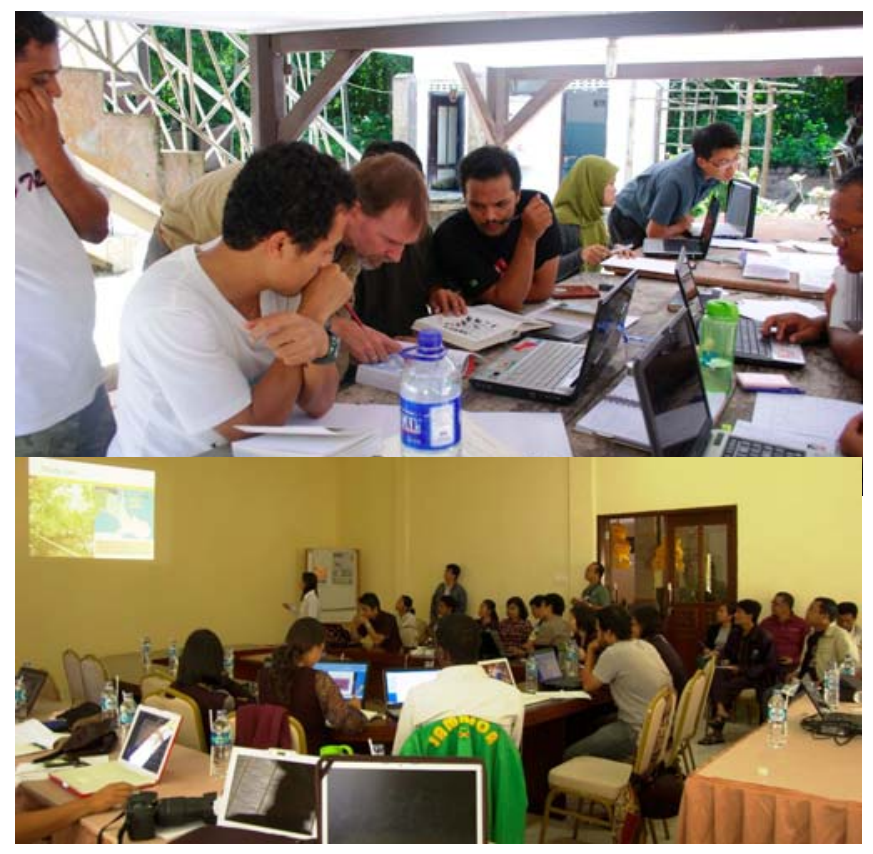

\section{CBA2010-03NSY-Indrawan}

Developing the Capacity for Teaching Biodiversity and Conservation in the AsiaPacific Region

uilding on previous efforts, particularly those by
DIVERSITAS in Western Pacific and Asia (DIWPA),
Centre for Tropical Forest Science, and Association for Tropical Biology and Conservation Asia-Pacific Chapter, this Project is implementing capacity building activities on conservation biology focusing primarily on junior faculty members and young researchers in developing countries in Asia and the Pacific.

The junior faculty are more likely to incorporate what they learn into their own research and teaching agendas, thus maximising the impact by ensuring long-term effectiveness and direct benefits. This project was composed of four main training components: i) Experimental design and data analysis courses (the Bali Botanic Gardens 12-15 July 2010); ii) Science writing courses (the Bali Botanic Gardens 16 July 2010); iii) Field biology training courses; and iv) Symposia, which emanated from the field course.

A Field Course on Biodiversity, Conservation and Sustainable Development entailed six weeks of field work in two national parks in East Java, Alas Purwo and Baluran, before crossing Wallace's Line into Rinjani National Park in Lombok. Biologists from around the globe committed their time and expertise as resource staff, offering lectures and hands-on training in their fields of expertise.

The Field Course captured multidisciplinary approaches to biodiversity conservation and global climate change. Throughout the Field Course, participants engaged in their own student research projects, and presented their results at a concluding field course symposium. To educate the Indonesian public about our activities and to widen the audience's awareness of educational activities, the media were also invited to attend.

The project also allowed for extending scholarship support to scientific and capacity building activities of global change, namely the meeting of the Association for Tropical Biology and Conservation (ATBC) 2010 -"Tropical Biodiversity: Surviving the Food, Energy and Climate Crisis," held in Sanur, Bali, Indonesia from 19-23 July 2010.
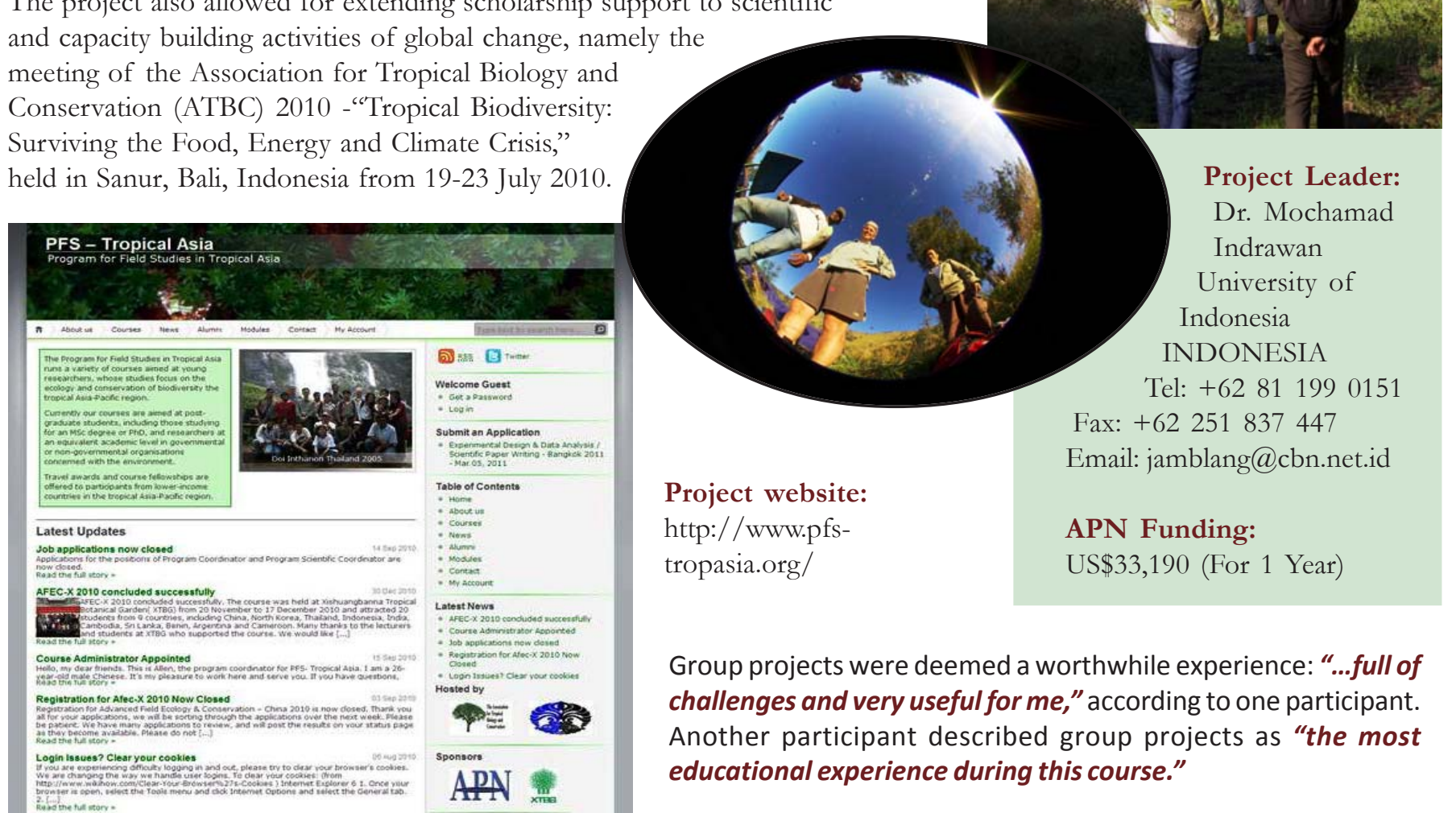

Group projects were deemed a worthwhile experience: “...full of challenges and very useful for me," according to one participant. Another participant described group projects as "the most educational experience during this course." 


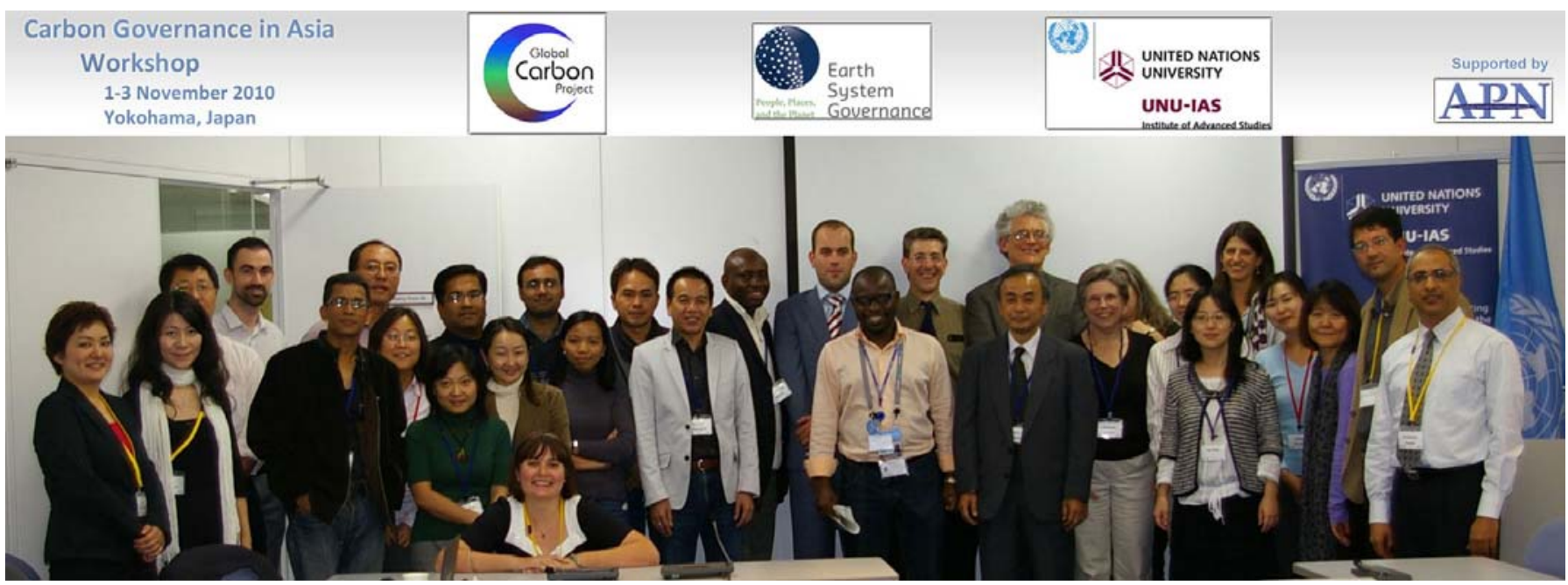

\section{CBA2010-04NSY-Dhakal}

\section{Carbon Governance in Asia: Bridging Scales and Disciplines}

he workshop titled 'Carbon Governance in Asia: Bridging Scales and Disciplines' was organised from 1-3 November 2010 as a capacity building event for Asia-Pacific young researchers through the collaborative efforts of GCP, ESG-IHDP, and the United Nations University-Institute for Advanced Studies (UNU-IAS). The workshop provided a platform and opportunity for early-career researchers to interact with senior scholars on approaches towards sound carbon governance and developing low carbon societies in Asia. The workshop was attended by fifteen early-career researchers from Japan, India, China, Indonesia, Bangladesh, Nigeria, Nepal, Thailand and Australia. They were supported and mentored by seven senior scholars from Colorado State University, University of Minnesota, Australia National University, NIES, Tokyo Institute of Technology, Renmin University of China and University of Maryland.

There was a series of overview lectures provided by leading scientists on the established themes followed by presentations of papers by the early-career participants, allowing on each occasion ample time for discussion. The workshop helped bridge scientific disciplines and created an environment with extensive opportunity for discussions where young researchers received feedback on their work and explored future collaborative opportunities. The workshop also provided opportunities for the researchers to interact with decision-makers at national and city levels through presentations and discussions with high-level officials of the Ministry of Environment Japan and the Tokyo Metropolitan Government.

Key message of the workshop

Pathways of regional development are sequences of interrelated changes in social, economic and governance systems. They vary from place to place and over time, are based on different drivers and problem perceptions in ways that are likely to bave different consequences on how carbon governance is being shaped. Carbon governance takes place at local, national and regional levels and between these levels. The workshop emphasised that this multilevel characteristic requires a better scientific understanding and political awareness of norms and standards in carbon governance. The message was also formulated by the co-organisers as a press release for the Asia-Pacific Economic Cooperation (APEC) Leaders' meeting following the workshop in the same place.

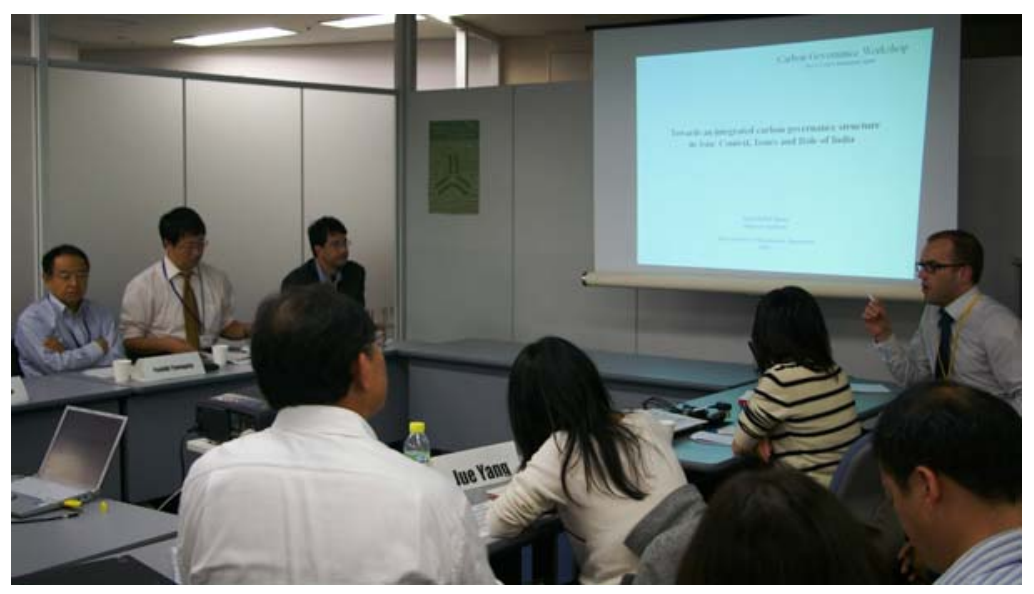

Project Leader:

Dr. Shobhakar Dhakal

Global Carbon Project (GCP)

National Institute for Environmental

Studies (NIES)

JAPAN

Tel: +81298502672

Fax: +81298502960

Email: shobhakar.dhakal@nies.go.jp

APN Funding:

US\$29,770 (For 1 Year)

Project Website:

http://www.gcp-urcm.org/CG/HomePage 


\section{Improving Pacific Island Meteorological Data Rescue and Data Visualisation Capabilities through Involvement in Emerging Climate Research Programmes}

\section{The workshop on "Improving Pacific Island Meteorological Data Rescue and Data Visualisation Capabilities through Involvement in Emerging} Climate Research Programmes" was held in Auckland, New Zealand from 27-29 September 2010. The workshop saw participants from Australia, Europe, New Zealand, U.S.A., South America, and the island nations of the southwest Pacific in attendance. The attendees engaged on current issues of data rescue and the use of the data in new visualisation platforms for climate and weather research. An overarching theme at the workshop was to garner support for the Atmospheric Circulation Reconstructions across the Earth (ACRE) initiative, which is feeding daily weather observations into new surface pressure-based reanalysis data sets (the $20^{\text {th }}$ Century Re-analysis [20CR] and Surface Input Reanalysis for Climate Applications [SIRCA]). The ACRE initiative received a unanimous endorsement from the World Meteorological Organisation (WMO) Regional Association $\mathrm{V}$ at the $13^{\text {th }}$ Regional

Meteorological Service Directors meeting, and was seen as a critical opportunity to improve climatology analysis and climate/weather forecasting capabilities for the region. The general feeling at the workshop indicated that data rescue and data sharing were very important issues for consideration.

Development of new climate and weather data visualisation tools were demonstrated in Google Earth at the workshop, and illustrated how the 20CR, tropical cyclone tracks, and station-based rainfall could be used in hands-on demonstrations. Significant feedback about the use of Google Earth as a tool was provided by all of the representatives. This feedback is resulting in improvements to first-issue releases of several products that are nearing completion, such as the South Pacific Rainfall Atlas (SPRAT) and the South Pacific Extended Archive of Tropical Cyclones (SPEAR-TC).

Common interests that were identified at the Auckland workshop through break-out sessions highlighted the desire

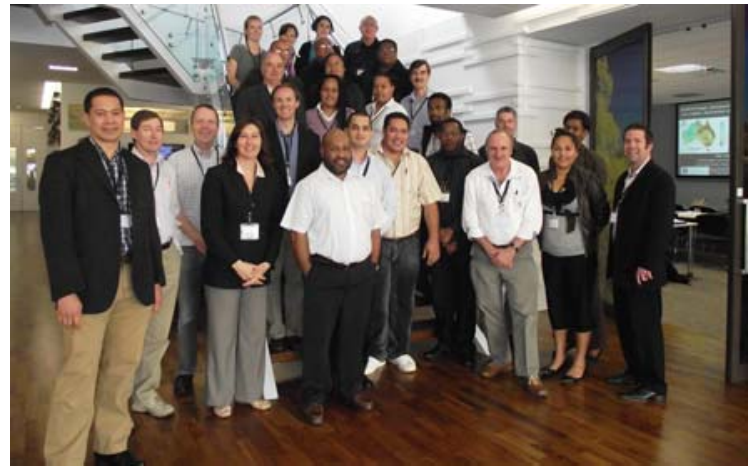

to increase support for current monitoring and data gathering in the southwest Pacific. When viewed from a long-term perspective, the spatial coverage of environmental monitoring on land is on the decline because of high costs associated with upkeep of instrumentation. More support for the meteorological services is needed to maintain and expand current monitoring programmes. In addition, many paper data exist in archives, so fostering capabilities for Pacific Island meteorological services to conduct data rescue exercises in-house are also required.

A central point of discussion highlighted the importance of fostering data base development for the continued longevity and support of the Pacific Island meteorological services. To that end, regional assistance from organisations like NIWA and the Australian Bureau for Meteorology (BOM), through the Pacific Climate Change Science Programme (PCCSP), are expected to reach goals of longterm secure data storage and access, database development, and crafting of new analysis tools connected to the databases that are relevant for the services provided to end users of climate and weather guidance. The meeting also saw the development of the ACRE Pacific faction, which will seek to foster and continue the region-wide collaboration to address the central issues identified at the Auckland workshop. Thus far, a highlight of the postworkshop collaboration in ACRE Pacific has seen the significant contribution of four long daily surface pressure observations from the Cook Islands Meteorological Service to the International Surface Pressure Databank in support of the extended reanalysis. Similar contributions are expected from the other Pacific Meteorological Services in the near future. Directed assistance to the Pacific Island Meteorological services will occur in the future through the ACRE Pacific faction via several pilot projects, including development of a data rescue planning and execution routines specific to the

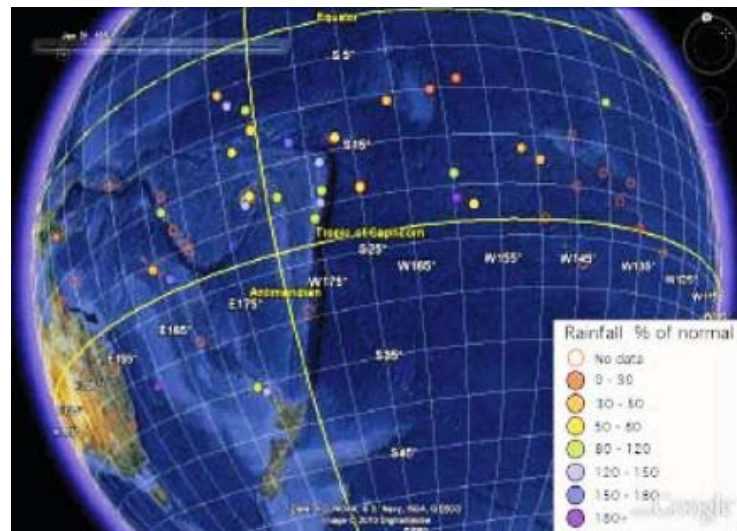

Project Leader:

Dr. Andrew Lorrey

National Institute of Water and Atmospheric Research, Ltd. (NIWA) NEW ZEALAND

Tel: +64 93752055

Fax: +6493752051

Email: a.lorrey@niwa.co.nz

APN Funding: US\$40,000 (For 1 Year) southwest Pacific islands. An additional spin-off will see colleagues from

MeteoFrance becoming involved in the regional effort to rescue surface and marine observations from traditional meteorological registers and non-traditional archives (like ships logs). 


\section{CBA2010-06NSY-Kench \\ Improving Understanding of Local-Scale Vulnerability in Atoll Island Countries: Developing Capacity to Improve In-Country Approaches and Research}

$\mathrm{I}$ $\mathrm{n}$ order to build the skills of scientists in Pacific atoll countries to undertake physical vulnerability

assessments, this Project has targeted collaboration with two Pacific atoll countries, The Marshall Islands and Tuvalu. Workshops and field-based case studies have been designed to provide training on methods to undertake rapid assessment of vulnerability of reef islands. The use of case studies of different environments will allow the comparison of local scale variations in vulnerability.

Since this Project started, the first phase of capacity building was undertaken in the Marshall Islands over a three-week period in September 2010. Collaborators included members of the Marshall Islands Conservation Society, the Environmental Protection Authority, College of the Marshall Islands and Ailinglaplap Council. The capacity building activities involved: i) a two-day workshop on methods of vulnerability assessment, held at the Long Island Hotel, Majuro Atoll; ii) a 10-day field trip to Jeh Island, Ailinglalap Atoll and Jabót island. On each island the project team undertook detailed field surveys of rural villages documenting land levels with respect to mean sea level and community assets; iii) a 2-day closing workshop in which field data was analysed, and the vulnerability of rural villages to increased sea level was established; and, iv) a

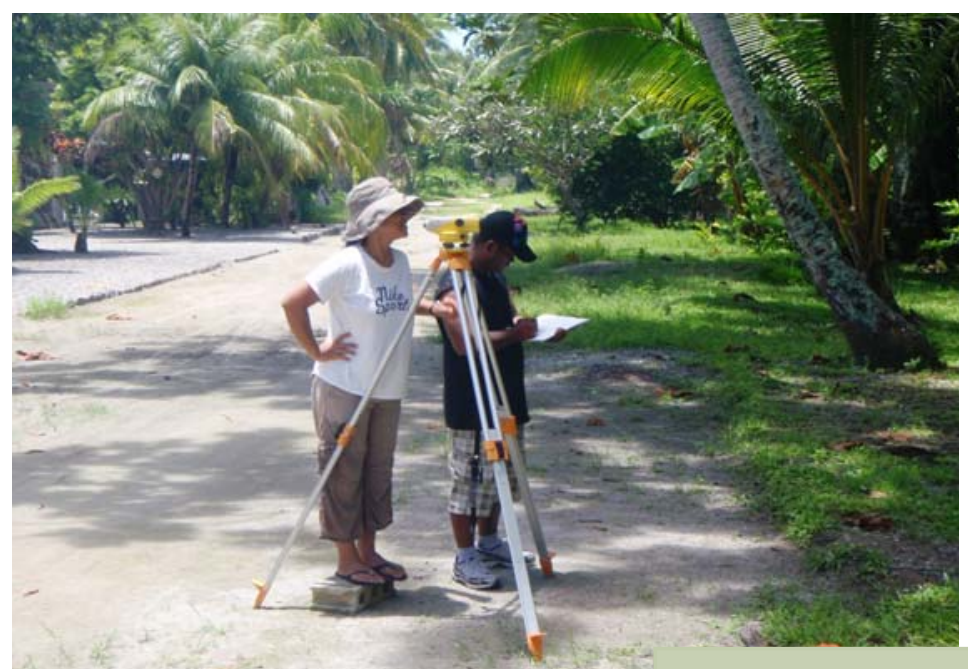

Project Leader:

"The work was valuable in helping us understand the vulnerability of our remote outer-islands to the impacts of climate. The training provided the tools and knowledge for us to apply these techniques to other islands."

Deborah Barker-Manase, General Manager, Republic of the Marshall Islands Environmental Protection Authority NEW ZEALAND

APN Funding:

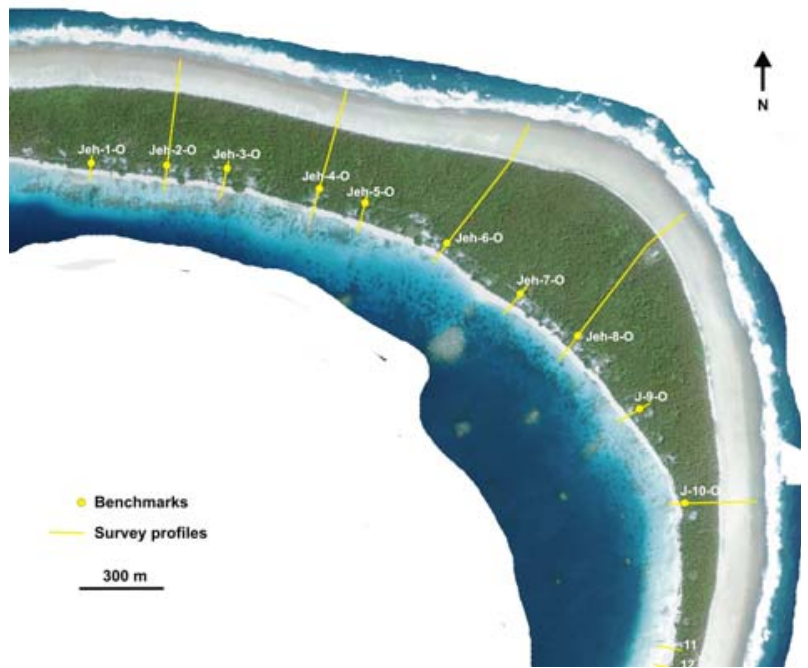

final closing workshop to senior government officials and ministers presenting the results of the work. Planning is well underway for the second major field component in Tuvalu in February 2011.

The project team has developed training materials to assess small island vulnerability to sea level change and written two case study reports of the vulnerability of islands to sea level change.

- Kench, P.S., Owen, S.D, Ford, M.R., Trevor D., Fowler, S., Langrine, J., Lometo, A., 2010. Improving Understanding of Local-Scale Vulnerability in Atoll Island Countries: Case Study 1: Jeh Island, Ailinglaplap Atoll, Republic of Marshall Islands, 12 pages.

- Kench, P.S., Owen, S.D, Ford, M.R., Trevor D., Fowler, S., Langrine, J., Lometo, A., 2010. Improving Understanding of Local-Scale Vulnerability in Atoll Island Countries: Case Study 2: Jabót Island, Republic of Marshall Islands, 10 pages.

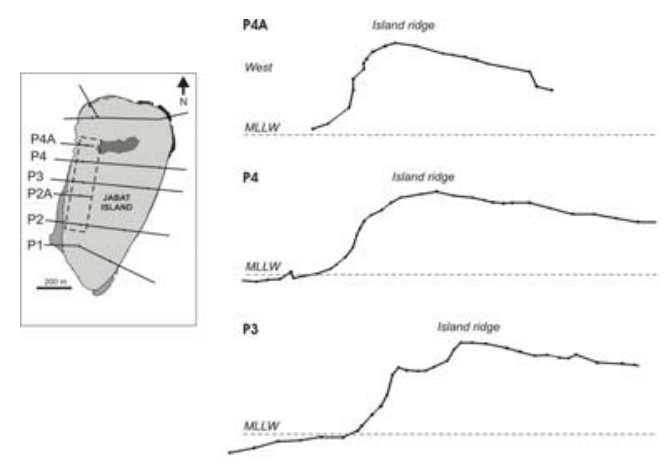

Assoc. Prof. Paul Kench The University of Auckland

Tel: +64 93737599 ext. 88440

Fax: + 6493737434

Email: p.kench@auckland.ac.nz

US\$29,760 (For 1 Year)

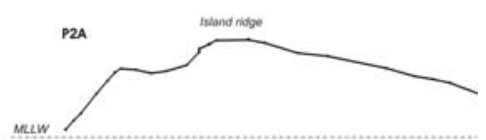

p2
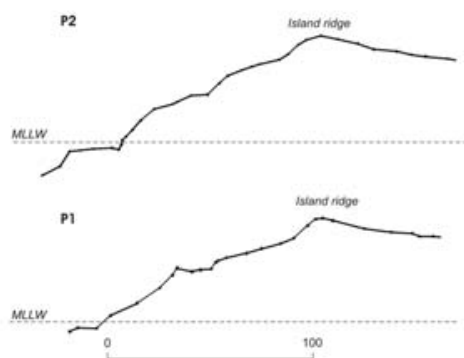
CBA2010-07NSY-Stone

Web-based 'Discussion-support'

Agricultural-Climate Information for Regional India

$\mathrm{R}$ ecognising the importance of farmers needing to develop practical and appropriate management systems to help cope with high-impact climate variability and climate change, this innovative Project is already developing new processes based on ' 2 nd life education systems and avatars' to assist decision-support and what is known as 'discussion-support' for farmers in an important region of Andhra Pradesh, India. To achieve this result, a number of targeted workshops and meetings have been held and facilitated by core collaborators in the project: ANGRAU University in Hyderabad. The main weather and climate inputs and '2nd life' development is being undertaken by key personnel at the University of Southern Queensland, Toowoomba, Australia, in conjunction with the India Meteorological Department.

An initial major scientific and extension specialist workshop was also held at ANGRAU University, on 28 September 2010 , so that key researchers already working in the region with leading farmers could provide input and gain ownership of this Project. Following this successful workshop and series of meetings with key senior staff, meetings and workshops have been held in Andhra Pradesh, India at both the village and farm levels with leading farmers and at towncentre internet kiosks.

A surprising and heart-warming aspect of these farmers' meetings has been the keen interest shown in the climate and weather products that would be made available to them in their own language (Telugu). The overall result has been very useful input into the prototype development of '2nd life avatars' farmerorientated weather and climate discussion videos by the

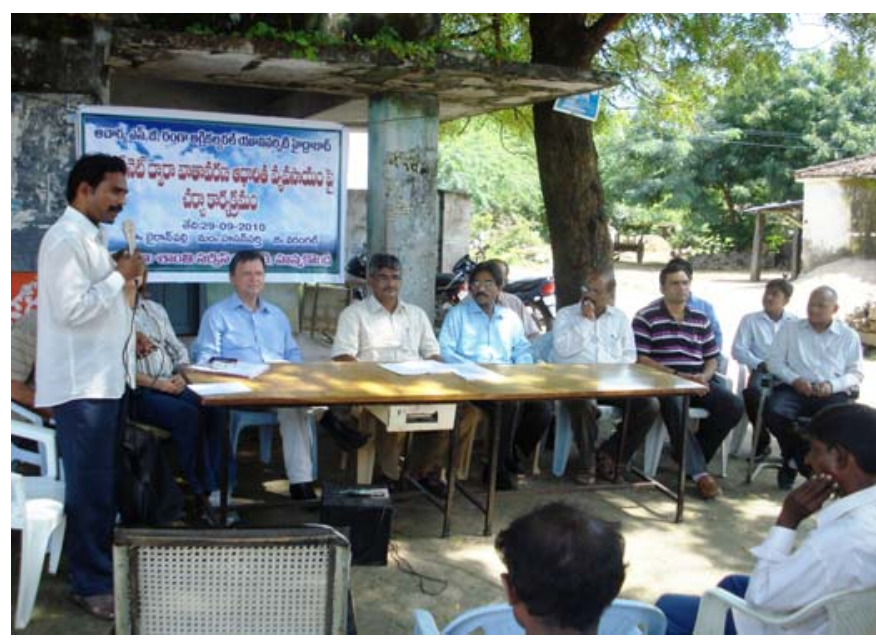

farmers direct to the scientists involved in the compilation and production of these videos. As a result, the scientists involved have already gained improved understanding of the need to further improve the style and relevance of weather and climate information so that it directly impacts straight to the decisions being considered by the farmers.

However, this Project has already also learned that all aspects regarding climate and weather information delivered through electronic means must be considered in these outputs - right through to ensuring that such aspects as the clothes and ages of the

"It's great to see some top scientists from Australia and India coming all this way to our village to tell us about climate and weather - this included experts from IMD and ANGRAU."

"It is so good to learn about weather and climate forecasts that will help our farming." -

Farmers from Biranpalli, Andhra Pradesh farmers are properly represented by any 'actors' in farmer-orientated videos, as well as ensuring that all the scientific information is completely correct and relevant.

A lesson already learned through this Project is that 'scientific information,' by itself, does not sell a required message regarding climate information needed by farmers. This means that all other associated aspects, no matter how seemingly peripheral, must be included and be properly represented when delivering climate information through electronic media. Otherwise, the entire purpose of the discussion and decision-support process may be lost.
Project Leader:

Prof. Roger Stone

University of Southern Queensland AUSTRALIA

Tel: +61 746312736

Fax: +61 746315581

Email: stone@usq.edu.au

APN Funding:

US\$34,596 (For 1 Year)

Project Website:

www.usq.edu.au/acsc/apnproject

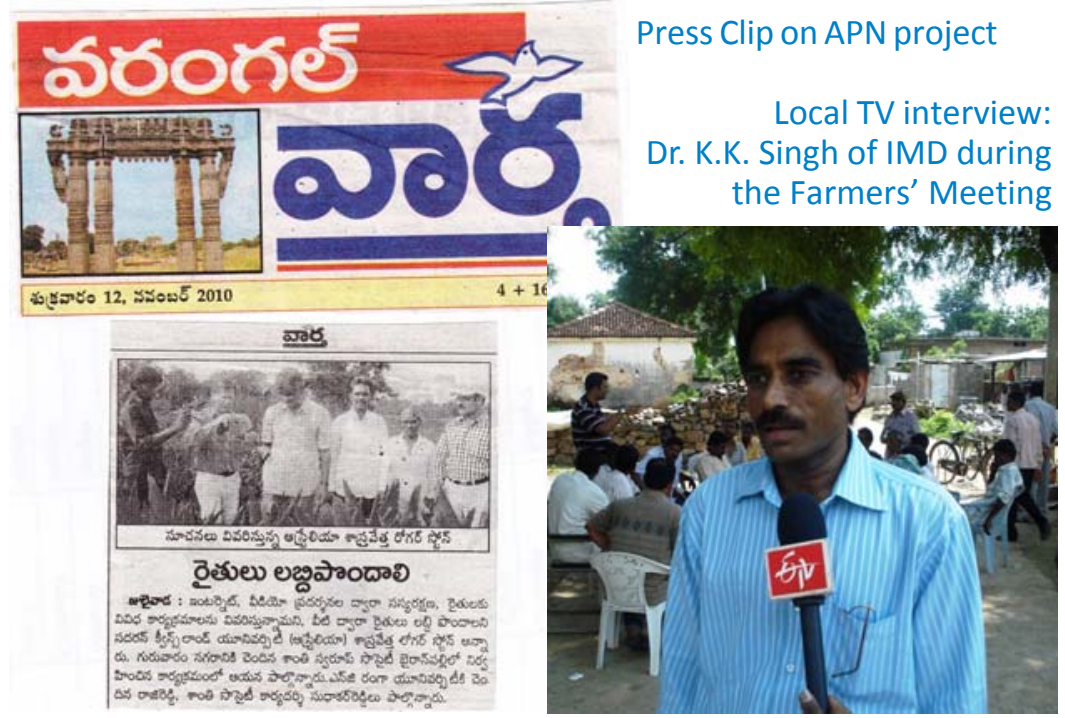



he present Project was developed to take stock of a number of important issues facing the agricultural communities around the world including rising populations with the consequent increase in demand for food; the pressures on the world's food producers due to climate variability and change, as well as socioeconomic conditions; the need to use natural resources productively, but sustainably; and the need within the agriculture communities for increased knowledge and better tools for risk management and adaptation.

A workshop was held bringing together leading experts in the field who prepared and

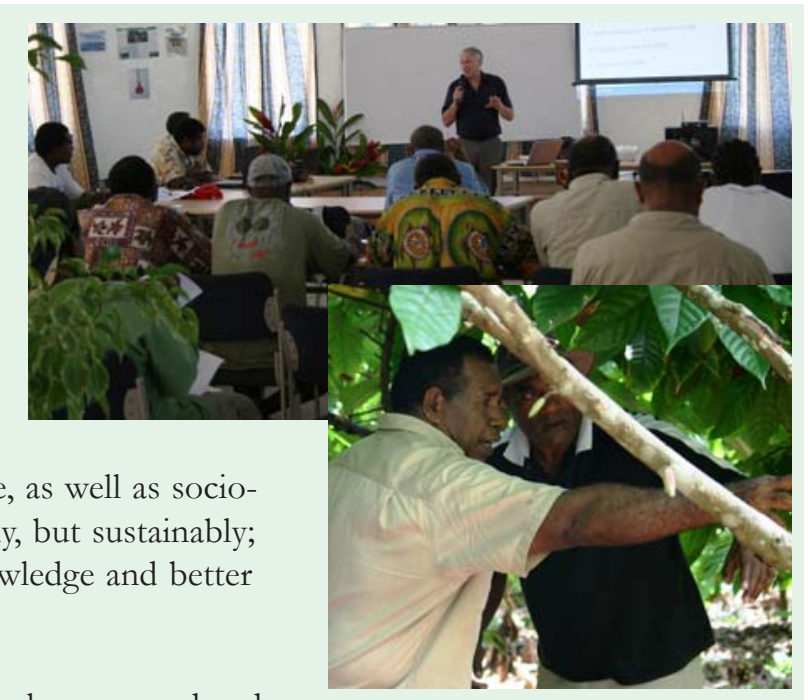
presented state-of-the-art discussion papers to address the objectives of the workshop. The programme was designed to engage all participants in discussions on topics of their interest to facilitate interactive dialogue and develop appropriate recommendations. Through the workshop, a set of key recommendations were developed and adopted at the fifteenth

\footnotetext{
Project Leader:

Dr. Jim Salinger

Honorary Research Associate

School of Environment

University of Auckland

NEW ZEALAND

Tel: +6493737599

Fax: +6493737434

Email: j.salinger@auckland.ac.nz

APN Funding:

US $\$ 20,000$ (For 1 Year)
}

session of the Commission for Agricultural Meteorology, particularly while prioritising the future work of the Commission for the upcoming 2011-2013 period. Participants from APN countries were encouraged to promote linkages between science and policy discussed during the workshop.

A follow on workshop was held in Luganville, Santo, Vanuatu from 11-13 December 2010 where farmers from each province of Vanuatu met with climate change scientists and agricultural advisers to devise strategies to help cope with climate variability and climate change. This provided capacity building in the area of strategies for more targeted weather and climate information and forecasting for increased preparedness to sustainable agricultural development, especially in the Asia-Pacific region, and also assisted policy-makers and civil society in responding effectively to varying weather and climate conditions.

\section{CBA2010-09NSY-Okayama}

\section{Scientific Capacity Development of Trainers and Policy-Makers for Climate Change Adaptation Planning in Asia and the Pacific}

T he present Project aims at building capacity of key stakeholders such as trainers, policy-makers, and development practitioners in the Asia-Pacific region in order to mainstream climate change adaptation principles and practices into development planning in some of the targeted countries of the Asia-Pacific Adaptation Network (APAN). It also aims to transfer knowledge and skills on vulnerability assessment methodologies and tools, the use of climate information for decisionmaking, and adaptation planning under uncertainty from developed countries to developing countries through involving members of the Network. The main objectives of this Project are to undertake an appraisal of training needs in terms of knowledge and skill areas for effective adaptation and to design training modules for imparting knowledge and skills for effective adaptation.

Beginning in October 2010, the project team planned detailed activities and a timeframe for its objectives. In order to develop the capacity of training institutes where policy-makers are trained, the team has also started to undertake a training needs assessment (TNA) in terms of knowledge and skill areas for effective adaptation. The training institutes in five targeted countries of Cambodia, Lao PDR, Mongolia, Bangladesh and Nepal have been identified and the detailed activities of the TNA have been designed. The target sectors are kept on track of agriculture and water related to agriculture. Based on forthcoming TNA results, this Project will support the targeted training institutes to develop training modules, which then will be implemented for key policy-makers in the region. Bringing together representatives from five collaborating nations, the project team organised the TNA meeting as the first step for the design and development of this capacity building activity at the Asian Institute of Technology, Thailand on 31 January 2011. 


\section{Promoting a Data Sharing Environment within the Earth Observation System of Systems: The Asia-Pacific Perspective}

$\mathrm{B}$ oth scientists and policy-makers recognise the importance of widespread data sharing for scientific research, capacity building, and sustainable development. However, many legal, economic, technological, and political barriers must be overcome before an effective working environment for data sharing can be realised.

This Project aims to highlight specific barriers to data sharing important in the AsiaPacific region and to develop strategies to overcome them. It will bring together major stakeholders from the scientific, legal, and policy communities within the region, reviewing experiences around the world, suggesting solutions based on best practices, and identifying useful models and tools, e.g., open access licenses. It will highlight and promote the importance of data sharing within and between Earth observation systems in the Asia-Pacific region for research and applications in the GEOSS key societal benefit areas, e.g., disasters, health, energy, climate, water, weather, ecosystems, agriculture, and biodiversity.

The project team organised a meeting, "Symposium on the Data Sharing Action Plan for GEOSS and the Benefits of Data Sharing" on 2 November 2010 as a prior event to the Seventh Group on Earth Observations (GEO-VII) Plenary Session and Beijing Ministerial Summit in Beijing, China. The event was a platform for networking and discussion of open-access data sharing drawn from different sectors and national and international contexts between international experts and Earth observation systems for research and applications in the key societal benefit areas. Aside from this symposium, this Project will also organise a series of workshops and meetings to enable and facilitate understanding about the importance of full and open access to data as well as about how existing international agreements and national policies and laws affect data sharing in ways that lead to increased societal as well as scientific gains.
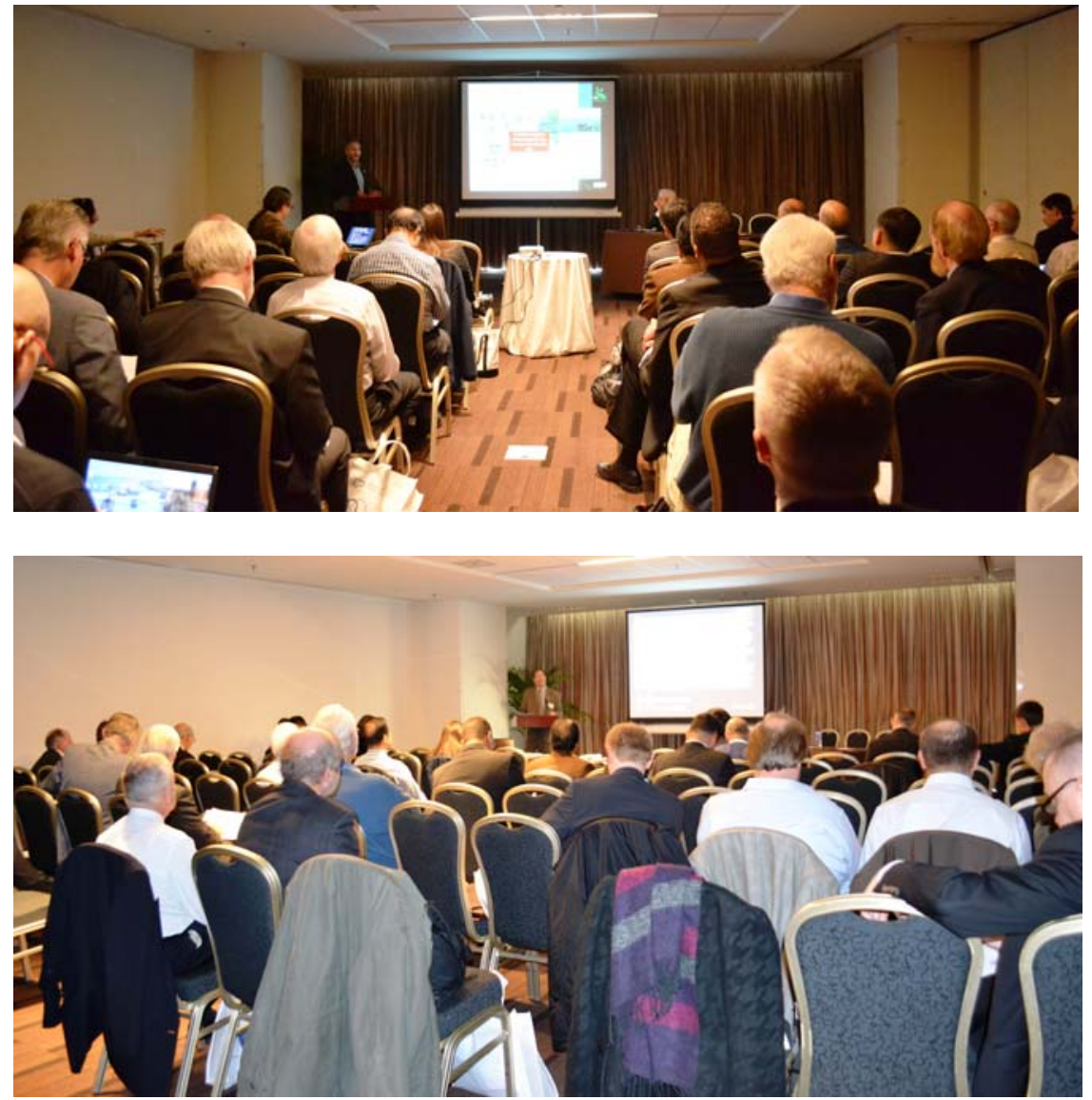

Project Leader:

Dr. Robert S. Chen

Committee on Data for Science and

Technology (CODATA)

Centre for International Earth Science

Information Network (CIESIN)

Columbia University

USA

Fax: +1 8453658922

Email: bchen@ciesin.columbia.edu

APN Funding:

US\$40,000 (For 1 Year)
Tel: +1 8453658952
Changes in the Earth system are having a profound impact around the world. This has led to increasing global demand for Earth observation data at local, regional, and global scales. 


\section{CBA2010-11NSY-De Guzman \\ Capacity Building for Research and Monitoring of Marine Protected Areas (MPA): An Adaptive Mechanism for Climate Change in the Asia-Pacific Region}

$\mathrm{R}$ ecognising the need to build local and regional capacity for marine protected area (MPA) monitoring, this

Project builds the capacity of MPA managers and technical staff of local government units in selected coral reef-rich countries in the Asia-Pacific region and within the Coral Triangle Initiative. Since its implementation the project has produced an MPA Training Manual, conducted two training activities, and trained a total of $40 \mathrm{MPA}$ managers and monitoring staff.

A Local Training in MPA Monitoring was held from 23-27 August 2010 and attended by 20 participants from various government agencies, local government units (LGUs), academic institutions, and non-government organisations (NGOs) in Mindanao Island, Philippines, including a municipal mayor of a remote town in the Zamboanga province. Participants were taught standard and emerging techniques in assessment and monitoring of coral reefs (corals, fish, and other benthos), seagrass beds, and mangrove ecosystems. Lectures on monitoring techniques were supplemented by field and diving activities in selected MPA sites where actual data was gathered and used to demonstrate data management and report preparation.

Regional Training in MPA monitoring was held from 26-30 November 2010 in the municipality of Maria in Siquijor Island,

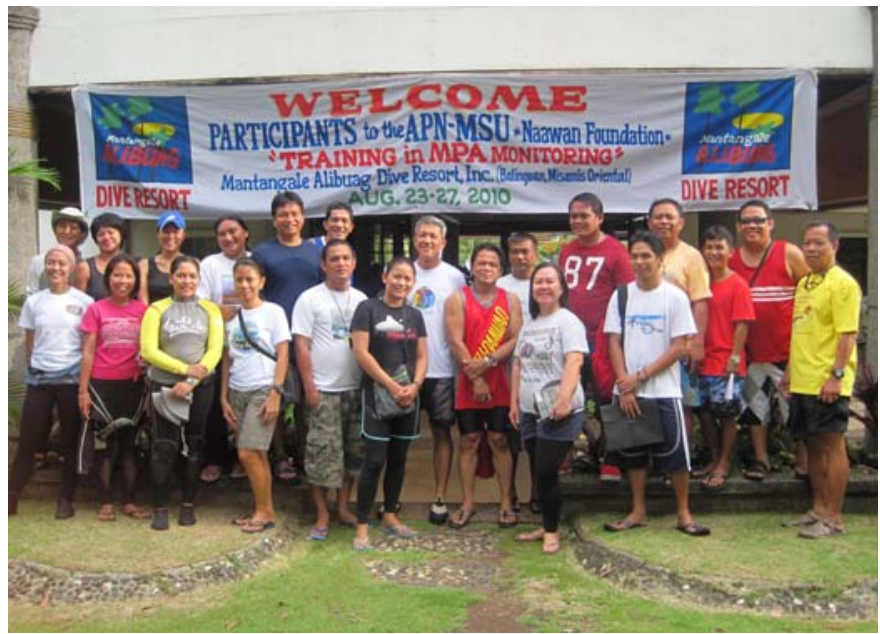

central Visayas, Philippines. The training was attended by 20 participants from different countries in the Asia-Pacific Region, namely Indonesia, Thailand, Viet Nam, Timor Leste, and Philippines. The five-day training covered the same topics as the Local Training and opened with a rich sharing of experiences in MPA monitoring and management initiatives among participants from five countries. Participants were also trained in data management and preparation of monitoring reports. Participants from each country drafted an MPA monitoring plan which they hope will guide them in improving MPA management in their respective countries.
Project Leader:

Dr. Asuncion De Guzman

Institute of Fisheries Research and

Development

Mindanao State University

PHIILIPPINES

Tel: +63917 7120171

Email: sony_deguzman@yahoo.com

APN Funding:

US\$35,600 (For 1 Year)

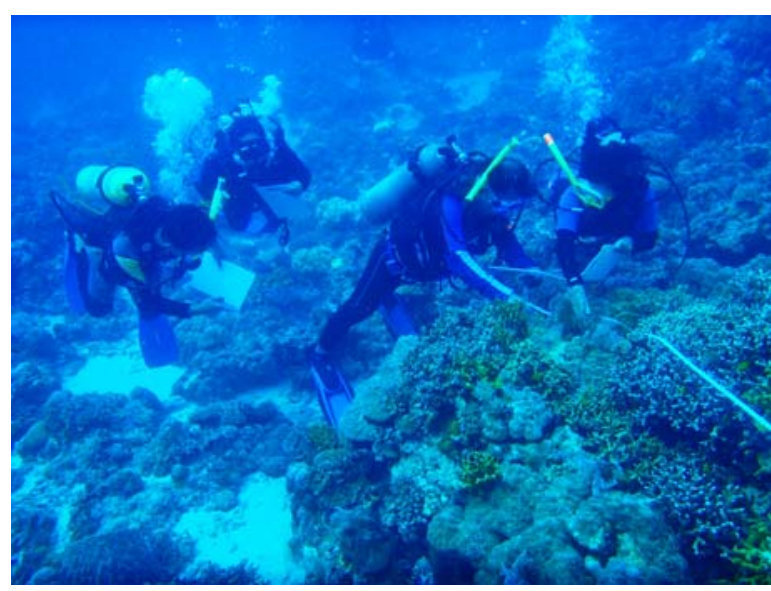

Diving and monitoring activities in selected marine protected areas as part of the Regional Training
Training is indeed very useful in improving the management of their respective MPAs through monitoring and evaluation.

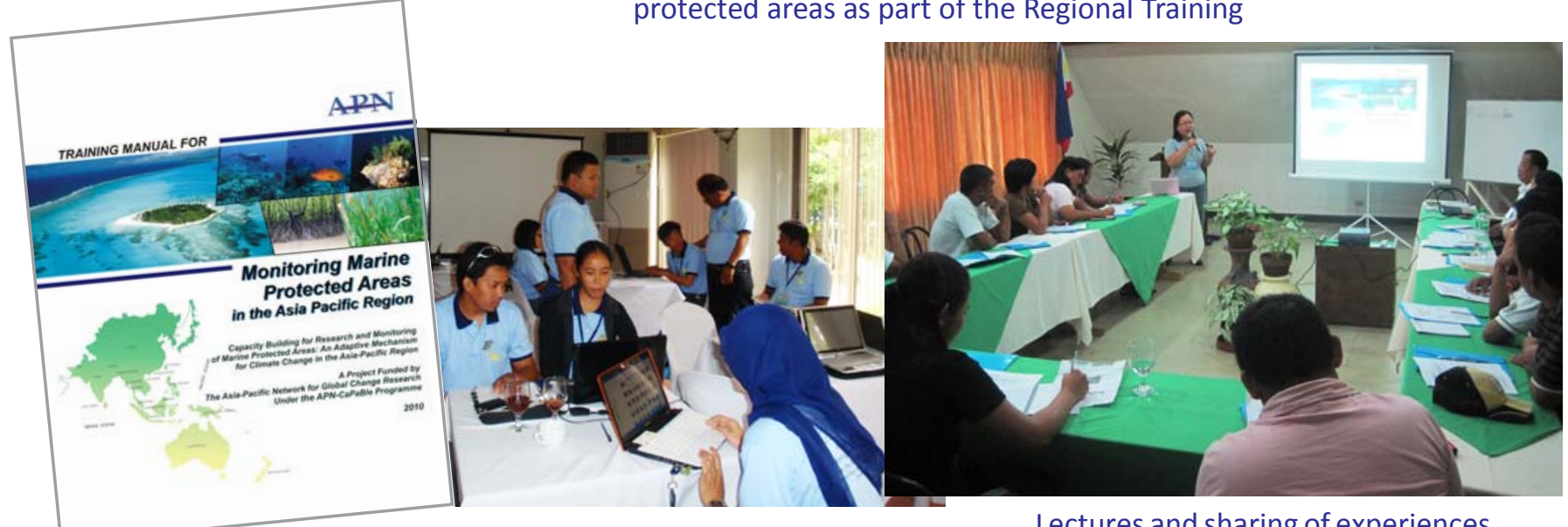

Lectures and sharing of experiences

APN Science Bulletin Issue 1] March 2011 


\section{CBA2010-12NSY-Pradhananga Graduate Conference on Climate Change and People}

$\mathrm{T}$ he International Graduate Conference on Climate Change and People was organised in Nepal from 15-19

November 2010. The conference mainly focused on scientific capacity building of graduate students of different academic majors/disciplines through their knowledge- and experience-sharing with experts in climate affairs. Coupled with climate change knowledge, the focus was directed on regional climate change-related concerns. Targeting graduate students in Greater South Asia, this Project successfully contributed to developing the capacity of students in the region to become climate leaders and climate agents in their respective fields of endeavour.

In the conference, seventeen experts from a variety of fields including social science, biodiversity, water resources, climate change science, natural hazards, policy, equity and ethics, etc., shared their experiences and opinions among 130 delegates representing 17 countries from Greater South Asia and beyond. It was jointly organised by The Small Earth Nepal (SEN) and the Consortium for Capacity Building (CCB), University of Colorado, U.S.A. with base funding from the APN.

As a result, an Eco Generation Network was initiated among the delegates (and beyond) to share information regarding research findings related to climate change and society. A newsletter, The Eco Generation, was published each day of the conference.

The conference concluded with a declaration, which is a collaborative statement from the students who attended the conference. The declaration called on world leaders attending the United Nations Framework Convention on Climate Change Sixteenth Meeting of the Conference of the Parties (UNFCCC-COP16) to hear the voices of the Eco-Generation, which is the younger generation of concerned student-scientists and future policy-makers.
The declaration is divided into seven Themes of Action: Listen, Understand, Act, Engage, Empower, Embrace and Impart.

It demands that policy-makers listen to the voices of youth, to stakeholders at all scales, and to vulnerable and marginalised communities; to understand the urgent action needed to create preventative and mitigation policy; to act to develop and promote programmes that encourage more sustainable development; to engage with local communities to better address local needs; to empower marginalised communities and indigenous knowledge

systems to help cope with growing change; to embrace intergenerational representation; and, finally, to impart knowledge to the global community through both informal and formal communication channels.

The declaration was brought to and distributed at Cancun, Mexico during the COP16. In Nepal, the declaration was handed over to government representatives and other appropriate persons organising a policy-relevant programme to celebrate the Global Day of Action on 4 December 2010. The declaration was also sent to concerned ministries of the Government of Nepal.

As a post activity of the conference and one of the activities of the Eco-Generation Network, a Virtual COP16, which gathered 122 participants, was conducted from November 29 to December 11, 2010 among the network members with the intention of informing youth about COP16 through online discussions and a media camera. All major concerns were based on the so-called "blame game" between developed and developing nations. A forgotten group 'Twenty Something' was proposed and discussed. Though this Virtual COP16 did not have visible impact, it was very successful to table the issues of Young People.

\section{Why the Graduate Conference?}

- Research is too scientific and needs to be transformed into a societal model

- The impacts of climate change vary according to age, time and location and so needs to be discussed in a single platform

- Climate change should be addressed on a multi-sectoral basis

- Youth are ambassadors of information and future decision-makers and so should have their capacity enhanced

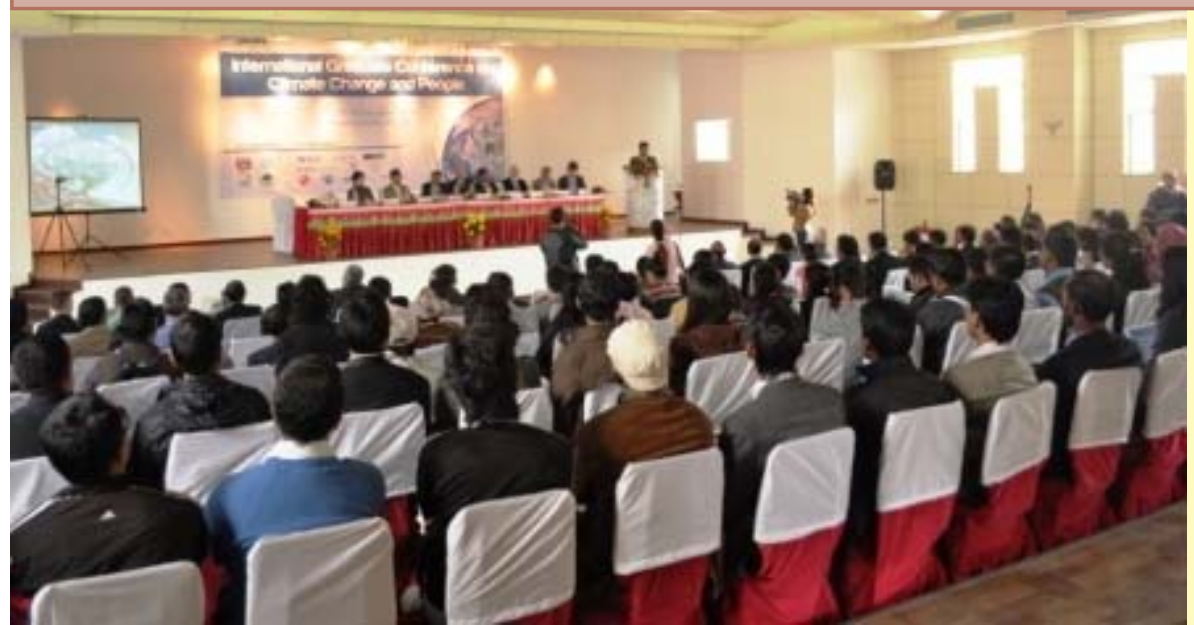

Project Leader:

Mr. Dhiraj Pradhananga

The Small Earth Nepal (SEN)

NEPAL

Tel: +97714782738

Email: dhirajmet@hotmail.com;

smallearth@wlink.com.np

APN Funding:

US\$26,000 (For 1 Year)

Project website:

http://gradconference.wordpress.com/ 


\section{CBA2010-13NMY-Kawai \\ Capacity Building of Biodiversity Research in the Coastal Zones of the Asia-Pacific Region: Phycology Taxonomy Analysis Training Using Genetic Marker}

$\mathrm{P}$ roviding capacity building for young researchers from developing countries in Southeast Asia, the International EMECS Centre organised a training programme for taxonomy identification from 2-13 July 2010 in Kobe, Japan. Taxonomy is regarded as one of the bases for biodiversity knowledge, and is a prerequisite in establishing certain objective standards to identify alien species, together with conventional morphological approaches. In this sense, the methodology for identification using genetic markers is recognised these days as reinforcing the shortcomings of traditional approaches. Equipping deoxyribonucleic acid (DNA) analysis skills with genetic markers, this training programme has contributed to the knowledge and experience of macroalgal taxonomy among young researchers, providing them with the precise identification skills to distinguish native and alien seaweed species.

Six trainees from China, Indonesia, Malaysia, Thailand, and Viet Nam were divided into three groups for individual technical divisions: Faculty of Science, Kobe University; Faculty of Science, Hokkaido University and Faculty of Marine Biosciences, Fukui Prefectural University. The training programme fruitfully enabled trainees to obtain the skills of taxonomy identification with genetic markers, and aimed to contribute to the United Nations Convention on Biodiversity (UNCBD).

\section{Project Leader:}

Prof. Hiroshi Kawai

Environmental Management of Enclosed Coastal Seas (EMECS)

Kobe University Research Centre for Inland Sea

JAPAN

Tel: +81782520234

Fax: +81782520404

Email: kawai@kobe-u.ac.jp

APN Funding:

US\$30,000 (For Year 1)

(Year 2 expected funding is US\$15,000)

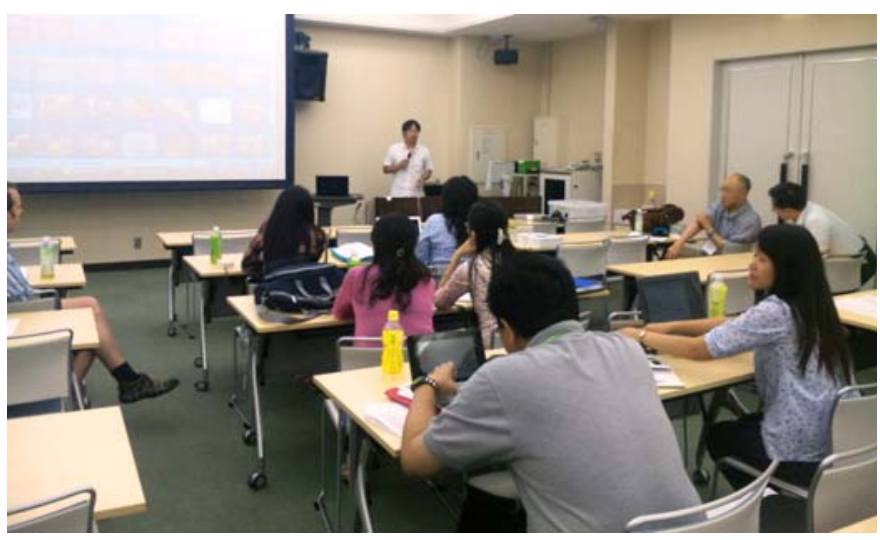

This training programme offered a very good approach to training and provided representatives from each country with new knowledge. As the first attempt in promoting a network based on molecular analysis in a way that is complementary to the traditional taxonomy group, the training was carried out very successfully. The knowledge we obtained is important for us to pass on to new students, as well as to build up the next generation of seaweed taxonomists in each university and country. - Woan-Shien NG, Trainee from University of Malaya, Malaysia

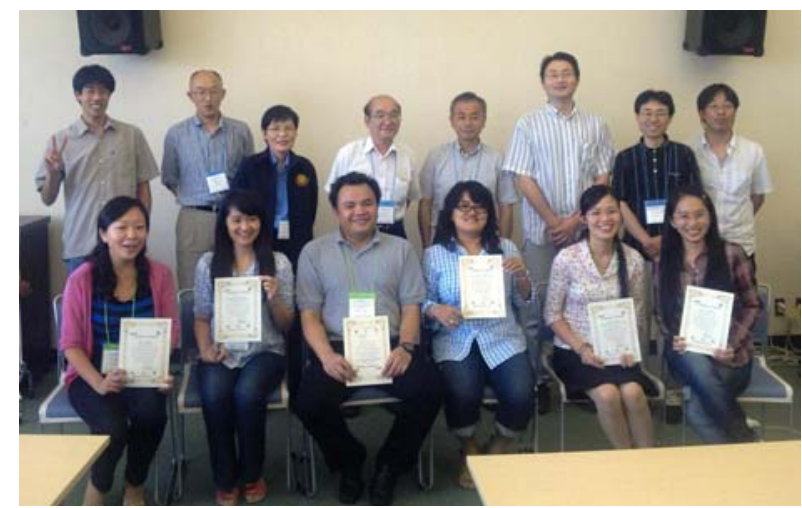

Laboratory training at Kobe University

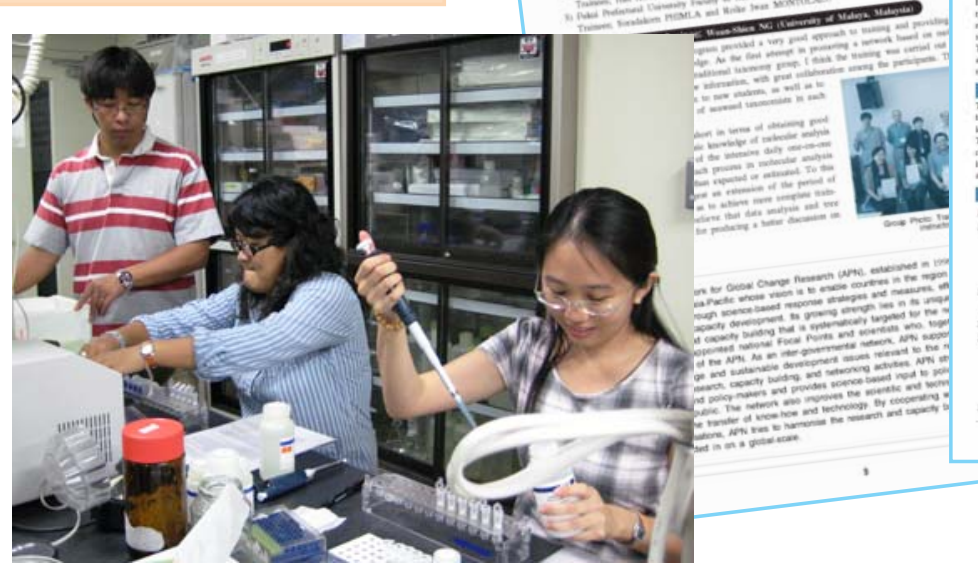

APN Science Bulletin Issue 1 March 2011

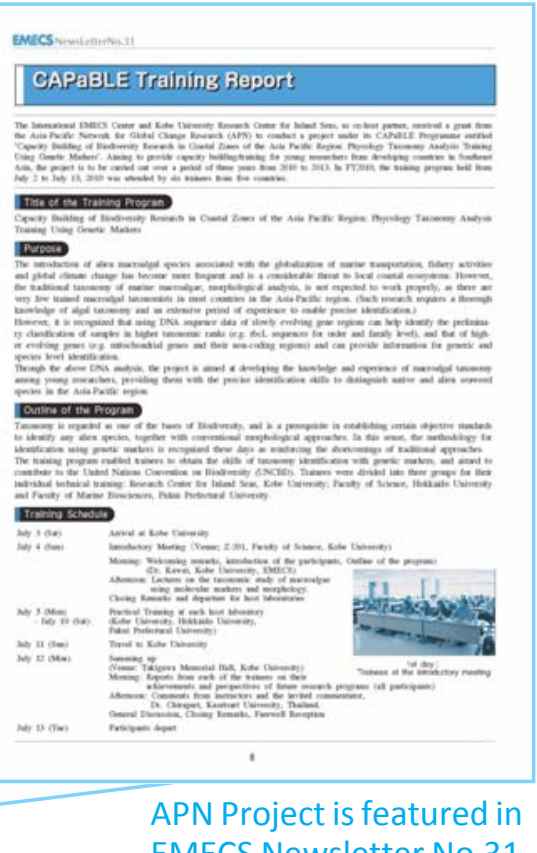

EMECS Newsletter No.31 


\section{CBA2010-14NMY-Kaihotsu \\ Drought Monitoring System Development by Integrating In-situ Data, Satellite Data and Numerical Model Output}

T his Projects aims to build up a drought monitoring and researching network to share and improve necessary regional datasets. In this endeavour, the project team has been working to develop technical and scientific capacity in the respective Asian countries. In order to discuss project progress and exchange updates, the project team organised a joint meeting with AWCI at the University of Tokyo in early October 2010, and the Asian Drought Workshop on 20 January 2011. The next joint meeting is scheduled in March 2011 back to back with the $5^{\text {th }}$ GEOSS Asia-Pacific Symposium.

In strong cooperation with the AWCI and the Drought Working Group of GEOSS, a scientific team of six scientists supports the present Project in the algorithms and methodology of drought monitoring and numerical analysis.

For the data bank, the project team has already collected datasets of soil moisture and soil physical properties of the routine in-situ observations and is checking the respective quality against 2008 standards in cooperation with the Coordinated Energy and Water Cycle Observations Project (CEOP) of the Global Energy and Water Cycle Experiment (GEWEX). To date, the data bank maintains useful datasets of in-situ soil moisture in China, Bangladesh, Mongolia and Pakistan for periods between 2002 and 2008. Currently, the satellite data of Advanced Microwave Scanning Radiometer - Earth Observing
System (AMSR-E) soil moisture estimation and Moderate Resolution Imaging Spectroradiometer Normalised Difference Vegetation Index (MODIS NDVI) are being obtained for 2010 and 2011.

While the AMSR-E soil moisture data in Asia is being processed and analysed on a daily basis; it is challenging to provide specific data and to present an early warning system of drought hazard information to some countries. Furthermore, the project team members are working on the datasets acquiring the numerical model products of drought and climate change in Asia.

Project Leader:

Prof. Ichirow Kaihotsu

Hiroshima University

JAPAN

Tel: $+81-82-424-6497$

Fax: +81-82-424-0758

Email: kaihotu@hiroshima-u.ac.jp

APN Funding:

US\$40,000 (For Year 1)

(Year 2 expected funding is US\$40,000)
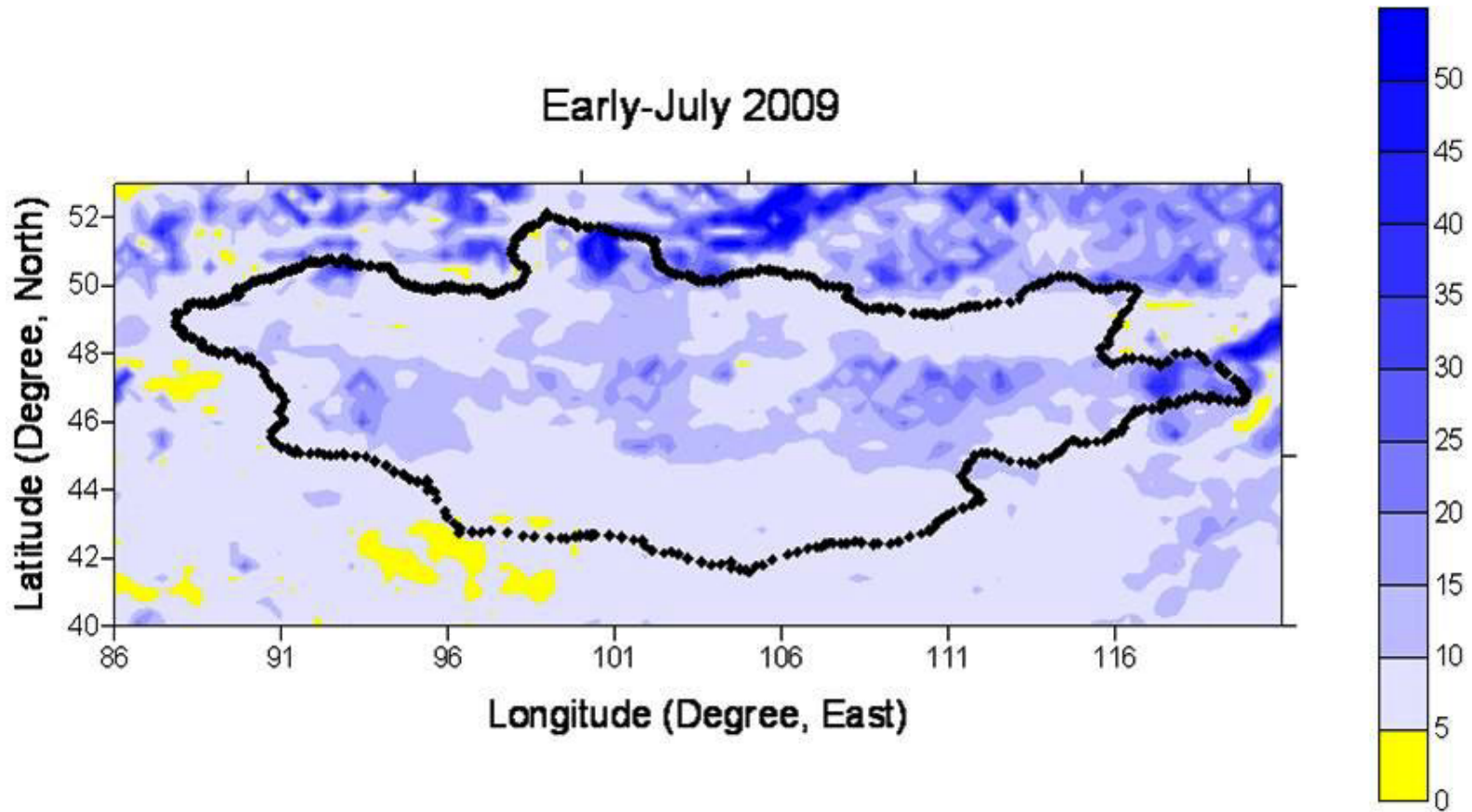

SM (\% by volume)

AMSR-E soil moisture estimation in early-July of 2009 in Mongolia 


\section{CBA2010-15NSY-South \\ Global Change and Coral Reef Management Capacity in the Pacific: Engaging Scientists and Policy-Makers in Fiji, Samoa, Tuvalu and Tonga}

1 our successful workshops on Climate Change Adaptation were held for 130 senior officials from Fiji, Samoa, Tonga and Tuvalu between June and August 2010. These workshops, organised by the University of the South Pacific, featured briefings on likely impacts of climate change on Pacific Islands and sought suggestions for policy changes for island adaptation. Climate change will increase existing threats to coral reefs due to unsustainable fishing, pollution from the land and habitat destruction via sea level rise, sea temperature rise, ocean acidification and increased strengths of cyclones. Rapid population growth will exacerbate these. All countries recognise the threats posed by climate change and have signed relevant United Nations (UN) Conventions and Agreements.

They all have policies to tackle climate change threats. However, the governments have a lack of capacity to seriously address climate change threats and these are yet to be incorporated as a cross-cutting theme among the relevant government departments. The countries recognise a need to raise awareness of the issues and include these in school curricula, which are often based on developed country models. Tonga recognises that existing government departments will need to improve communication and coordination to develop an integrated approach. Fiji questions whether a national ocean policy could serve the purpose of addressing issues such as sustainable fisheries management (including ecosystem-based management), cross-sectoral corporation, linking scientists with policy

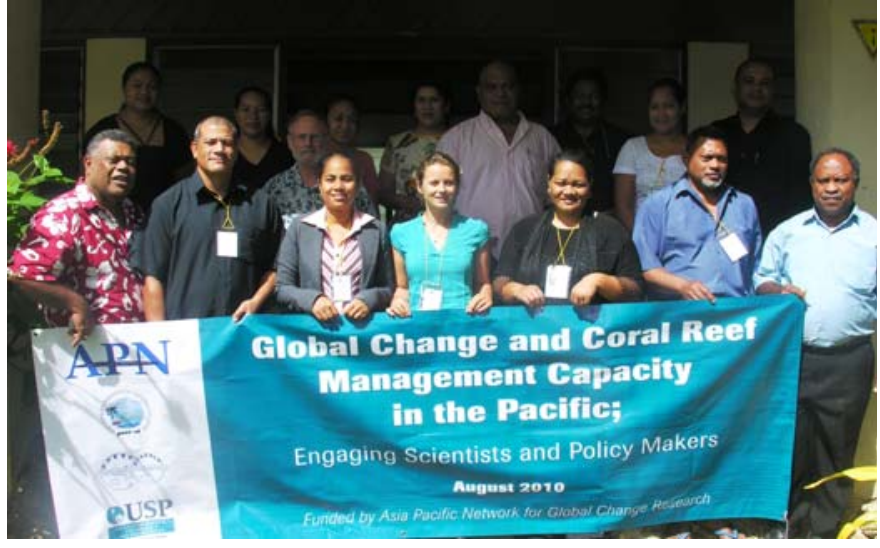

Participants of the workshop held in Tonga

makers, education and awareness. Samoa recognises the challenges presented by developing an integrated approach, which involves cutting across ministries. Tuvalu has several existing social and economic threats despite their traditional leadership system.

The governments recognise that an expansion of Marine Protected Areas offers a potential mechanism, however only Fiji and Samoa have active MPA programmes in association with user communities. The countries recognised that building on the Regional Oceans Policy template approved by the Forum Leaders in 2002 was an essential first step in improving policy and all recognise the important role of climate change in the long-term sustainability of their marine resources and food security.

Project Leader:

Prof G. Robin SOUTH

Institute of Marine Resources

University of the South Pacific

FIJI

Tel: +679323 2151

Fax: + 6793232158

Email: robin.south@orda.com.au; south_g@usp.ac.fj

APN Funding:

US $\$ 40,000$ (For 15 months)

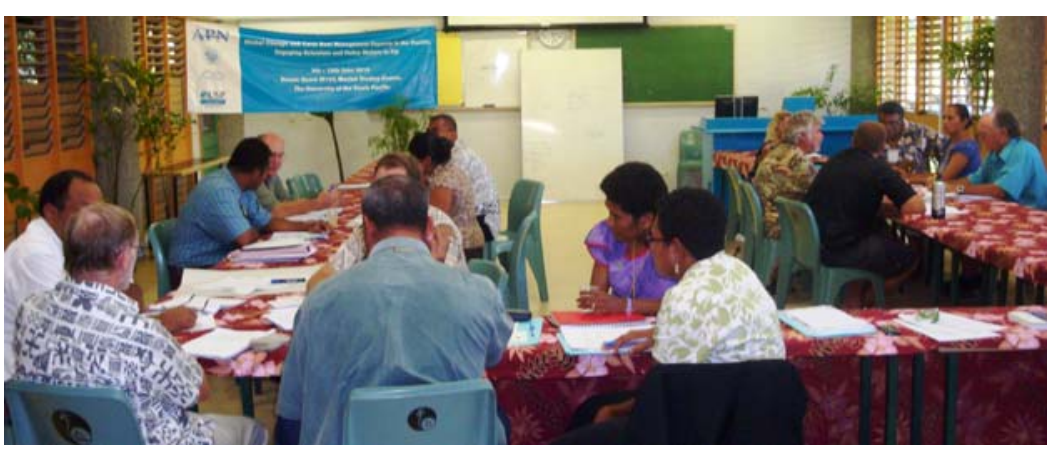

Workshop in Fiji

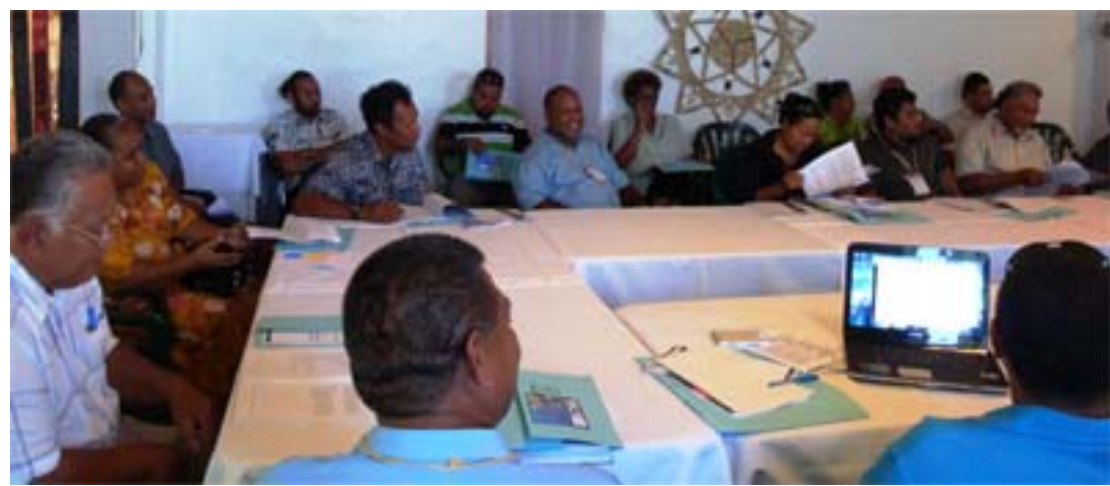

Workshop in Tuvalu

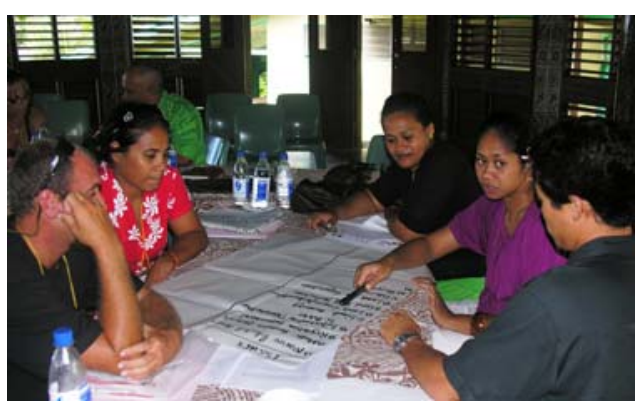

Workshop in Samoa 


\section{CRP2010-01CMY-Weber Vulnerability Mapping as a Policy Tool in Developing Countries}

A key to better manage risk lies in knowing the spatial distribution of vulnerable people as well as how hazards affect space. Mapping vulnerability looks at where the most vulnerable people live and how hazards impact space. This Project investigates the vulnerability of people to climate change impacts, focussing on the ways in which they sustain their livelihoods and how they cope with or adapt to adverse events in the Pacific Islands, Southeast Asia and South Asia.

Vulnerability mapping is regarded as a comprehensive research tool. It is instrumental to predict where the most vulnerable people who will need to be evacuated first are living, and bring them to new homes. With support of GIS, research on social vulnerability and its spatial distribution looks at the factors that make some people more vulnerable than others; it looks at how spatial aspects play a role. Awareness and perception of climate change will be very important when adaptation measures become necessary. An ultimate vision of this Project is to establish an Asia-Pacific Spatial Vulnerability Reporting System, which should become an easily accessible tool for communities to report social aspects of vulnerability.

After a workshop in Bangkok in August 2009 where the project team developed methodology suitable to measure people's vulnerability and its spatial distribution, the project partners initiated research activities at their

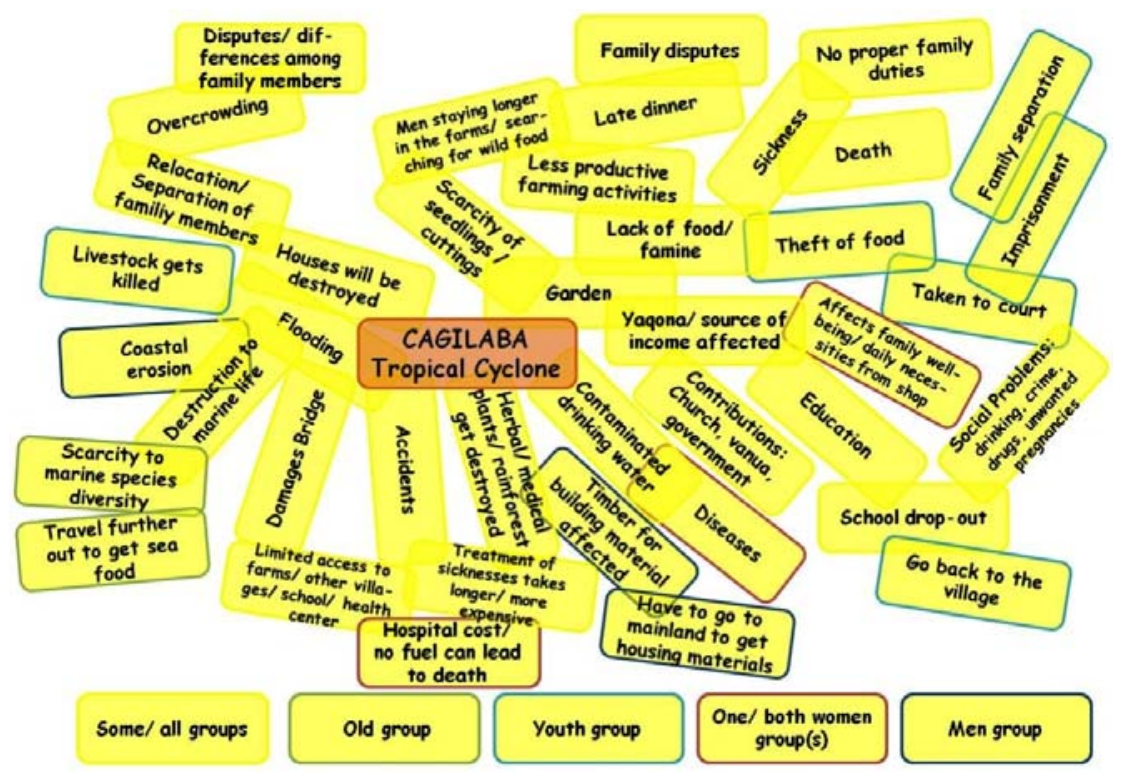

Impacts of tropical cyclone in Gau Island, Fiji, participatory research

respective institutions in their home countries. In order to do this effectively, one needs to spend much time with the people concerned, observe their day-today lives, and analyse how they earn their livelihoods and what exactly places them at risk. Activities in Fiji, India and Viet Nam address this using different methods. Also, partners from other countries have joined the activity bringing in additional funds and looking at aspects that are crucial but cannot be covered by the present Project activities.

The India project team has worked on producing a hazard map for a $30 \mathrm{~km}$ long coastal stretch of the Chennai coast, and they have looked at people's vulnerability to erosion and coastal flooding associated with sea level
Project Leader:

Dr. Eberhard Weber

School of Geography, Earth Science and

Environment

The University of the South Pacific

FIJI

Tel: +67 93232222

Fax: +6793231558

Email: weber_e@usp.ac.fj

APN Funding:

US $\$ 100,000$ (For 2 Years)

(Year 3 expected funding is US\$45,000) rise. In Thailand, the project team conducted research on Flood Hazard and Vulnerability Assessments at Yen Bai, Viet Nam. In Fiji, research was undertaken in Nadi, where investigation on the town's vulnerability to flooding was carried out. Another research activity was started on Gau Island, where community vulnerability and resilience to natural hazards was at the centre of interest.

Year 3 of the Project will continue the present research and report on the main outcomes of the present activities.

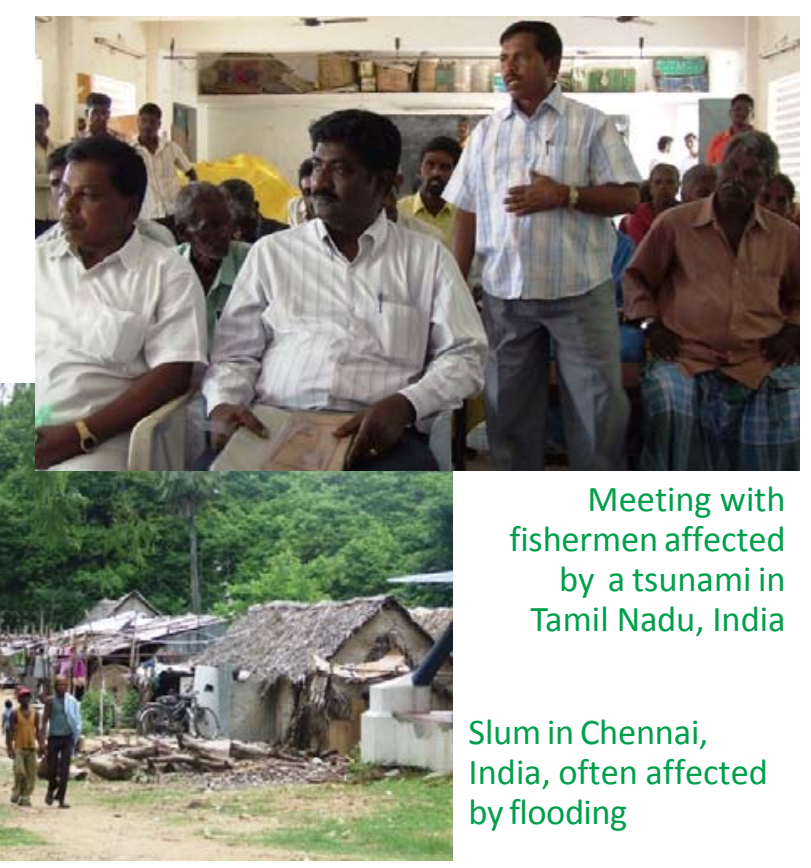




\section{Strengthening Capacity for Policy Research on Mainstreaming Adaptation to Climate Change in Agriculture and Water Sectors}

nalysis of policies in select
countries revealed that
important decisions in the agriculture and water sectors are implemented without consideration of projected impacts of climate change. One of the most important barriers identified was the limited capacity of researches in the region to provide adaptation policy-relevant information. Networking and communication among researchers and policy-makers focusing on adaptation is also extremely limited.

In order to strengthen research capacity on mainstreaming climate change adaptation concerns into agricultural and water policies and to create a network for adaptation policy research in Asia, this Project has adopted a three-pronged approach. Firstly, identification of practical options for mainstreaming and metrics for monitoring the effectiveness of adaptation policies and measures; secondly, exchange of adaptation policy-relevant information through creation of an adaptation research and policy network; and lastly, dissemination of outputs beyond the project boundaries. This Project contributes to the characterisation of adaptive policies and identifying gaps in existing agricultural and water

Project Leader:
Dr. Joy Jacqueline Pereira
Institute for Environment and
Development (LESTARI)
Universiti Kebangsaan Malaysia
(UKM)
MALAYSIA
Tel: +6 38 921 4149
Fax: +638 925 5104
Email: joy@ukm.my
APN Funding:
US\$140,000 (For 2 Years)
Year 3 expected funding is
US\$70,000)
Project Website:
www.ukm.my/apn

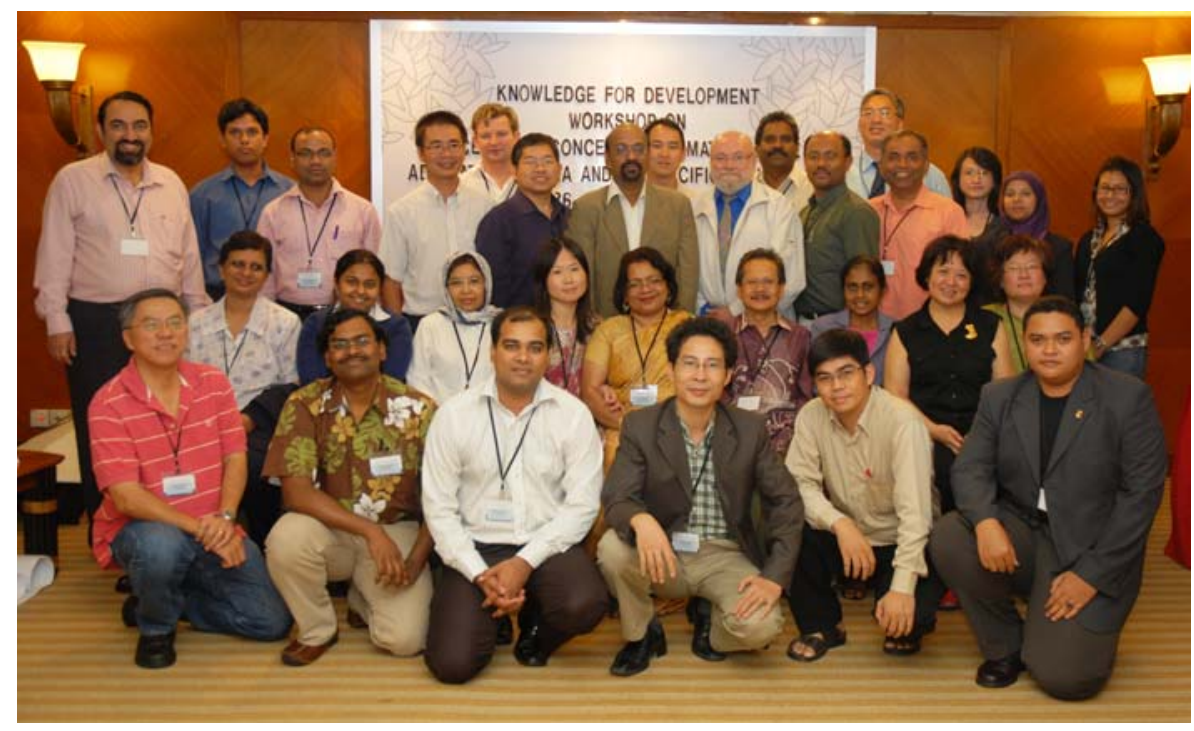

policies. A framework for developing adaptive policies and assessing the effectiveness of adaptation investments assists decision-makers by providing a reference against which evaluators and stakeholders at all levels can monitor progress on adaptation.

A meeting was held on 26 June 2010 in conjunction with the Workshop on Scenarios Concerning Climate Change Adaptation in Asia and the Pacific by Year 2030, jointly organised by ORBICOM, an international Network of UNESCO Chairs in Communication and Universiti Kebangsaan Malaysia (LESTARI and Southeast Asia
Disaster Prevention Research Institute [SEADPRI-UKM]). The project partners and affiliates supported the workshop, in particular for reviewing the Background Paper for East and Southeast Asia prepared by LESTARI/SEADPRI-UKM and also for providing inputs for the experts survey on knowledge drivers for climate change adaptation in the AsiaPacific region. The project meeting discussed work progress, Adaptation Research and Policy Network for Asia and Pacific (ARPNAP) development, publication, financial matters and the future plan.

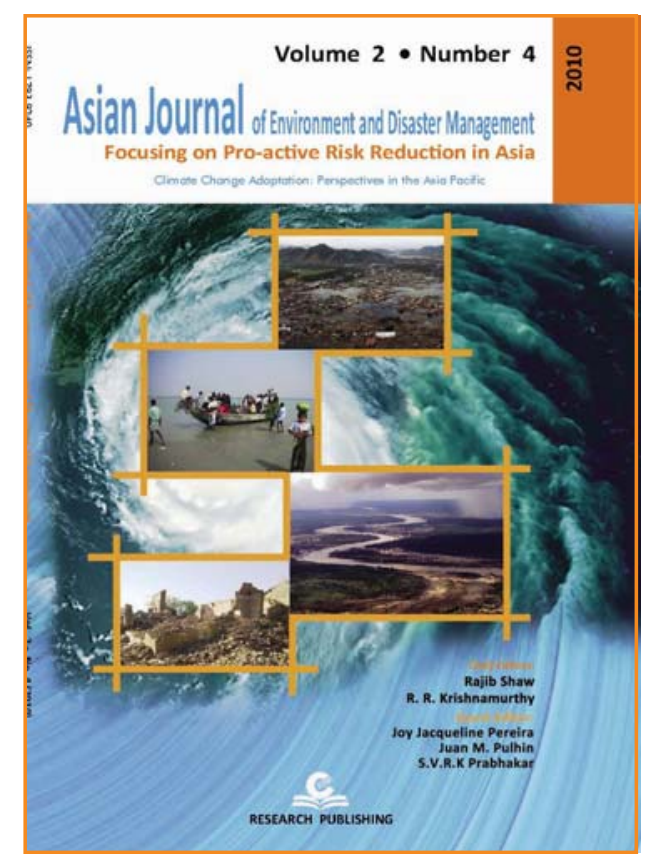

Publications

- Climate Change Adaptation: Perspectives in the Asia Pacific. 2010. Asian Journal on Environment and Disaster Management Volume 2 Issue 4.

- Prabhakar, SVRK. 2010/ 10. Climate Change Impacts in Japan and Southeast Asia: Implications for Crop Adaptation. In Crop Adaptation to Climate Change, edited by S. Yadav, B. Redden, J. L. Hatfield, and H. Lotze-Campen. 30. USA. Wiley-Blackwell. In print. 


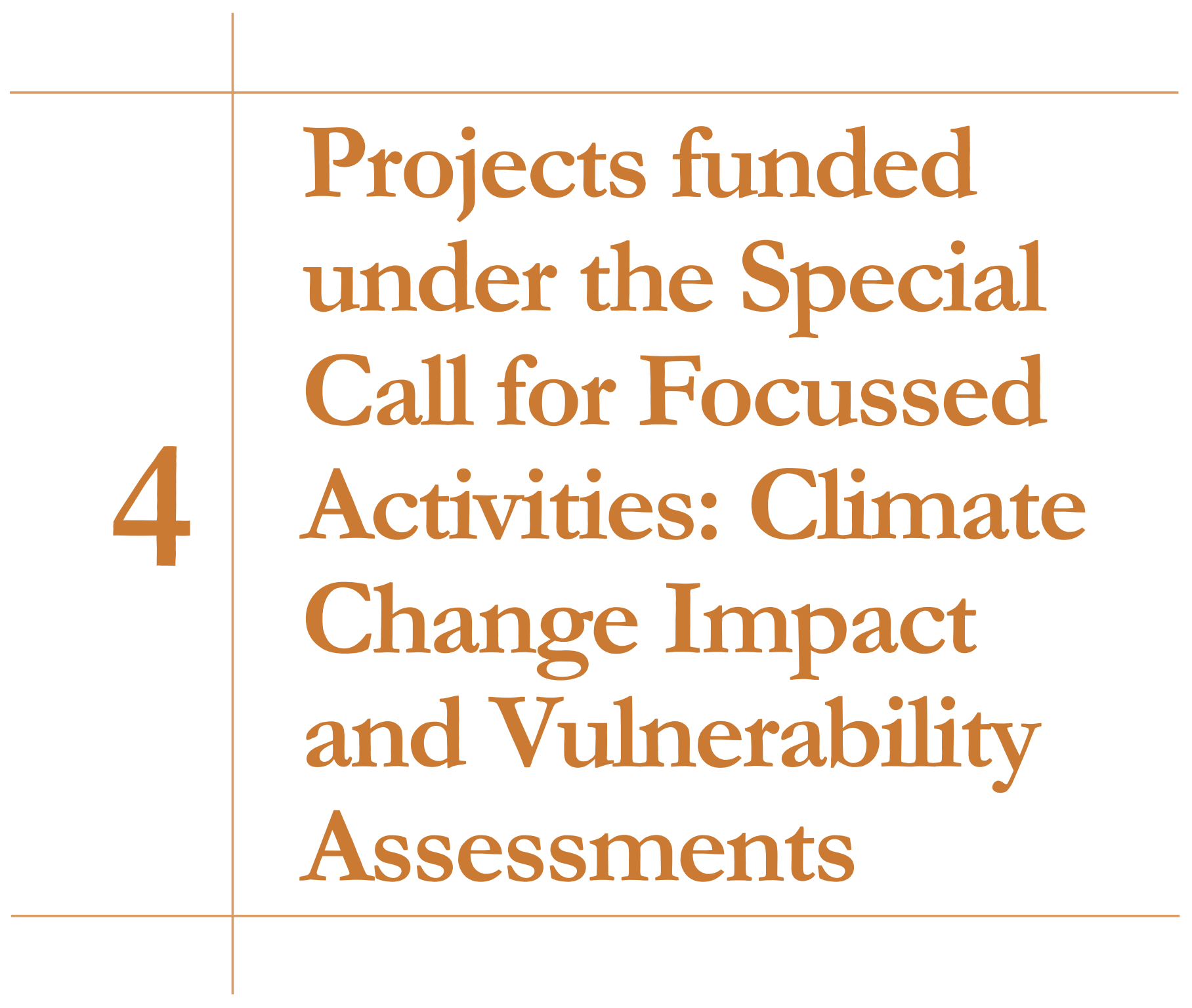



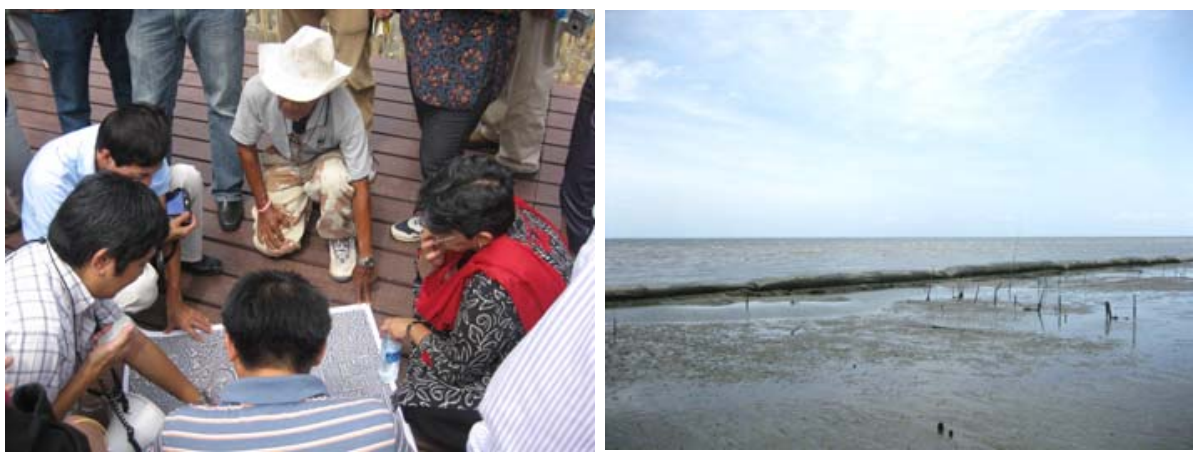

\section{CIA2009-01-Snidvongs}

\section{Climate Change Vulnerability Assessment of Floods and Urban Development Planning for Asian Coastal Cities}

Whis 'Cities at Risk' workshop,
Climate Change Vulnerability
Assessment and Urban Development

Planning for Asian Coastal Cities, was built on the first workshop held in 2009 in Bangkok, and specifically addressed the limited capacity to carry out risk and vulnerability assessments in coastal Asian cities. It brought together over 40 participants including academics, urban planners/

government representatives, and experts in disaster management.

The workshop clarified the current information/knowledge gaps and challenges, and identified future research opportunities for addressing climate change-related risks and vulnerability assessments in Bangkok, Ho Chi Minh, Jakarta, Manila and Mumbai. Key findings distilled from the workshop were grouped into three categories: (i) assessment of climate change related risk; (ii) information/ knowledge management; and (iii) governance. Specific observations and recommendations for future research were identified.

The workshop participants looked at the best ways to assess/map climate risks taking into account the possible effects of current and future climate change. City teams were formed and were asked to share how social/ economic vulnerability to climaterelated risks have been assessed and mapped, for whom this is targeted, who is doing this type of mapping exercise and details of the assessment. Interesting discussions focussed on information/knowledge management in identifying effective approaches on communicating climate risk and vulnerability. The discussion also touched on existing urban Geographic Information System (GIS)

information base that may be used for climate risk and vulnerability assessments.

On governance, the city teams identified the role of agencies and institutions in risk and vulnerability assessments as well as the skill level and capacity needed to perform such roles. Discussions also ensued that tackled urban master plans, the effectiveness of current building codes, land use regulations, sanitation codes and other factors being enforced, the effectiveness of existing early warning systems, and problems encountered in implementing evacuation and/or emergency response plans for various types of weather and climate-related disasters.

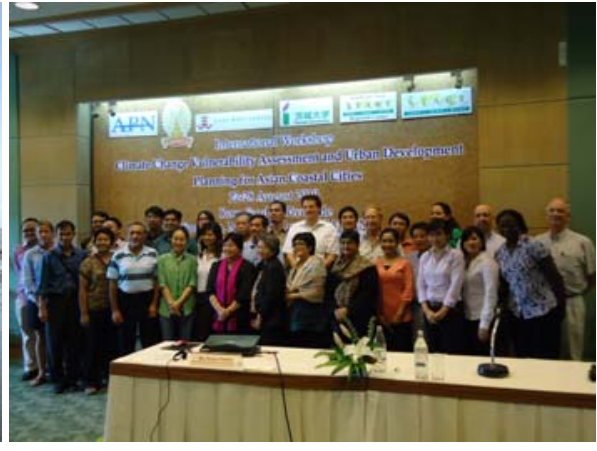

Project Leader:

Dr. Anond Snidvongs

Southeast Asia START Regional Centre (SEA START RC)

Chulalongkorn University

THAILAND

Tel: +66 22189469

Fax: +66 22519416

Email: anond@start.or.th

APN Funding:

US\$45,000 (For 1 Year)

Two major Projects are anticipated to commence in 2011, one of which is also funded by the APN (ARCP201009NSY-Patankar: Enhancing Adaptation to Climate Change by Integrating Climate Risk into Longterm Development Plans and Disaster Management), thereby offering the opportunity to address the identified gaps in information/ knowledge faced by the cities under study. These projects demonstrate how the 'Cities at Risk' workshops are encouraging communication and generating collaboration and partnerhips in addressing the impacts of climate change on cities in Asia and beyond.

A Second International Conference on Cities at Risk: Adaptive Capacities for Managing Climate Change Risks in Asian Coastal Cities will be held from 11-13 April 2011 in Taipei, Taiwan.
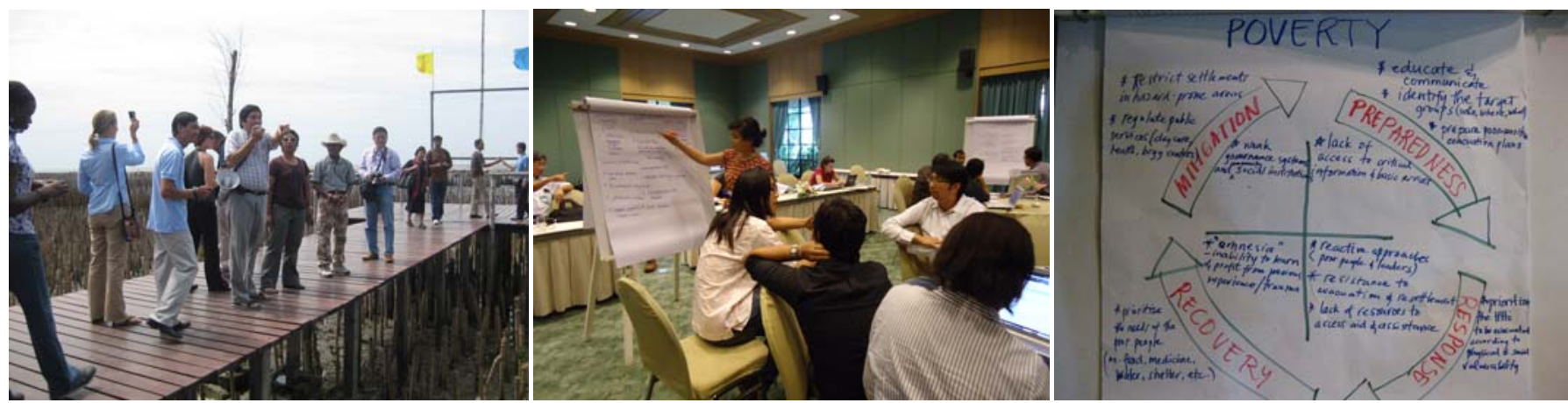


\title{
Capacity Development on Integration of Science and Local Knowledge for Climate Change Impact and Vulnerability Assessments
}

\begin{abstract}
A City, Albay, Philippines. This was attended largely by the planning development officers and staff from different Local Government Units (LGUs) of the province. SimCLIM is a software package for examining the effects of climate variability and change over time and space and is designed, as well, to support decision-making and climate proofing.
\end{abstract} s a part of this pilot Project, a training programme on the basic concepts of vulnerability and adaptation assessments and the - Luse of SimCLIM was held from 26-29 April 2010, in Tabaco

Through hands-on training on the use of a customised SimCLIM for Albay -

AlbayCLIM - participants generated climate change and sea-level rise scenarios using various GCMs, and conducted extreme events analyses and water tank modelling. Results of the climate and sea-level modelling were deemed highly useful in the revision of the Comprehensive Land Use Plan that the province of Albay was undertaking, thus demonstrating the direct link of the capacity building project to policy and practice.

Following the concepts learned during the training programme, two case study sites were chosen at the municipalities of Bacacay and Oas in Albay. Vulnerability and adaptation strategies of the communities in the study sites were assessed using a participatory approach adapted from the

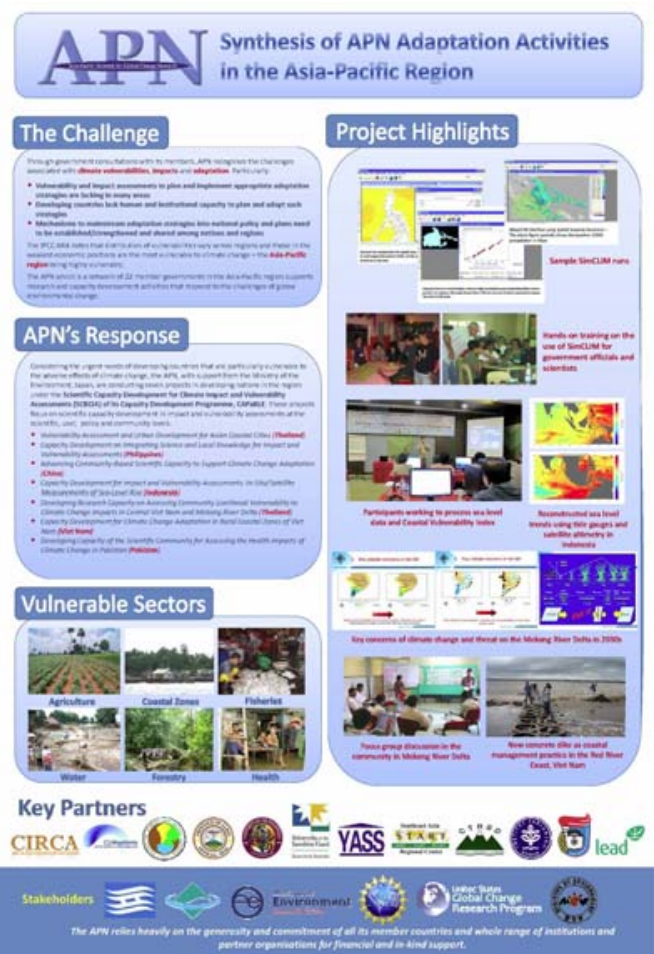

SCBCIA poster presented at the 2010 International Climate Change Adaptation Conference, Queensland, Australia

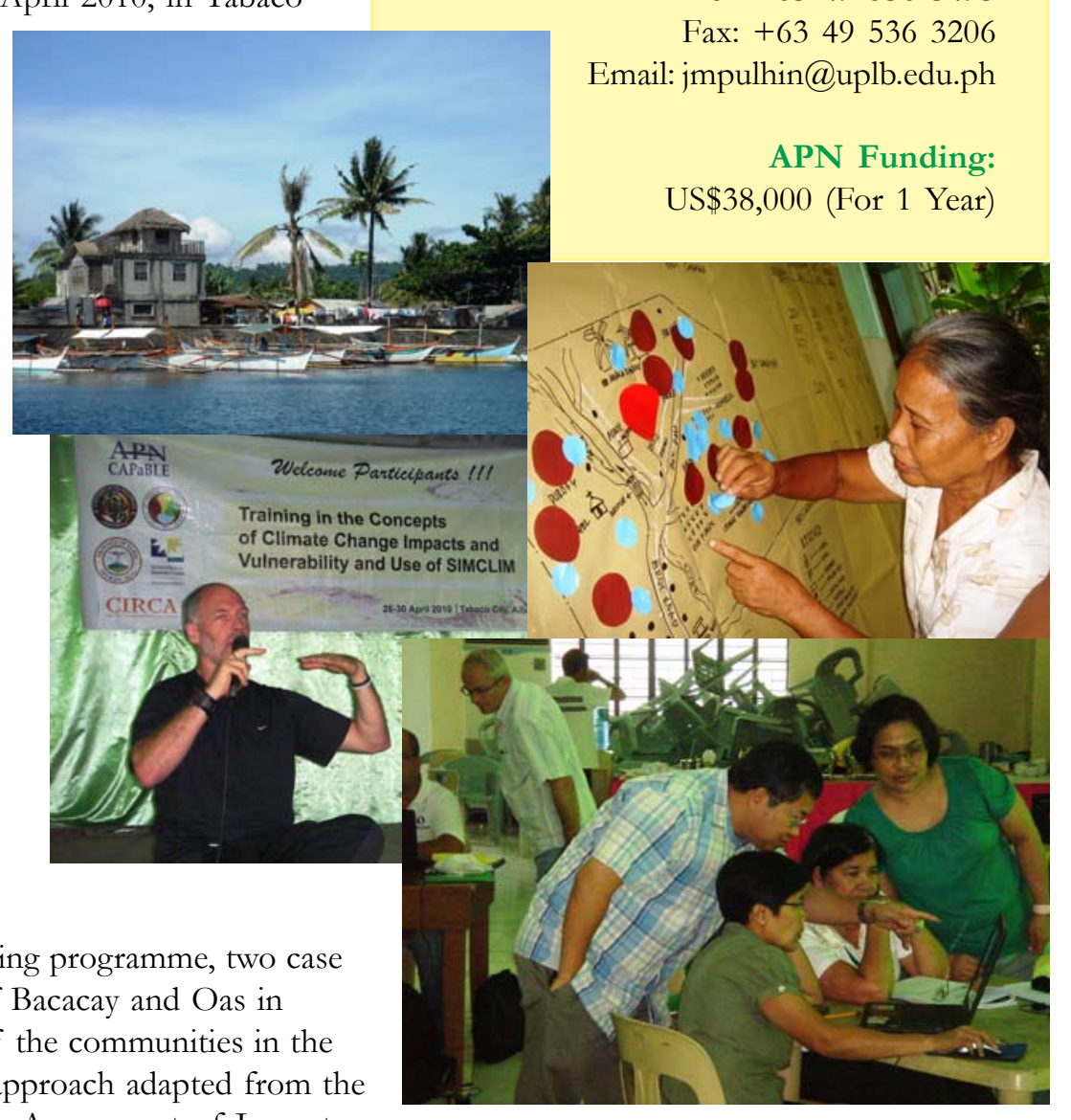

Assessment of Impacts

and Adaptation to Climate Change (AIACC) study in the Philippines. Furthermore, sea-level and climate scenarios were generated using the AlbayCLIM and presented to the communities. The community members were asked about the potential impacts of the scenarios in their areas, as well as their potential responses to cope with the projected changes.

Results of the assessment using SimCLIM and knowledge generated from the local people are currently being analysed. These will be presented to relevant stakeholders at the municipal and provincial levels, as well as at the national level through the Philippine Climate Change Commission. Implications of the assessment to relevant policies, programmes and projects will be identified, together with recommendations for their improved implementation. Lastly, the outputs of, and the processes involved in, the Project are being seen to significantly contribute to the Climate Change Academy recently launched by the Provincial Government of Albay.

Thanks to our partners for the affirmation of our adaptation initiatives. This one features Albay at the Australian National Conference on Climate Change. We really need this pat on the back as it spices our routinised practice of climate adaptation. [Dr. Joey Sarte Salceda is the $26^{\text {th }}$ Governor of the Province of Albay. He is known as The Green Economist, for his expertise in the fields of Economics and Finance, as well as in the fields of Climate Change Adaptation and Disaster Risk Management.] 


\section{Climate Change Adaptation}

W

ith help from the Deqin Tibetan Medical Association of local experts, this Project has successfully established a Climate Field School to systemically organise training programmes on climate change, natural resources and data collection. The school also runs respective scientific capacity development for local participants. A number of research activities were organised at the school

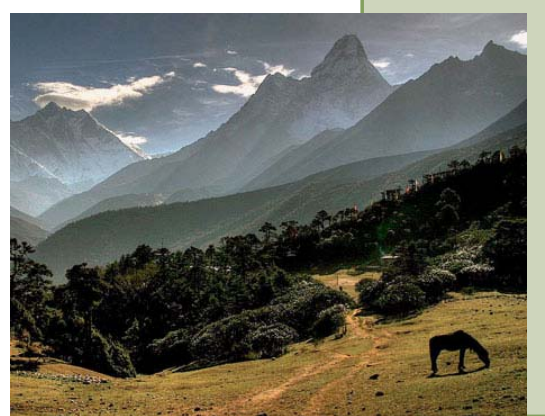
Project Leader: Dr. Yin Lun Centre for Tibetan Regional Sustainable Development Yunnan Academy of Social Science CHINA

Tel: +868714123519

Fax: +868714124871 Email: lun.yin@gmail.com throughout summer 2010. The school collected data from a high altitude zone with both quantitative and qualitative streams. According to altitude, the association categorised investigation zones as a high altitude zone $(>3500 \mathrm{~m})$, a middle zone $(2500-3500 \mathrm{~m})$, and a local altitude zone $(<2500 \mathrm{~m})$.

Before data collection, field training actively involved some 102 villagers and locals including 37 women. In Hongpo Village, the training facilitated the Tibetan women organisation "Sisters Association," which empowered 15 local women and 20 local experts, to carry out an investigation on traditional subsistence of half agriculture and half herding, non-timber forest products, herbs and gynecopathy in the context of climate change. Over two months, 120 plant samples were collected.
Through the above activities, locals have begun to recognise the impacts of climate change in their environment and to positively contribute by using their indigenous knowledge of plant ecology in the face of climate change. Consequently, the project team has observed that local villagers are practical in implementing possible prevention and adaptation measures to climate change impacts and related natural disasters.

\section{CIA2009-04-Gaol}

\section{Increasing Capacity of Local Scientists for Climate Change Impact and Vulnerability Assessments in Indonesia Archipelagos: Training in In-Situ/Satellite Sea Level Measurements}

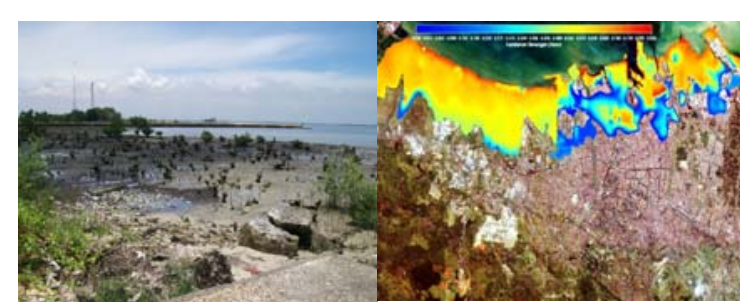

of sea level rise on coastal inundation in their own home islands. As result of the intense and informative training, the project team produced a GIS training module of the satellite SLR data processing, a module of the analysis of coastal inundation, and a module of coastal vulnerability.

The significance of this Project is attributable to the vast amount of data obtained. For example, high quality data (in-situ and satellite) was obtained using Tide Analysis and Prediction Software of Coordinating Agency for

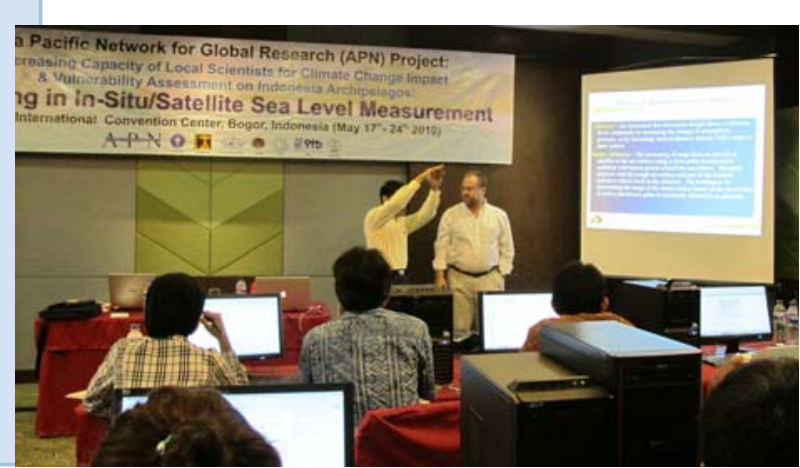

Surveys and Mapping, Indonesia (BAKOSURTANAL) and Matlab software for satellite altimeter data from AVISO and CCAR (1993-200).

For coastal inundation analysis, a coastal vulnerability index (CVI) was used to map the relative vulnerability of the coast to future sea level rise in the coastal inundation area due to SLR 20-50 years.

Overall the workshop provided policymakers and researchers with a platform to understand and discuss adaptation and mitigation approaches
Dr. Jonson Lumban Gaol

Department of Marine

Science and Technology

Bogor Agricultural University

INDONESIA

Tel: +62 2518623644

Fax: +62 2518623644

Email: jonsonrt@yahoo.com

APN Funding:

US\$28,500 (For 1 Year) to overcome the impacts of sea level rise. As a follow-up to the workshop, participants from local institutions are also planning to implement such adaptive mitigation measures as mangrove planting, etc., in 2011, to reduce erosion caused by sea level. 


\section{CIA2009-05- Jitpraphai}

\section{Building Research Capacity on Assessing Community Livelihood Vulnerability to Climate Change Impacts in Central Viet Nam and the Mekong River Delta}

The framework of the climate change vulnerability and adaptation (V\&A) assessment which was

introduced in this Project has broadened the frame of thought on V\&A assessments from conventional approaches that take climate change as a single issue and assesses impact, risk, vulnerability and adaptation based on sector basis. The pilot assessment under the present Project exercised the integration of other socio-economic conditions into the vulnerability assessment, which provides a more realistic picture of community livelihood vulnerability to the impacts of climate change.

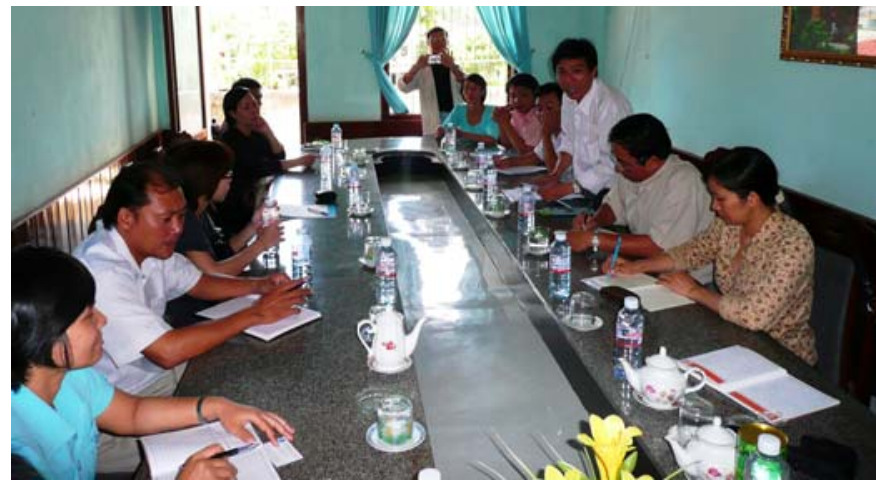

Project Leader:

Dr. Somrudee Jitpraphai

Southeast Asia START Regional

Centre (SEA START RC)

Chulalongkorn University

THAILAND

Tel: +66 22185394

Fax: 6622550780

Email: somdeem@yahoo.com

APN Funding:

US $\$ 28,500$ (For 1 Year)
This Project has undertaken vulnerability assessment case studies in the Mekong River Delta and Central Viet Nam and consequently raised awareness of climate risks among local communities and stakeholders. The assessment exercises conducted at pilot study sites also raised awareness of local stakeholders as well as local government officials on climate change issues in the local context. Moreover, the results from the pilot studies in two areas can be used as a foundation or initial step to trigger policy toward full assessment in the future.

By applying climate projection data to assess climate change risk in key sectors, this Project has facilitated experts to develop and enhance their research capacity at two newly established research centres: the Research Institute for Climate Change of Can Tho University (DRAGON-Institute-Mekong) and the Climate Change and Development Centre (CCDC) of Nong Lam University.
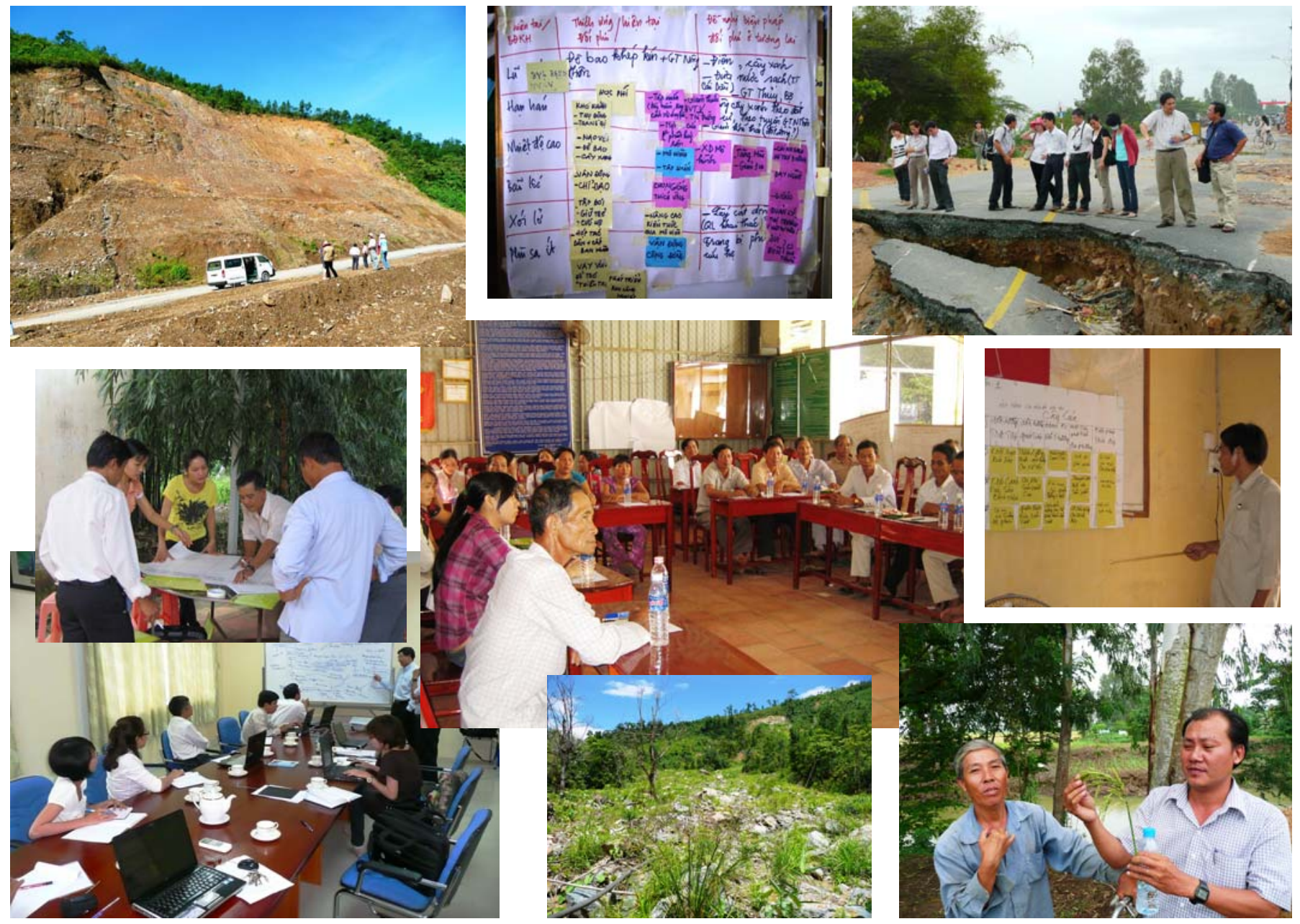


\section{Capacity Development for Adaptation to Climate Change in the Rural Coastal Zone of Viet Nam}

\author{
C \\ limate change is the most serious environmental problem facing \\ the world today and places more pressure on all socio- \\ economic activities. In terms of climate change-related losses, \\ one can easily recognise the much larger potential damage in urban \\ areas compared with rural areas. Therefore, much effort is being \\ focussed on urban areas, especially in coastal megacities, and rural \\ areas are not being properly considered in some cases
}

Addressing the research focus on rural areas, this Project has investigated the potential vulnerability of the rural coastal zone in Viet Nam. It has aimed to help local authorities and the community to learn about and understand new risks posed by climate change resulting in the creation of an initiative to address adaptation options to climate change, develop capacity and exchange experiences related to risk assessment and coastal protection. Activities were concentrated on scientific capacity building, a pilot study and dissemination of the research outputs.

The short training courses on "Reduction of Risks due to Climate Change in the Coastal Zone" and "Coastal Engineering and Vulnerability Assessment" were organised for local managers (commune and district level) and technical practitioners, respectively. The pilot study was implemented at the Hai Hau coast (Nam Dinh

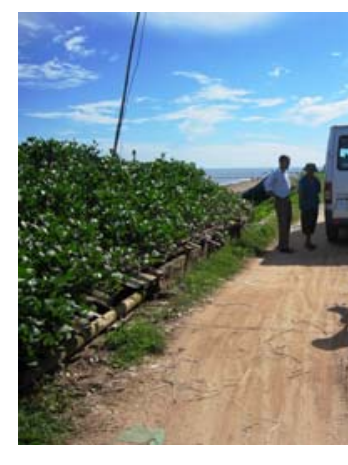

province) - one of the most severely eroded coasts in Viet Nam. The research contributed to clarifying the intensification of natural hazards related to climate change, reviewing the capacity for implementing countermeasures, proposing suitable adaptation options, and avoiding maladaptation.

Focusing on wise (smart) climate change adaptation, vulnerability and risk, two international workshops entitled, "Capacity Development for Adaptation to Climate Change in the Rural Coastal Zone of Viet Nam" and

\section{Publications}

- Do Minh Duc, 2010. Coastal Protection in the Context of Climate Change: A Case Study of Hai Hau Coast. Vietnam Geotechnical Journal (English Series).

- Do Minh Duc, Mai Trong Nhuan, and Chu Van Ngoi, 2010. An Analysis of Coastal Erosion in the Tropical Rapid Accretion Delta of the Red River, Viet Nam (submitted). Journal of Asian Earth Sciences.

Project Leader:

Assoc. Prof. Dr. Do Minh Duc

Faculty of Geology

Hanoi University of Science

VIET NAM

Tel: +8443558 8739

Fax: +84 438583061

Email: ducdm@vnu.edu.vn

APN Funding:

US\$28,500 (For 1 Year)

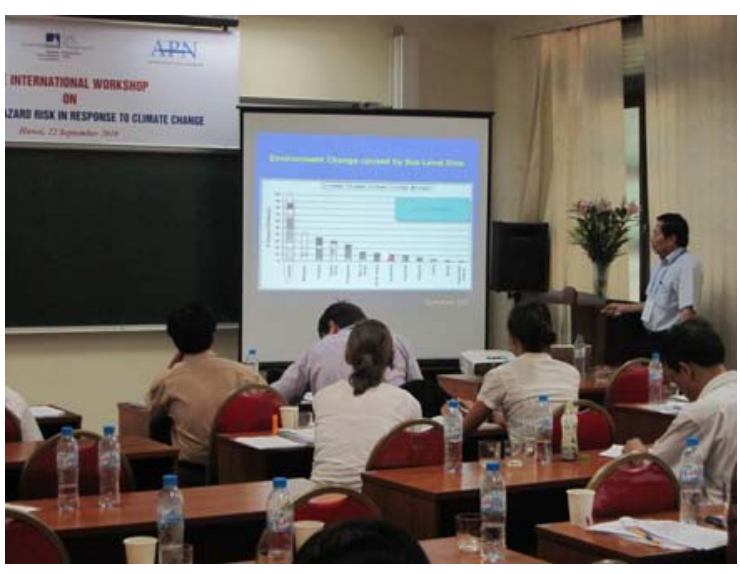

Based on the activities conducted, this Project identified the following as elements of wise (smart) adaptation measures: (i) impact/vulnerability assessment at the local level; (ii) monitoring and early warning; (iii) incorporating renewal cycles for infrastructure; (iv) co-benefit approaches for mitigation and adaptation; (v) collaboration of ministries; and (vi) participation of stakeholders and capacity building. The project team also developed postgraduate (Masters) programme syllabi on "Climate Change Adaptation" and

"Geoenvironment and Geohazards" at the Hanoi University of Science. 

Assessing the Health Impacts of Climate Change

$\mathrm{U}$ Tnder this Project a twelve-member cadre of Public Health Professionals from across Pakistan were selected to undertake a series of three training workshops. Of these, the first two were held at the national level and the third and final was held at the international level.

The First National Level Workshop was organised in Islamabad, Pakistan from 12-15 June 2010. The four-day workshop entitled, 'Climate Change and Health Bridging the Gap,' was designed using LEAD Pakistan's training methodology of experiential learning and included interactive talks, presentations, group work, panel discussions, screening of documentaries and a field visit to the Pakistan Meteorological Department (PMD) to acquaint the members with assessing particular aspects of the climate change-health relationship.

The Second National Level Workshop, held from 5-6 August 2010, was designed to assist the research groups formed in the first workshop in conducting muchneeded vulnerability and impact assessments in the under-explored area of climate change and health. During the workshop, each group presented its research synopsis for discussion and deliberation. Feedback received from the

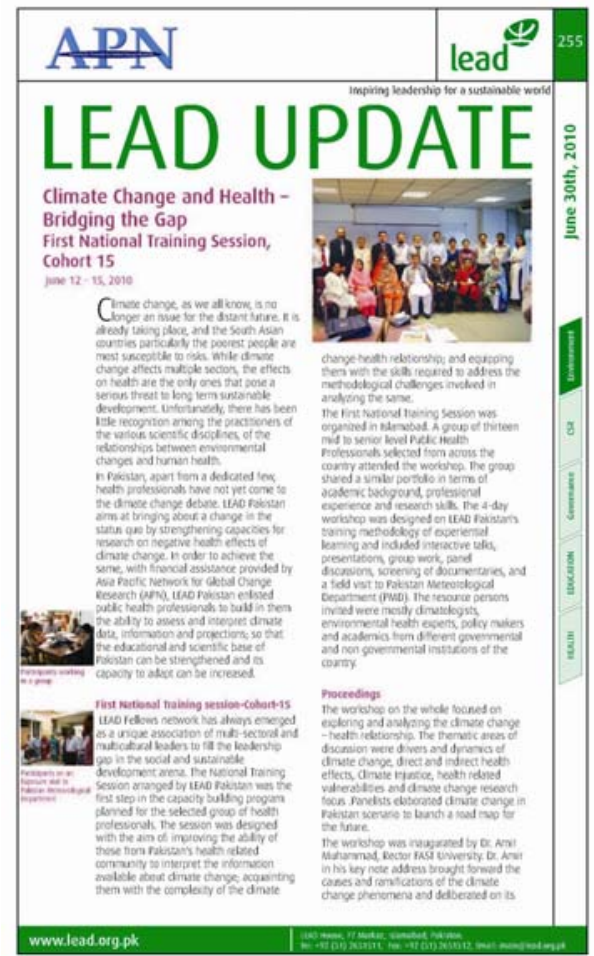
other cohort members as well as LEAD's three-member Panel of Experts enabled the groups to improve and finalise their research plans.

Participation in the International Level Workshop, Port Elizabeth, South Africa from 31 October to 6 November 2010 by LEAD International, provided the members with the opportunity to network with relevant stakeholders from around the world. Most importantly, it served as a forum to showcase their research work to a much larger audience and share the results of their endeavours with a number of experts.

Project Leader:

Ms. Hina Lotia

Leadership for Environment and Development (LEAD)

PAKISTAN

Tel: +92512651511

Fax: 92512651512

Email: hlotia@lead.org.pk

APN Funding:

US\$33,000 (For 1 Year)
Enriched with the feedback received and the insights gained during the final workshop, the members upon their return concentrated their efforts on finalising their respective research work.
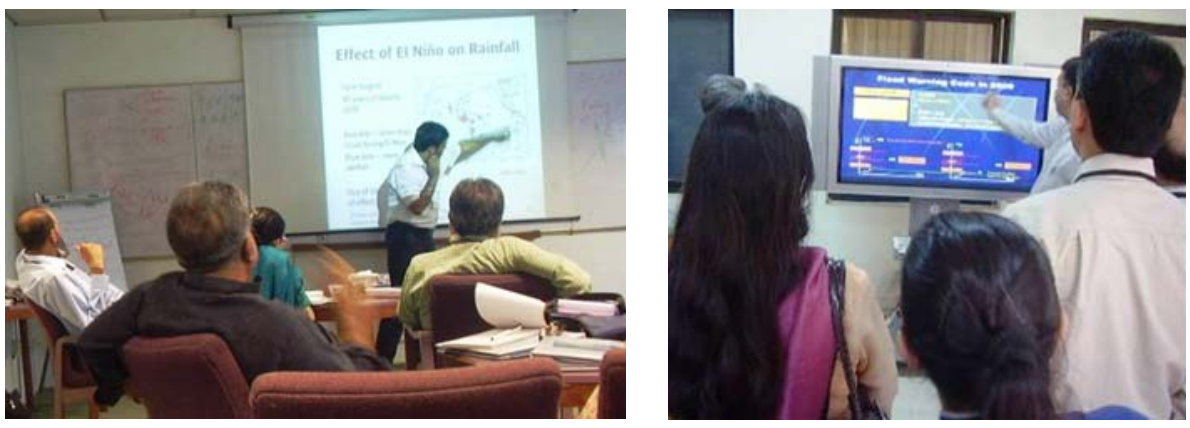

\section{Statements from the Cohort Members}

\section{$1^{\text {st }}$ National Training Workshop}

- This is what a 'true' capacity building exercise should be like. - Dr. Samina Mobsin Khan

- I teach undergraduate and graduate students and now I know what area my students will be concentrating their research on next year - climate change effects on population health. - Dr. Seema Nigab-e-Mumtaz.

\section{$2^{\text {nd }}$ National Training Workshop}

This workshop was such a great help. As the climate change interplay with human health is a new field for me, the input by fellow cohort members really helped me in fine tuning my research synopsis. - Dr. Mukhtar Ali Zehri

\section{International Training Workshop}

It was a great experience. An opportunity to meet such seasoned professionals from around the world. Most importantly our research work shared in the Networking Fair attracted so much interest from the participants. Everyone who came wanted to learn how we had undertaken the research, from where we collected data, and what our forecast was for the future. I could tell that this area will generate a lot of research in the coming years. - Professor Dr. Irfan Ullah Siddiqui 


\section{APN Scientific Planning Group (SPG) Representatives}

The SPG Members recommend a scientific programme including proposals for priority of funding and

Lallocation of current available funding for consideration by the Inter-Governmental Meeting (IGM); works with the Steering Committee and the Secretariat in arranging scientific programme activities; and interacts on the APN's behalf with other international research programmes on global change. SPG Members also interact with the national Focal Point of their respective countries, the Secretariat, and the national and global change communities.

\section{AUSTRALIA \\ VACANT}

BANGLADESH

Md. Giashuddin MIAH

Email: giash1960@gmail.com

\section{BHUTAN}

Peldon TSHERING

Email:Peldon@nec.gov.bt

\section{CAMBODIA}

\section{Khieu HOURT}

Email: hourt-2010@hotmail.com

\section{CHINA}

Wenjie DONG

Email: dongwj@bnu.edu.cn

$$
\begin{aligned}
& \text { FIJI } \\
& V A C A N T
\end{aligned}
$$

\section{INDIA}

B.N. GOSWAMI

Email: goswami@tropmet.res.in

\section{INDONESIA}

\section{Erna Sri ADININGSIH}

Email: ernas@lapan.go.id; ernasri@yahoo.com
JAPAN

Kensuke FUKUSHI

Email: fukushi@ir3s.u-tokyo.ac.jp

LAO PEOPLE'S DEMOCRATIC

RREPUBLIC

Oulaphone ONGKEO

Email: oulaphone75@yahoo.com;

oulaphone@wrea.gov.la

MALAYSIA

Subramaniam MOTEN

Email: subra@met.gov.my

\section{MONGOLIA}

Tsogtbaatar JAMSRAN

Email: geoeco@magicnet.mn

\section{NEPAL}

Madan Lall SHRESTHA

Email: madanls@hotmail.com

NEW ZEALAND

Andrew MATTHEWS

Email:wa.matthews@gmail.com

\section{PAKISTAN}

\section{Amir MUHAMMED}

Email: amir.muhammed@nu.edu.pk; amir.muhammed@gmail.com

\section{PHILIPPINES \\ Marcial AMARO Jr \\ Email: erdb@denr.gov.ph;}

\section{REPUBLIC OF KOREA \\ Chang-keun SONG \\ Email: cksong@me.go.kr}

\section{RUSSIAN FEDERATION}

Alexander STERIN

Email: sterin@meteo.ru

\section{SRI LANKA}

G.B. SAMARASINGHE

Email: sbaladev_24@yahoo.com

\section{THAILAND \\ Jariya BOONJAWAT}

Email: jariya@start.or.th

UNITED STATES OF AMERICA Luis TUPAS

Email: ltupas@nifa.usda.gov

\section{VIET NAM}

Dr. Kim Chi NGO

Email: chikimngo2@yahoo.com; chikimngo2008@gmail.com

\section{Invited Experts to the APN Scientific Planning Group}

\section{Congbin FU}

Director, START Regional Committee for

Temperate East Asia, CHINA

Email: fcb@tea.ac.cn

\section{Chao Han LIU}

Chairman, Southeast Asia START Regional Committee CHINESE TAIPEI

Email: chliu@cc.ncu.edu.tw

\section{Kanayathu Chacko KOSHY}

Professor, Centre for Global Sustainability Studies,

Universiti Sains Malaysia, MALAYSIA

Email: kanayathu.koshy@gmail.com

\section{ISSN 2185-761X}

\section{Published by:}

The APN Secretariat

East Building $4^{\text {th }}$ Floor

1-5-2 Wakinohama Kaigan Dori

Chuo-ku, Kobe 651-0073, JAPAN

Tel: +81 078230 8017; Fax: +81 0782308018

Email: info@apn-gcr.org; Website: www.apn-gcr.org

Executive Editors: Luis Tupas and Erna Sri Adiningsih Managing Editor: Linda Anne Stevenson

Design and Layout: Perlyn Pulhin and Lizhier Coralde

\section{APN Scientific Themes}

- Climate Change and Climate Variability;

- Ecosystems, Biodiversity and Land Use;

- Changes in the Atmospheric, Terrestrial and Marine Domains; and

- Resources Utilisation and Pathways for Sustainable Development 


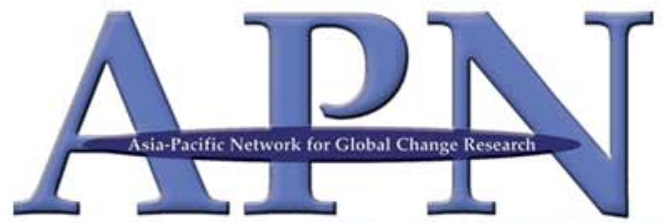

The Asia-Pacific Network for Global Change Research (APN) is a network of 22 member governments in the Asia-Pacific whose vision is to enable countries in the region to successfully address global change challenges through science-based response strategies and measures, effective science and policy linkages and scientific capacity development. 